\title{
MASTER
}

\section{THE FEASIBILITY OF USING A CONDUCTIVITY OR ULTRASONIC TYPE DETECTOR TO MEASURE VOID FRACTION IN THE LOFT REACTOR CORE INLET AND OUTLET}

\author{
M. E. BUCHANAN \\ R. W. SHURTLIFF
}

JASUARY 1918

EG\&G Idaho, Inc.

IDAHO NATIONAL ENGINEERING LABORATORY

\section{DEPARTMENT OF ENERGY}




\section{DISCLAIMER}

This report was prepared as an account of work sponsored by an agency of the United States Government. Neither the United States Government nor any agency Thereof, nor any of their employees, makes any warranty, express or implied, or assumes any legal liability or responsibility for the accuracy, completeness, or usefulness of any information, apparatus, product, or process disclosed, or represents that its use would not infringe privately owned rights. Reference herein to any specific commercial product, process, or service by trade name, trademark, manufacturer, or otherwise does not necessarily constitute or imply its endorsement, recommendation, or favoring by the United States Government or any agency thereof. The views and opinions of authors expressed herein do not necessarily state or reflect those of the United States Government or any agency thereof. 


\section{DISCLAIMER}

Portions of this document may be illegible in electronic image products. Images are produced from the best available original document. 


\section{EE\&E Idaho}

ditl: $\operatorname{HaN} 261978$

to DISTRIBUTION

Itom LOFT CDCS, TAN 602, Ext. 6329

subiec I DOCUMENT TRANSMITTAL

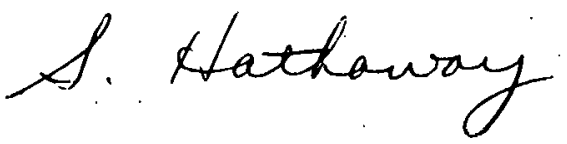

The following documents released by LOFT CDCS, are hereby transmitted for your use and information:

\begin{tabular}{|l|c|c|c|}
\hline DOCUMENT NO. & REV. & CHG. & DATE \\
\hline LTR 141-68 & 0 & & $1-17-78$ \\
\hline "The Feastb1lity of Using a Conductivity or UItrasonic Type \\
\hline Detector to Measure Void Fraction in the LOFT Reactor Core \\
\hline Inlet and Outlet"
\end{tabular}

Remarks :

The prototype of the ultrasonic detector was altered, to reflect the recommendations. The sending bar was altered to an eliptical shape, and a set of electronics was specifically constructed for the ultrasonic det.ector.

The conductivity detector development program is dormant, pending availability of funding. The recommendations will be included in the program.

DISTRIBLTION

B. O. Anderson

E. C. Anderson w/o Att

R. C. Gottula

A. E. Arave - 5

J. G. Arendts

R. G. Bearden - 5

M. E. Buchanan - 5

H. M. Burton

J. L. Clark

J. C. Commander

G. A. Dinneen

D. Engelman

B. L. Freed (Orig.

L. D. Goodrich - 2
R. C. Guenzler

J. C. Haire

K. Hofmann

G. L. Hunt w/o Att

F. K. Hyer w/o Att

N. C. Kaufman w/o Att

J. P. Kester

L. P. Leach -2

J. L. Liebenthal

A. S. Lockhart

L. S. Masson

S. Matovich

G. D. McPherson
ก. R. Mever wto Att

C. A. Moore

N. E. Pace

R. G. Rahl

R. R. Robrdanz - 2

R. W. Shurtliff -5

W. A. Spencer

L. Saukkoriipi

G. Stouz

R. B. Swartzwelder

R. E. Tiller

K. Tasaka - 2

C. R. Toole

E. D. Uldrich 
FORM EG8G-229

(Rev. 12-76)

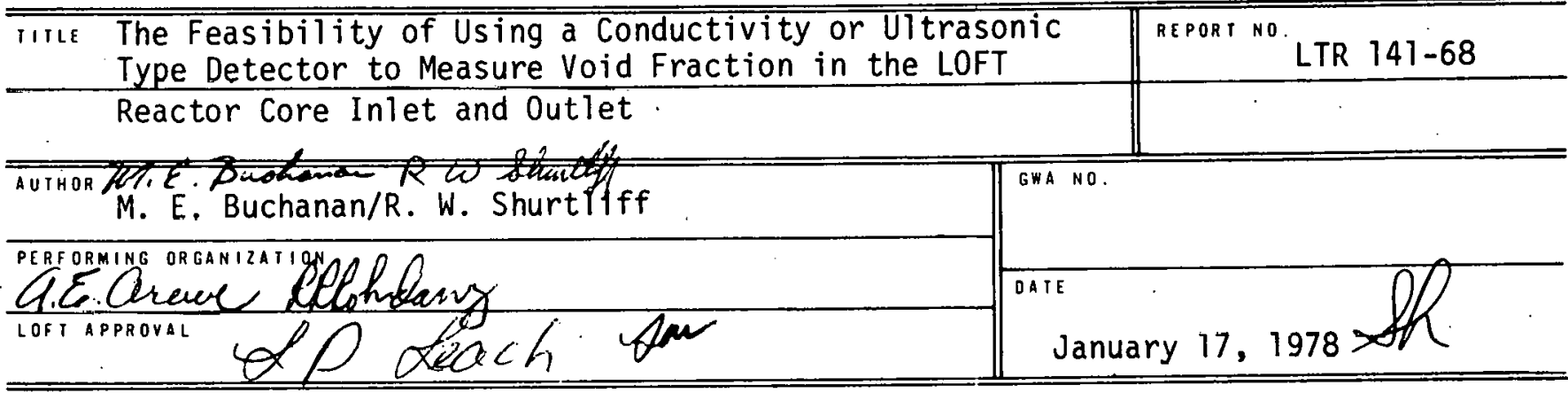

ABSTRACT

The feasibility of a conductivity or ultrasonic type detector meeting the LOFT reactor core inlet and outlet void fraction measurement requirements is explored. The tests that were performed to evaluate the existing LOFT liquid level detector electrode configuration as a conductivity void fraction detector and a prototype ultrasonic detector (fabricated by Panametrics, Inc.) are described. The results of these tests and the recommendations for improving the performance of each detector system are included. 
SUMMARY

This report describes the feasibility of using a conductivity and or ultrasonic transducer to measure void fraction in the LOFT reactor core inlet and outlet. The conductivity detector investigated was of the present LOFT liquid level design. The ultrasonic detector was designed and fabricated by Panametrics Incorporated of Waltham, Mass.

The detectors were fabricated for tests in the Semiscale air-water test loop where flow conditions are determined by volumetric flow rates of air and water. The conductivity void fraction system was tested in horizontal and vertical test sections of the loop, while the ultrasonic system was tested in the vertical section only. The test data points were selected to represent. flow regimes that could exist in the LOFT reactor core inlet and outlet. A single beam gamma densitometer was used as a reference instrument for monitoring the flow conditions and comparing the performance of the transducer systems.

The data from the detector systems and reference instrumentation was recorded on Frequency Modulating (FM) analog tapes and fed into the Semiscale HP 2100 computer data acquisition system where averages were calculated over a $20 \mathrm{~s}$ period for each flow condition. The same data was also digitized and processed through the Cyber system and statistically analyzed to determine calculation and power spectal densities, probability density functions, auto and cross correlation function.

The data indicate that both detector systems, conductivity and ultrasonic, are capable of measuring air-water void fraction or a function of void fraction. The accuracy relation to the gamma densitometer of the conductivity system. is approximately $+8 \%$ with repeatability of $\pm 6 \%$ of range yielding an overall accuracy of $\pm 10.0 \%$ of range. The accuracy relative to the gamma densitometer of the ultrasonic system is approximately $\pm 2 \%$ with repeatability of $\pm 12 \%$ of 
range giving an overall accuracy of $\pm 12.17 \%$ of range. The ultrasonic sensor appears to be mass flow sensitive.

Development of both detector systems should be continued. The ultrasonic transducer should be investigated to eliminate the mass flow sensitivity, and the conductivity detector should be investigated to. produce a more reliable ceramic seal for reactor environment. 
ABSTRACT. ........................

SUMMARY . . . . . . . . . . . . . . .

1.0 INTRODUCTION . . . . . . . . . . . . . . . . 1

2.0 SYSTEM DESCRIPTION . . . . . . . . . . . . 2

2.1 Introduction. . . . . . . . . . . . . 2

2.2 Measurement Requirements. . . . . . . . . . . 2

3.0 INSTRUMENT DESCRIPTION . . . . . . . . . . . . . . . . 5

3.1 Conductivity Void Fraction System ......... 5

3.1.1 Design Concept . . . . . . . . . . . . 5

3.1 .2 Signal Conditioning. . . . . . . . . . 5

3.2 Ultrasonic Void Fraction System . . . . . . . . . 11

3.2.1 Design Concept . . . . . . . . . . . 11

3.2 .2 Signal Conditioning. ........... 15

4.0 AIR-WATER FLOW LOOP TEST . . . . . . . . . . 20

4.1 Description of Air-Water Loop and Reference . . . . . . . 20

4.1.1 Air-Water Flow Loop Test Facility. . . . . . . 20

4.1.2 Air-Water Flow Loop Reference Instrumentation. . . 20

4.2 Description of Air-Water Tests For Conductivity Void Fraction System ............... 22

4.2.1 Horizontal Test of Conductivity Void Fraction System .................. 22

4.2.2 Vertical Test of Conductivity Void Fraction system ................. 26

5.0 DATA ANALYSIS FOR CONDUCTIVITY VOID FRACTION SYSTEM. . . . . . 27

5.1 Horizontal Test of Conductivity Void Fraction System. . . 27

5.2 Vertical Test of Conductivity Vnid Fraction System. . . . 27

5.3 Results of Analysis of Conductivity Void Fraction . . . . 36
System. . . . . . . . . .

5.3.1 Results of Horizontal Test of Conductivity Void Fraction System. . . . . . . . . . 36

5.3.2 Results of Vertical Test of Conductivity Fraction System. . . . . . . . . . . 36 
5.4 Conclusions of Analysis of Conductivity Void Fraction System. . . . . . . . . . . . . . . . 36

6.0 VERTICAL TEST OF ULTRASONIC VOID FRACTION SYSTEM . . . . . . 48

6.1 Results of Vertical Test of Ultrasonic Void Fraction System. ..................... 52

6.2 Conclusions of U1trasonic Void Fraction System. . . . . . 61

6.2.1 Detector Modeling. ............. 61

7.0 GENERAL CONCLUSIONS AND RECOMMENDATIONS. .......... 63

7.1 Conclusions . . . . . . . . . . . . . . . . 63

7.2 Recommendations.............. . 64

8.0 REFERENCES ...................... 65

APPENDIX A - CORE INLET FLOW AND VOID FRACTION SENSOR DESIGN REQUIREMENTS .................... 67

APPENDIX B - SPECIFICATION DENSITY SENSING SYSTEM FOR LOFT-ES-60188. . . . . . . . . . . . . . . . 77

APPENDIX C - SPECIFICATION - ULTRASONIC DENSITY SENSING SYSTEM FOR LOFT-ES-60203 . . . . . . . . . . . . 95

APPENDIX 0 - ANALYTIC AND EXPERIMENTAL INVESTIGATION OF ULTRASONIC PROBES FOR APPLICATION IN DENSITY SENSING SYSTEM................. 113

APPENDIX E - TEST PLAN FOR EVALUATION TESTING OF CONDUCTIVITY VOID FRACTION TRANSDUCER IN AIR-WATER FLOW LOOP. . 173

APPENDIX F - TEST PLAN FOR EVALUATION TESTING OF PANAMETRICS ULTRASONIC VOID FRACTION TRANSDUCER IN AIR-WATER

APPENDIX G - ANALYSIS OF CONDUCTIVITY PROBE IN A HORIZONTAL TEST SECTION . . . . . . . . . . . . . . 197

APPENDIX H - VERTICAL FLOW TESTS OF CONDUCTIVITY AND ULTRASONIC VOID FRACTION DETECTORS. ......... 253

APPENDIX I - ULTRASONIC SENSOR IN STEAM-WATER MIXTURES. . . . . . 291

APPENDIX $\mathrm{J}$ - ELECTRONIC CIRCUIT SIGNAL PROCESSING AND REDUCING CONOUCTIVITY VOID FRACTION DATA . . . . . 295

APPENDIX K - SELECTION MATRIX . . . . . . . . . . . . 307 


\section{FIGURES}

1. Drawing of the LLD conductivity detector. . . . . . . . 6

2. Photograph of the LLD conductivity detector. . . . . . . . . 7

3. Photograph of the LLD conductivity detector installed in an instrument washer................. 8

4. Block diagram of the conductivity void fraction system . . . . 10

5. Orawing of the ultrasonic void fraction detector . . . . . . 12

6. Photograph of the ultrasonic void fraction detector. . . . . 13

7. Photograph of the ultrasonic void fraction detector installed in an instrument washer. ............ 14

8. Photograph of ultrasonic detector showing magnetostrictive stub attached to a 304 stainless steel wave guide in extensional-torsional-extensional mode conversion arrangement.

9. Block diagram of the LOFT single beam gamma densitometer system . . . . . . . . . . . . . . . . . . .

10. Wave form characteristics of the ultrasonic signal conditioner.

11. Block diagram of the LOFT single beam gamma densitometer system.

12. Photograph of semiscale air-water loop arranged in horizontal configuration.

13. Orawing showing test configuration for conductivily vuid fraction test series in horizontal section of Semiscale air-water loop ...................

14. Photograph showing conductivity void fraction detector and single beam gamma densitometer installed in horizontal section of Semiscale air-water loop. . . . . . . . . . .

15. Graph showing time average data for conductivity detector in a vertical section (CD Series). . . . . . . . . . 28

16A. Time signature plot of CD-35 (conductivity detector) . . . . 29

16B. Time signature plot of CD-35 (densitometer). . . . . . . 30

17A. Power spectral densities plot of $\mathrm{CD}-35$ (conductivity detector). 
17B. Power spectral densities plot of CD-35 (densitometer). . . . 32

18A. Probability density function plot of $\mathrm{CD}-35$ (conductivity detector)....................... 33

18B. Probability density function plot of CD-35 (densitometer). . . 34

19. Cross correlation plot of CD-35. . . . . . . . . . . 35

20. Graph showing time average data for the conductivity detector in a horizontal section AV-33 through AV-78 . . . . 37

21. Graph showing time average data for the conductivity detector in a horizontal section AV-49 through AV-80 . . . . . 38

22A. Time signature plot of AV-64 (conductivity detector) . . . . 39

22B. Time signature plot of AV-64 (densitometer). . . . . . . . 40

23A. Power spectral densities plot of AV-64 (conductivity detector)....................... 41

238. Power spectral densities plot of AV-64 (densitometer). . . . . 42

24A. Probability density function plot of AV-64 (conductivity detector)..................... 43

24B. Probability density function plot of AV-64 (densitometer). . 44

25. Cross correlation plot of AV-64. . . . . . . . . . . 46

26. Photograph of Semiscale air-water loop arranged in vertical configuration.................. 49

27. Drawing showing test configuration for ultrasonic and conductivity void fraction test series in vertical section of Semiscale air-water loop. . . . . . . . . . .... 50.

28. Photograph showing ultrasonic void fraction detector and single beam gamma densitometer installed in vertical section of Semiscale air-water loop............. 51

29. Graph showing time average data for ultrasonic detector in a vertical section (VF Series). . . . . . . . . . . . 53

30A: Time signature plot of VF-35 (ultrasonic transducer) . . . . 54

30B. Time signature plot of VF-35 (densitometer). . . . . . . . 55

31A. Power spectral densities plot of VF-35 (ultrasonic transducer)..................... 56 
31B. Power spectral densities plot of VF-35 (densitometer). . . . 57

32. Cross correlation plot of VF-35. . . . . . . . . . . 58

33A. Probability density function plot of VF-35 (ultrasonic transducer)..................... 59

33B. Probability density function plot of VF-35 (densitometer). . . 60

\section{TABLES}

I. Design and Performance Requirements. . . . . . . . . . . 4

II. Performance Characteristics as Indicated by Analysis of Test Data. . . . . . . . . . . . . . . . . . . 63 
THE FEASIBILITY OF USING A CONDUCTIVITY

ANO/OR ULTRASONIC TYPE TRANSDUCER TO MEASURE VOID FRACTION

IN THE LOFT REACTOR CORE INLET AND OUTLET

\subsection{INTRODUCTION}

The purpose of the investigation is to determine the feasibility of a conductivity and/or ultrasonic type detector meeting the requirements for measuring void fraction in the LOFT reactor. core inlet and outlet as outlined in the Proposal for Additional LOFT Instrumentation under NRCFederal Republic of Germany Cooperative Agreement. [1] The conductivity type detector configuration was that of the present LOFT. liquid leve? design, while the ultrasonic type detector was designed and fabricated by Panametrics Inc. of Waltham, Mass. Both were designed and fabricated so they could be tested in an air-water test loop. The test data was statistically evaluated to aid in comparison of the performance of the transducers with the reference instrument, a single-beam gamma densitometer. 


\subsection{Introduction}

Two independent systems were designed and fabricated for measuring void fraction. The first system using, a conductivity type detector, consisted of a LOFT liquid level detector (LLD) electrode and a modified set of LLD signal conditioning electronics.

The second system, using ultrasonic techniques for measuring void fraction, consisted of a detertor with a rcctangular stainless steel bar attached to transmit and receive exciting coils. The signal conditioning electronics of the LOFT ultrasonic thermometer system were modified to be used in the present application.

\subsection{Measurement Requirements}

Two specifications were generated to define the detector system. requirements. The first was general (Appendix $B$ ) specifying a density sensing system for LOFT; the second was detailed particularly for the ultrasunic density sensing system (Appendix $C$ ).

The requirements are that sensors be developed which will measure void fraction $(\alpha)$, defined as the time-averaged volumetric fraction of vapor in two-phase mixture. The measurement should be over a large volume and provide an average time measurement, which, when combined with velocity will yield flow accuracies $5 \%$ of range. (The design and performance requirements (Appendix $A$ ) used th achiove the above measurement are given in Table I.)

Sensors are to be developed, and mounting hardware designed for installing the sensor in the following reactor vessel locations: 
(1) The lower tie plate of the center fuel module, which averages the density, is located such that sensor(s) span two holes in the core support plate.

(2) The region of the upper core support structure center fue assembly, covering an area from an elevation near the bottom of the upper core support structure to an elevation approximately two feet above the bottom of the upper core support structure.

(3) The upper core support structure center fuel assembly, located as close as possible to the DTT.

The first prototypes were designed to meet the physical size and sensing region requirements for the lower tie plate location. 
TABLE I

DESIGN AND PERFORMANCE REQUIREMENTS ${ }^{[a]}$

Performance Characteristics - The detector must meet the following measurement capabilities:

Range System Accuracy [b] . Response

0.80 to $1000 \mathrm{~kg} / \mathrm{m}^{3}$

$\left(0.05\right.$ to $\left.62.4 \mathrm{ibm} / \mathrm{ft}^{3}\right) \quad \pm 5 \%$ of range $100 \mathrm{~ms}$ (10 to $90 \%$ rise)

Temperature - The detector should be operable over a temperature from room temperature to $343.3^{\circ} \mathrm{C}\left(650^{\circ} \mathrm{F}\right)$ with peak temperature for short durations (30 to $60 \mathrm{~s}$ ) in $537.8^{\circ} \mathrm{C}\left(1000^{\circ} \mathrm{F}\right)$ steaiil during each loss-ofcoolant experiment (LOCE).

Pressure - LOFT Maximum operating pressure: $17.2 \mathrm{MPa}$ (2500 psig) Maximum cold hydrostatic: $25.9 \mathrm{MPa}$ (3750 psig)

Radiation - Total neutron exposure $=7.2 \times 10^{20} \mathrm{nvt}$ Total gamma exposure $=2 \times 10^{12} \mathrm{R} / \mathrm{hr}$

Water Chemistry - The LOFT primary coolant system chemistry specifications are shown in Appendix B, Table I.

Flow Velocity - 0.6 to $6.0 \mathrm{~m} / \mathrm{s}(2.0$ to $19.7 \mathrm{ft} / \mathrm{s})$

Flow Momentum - 300 to $3130 \mathrm{~kg} / \mathrm{m}^{-\mathrm{s}^{2}}\left(0.20\right.$ to $\left.2.10 \times 10^{3} \mathrm{lb} / \mathrm{ft}-\mathrm{s}^{2}\right)$

Design Life - 10,000 hours including 2000 effective full power hours

[a] Refer to Appendix A.

[b] System accuracy represents the acceptable error total of all contributory measurement system errors (detection, transmittal, digitizing, long term stability, and changing environmental conditions, etc.) 


\section{0 INSTRUMENT DESCRIPTION}

\section{1 Conductivity Void Fraction System}

3.1.1 Design Concept. The conductivity void fraction system consists of one electrode and modified signal conditioning electronics from the LOFT LLD ${ }^{[2]}$. The detector, as shown in Figures 1 and 2 , is a single electrode with associated shroud, spaces and cables that exist in the LLD. The purpose of this design was to simulate the existing LLD to determine its usefulness as a void fraction detector. The shroud and cabling on the test device were mounted so that the detector could be mounted in a lexan instrument washer (Figure 3 ) for testing in the Semiscale air-water loop.

The electrode has an active sensing region approximately $25.4 \mathrm{~mm}$ (one inch) long with an outside diameter of $3.18 \mathrm{~mm}(0.125$ inch), see Figure 1. The ground plane which consists of shroud and cabling has a clearance approximately $3.18 \mathrm{~mm}(0.125 \mathrm{inch})$ from the electrode. The detector measures the impedance of the medium between the electrode and surrounding ground plane. The impedance of the electrode to ground is a function of the conductivity of the median and the ratio of vapor to iqquid in the two-phase mixture. The conductivity of the media is a function of temperature and chemistry.

A conductivity study on the liquid level detector has been made ${ }^{[3]}$ and the parameters that effect the operation of the detector in test conditions of air-water were analyzed. Graphs were made showing how the temperature and chemistry of the water effects the conductivity. Given the LOFT reactor water chemistry, the conclusion was that a step change in the resistance of the media from wet to dry is sufficient to provide an accurate measurement of void fraction.

3.1.2 Signal Conditioning. The electronic system used for the conductivity detector is a modified part of the new design of the liquid level electronics. An analog output, the amplitude of which is propor- 


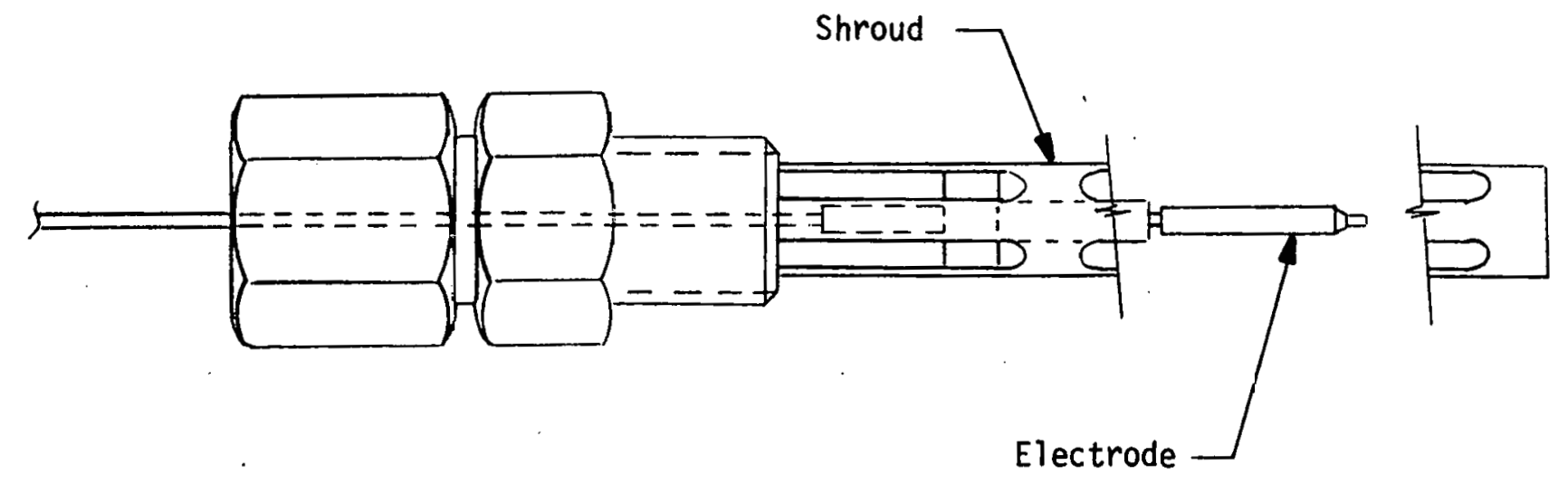

Figure 1: Drawing of the LLD conductivity detector. 


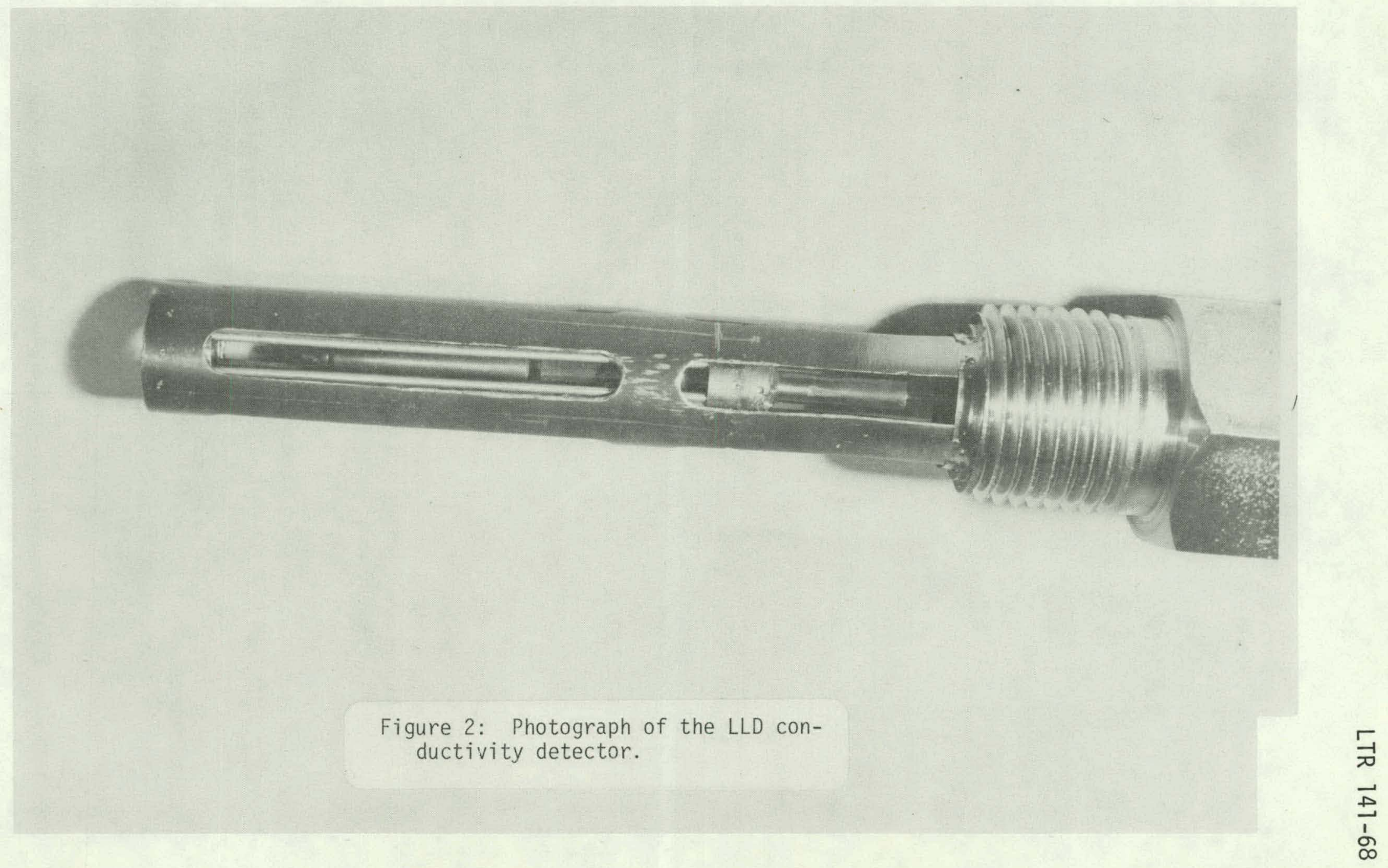




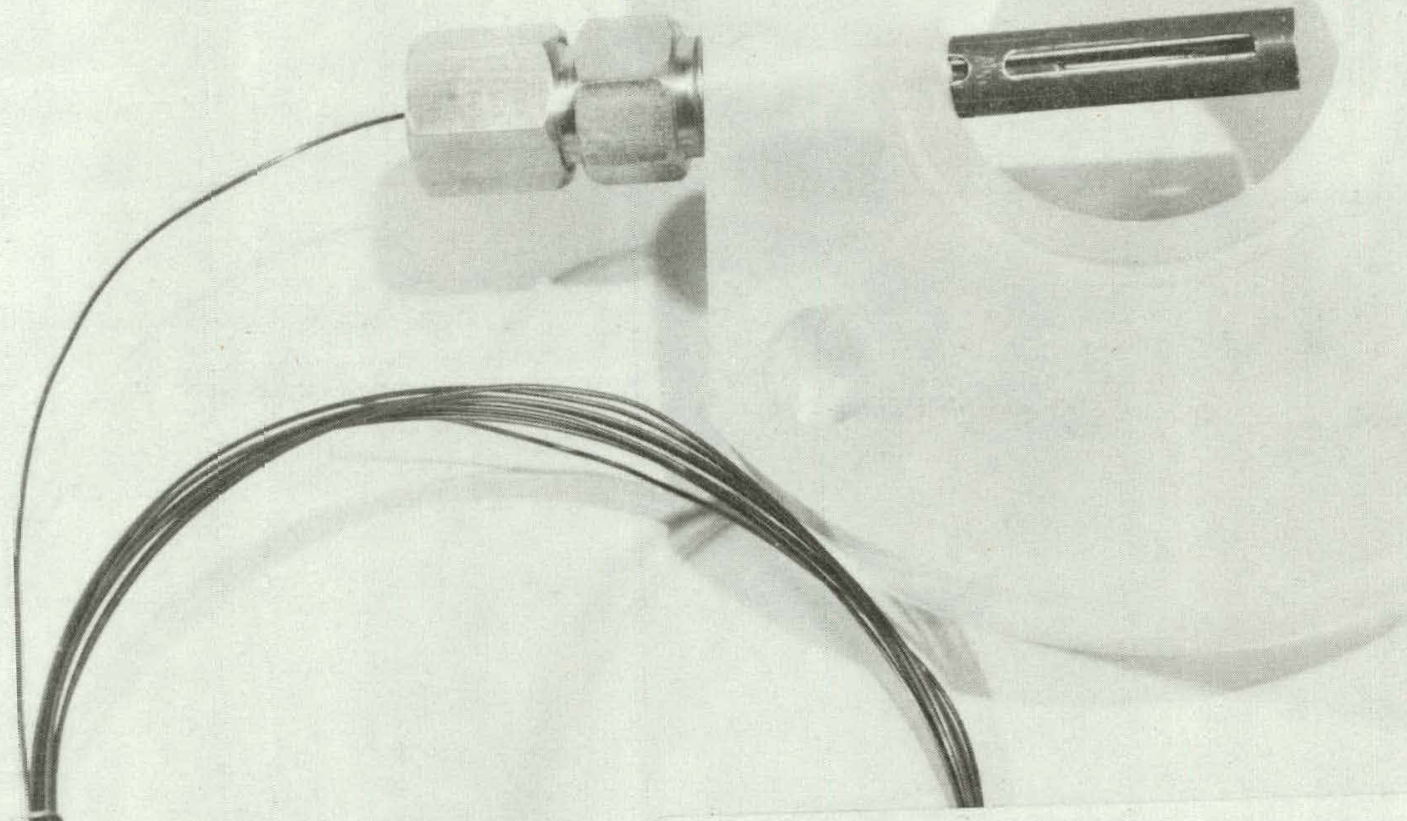

Figure 3: Photograph of the LLD conductivity detector installed in an instrument washer.

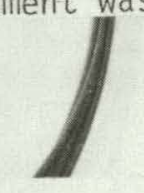


tionate to the resistance across the detector, is provided in a liquid level electronics. A block diagram of the system is shown in Figure 4 and a description of it's operation follows.

A $200 \mathrm{~Hz} 15$ volts peak to peak squarewave (Figure 4) is generated by a Tektronix function generator. This square wave is applied to an adjustable current driver set for $0.1 \mathrm{ma}$, but having the range of $0.1 \mathrm{ma}$ to $1.6 \mathrm{ma}$ in octave steps. The output of the current source is capacitor coupled to the probe through $200 \mu \mathrm{f}$ blocking any $D C$ from the detector. This circuit was designed such that the average current flow through the detector in $100 \mathrm{~ms}$ period is zero. The $100 \mathrm{~K} \Omega$ resistor parallel to the detector shunts any charge tending to build up on the detector. The output of the detector is capacitor-coupled to a voltage follower to provide a low impedance source to the full wave detector. The $5 \mu$ fapacitor prevents any bias current in the voltage follower from reaching the detector.

The original LLD electronics was modified and a precision full wave detector was added to provide a DC signal. This consisted of a half wave rectifier having an output that is multiplied by a minus two and then added to the original signal.

The variable filter is a 2-pole low-pass active filter with band width determined by a selector switch. The adjustable bandwidth has an adjustable range of 6 octaves, $5 \mathrm{~Hz}$ to $160 \mathrm{~Hz}$. For the test $80 \mathrm{~Hz}$ was chosen. Due to the inverting of the signal through the precision full wave detector, the last stage is an inverter which provides a 0 to a positive voltage output. (For more information on the frequency response and step response on the circuit refer to the Liquid Level Detector Redesign. ${ }^{[4]}$ )

When the test was conducted, two calibration points were taken: an all water and an all air point. The indicated delta change of voltage level is about 2.5 volts (2 volts to 4.5 volts), the higher voltage level representing all air. This sytem has a $12.5 \mathrm{~ms}$ response. 
$200 \mathrm{~Hz} 15 \mathrm{Vp} / \mathrm{p}$ for Function Generator

V or I

0

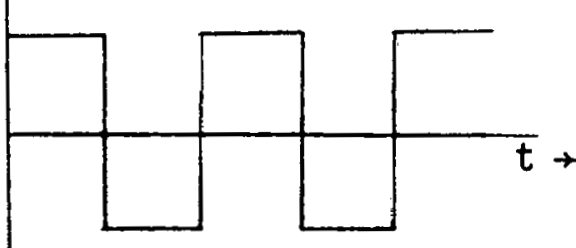

$0.1 \mathrm{ma} 200 \mathrm{~Hz}$ for Current Driver
Voltage across Probe

-or a change in Probe Resistance

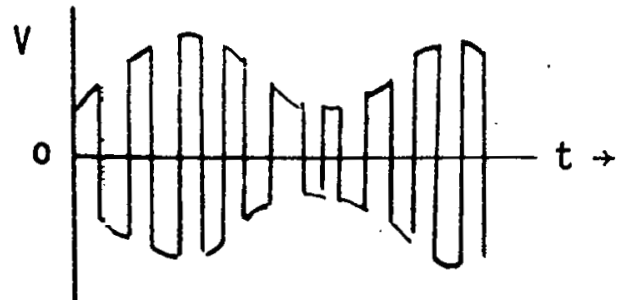

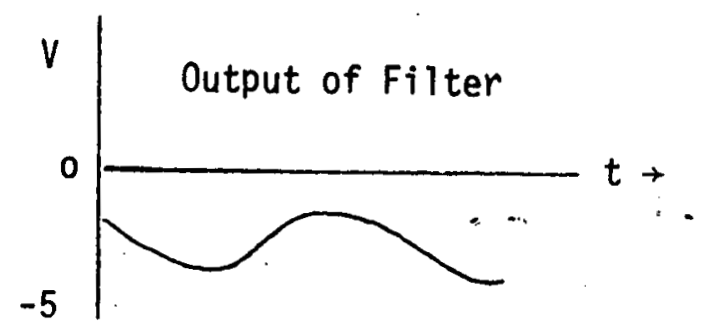

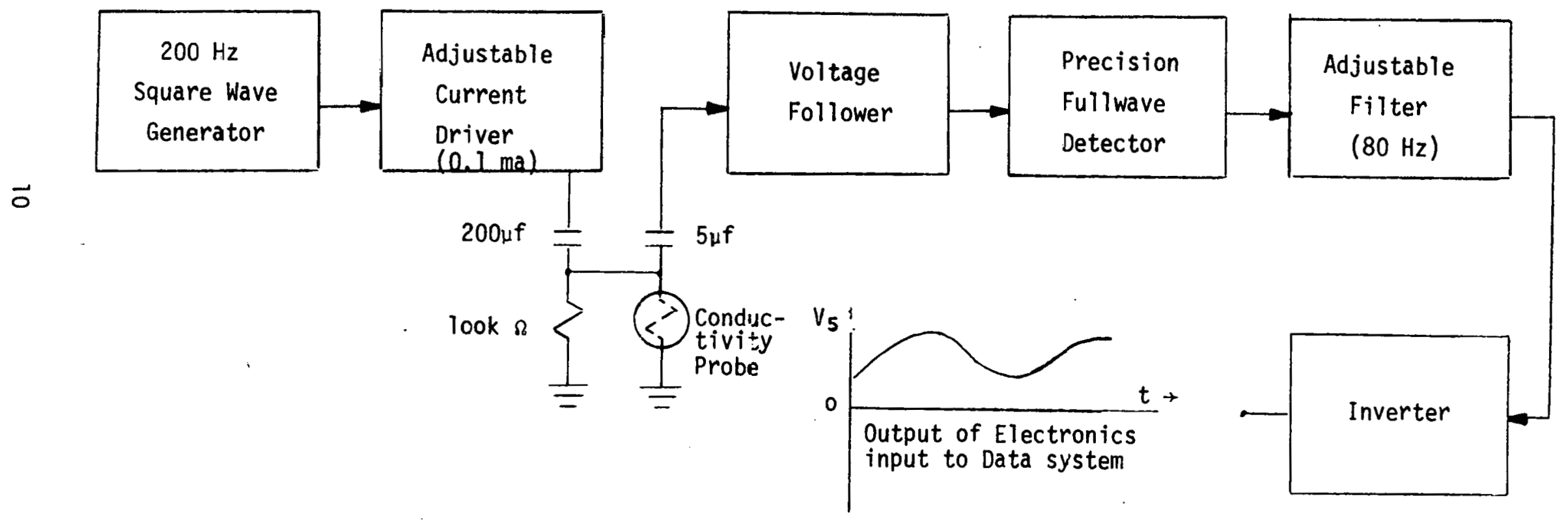

Figure 4: Block ciagram of the conductivity void fraction system. 


\subsection{Uiltrasonic Void Fraction System}

3.2.1 Design Concept. Historically, ultrasonics have been used at INEL to measure center line temperature in fuel rods and studies [5] using ultrasonic techniques have been performed for measuring void fraction. Panametrics of Waltham, Mass., was requested to perform an analytic and experimental investigation to determine the most feasible type ultrasonic detector for measuring void fraction in the LOFT reactor environment.

The Panametrics report (Appendix D) indicated that the density can be linearly gaged using a sensor of suitable shape to measure the transit time of the ultrasonic wave in a stainless steel wave guide. The sensor shape should be rectangular with a width to thickness ratio $(b / d)$ of about three to one. The preferred wave type is a broadband torsional pulse (as indicated by Panametrics) with a center frequency of $100 \mathrm{kHz}$. The sensor should be excited by a magnetostrictive transduction with a mode conversion of extensional-torsional-extensional. The transit time increment $\Delta t$ of the torsional wave can be calibrated from a wet to dry condition to give a linear relationship of density.

A prototype detector (Figures 5 and 6 ), constructed by Panametrics for testing at INEL, was designed to be mounted in a lexan instrument washer (Figure 7) for testing in the Semiscale air-water flow loop. The detector has an active sensing region of $66.04 \mathrm{~mm}(2.60 \mathrm{inch})$, the length determined by the requirements for measuring void fraction in the lower tie plate region, which requires that the detector(s) span two $69.85 \mathrm{~mm}$ (2.75 inch) diameter holes in the core support plate. Panametrics proposed a detector of approximately $152 \mathrm{~mm}$ ( 6 inch) active sensing region, but due to physical size constraints and ease of testing the $66.04 \mathrm{~mm}$ (2.6 inch) region was more feasible for present application. The smaller active sensing region reduces the sensitivity which can be compensated for by using a larger $b / d$ ratio and higher resolution electronics. 


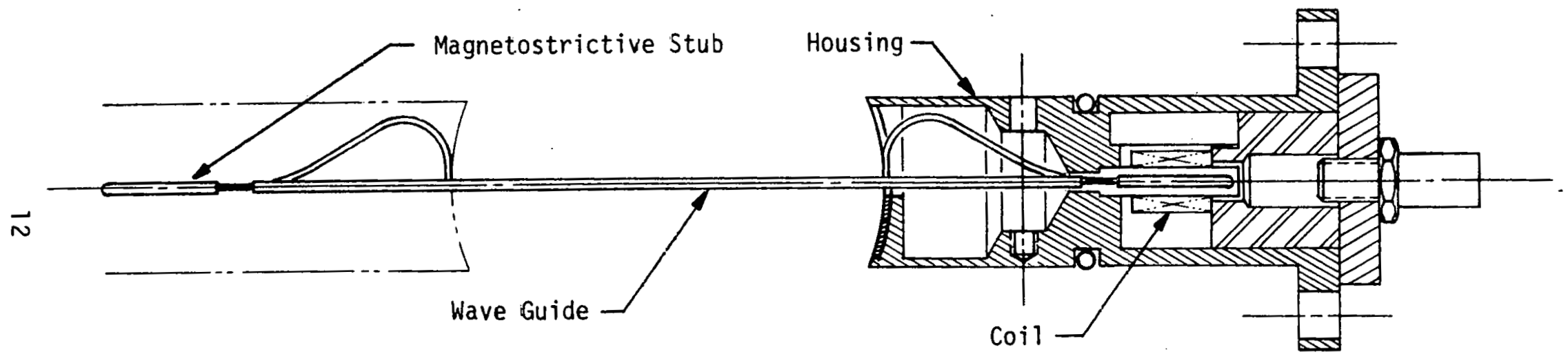

Figure 5: Drawing of the ultrasonic void fraction detector. 


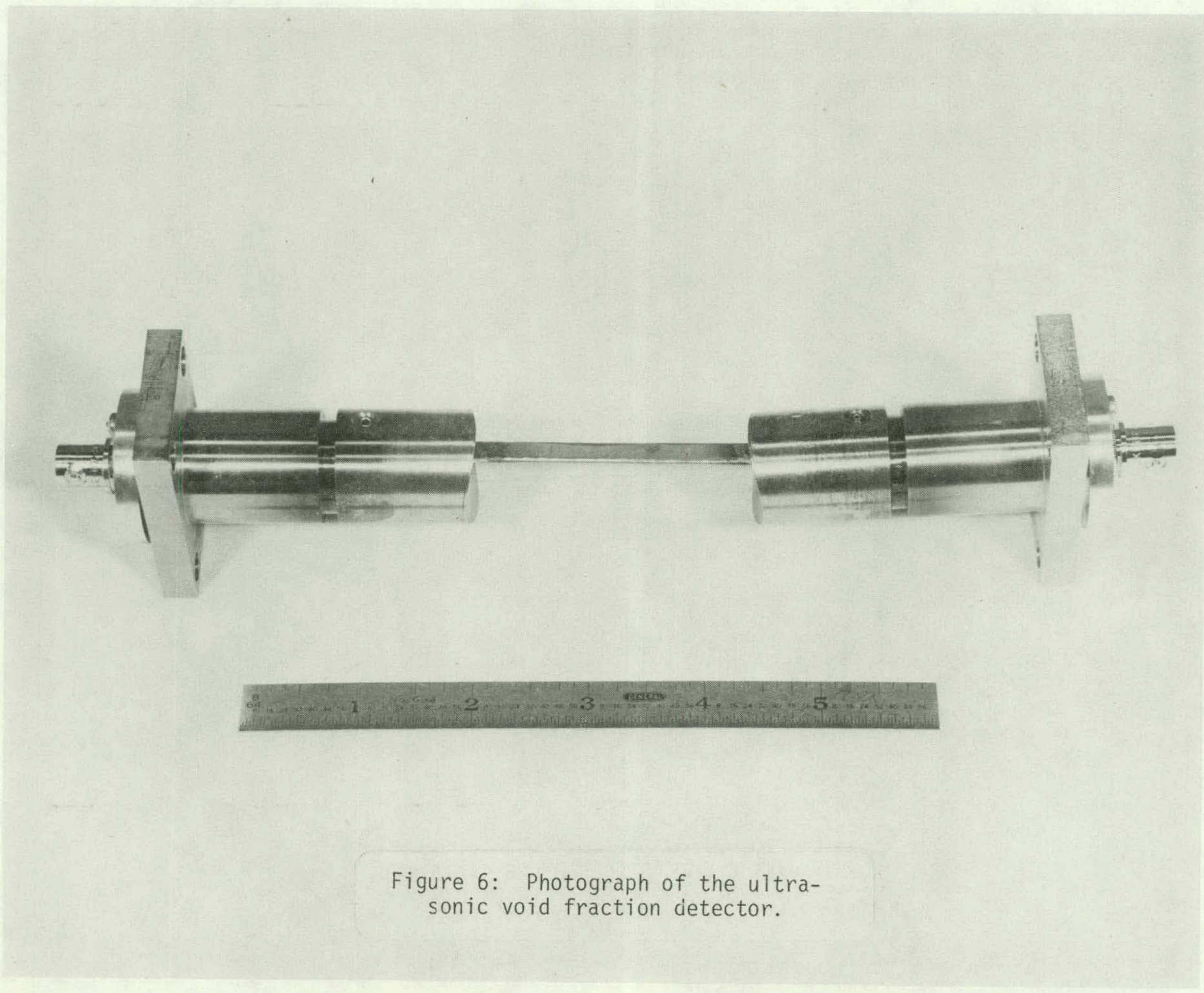




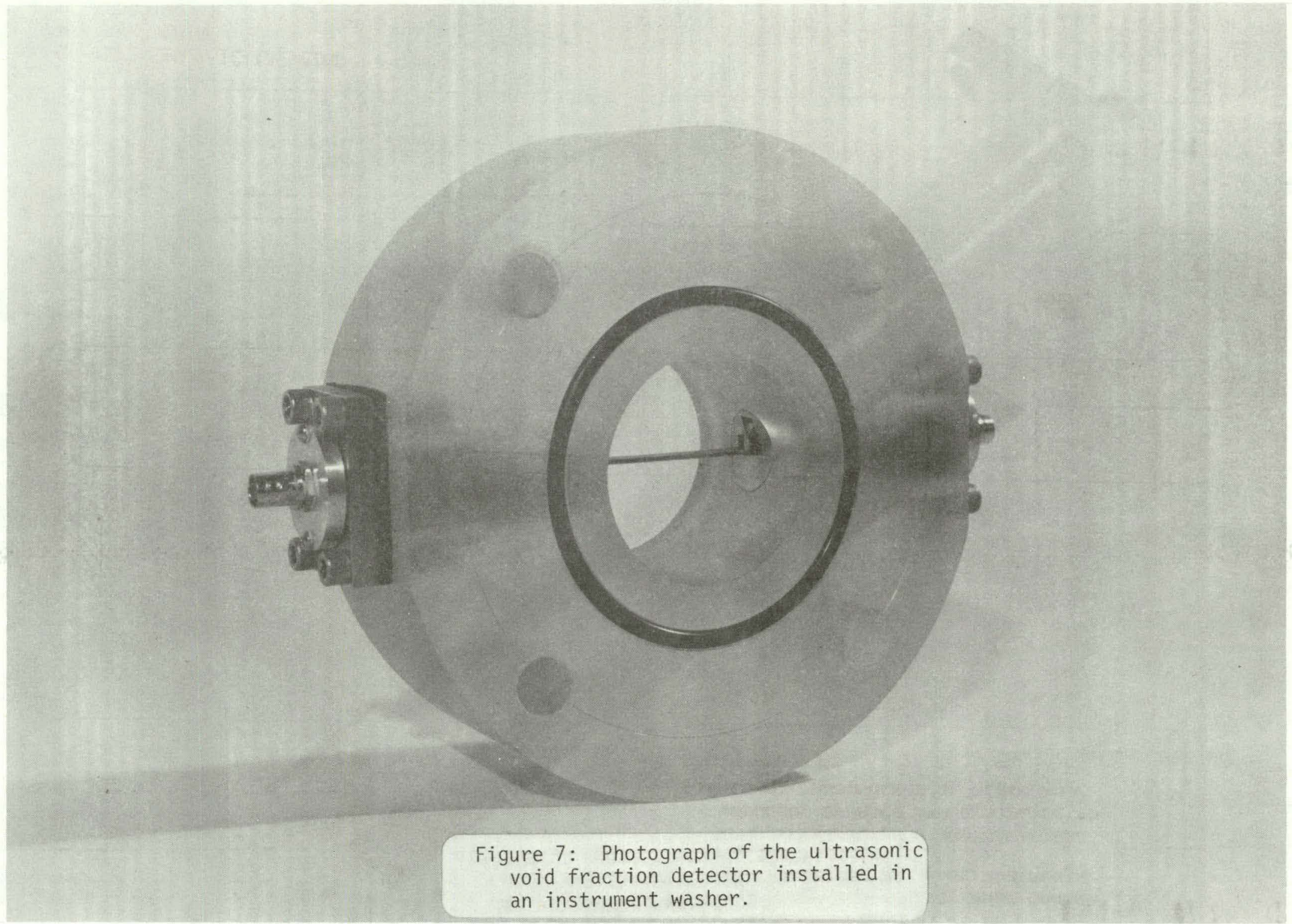


The detector uses a transmit and receive magnetostrictive stub (Figure 8 ) attached to a 304 stainless steel wave guide. This arrangement uses the extensional-torsional-extensional mode conversion technique (Appendix D).

The wave guide sensor has a width of approximately $6.35 \mathrm{~mm}$ (0.25 inch) and a thickness of approximately $1.59 \mathrm{~mm}(0.0625$ inch), giving a b/d ratio of approximately four to one for greater sensitivity, which helps compensate for the reduced sensor length. The transducer coils are enclosed in a sealed housing so water does not reach the electrical leads.

3.2.2 Signal Conditioning. The electronics developed for the Ultrasonic Thermometer ${ }^{[6]}$ used by the Power Burst Facility (PBF) for measuring fuel rods centerline temperature, was modified to meet the needs of the ultrasonic void fraction detector. A block diagram of the system is provided in Figure 9, and wave characteristics at different parts of the circuit are shown in Figure 10.

A 10v 3 us pulse width and $500 \mathrm{~Hz}$ repetition rate are generated by a Function Generator and applied to transmit coil A of the detector. The ultrasonic wave propagates down the transmission line and is picked up by the receiver coil $\mathrm{B}$. The total propagation time is approximately $65 \mu \mathrm{s}$ when the sensor is dry. The signal is then applied to a bandpass filter with a selected adjustable gain of 10 . The signal band width is limited by a passive LC filter having a center frequency of $130 \mathrm{KHz}$, $\pm 70 \mathrm{KHz}$ at $3 \mathrm{~dB}$ down. This provides the system with some immunity to signals well removed from the ultrasonic oscillation frequency. Noise is eliminated by using a circuit that blanks out the signal until the ultrasonic wave arrives.

For accuracy, zero crossings were chosen as a means of measuring the transit time, thus avoiding amplitude variations. Two pulses are needed to operate the counter: one is provided by the pulse generator and the other is supplied by the zero crossing unit. Front panel controls determine which zero crossing is used to measure the transit 
A - HOUSING

C - MAGNETOSTRICTIVE STUB

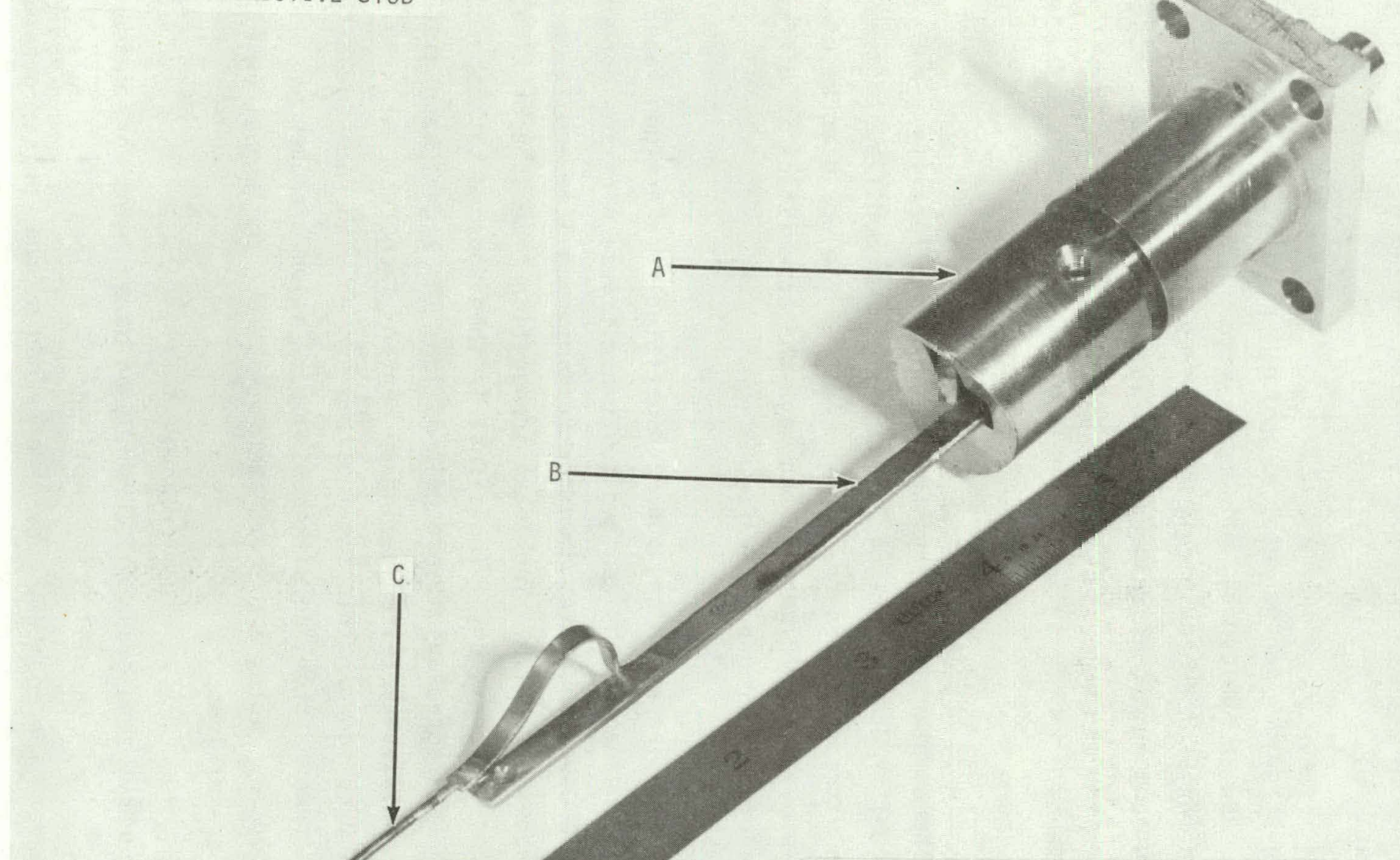

Figure 8: Photogr $\equiv$ oh of 17 trasonic detec tor showin: nagnetostrictive stub attached to $a 304$ stainless

steel wave guide in ex-ensionaltorsional-extens onal rode conversion crrangement. 
Figure 9: Block diagram of the LOFT single beam gamma densitometer system.

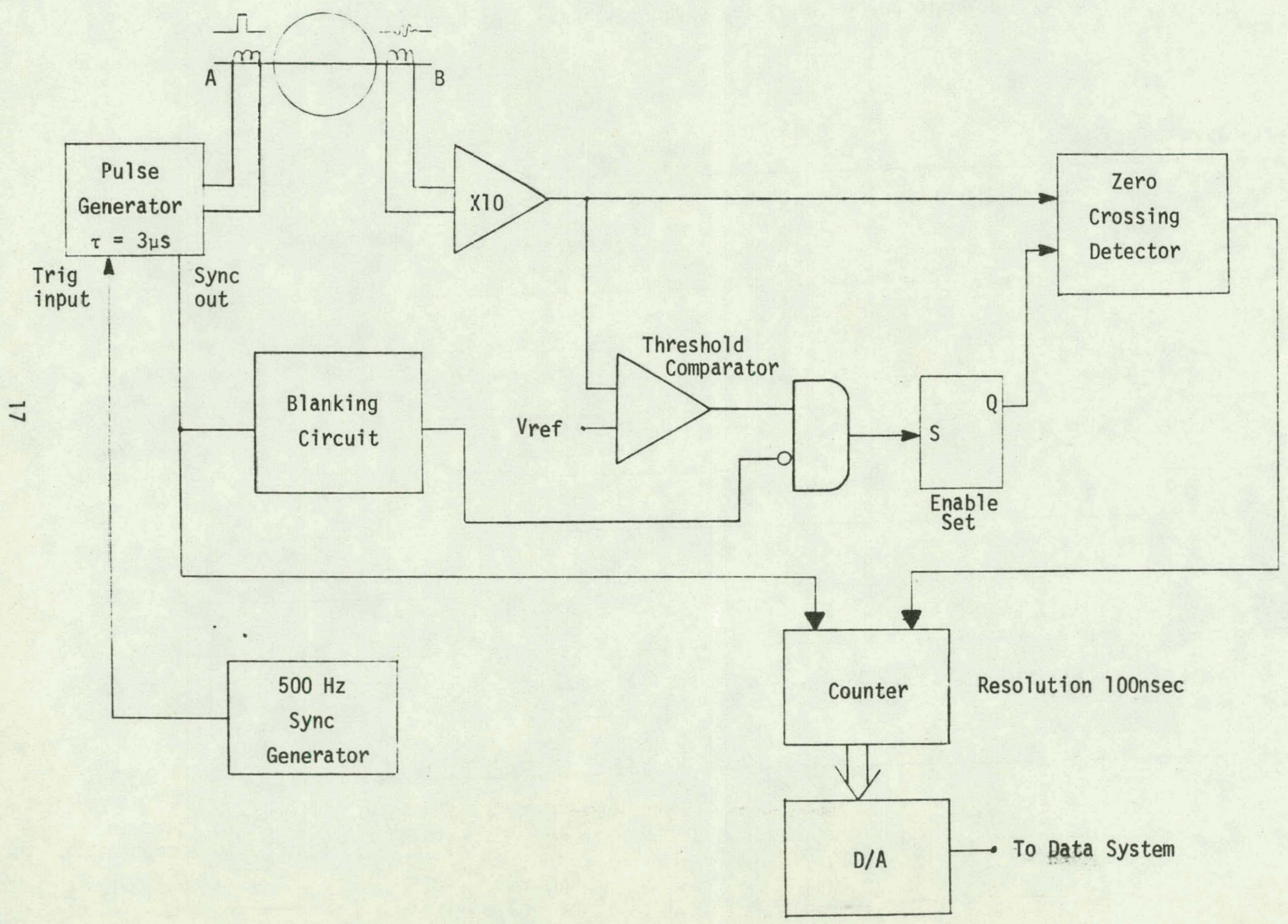




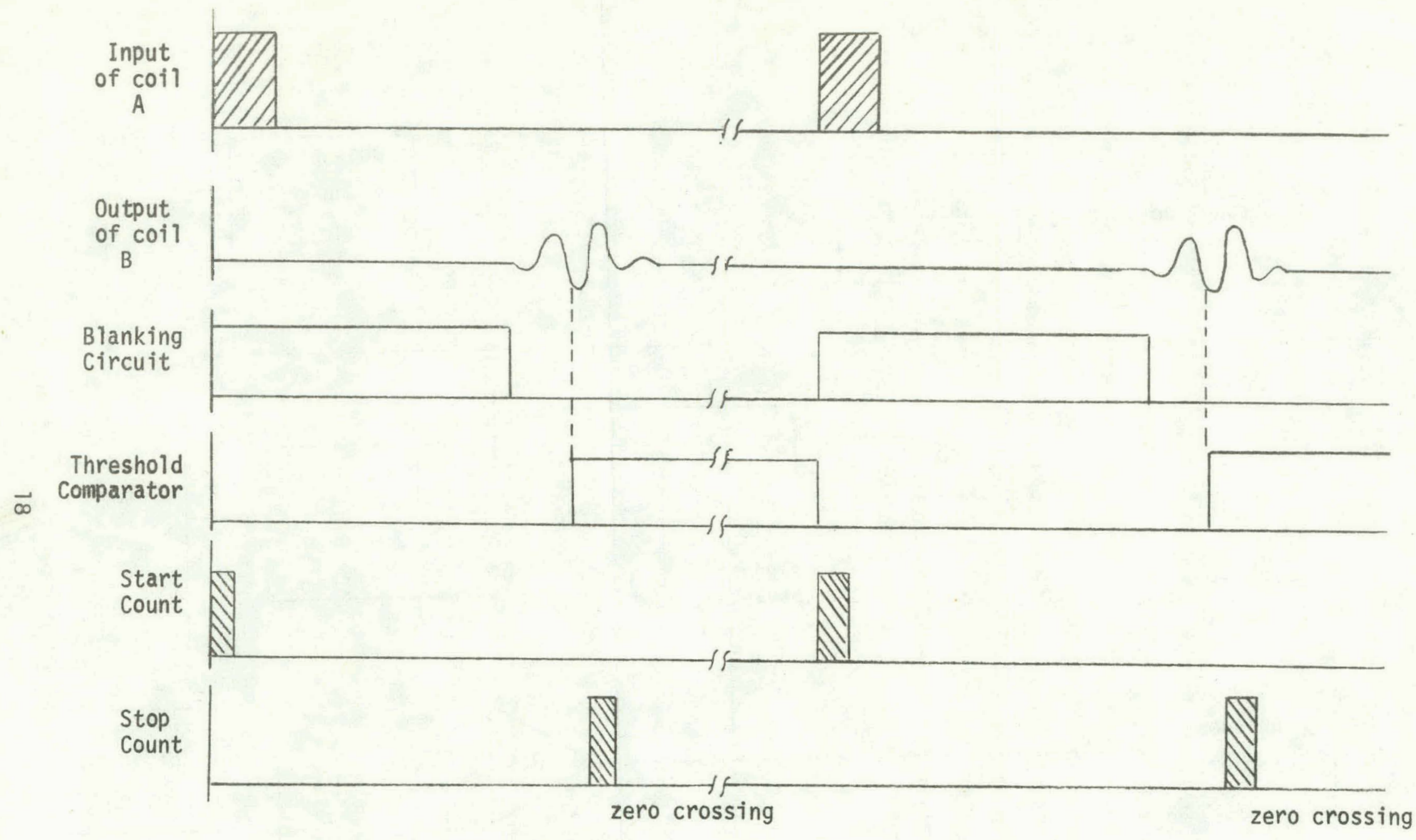

Figure 10: Wave form characteristics of the ultrasonic signal conditioner. 
time. A stop pulse is sent to the counter following the transmitted wave, first negative peak above a given amplitude. As shown in Figure 10, the first large negative peak was chosen to measure the transit time of the propagation wave, thus providing some immunity from amplitude variations due to the affects of air and water on the sensor.

The time between the start and stop pulses is measured by the time interval counter (HP 5326A) with an eight place BCD digital output. The digital to analog converter unit converts the first three places of the digital output of the counter to an analog voltage. The resolution of this unit is $\pm 0.0125 \%$ with a specified temperature drift of less than $30 \mathrm{ppm} /{ }^{\circ} \mathrm{C} \quad\left(16.7 \mathrm{ppm} /{ }^{\circ} \mathrm{F}\right)$. Full scale output is 10 volts with 1 volt equaling $10 \mu \mathrm{s}$. The system is controlled by a $500 \mathrm{~Hz}$ sync generator, thus the ultrasonic signal conditioning system provides a $\pm 5 \%$ measurement with an update every $2 \mathrm{~ms}$, resolution of $100 \mathrm{~ns}$ and a $\Delta \mathrm{t}$ of approximately $4 \mu$ s from wet to dry. 


\section{0 AIR-WATER FLOW LOOP TESTS}

\subsection{Description of Air-Water Flow Loop and Reference Instrumentation}

4.1.1 Air-Water Flow Loop Test Facility. The air-water flow experiments were performed at the INEL Fluids Laboratory in the Semiscale three inch air-water loop. Briefly, the faciltiy consists of a centrifugal pump, separation tank, mixer, heat exchanger and associated valves and piping. Process instrumentation includes turbine meters measuring temperature and pressure, the values of which are used to calculate mass flow rates of air and water before mixing. Loop operating parameters are $0.35 \mathrm{MPa}(50 \mathrm{psia})$ and $37.8^{\circ} \mathrm{C}\left(100^{\circ} \mathrm{F}\right)$ nominal. The maximum water flow is $13201 / \mathrm{min}(350 \mathrm{gpm})$ and the maximum air flow is $2.55 \mathrm{~m}^{3} / \mathrm{min}(90 \mathrm{cfm})$ at $0.38 \mathrm{MPa}$ ( $\left.55 \mathrm{psia}\right)$.

Data acquisition is provided by a Hewlett-Packard 2100 computer. Detector output is first processed through signal conditioning electronics and amplifiers, then through a Data TEC analng to digital multiplexer which is accessed by the HP 2100. Data is stored on disks then transferred to digital magnetic tape.

4.1.2 Air-Water Flow Loop Reference Instrumentation. In each test the main reference instrument, a single beam gamma densitometer located as close as possible to, and with the same orientation as the detector, provided a continuous reference density. The block diagram of the LOFT gamma densitometer is shown in Figure 11.

A current-to-voltage converter and a preamp are attached to the back of the detector casing. The signal is applied through coax to the amplifier/controller module which amplifies the analog signal before being sent to the Semiscale data acquisition system. The output full scale of the data acquisition system is 0 to 1 volt.

A two-beam gamma densitometer (Semiscale) located several pipe diameters upstream, supplied an average density reference for the 


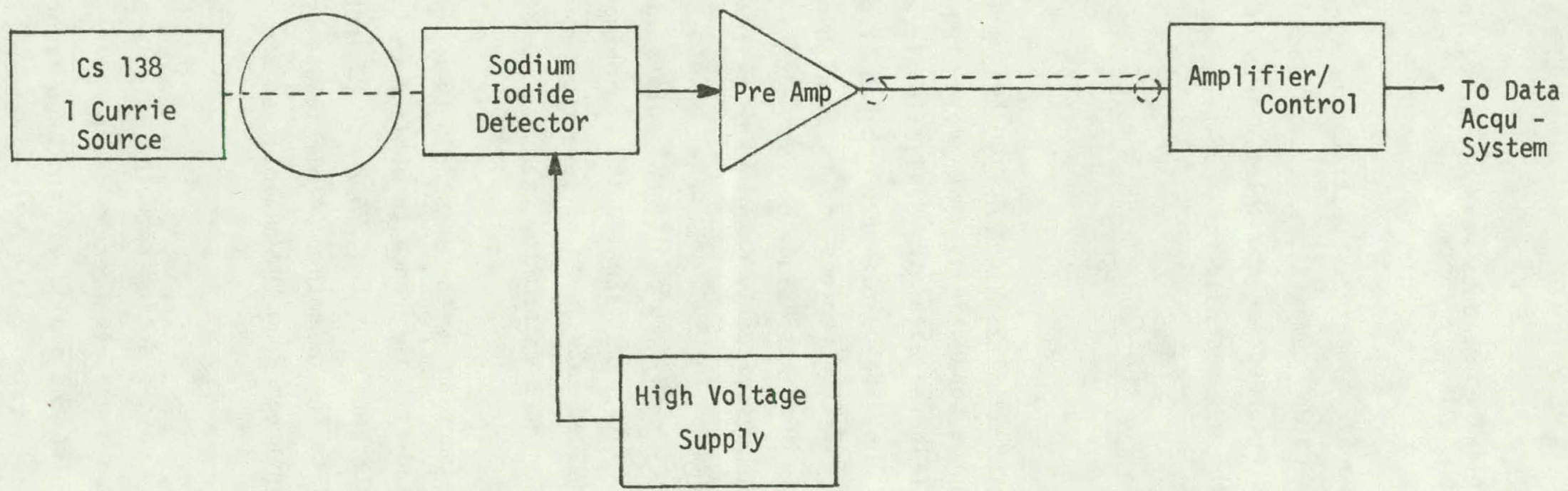

Figure 11: Block diagram of the LOFT single beam gamma densitometer system. 
horizontal test. The horizontal flow regime data was not useful for the vertical evaluation.

A thermocouple located several diameters upstream provided a continuous coverage of the test section temperature. For each data point the average temperature was recorded for the inlet values of both water and air, and the average value was recorded for loop pressure.

\subsection{Description of Air-Water Tests For The Conductivity Void Fraction System}

4.2.1 Horizontal Test of Conductivity Void Fraction System. A test plan (Appendix E) for testing the conductivity type void fraction detector in a horizontal section (Figure 12) of the Semiscale air-water flow loop is found in Appendix $E$. The data points were chosen from a flow map $[7]$ to represent different flow regimes and to be within the capabilities of the flow loop. This test was "piggy backed" with a drag screen test, but the drag screen was visually observed to be too far upstream to effect the flow regime. Thirty-four data points were seleclively chosen from this test with some additional points added. All water and all air calibration points were taken at the beginning and end of the test. The test was divided into seven differeul water flow rates with varying air flow rates for each water flow rate.

The detector was tested in conjunction with a single-beam gamma densitometer (Figure 13 and 14) used as a reference to monit.or the flow conditions. The gamma densitometer was mounted $76.2 \mathrm{~mm}$ ( 3 inches) upstream, with the beam parallel to the detector. A plexiglass spool piece was inserted upstream and downstream from the detector so the flow could be visually monitored.

The data from the conductivity void fraction detector, single-beam gamma densitometer and the loop temperature measurement were processed through signal conditioning electronics and amplifiers and then recorded on FM analog tape. This and other data taken upstream from other test instrumentation at the drag screen were processed and fed into a HP 2100 


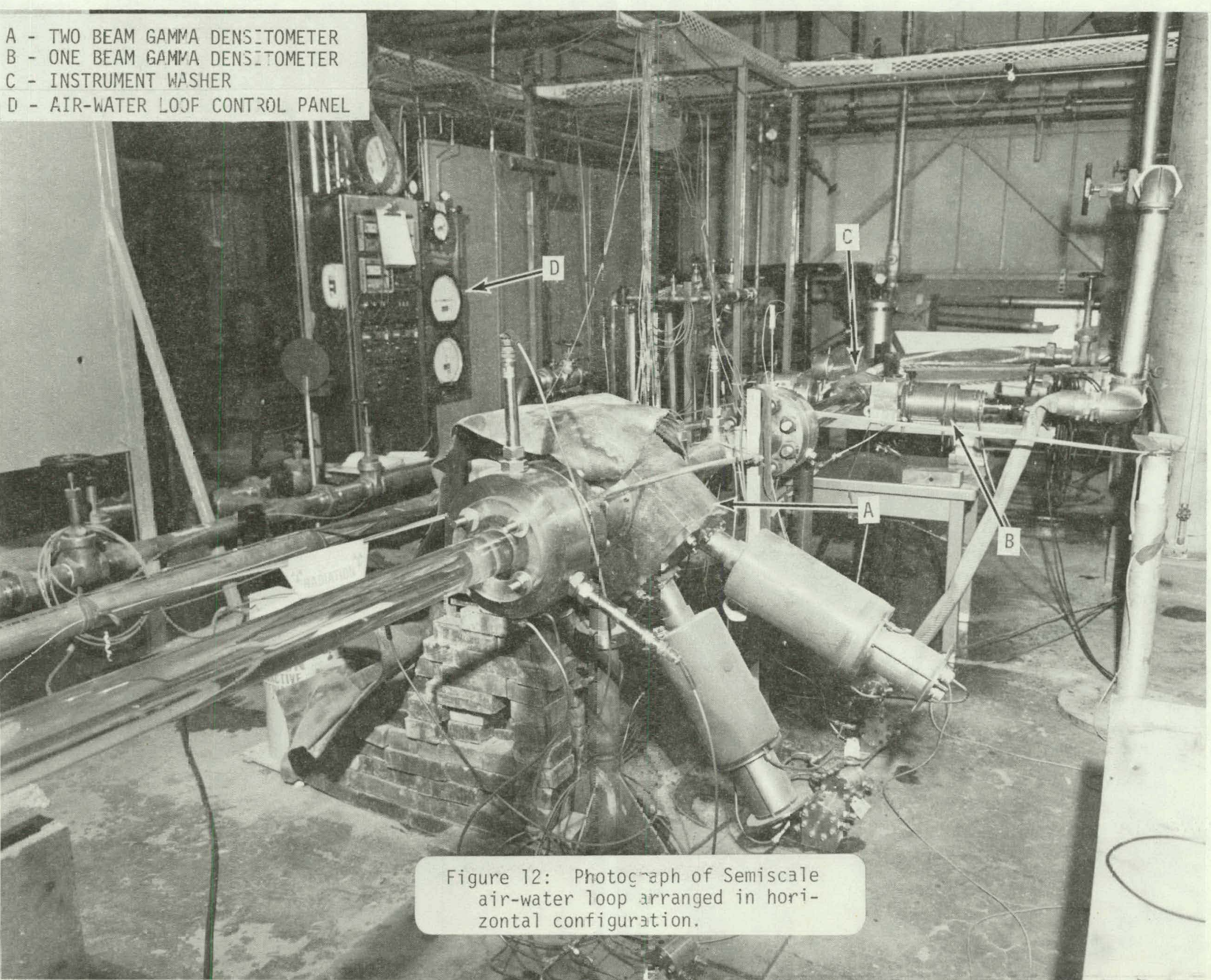




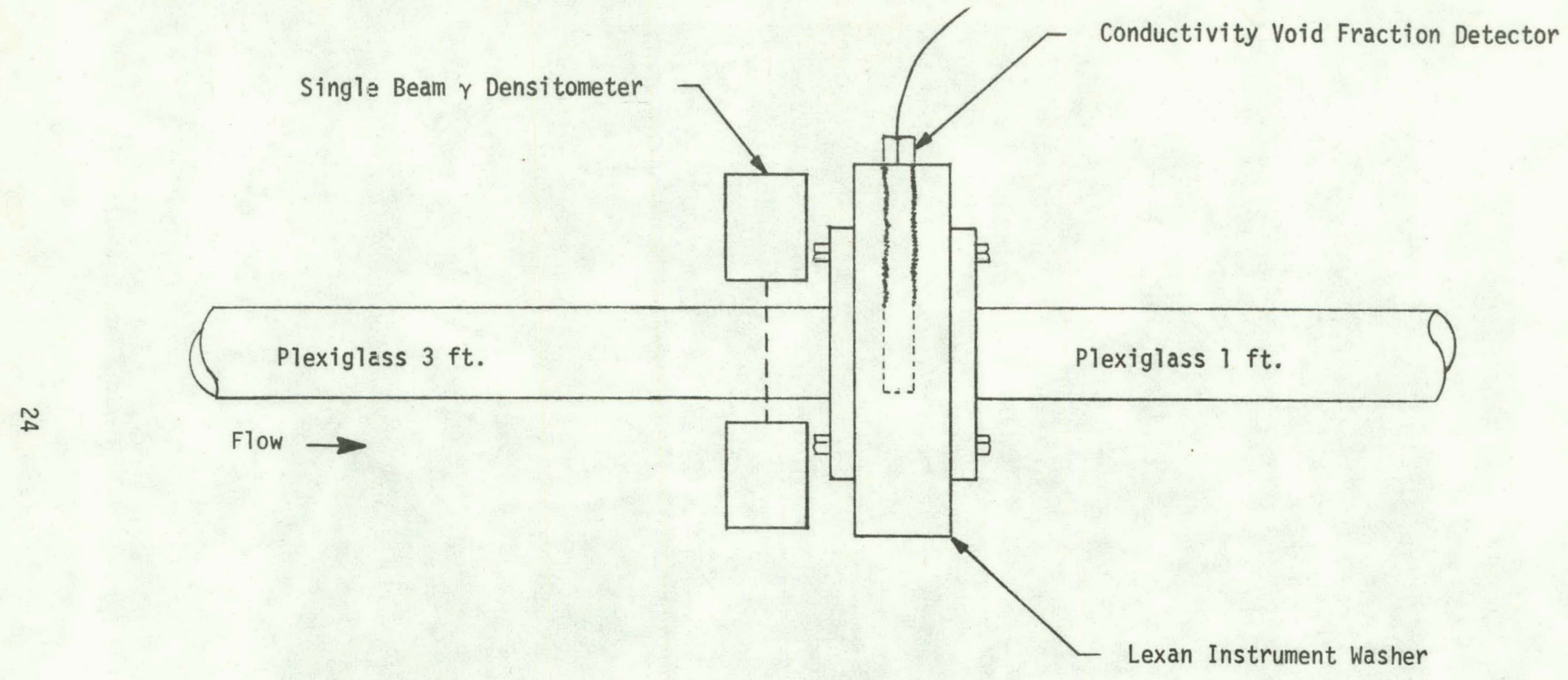

Figure 13: Drawing showing test configuration for conductivity void fraction test series in horizontal section of Semiscale air-water loop. 


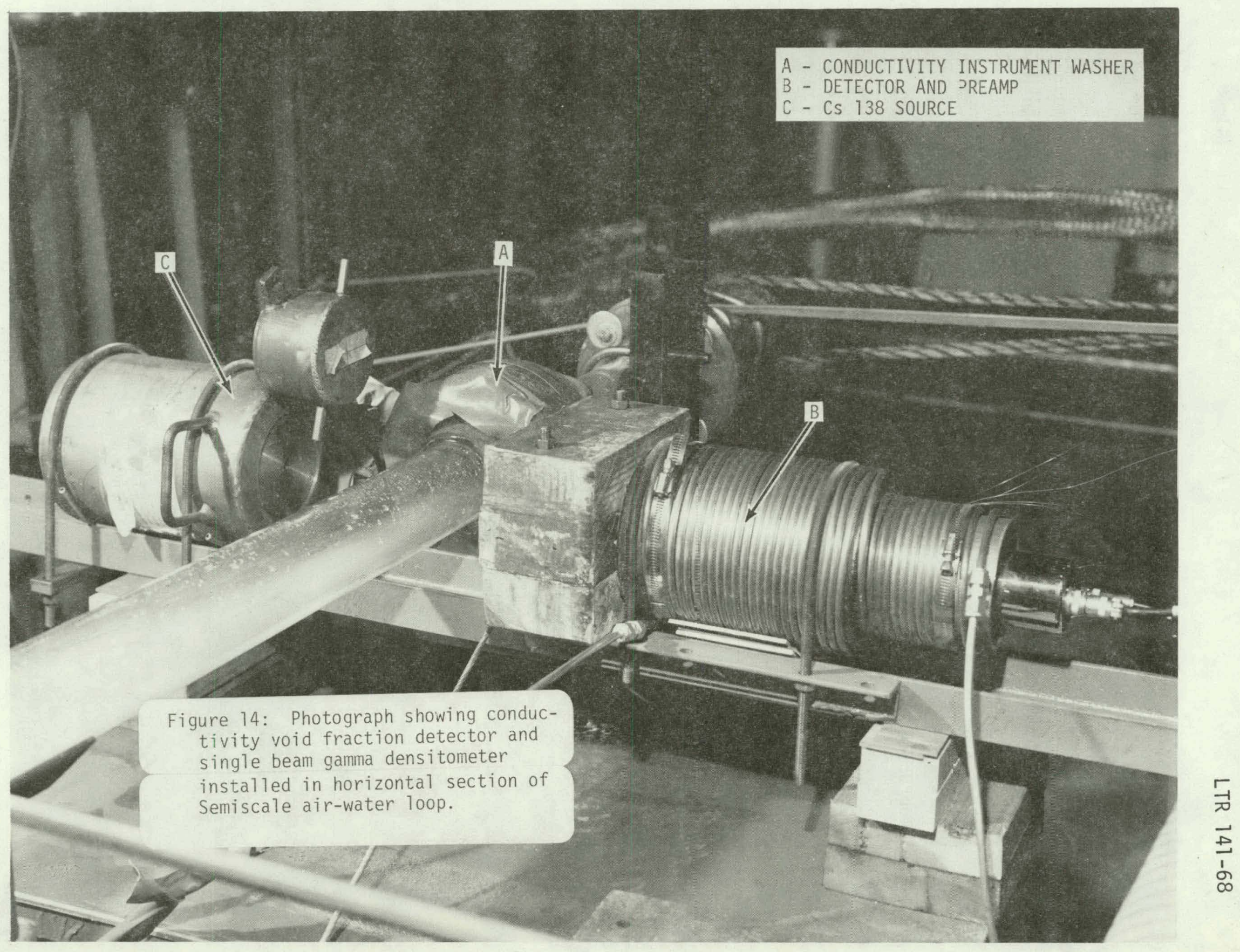


computer at the flow loop where averages taken over a $20 \mathrm{~s}$ period were recorded for each data point.

4.2.2 Vertical Test of Conductivity Void Fraction System. The purpose of this test was to obtain data from the conductivity detector under the same flow conditions as that obtained from the ultrasonic detector, then directly comparing the data. The detector was tested in the vertical section of the Semiscale air-water flow loop using the same test procedures, reference instrumentation, data points and data acquisition methods as were used for the ultrasonic void fraction vertical tests. The ultrasonic void fraction vertical tests are described in Section 6.0 below. 


\subsection{DATA ANALYSIS FOR CONDUCTIVITY VOID FRACTION SYSTEM}

\section{1 Horizontal Test of Conductivity Void Fraction System}

The data obtained from the horizontal test of the conductivity void fraction system was analyzed by the Measurements Performance Section of the LOFT Experimental Measurements Branch. The average data obtained from the Semiscale HP 2100 computer for the single-beam gamma densitometer, and two-beam gamma densitometer (both of which were reference instruments in the test), were converted from volts output to densities with the logrithmic densitometer equation [8]. This average of all the data sets was plotted to obtain an initial indication of the conductivity detector's performance compared with the gamma densitometer reference. The FM analog tapes were digitized to 500 samples/s. The resulting data were reformatted and processed on the Cyber system where the data was digitally filtered to $10 \mathrm{~Hz}$ and decimated to $20 \mathrm{samples} / \mathrm{s}$. Representative sets of filtered decimated data were statistically analyzed, including computation and conversion, in the areas of power spectral densities, probability density functions and, auto and cross correlations. The statistical analyses were designed to detect high noise levels and unexpected signal signatures, and to verify the analyses conducted on the time averaged data.

\subsection{Vertical Test of Conductivity Void Fraction System}

The data from the test of conductivity void fraction system in a vertical test section was analyzed in the same manner as the ultrasonic void fraction data. Average plots were made and statistical analysis was made on the digitized tapes. Data sets were used that were taken under the same flow conditions as the ultrasonic data. The same flow conditions were used so a direct comparison could be made between the ultrasonic and conductivity type detectors. Refer to Figures 15 through 19 for the statistics plots and Appendix $H$ for the report from the Measurement Performance Section. 
DENSITY FRDM EAMMA DENSITOMETEF VS CONDUCTIVITY VDLTS RLL POINTS

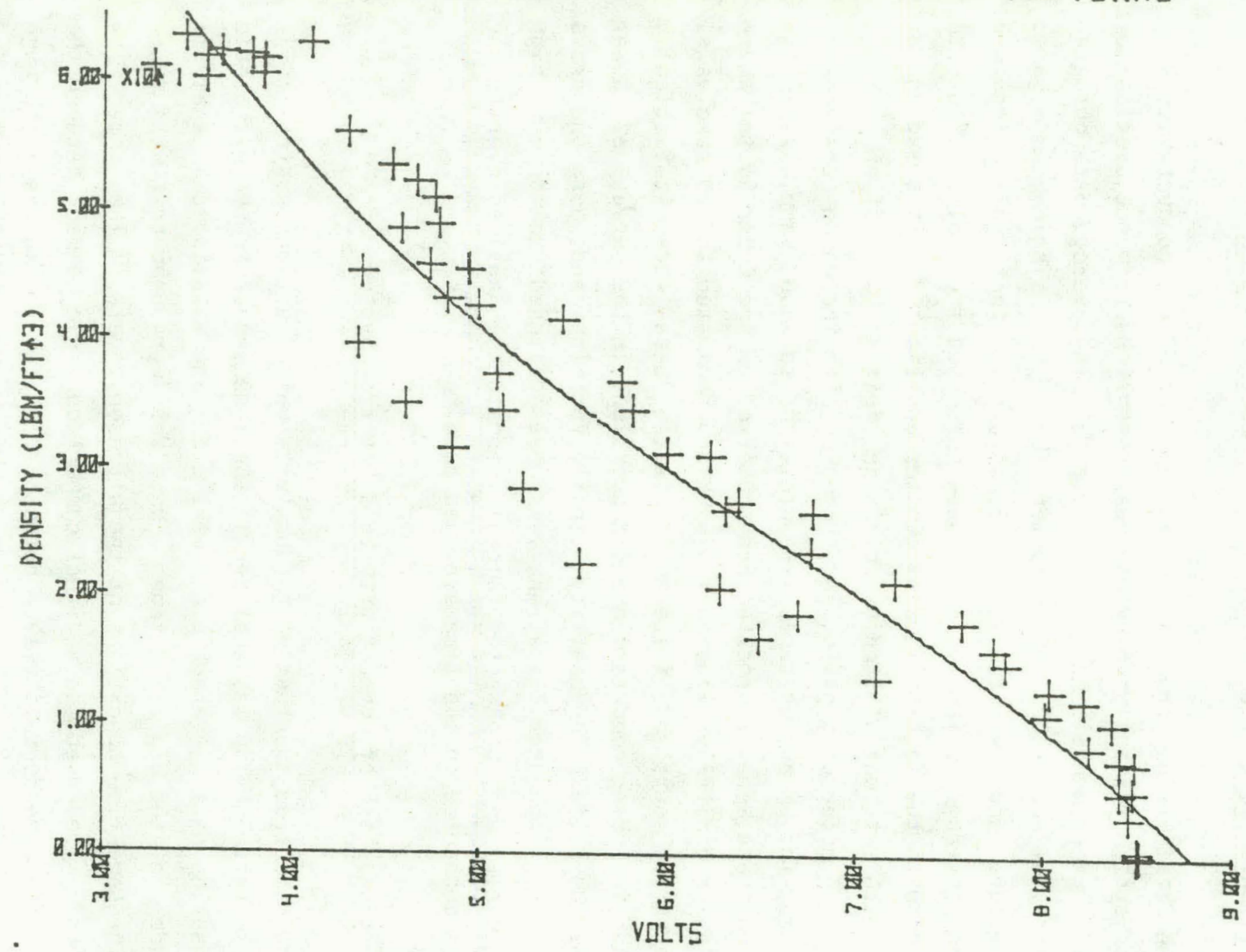

Figure 15: Graph showing time average data for conductivity 


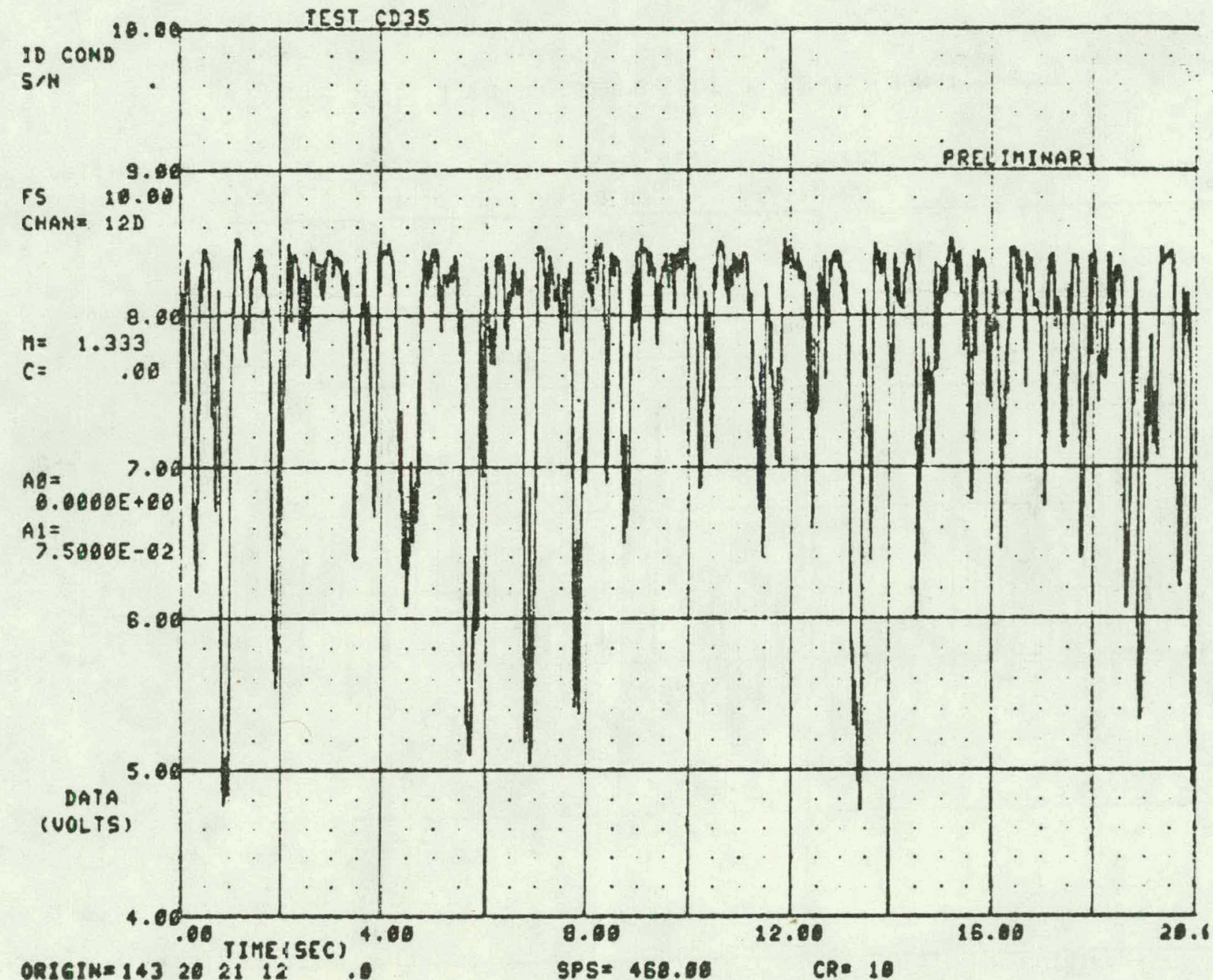

Figure 16A: Time signature plot of CD-35 (conductivity detector). 


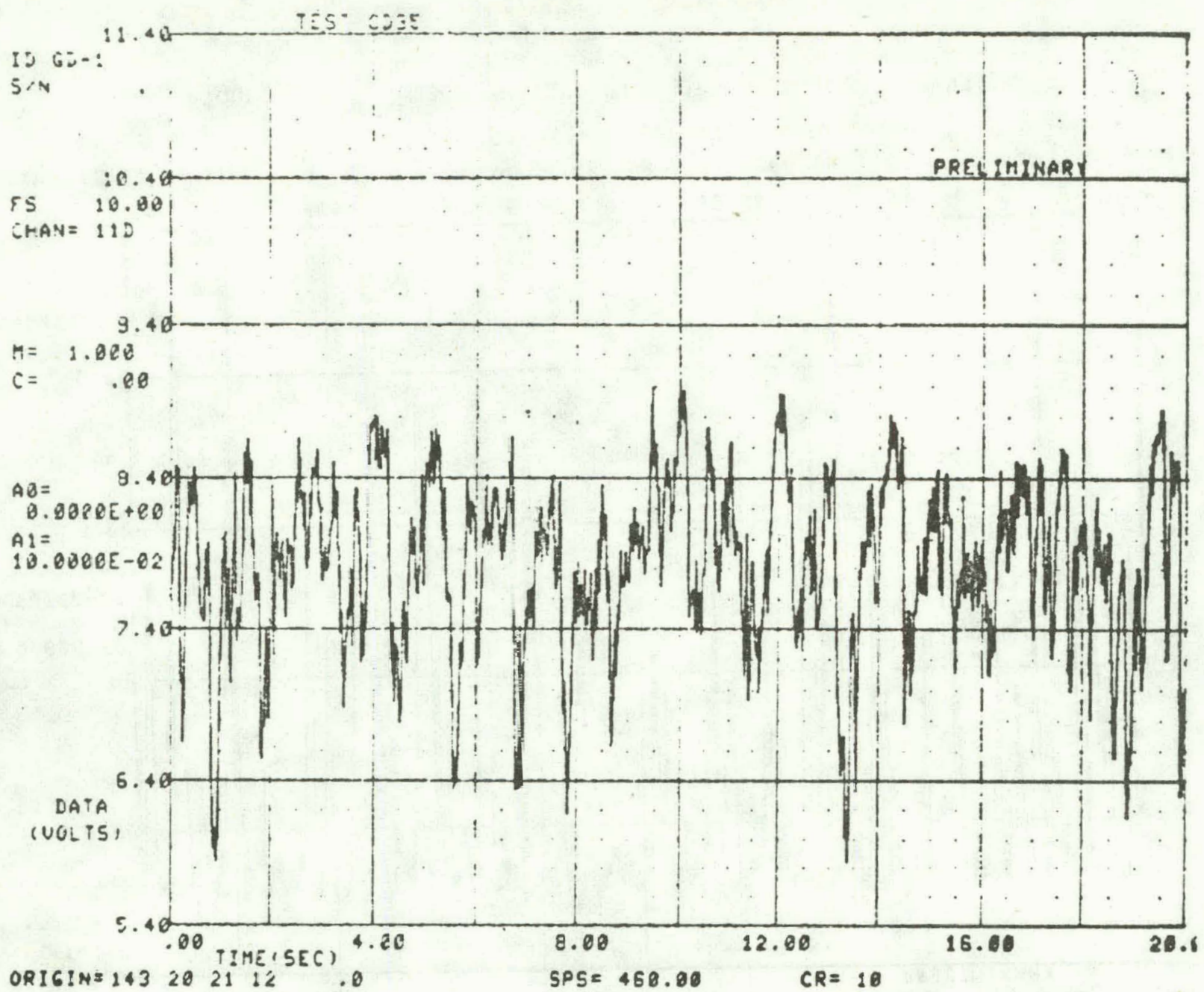

Figure 16B: Time signature plot of CD-35 (densitometer). 


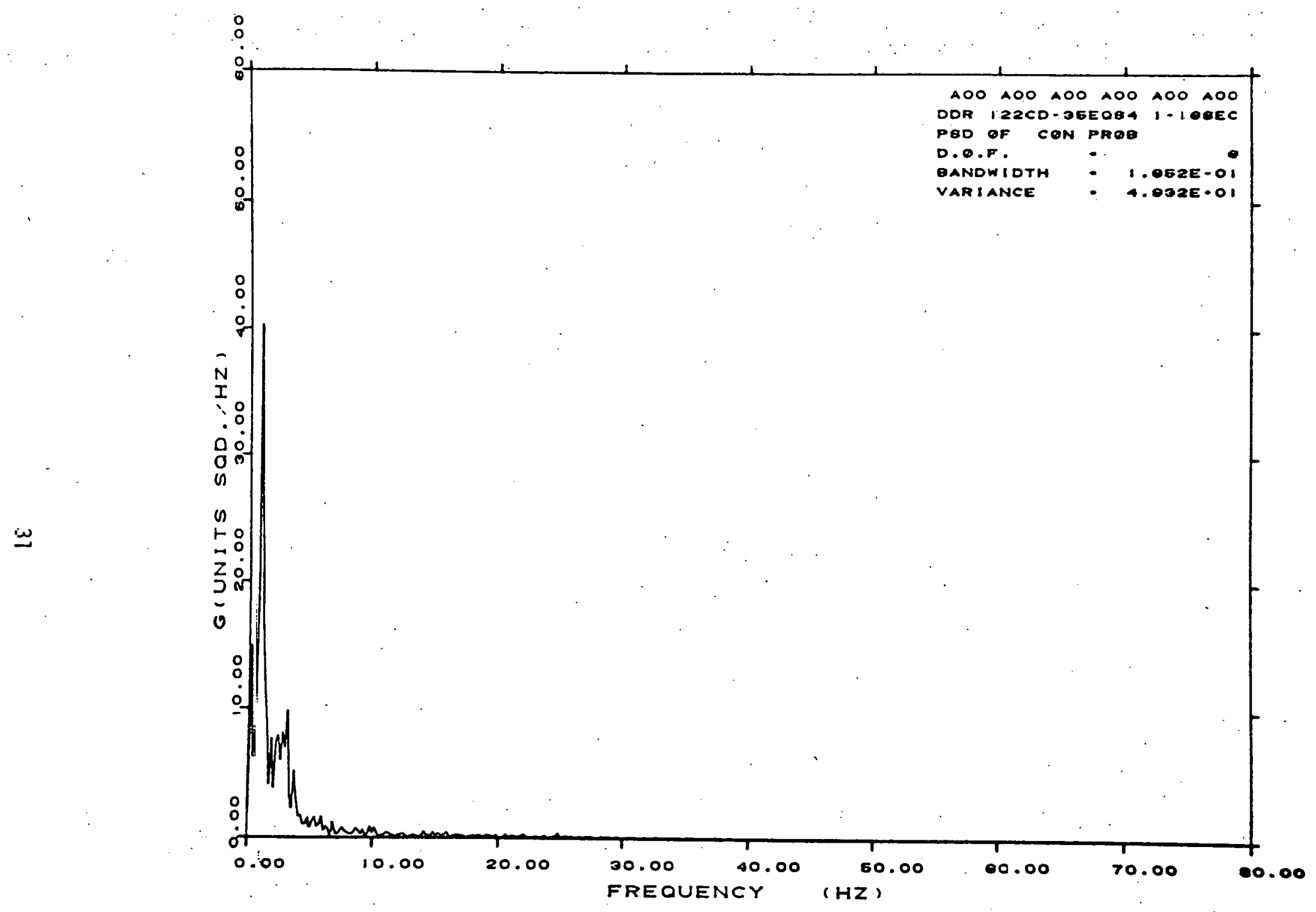

Figure 17A: Power spectral densities plot of CD-35 (conductivity detector). 


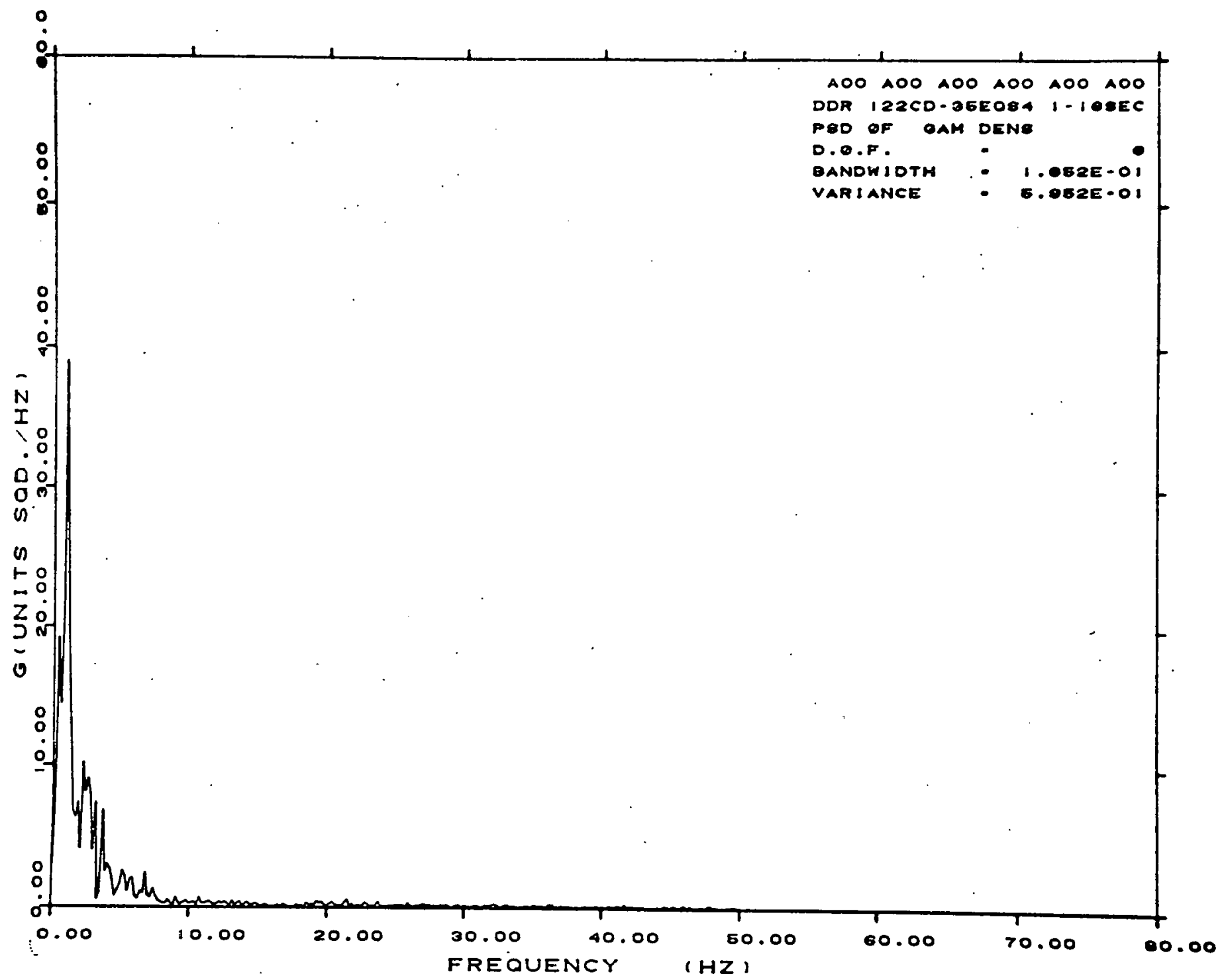

Figure 17B: Power speztral densities plot of $C D-35$ (densitometer). 


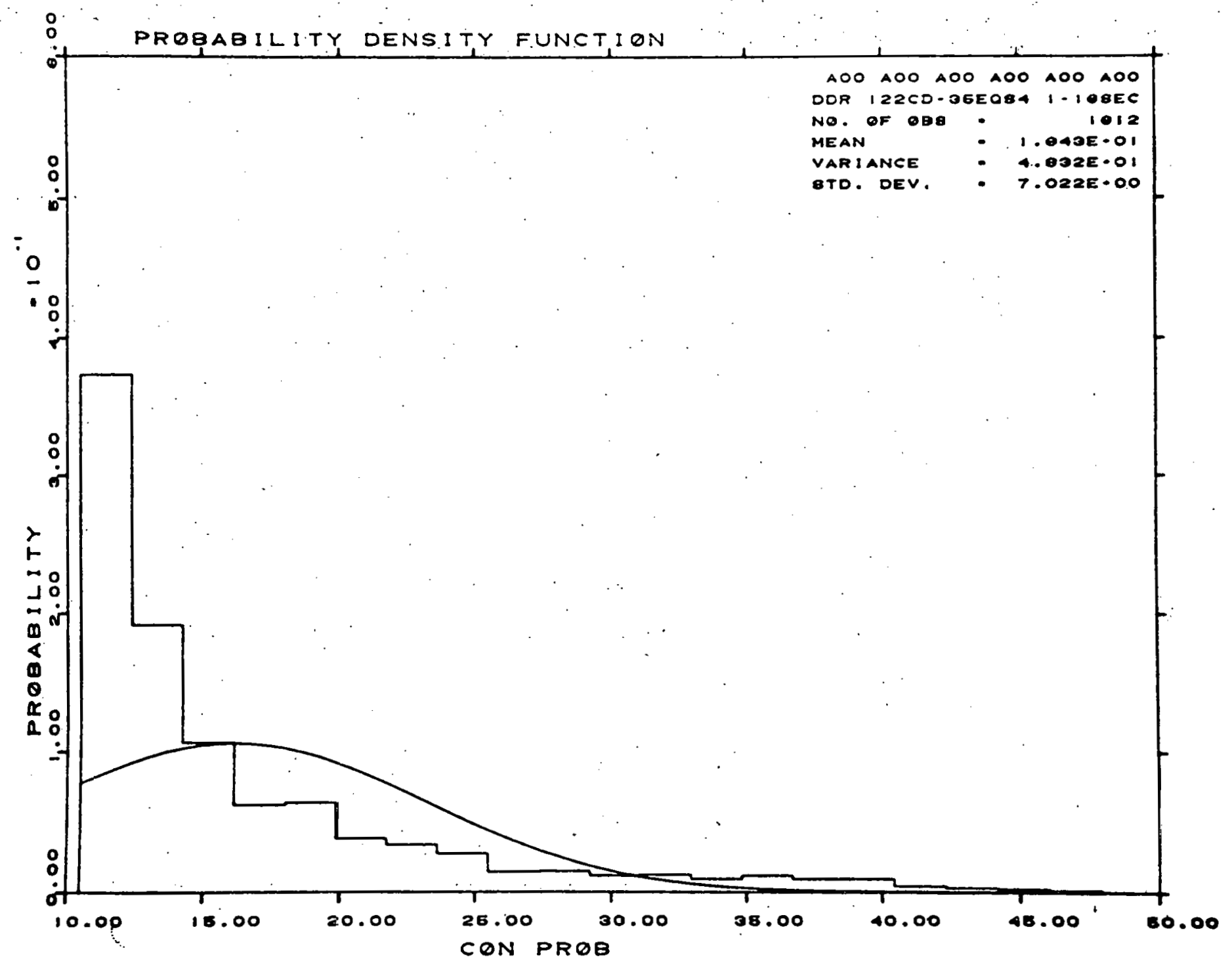

Figure 18A: Probability density function plot of $\mathrm{CD}-35$ (conductivity detector). 


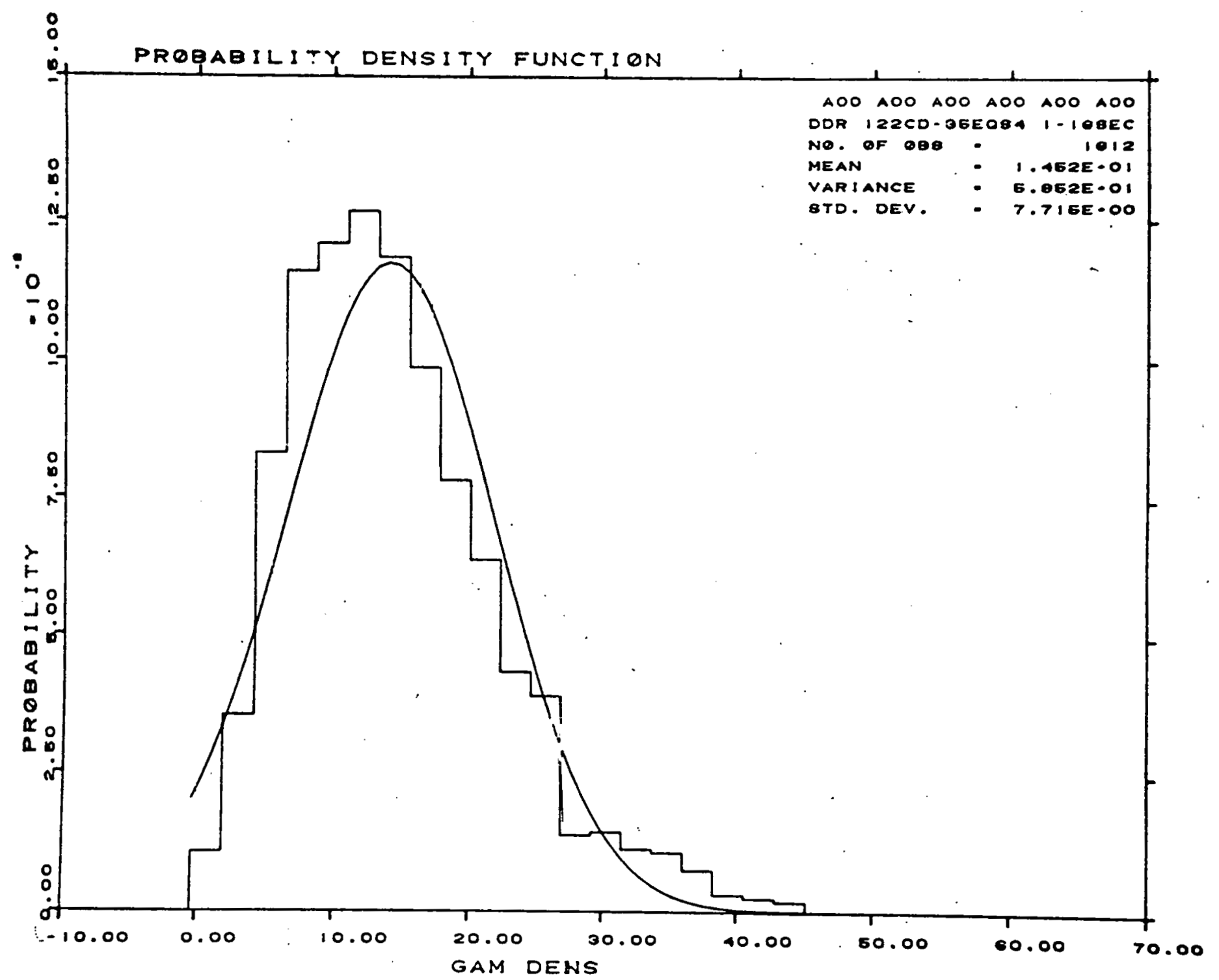

Figure 18B: Probability density function plot of $C D-35$ (densitometer). 


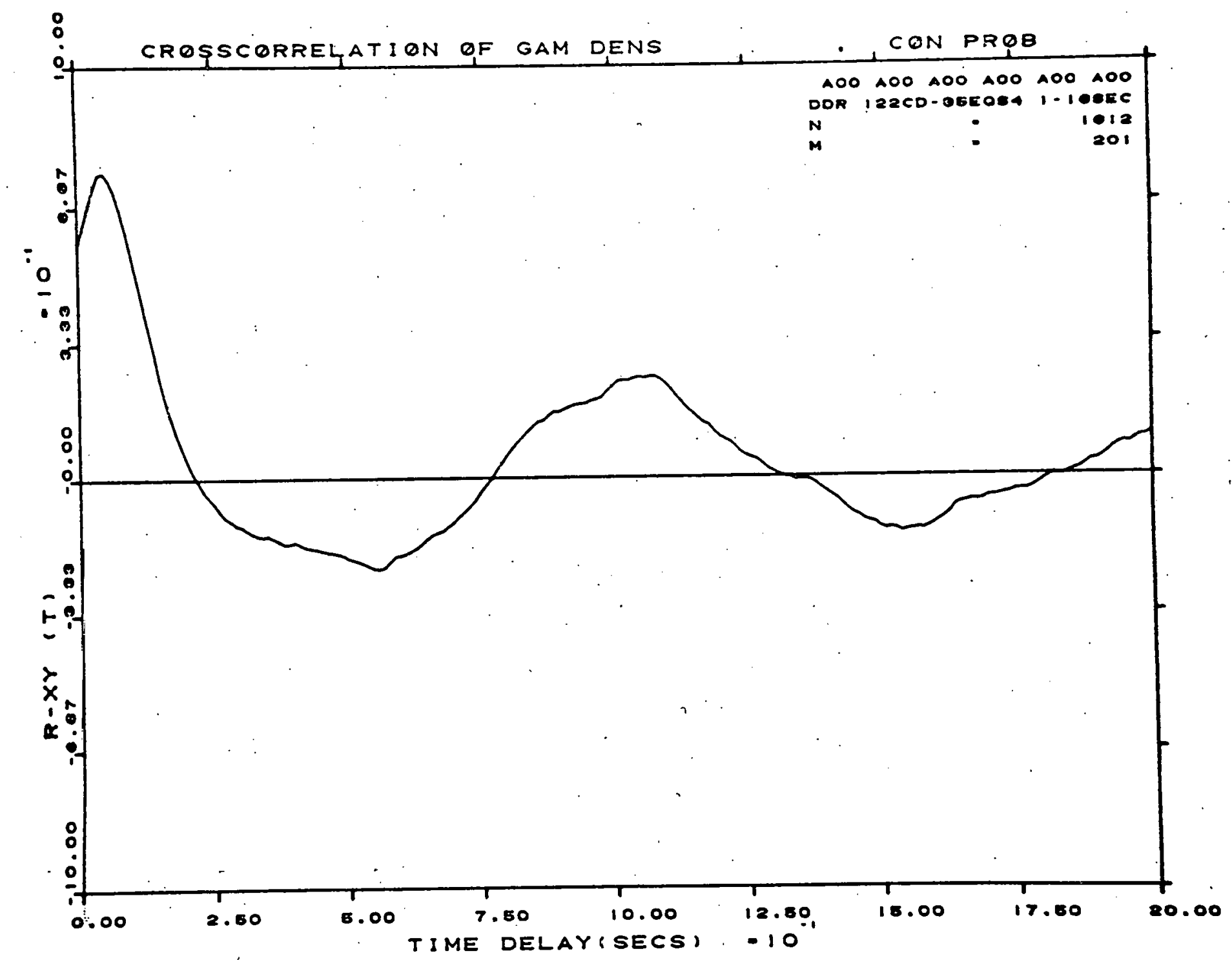

Figure 19: Cross correlation plot of CD-35. 


\subsection{Results of Analys is for the Conductivity Void Fraction System}

5.3.1 Results of the Horizontal Test for the Conductivity Void Fraction. System. The statistical analyses resiitted in detection of no high noise levels or unexpected signal signatures in the conductivity void fraction system. Those statistics were consistant with the time averaged dáta. (See Appendix $G$ for the report of the Measurements. Pérformànce Section.)

Figurès 20 and 21 present the time àvëragè dàta. Eàch line represents a set of data points takèn at a constant water flow rate and varying áir flow rate.

Datä set AV-64 was examined in detai1; . Figurès 22 through 25 represents the results. The test conditions for $A V-64$ were $2.27 \mathrm{l} / \mathrm{min}$ $(60 \mathrm{gpm})$ and $0.64 \mathrm{~m}^{3} / \mathrm{min}(22.5 \mathrm{cfm})$, a slug flow. Figures $22 \mathrm{~A}$ and $B$ show the time signatures of the conductivity detector and the single beam gamma densitometer. Figures 23 and 24 show the power spectral densities and probability density functions.

5.3.2 Results of the Vertical Test for the Conductivity Void Fraction System. As with the horizontal test, the statistical analysis resulted in detection of no high noise levels or unexpected signal signatures in the conductivity void fraction system. Those statistics were consistant with the time averaged data. (See Appendix $H$ for the report of the Measurements Performance Section.)

Data set $\mathrm{CD}-35$ was examined in detail. The test conditions for CD-35 were $2.27 \mathrm{l} / \mathrm{min}(34 \mathrm{gpm})$ and $0.64 \mathrm{~m}^{3} / \mathrm{min}(22.5 \mathrm{cfm})$, a slug flow. Refer to figures 15 through 19 for lie actual plots and statistical results of the test. 
CDNDUCTIVITY PREBE VDLTS VS. TWL BERM DENSITDMETER LC RYG. DENSITY

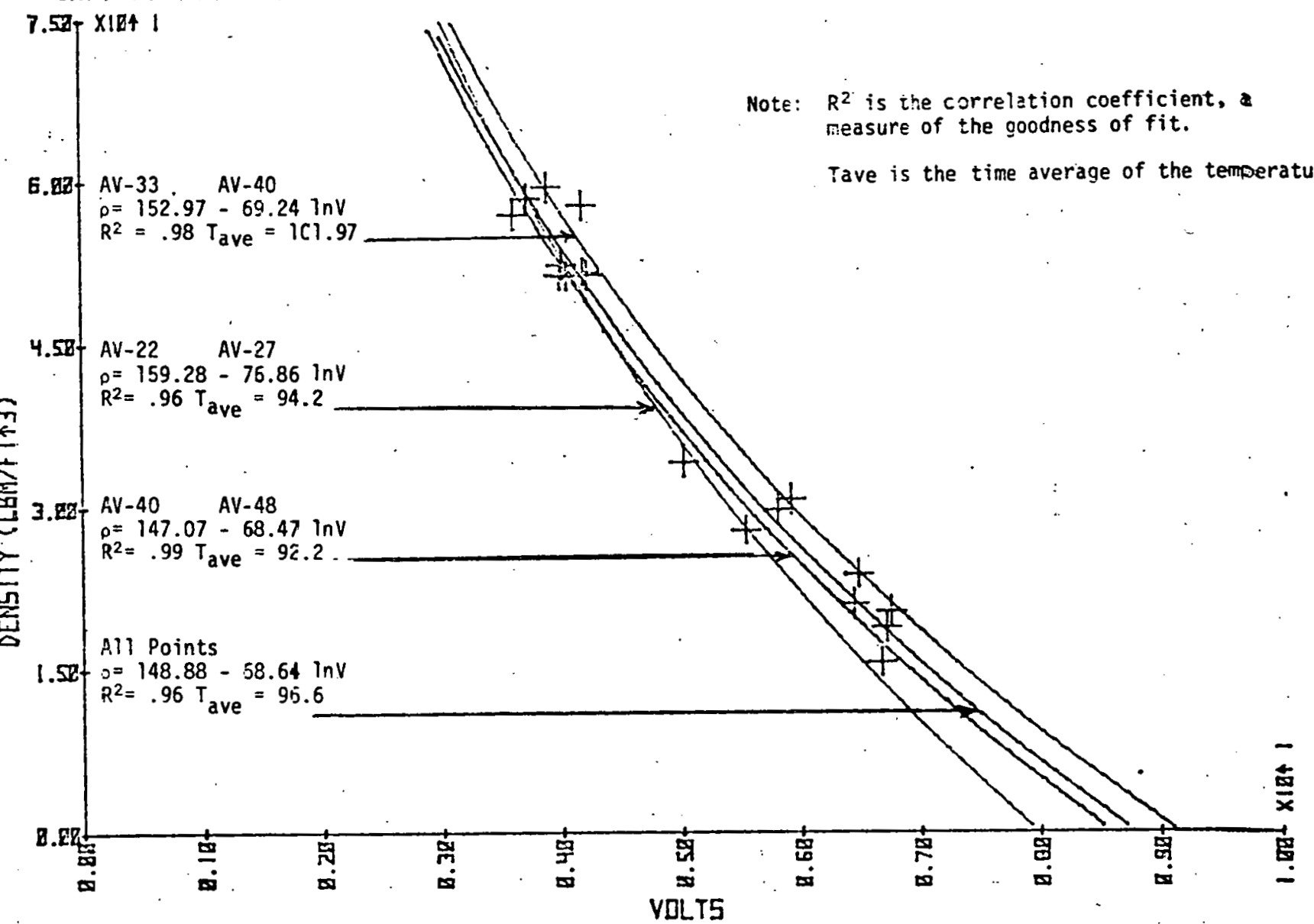

Figure 20: Graph showing time average data for the conductivity detector in a horizontal section AV-33 through AV-78. 
ZND TEST RLN CDNCUCTIVITY VDLTS VS TWD ZERM DENSITDMETER LC DENSITY

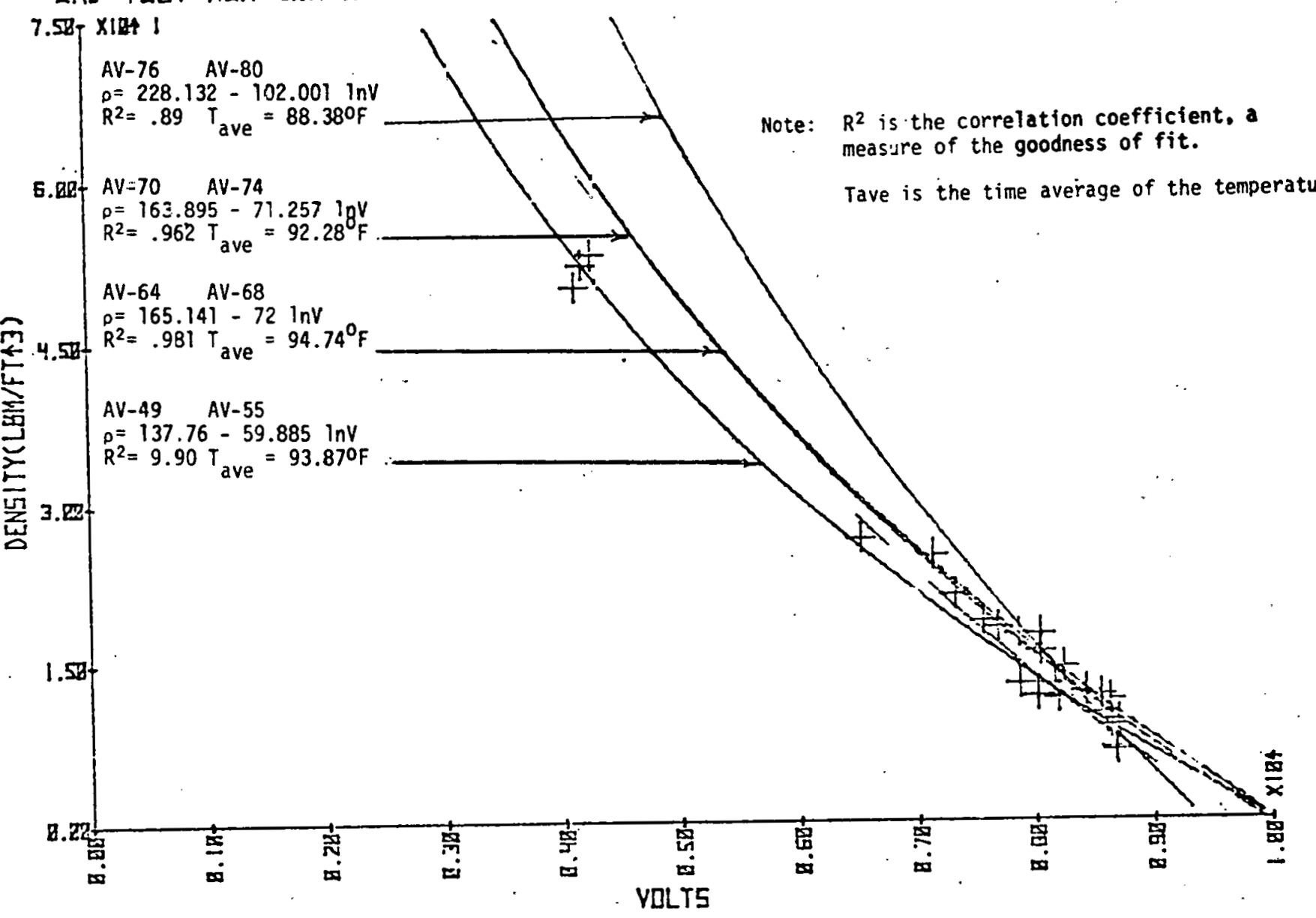

Figure 21: Griph showing time average data for the conductivity detector in a horizontal section AV-49 through AV-80. 
$w$

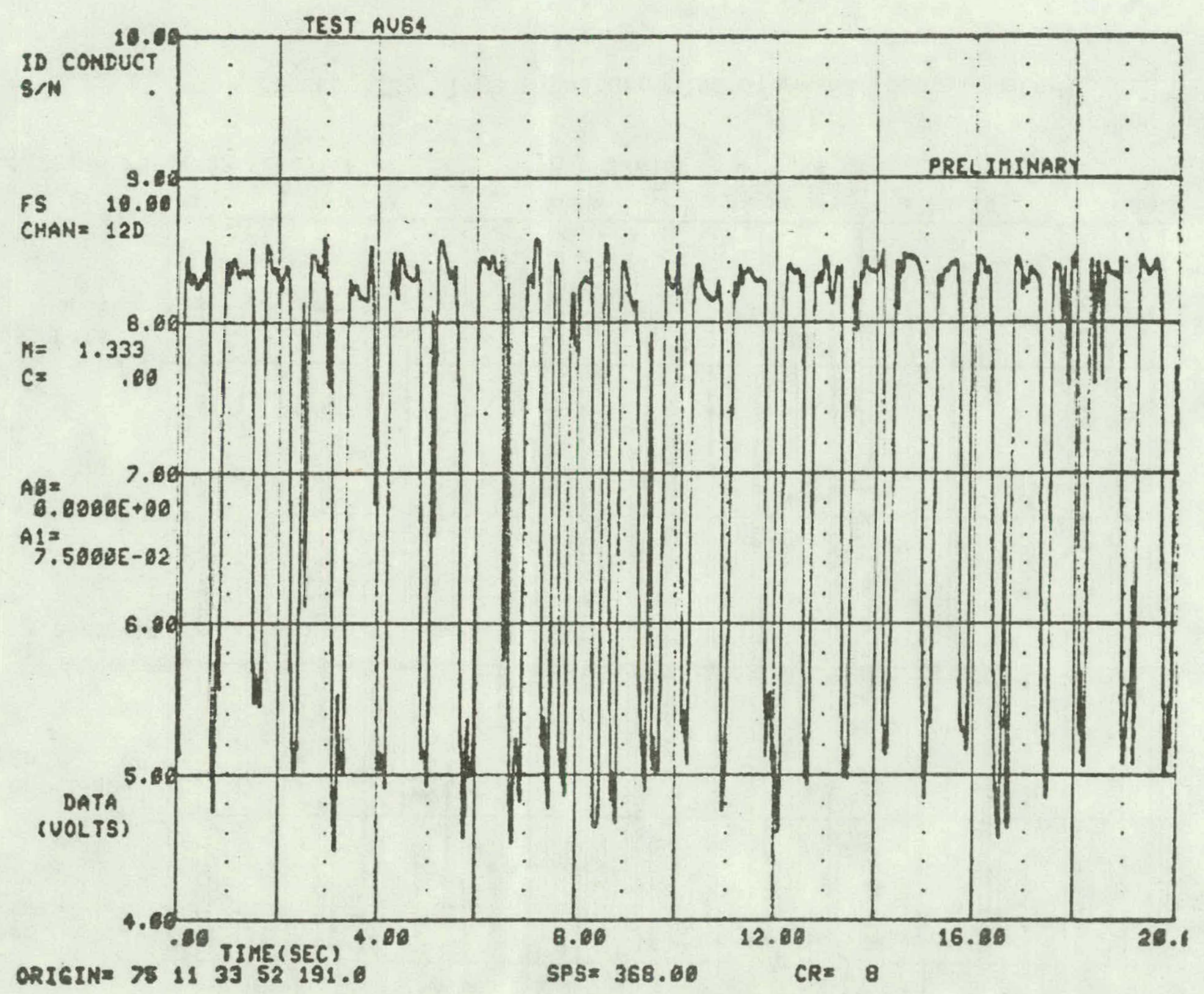

Figure 22A: Time signature plot of Av-64 (conductivity detector).

$\frac{1}{D}$
$\overrightarrow{ \pm}$
$\frac{1}{\infty}$ 


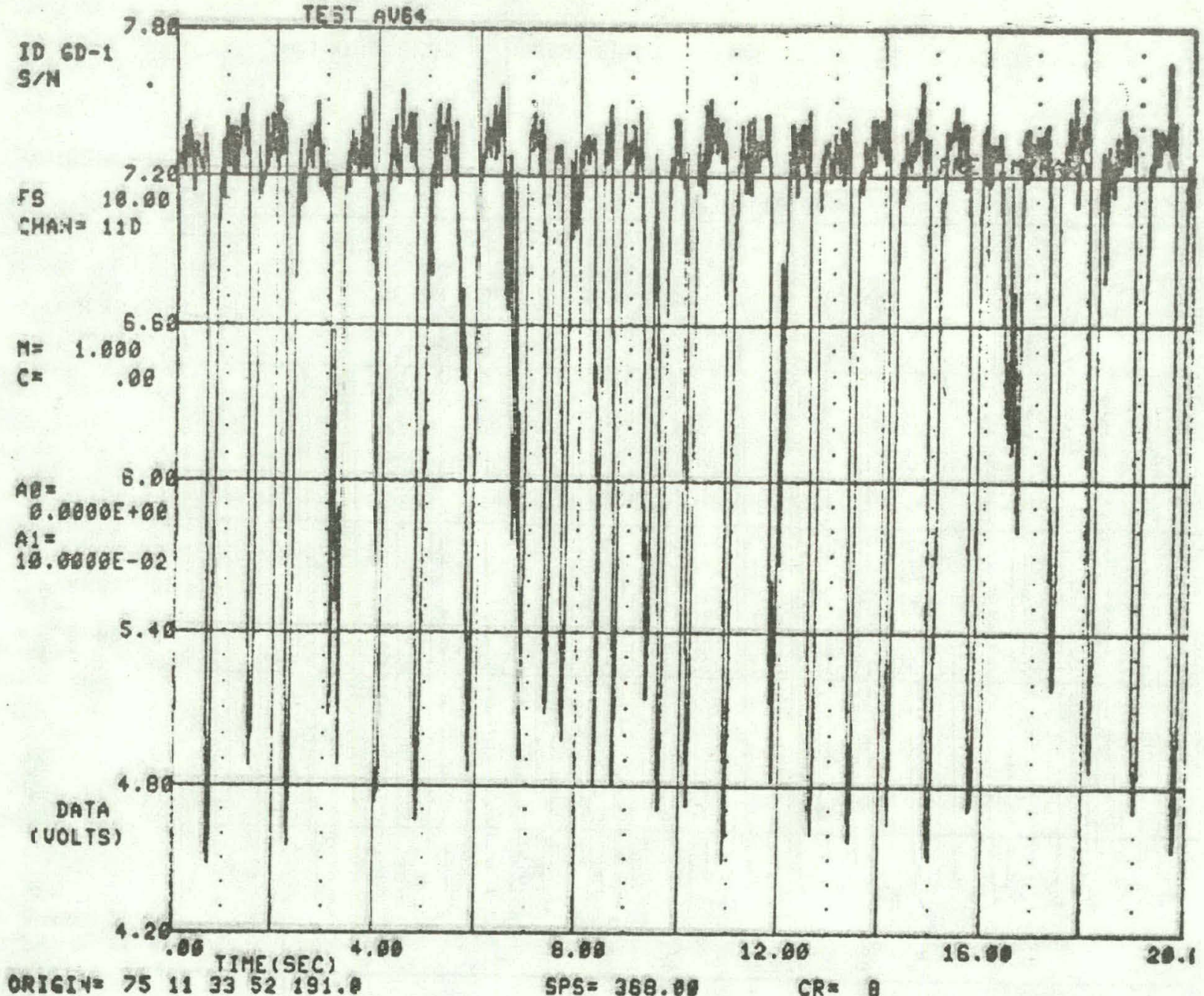

Figure 22B: Time signature plot of $A v-64$ (densitometer). 


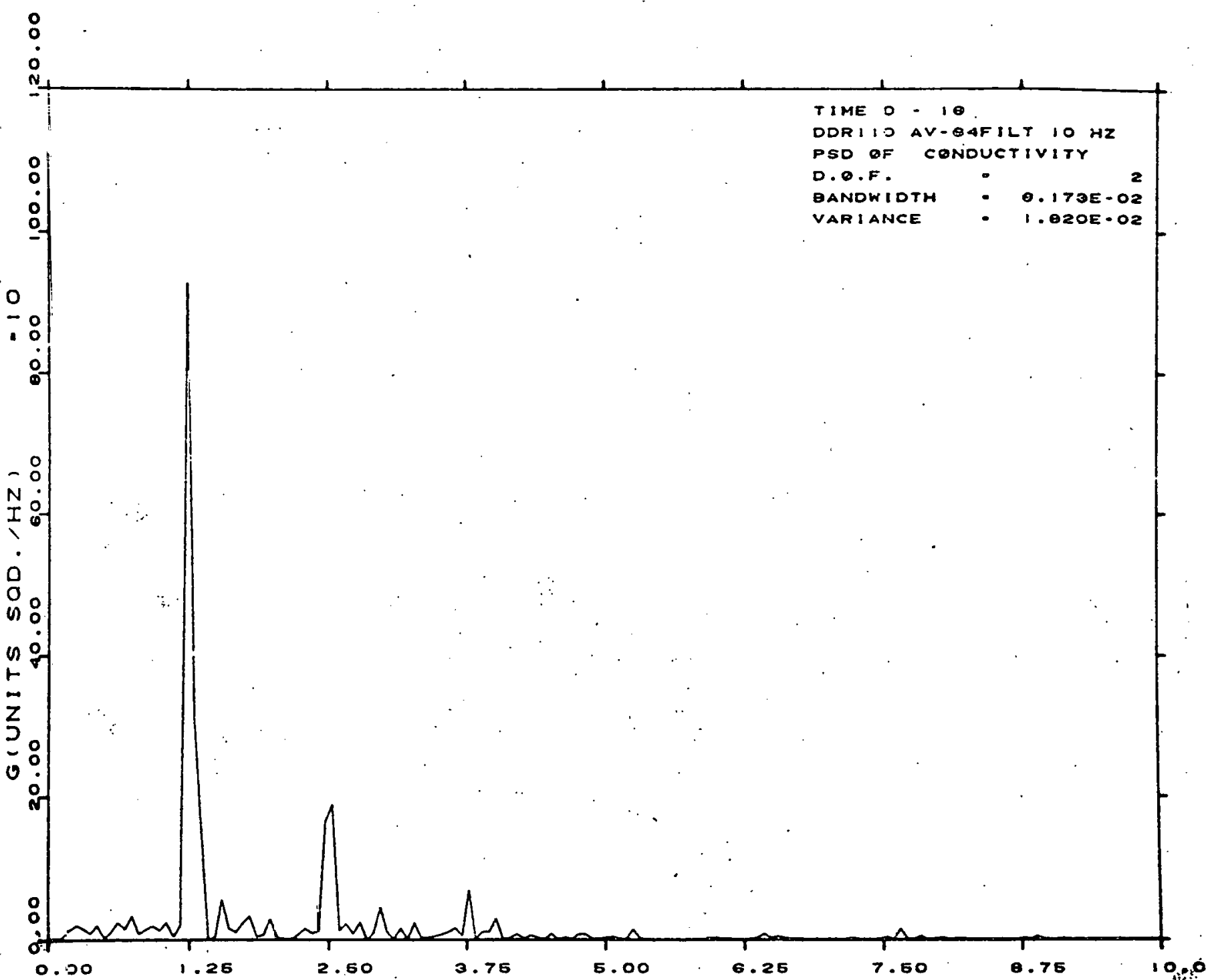

Figure 23A: Power spectral densities plot of AV-64 (conductivity detector). 


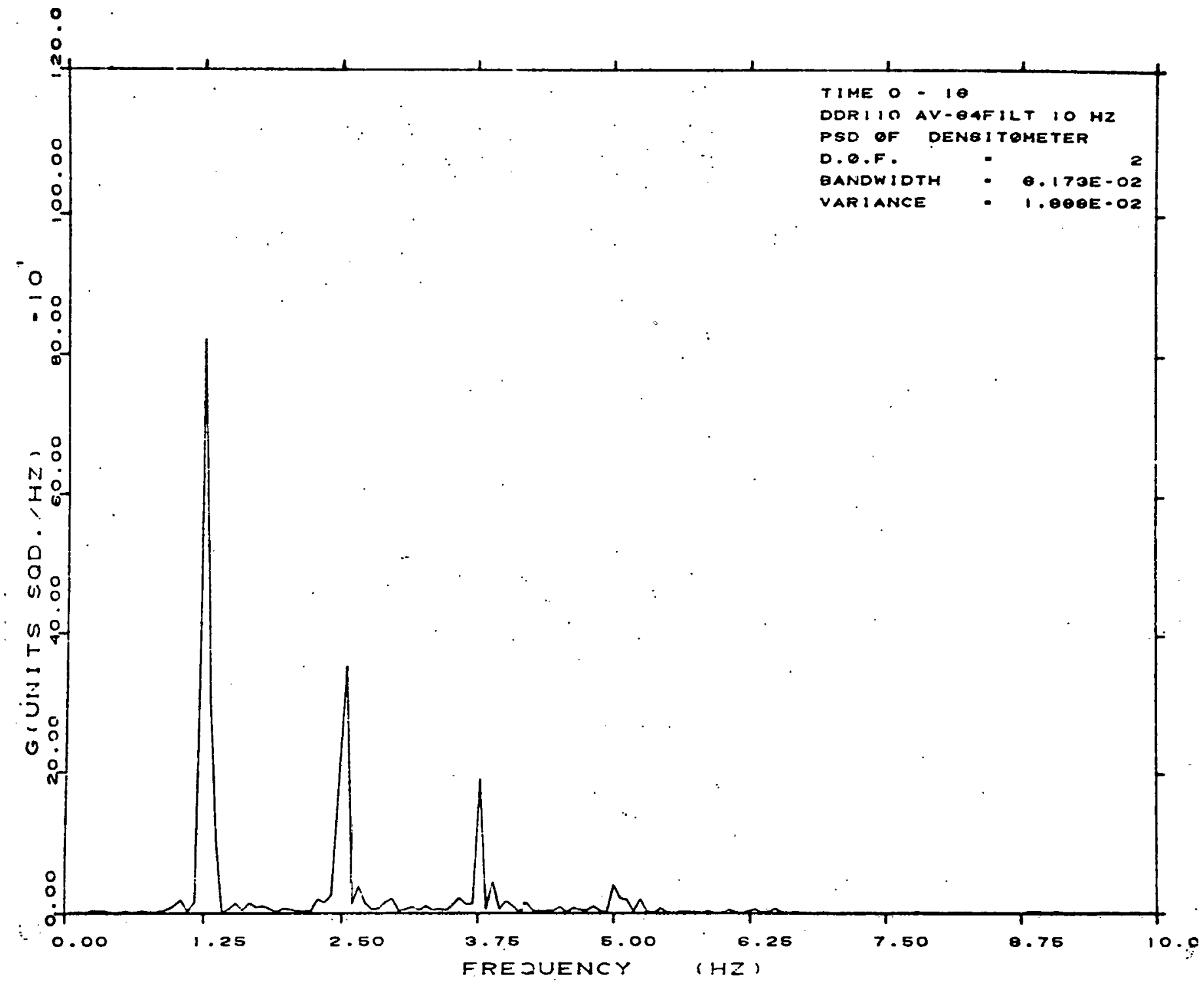

Figure 23B: Fower spectral densities plot of AV-64 (densitometer). 


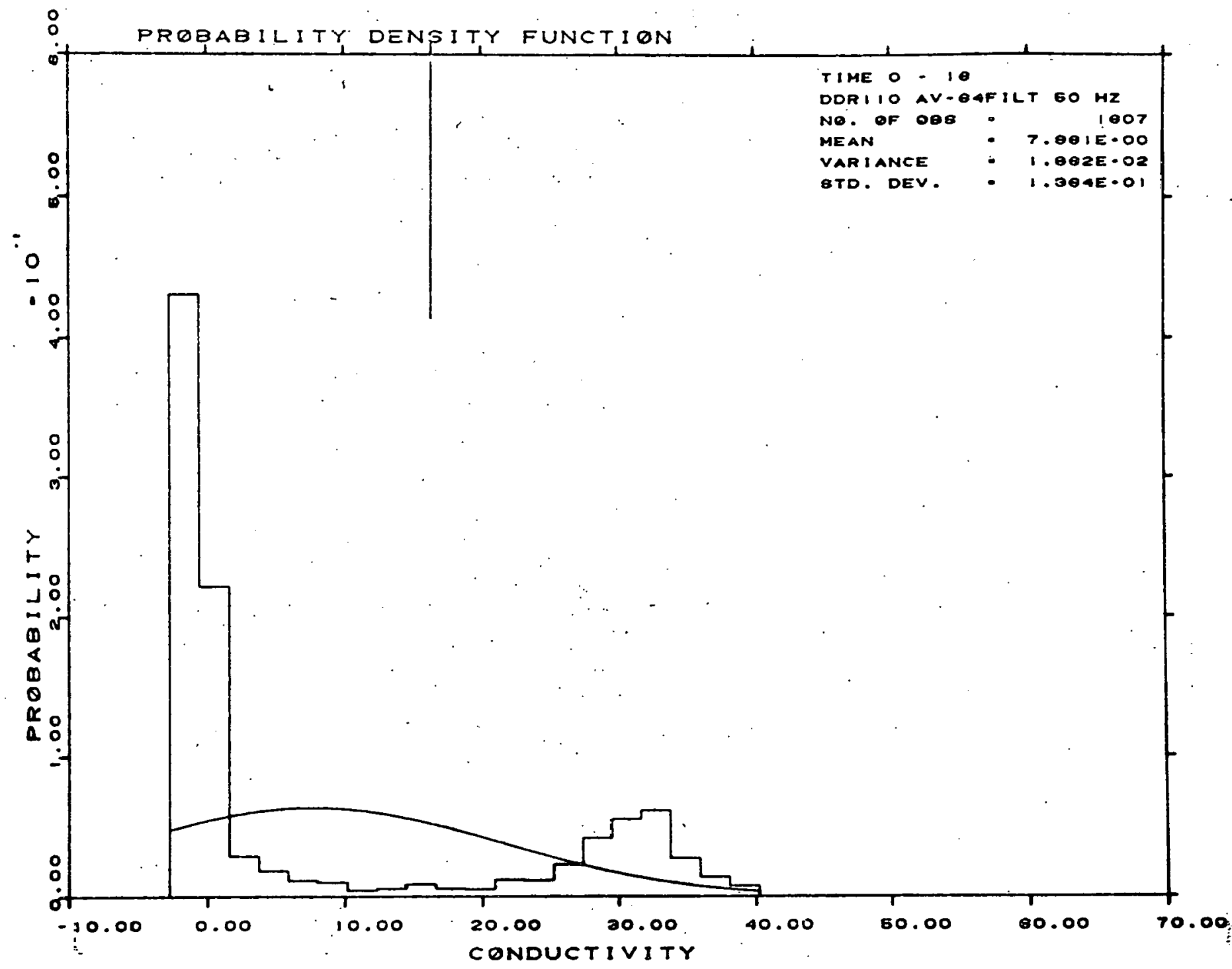

Figure 24A: Probability density function plot of AV-64 (conductivity detector). 


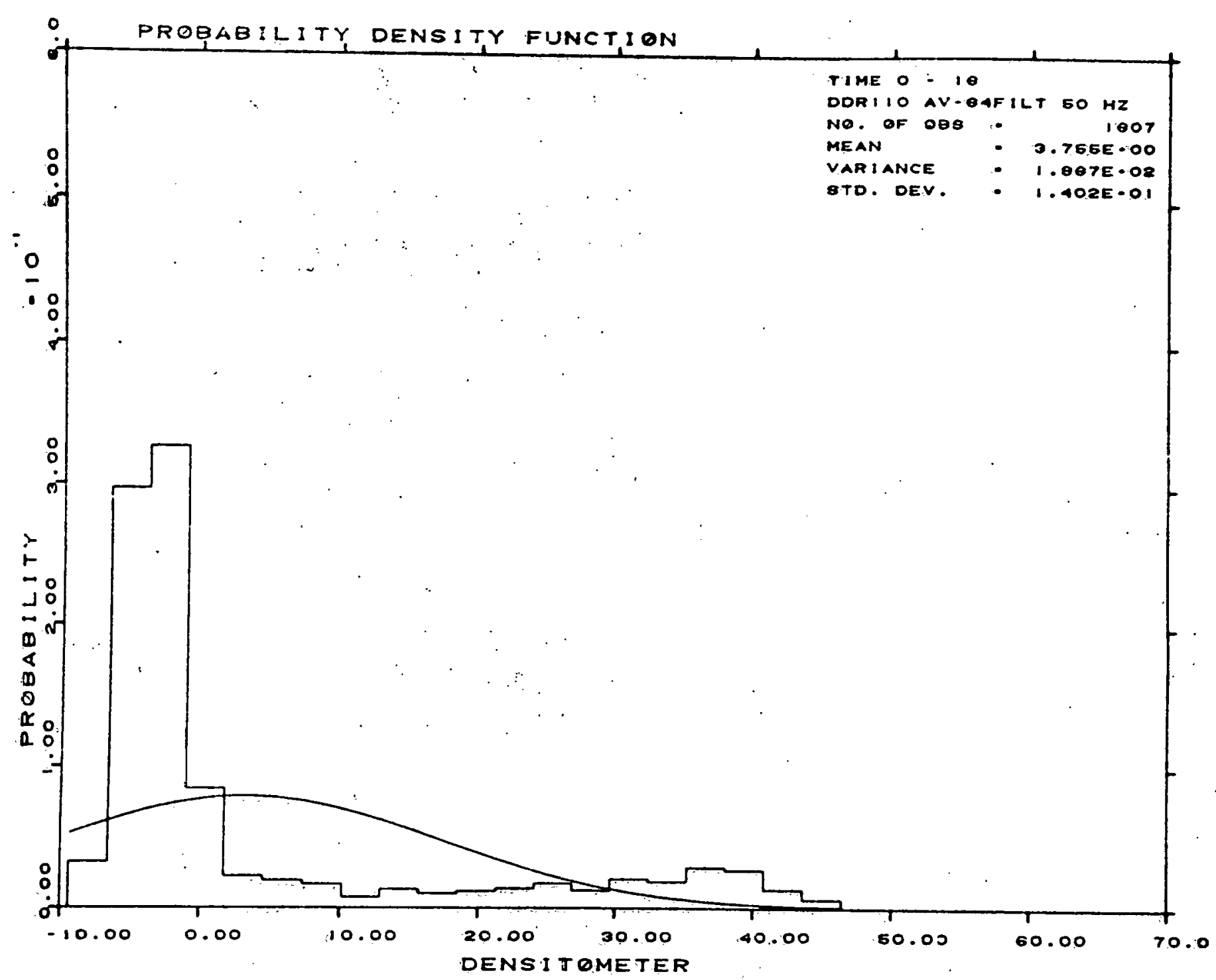

Figure 24B: Probability density function plot of AV-64 (densitoneter). 
5.4 Conclusions of the Horizontal and Vertical Test for the Conductivity Void Fraction System

In both horizontal and vertical tests the conductivity detector does measure void fraction and is insensitive to temperature over 21.1 to $37.8^{\circ} \mathrm{C}$ ( 70 to $100^{\circ} \mathrm{F}$ ). More data is necessary to verify sensitivity to mass flow rate. The relationship between conductivity detector voltage output and density can be approximated by:

$$
\rho=c_{1}-c_{2} \ln \cdot v_{c}
$$

where:

$$
\begin{aligned}
\rho & =\text { density } \\
c_{1}, c_{2} & =\text { constants } \\
v_{c} & =\text { output of conductivity detector. }
\end{aligned}
$$

Air and water both have conductivities which remain essentially constant over the range of test conditions employed. Thus, the conductivity of the media is dependent solely on the ratio of air to water or void fraction. Experimentally, this is confirmed in the cross correlation of the gamma densitometer output and the conductivity detector's output (Figure 25). The gamma densitometer output is a known function of the media density. With air and water having essentially constant densities over the range of test condition, the gamma densitometer output is a function of the ratio of air to water or void fraction. Lag times of less than $0.1 \mathrm{~s}$ indicate a correlation coefficient of approximatley 1, proving that both the gamma densitometer and conductivity detector are measuring void fraction within $10 \%$ accuracy. The power spectral densities showed that the signals of interest were less than $10 \mathrm{~Hz}$ (Appendix $\mathrm{H}$ ) for both conducitivity detector and gamma densitometers.

The initial assumption was that the conductivity detector is insensitive to temperature over the range of test conditions 21.1 to $37.8^{\circ} \mathrm{C}\left(70\right.$ to $\left.100^{\circ} \mathrm{F}\right)$. The conductivity of demineralized water and air 


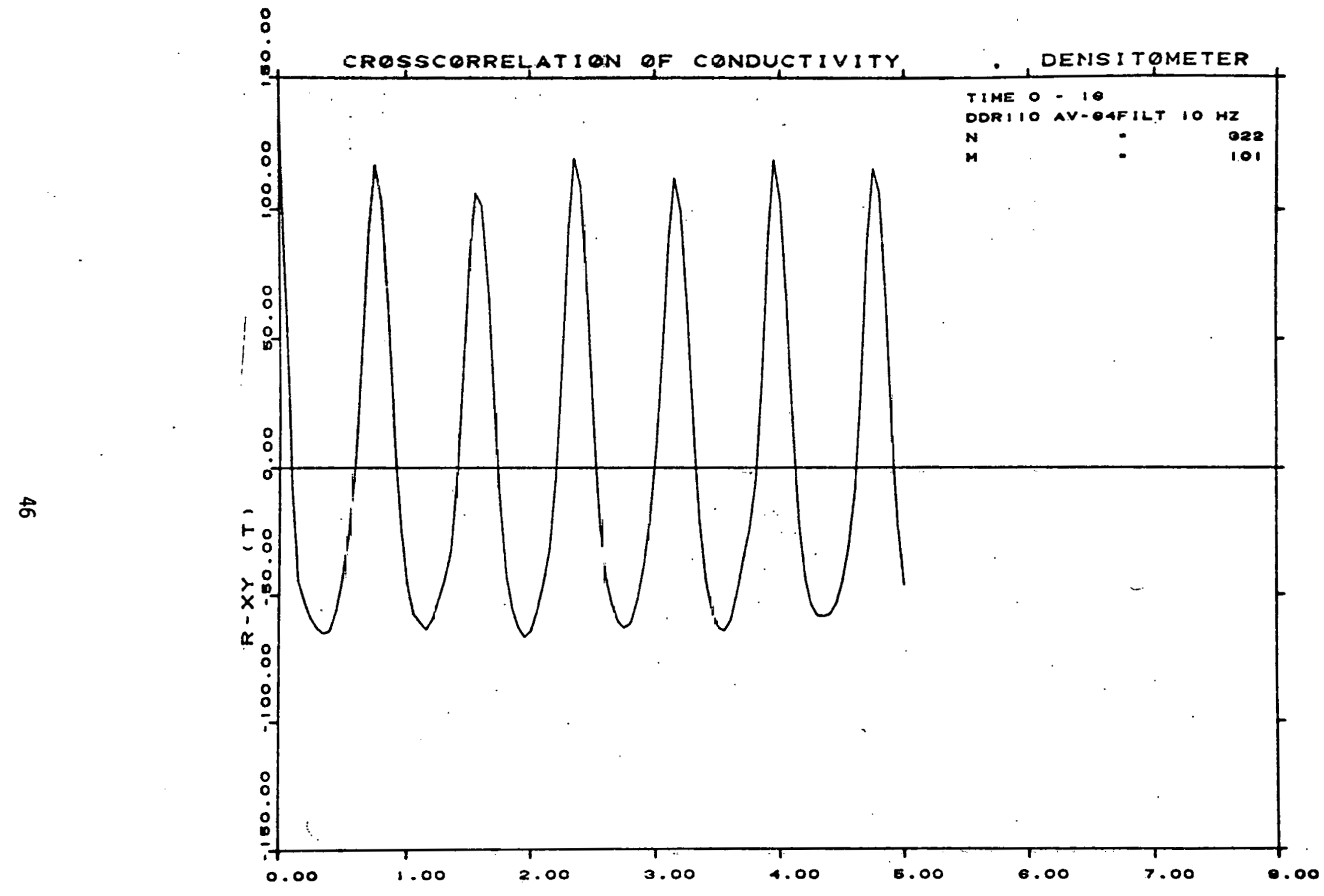

Figure 25: Cross correlation plot of AV-64. 
do not change appreciably over the range of 21.1 to $37.8^{\circ} \mathrm{C}$ (70 to $100^{\circ} \mathrm{F}$ ), thus the assumption is considered correct.

The horizontal test varied from the vertical test in that the Measurements Performance Section reports shifts in the coefficients $C_{1}$ and $C_{2}$ of the equation $\rho=c_{1}-C_{2} \ln V_{c}$ for each data set analyzed (Appendix G). These shifts appear to have some correlation with mass flow rate. More data is needed to correctly assign the effect mass flow has on the modeling coefficients. Vortex shedding caused by the complex ground plane of the LLD is suggested as a possible mechanism whereby mass flow rate could effect the output of the conductivity probe, and it is expected that accuracies better than $5 \%$ can be obtained if the effects of temperature and mass flow rate can be determined on the conductivity probe output.

Accuracy of the horizontal test showed $\pm 10 \%$ of range is possible with the present design conductivity detector. Accuracy of the vertical test showed $\pm 8 \%$ of range with a repeatability of $\pm 6 \%$ of range, giving an overall accuracy of $\pm 10 \%$ of range (Appendix $H$ ). 


\subsection{VERTICAL TEST OF ULTRASONIC VOID FRACTION SYSTEM}

A plan for testing the ultrasonic void fraction detector in a verticai test section (Figure 26) of the Semiscale air-water flow loop is found in Appendix $F$. Fifty-nine data points were chosen from a flow map [9] to represent different flow regimes and to be within the capabilities of the flow loop. The test was divided up into six different water flow rates with varying air flow rates for each water flow rate. An all water and an all air calibration point were each taken at the beginning and end of different water flow rates.

The detector, mounted in an instrument washer as shown in Figure 7 , was located approximately twenty pipe diameters from a ninety degree elbow that leads to the vertical section of the flow loop. A plexiglass spool piece was inserted upstream from the instrument washer so the flow conditions could be visually monitored.

The detector was tested in conjunction with a single beam gamma densitometer (Figures 27 and 28) which was used as a reference to measure the flow conditions. The densitometer was mounted so that a cordal average of the density would be measured approximately $152 \mathrm{~mm}$ (6 inches) upstream of the detector.

The data from the ultrasonic void fraction detector system, single beam gamina densitometer, thermocouple and two-beam gamma densitometer (used as a reference instrument) were processed through a signal conditioning electronics, and amplifiers, and then recorded on FM analog tape. These data were also processed and fed into a HP 2100 computer at the flow loop where averages taken over a $20 \mathrm{~s}$ period were recorded for each data point. 


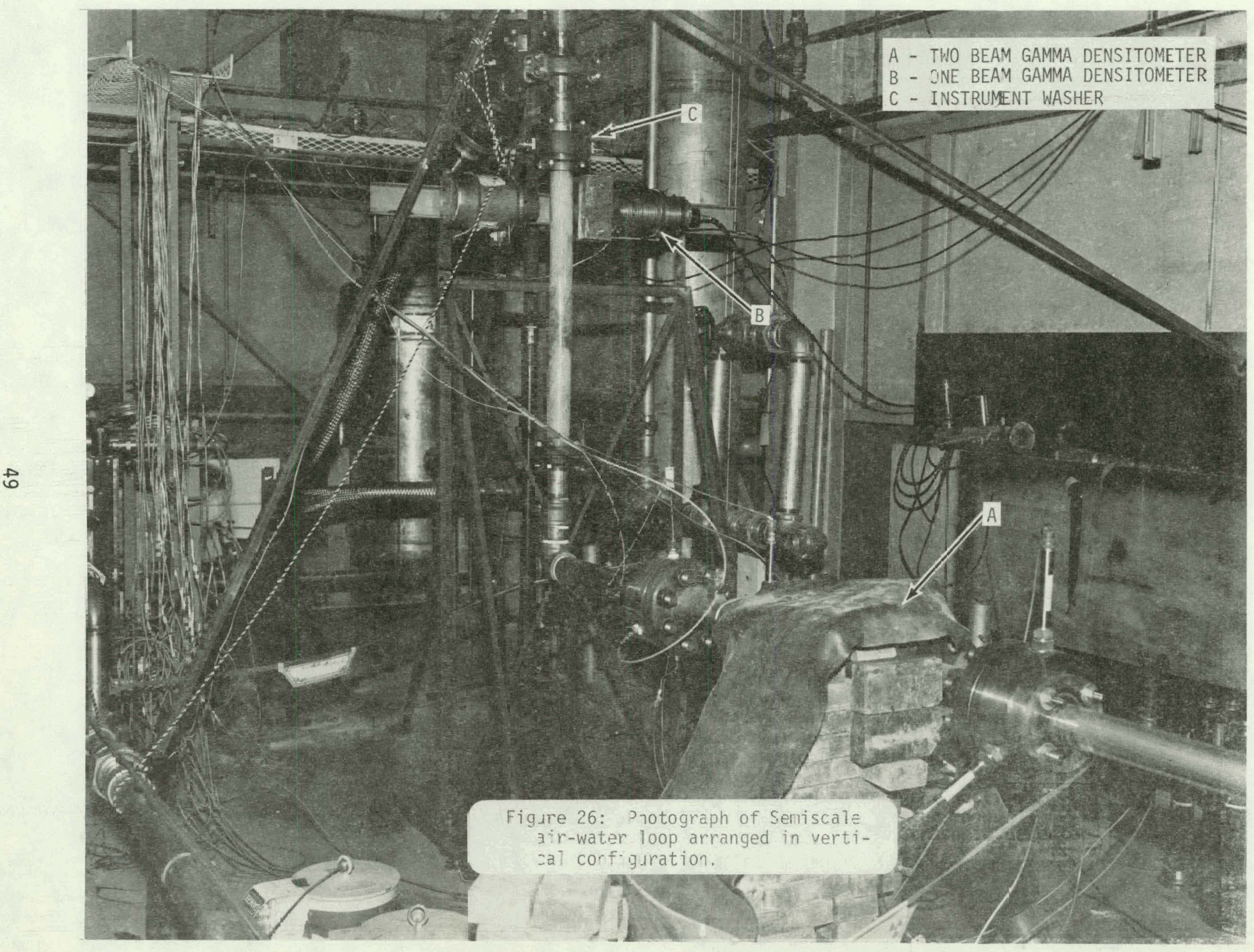



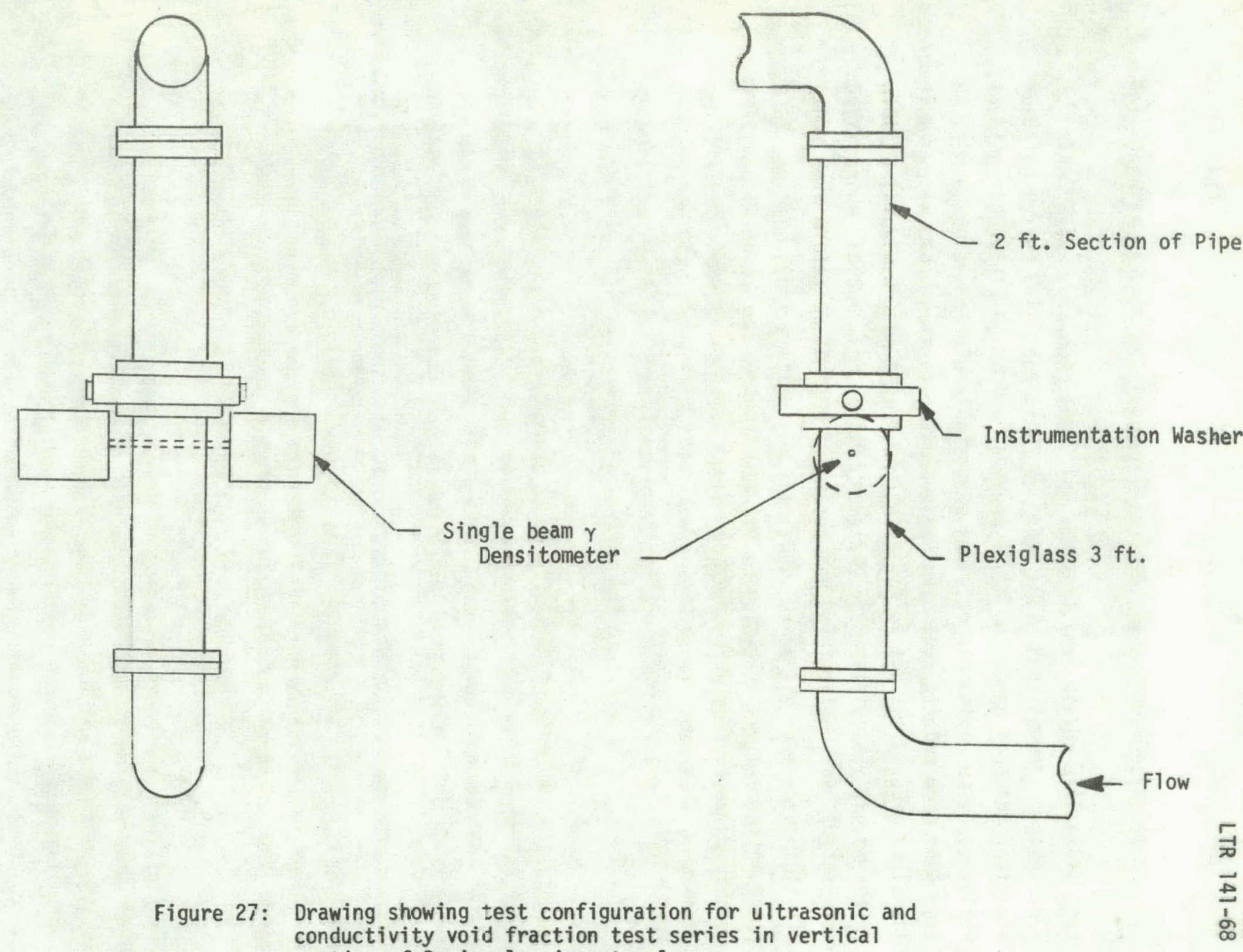

Figure 27: Drawing showing test configuration for uitrasonic and
conductivity void fraction test series in vertical conductivity void fraction test series
section of Semiscale air-water loop. 


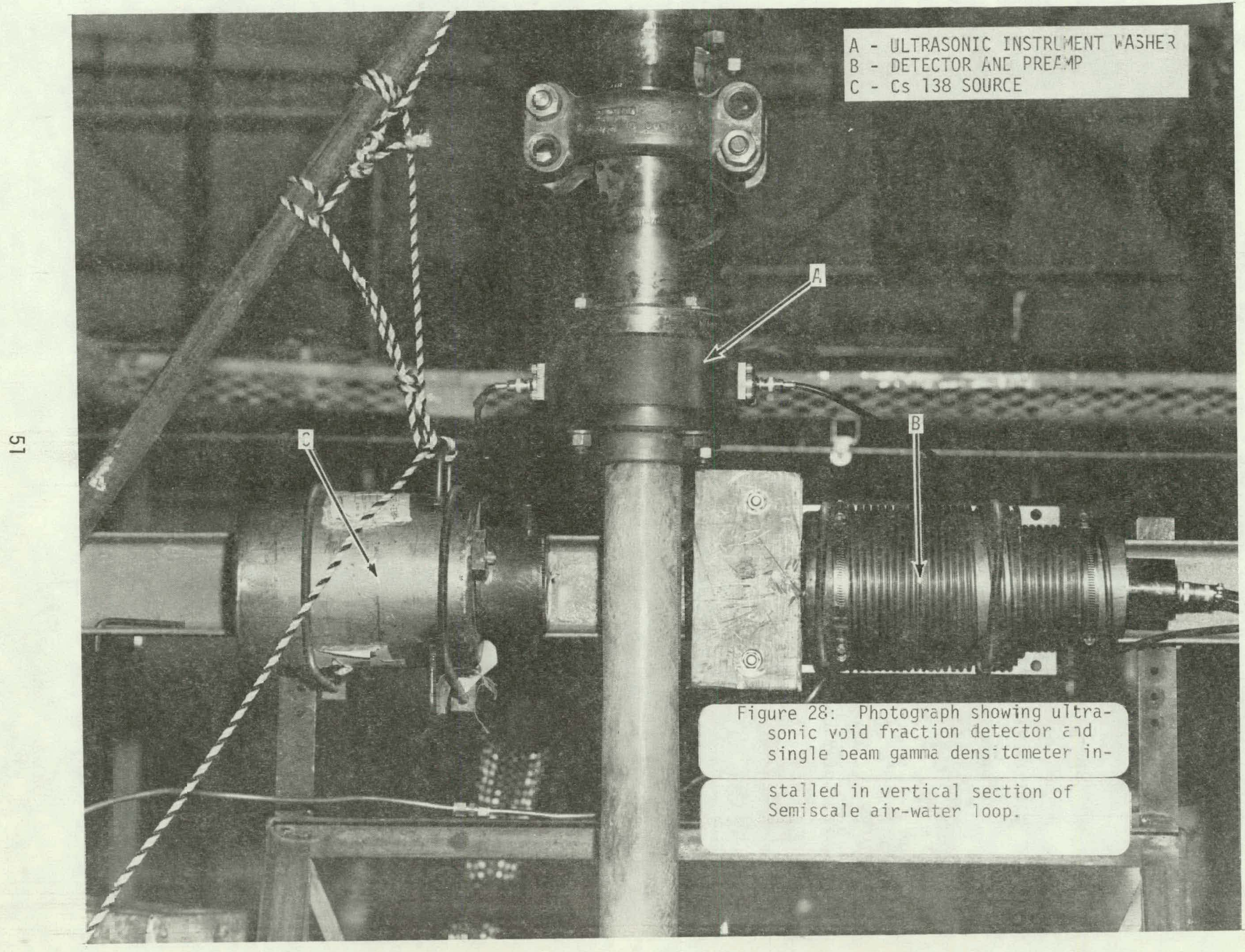

$\frac{}{\bar{D}}$ 


\section{1 Results of Vertical Test of Ultrasonic Void Fraction System}

The data obtained from the vertical test of the ultrasonic void fraction system were analyzed by the LOFT Measurements Performance Section (Appendix H). The average data obtained from the Semiscale HP 2100 computer for the single-beam gamma densitometer were converted from volts to densities. The average data from all the data sets were plotted (Figure 29) to obtain an indication of the ultrasonic detector performance versus the gamma densitometer reference. The FM analog tapes were digitized to $5000 \mathrm{samples} / \mathrm{s}$ and reformatted for implementation on the Cyber System. On the Cyber System the data were digitally filtered to $50 \mathrm{~Hz}$ and decimated to $100 \mathrm{samples} / \mathrm{s}$. Representative sets of filtered decimated data were statistically analysized, including computation and conversion, in areas of power spectral densities, probability density functions, and auto and cross-correlation. (See Appendix $\mathrm{H}$ for the report of the statistical analysis.)

Data set VF- 35 was examined in detail and Figures 30 through 33 present the results. The test conditions for VF-35 were $129 \mathrm{I} / \mathrm{min}$ (34 gpm) and $0.64 \mathrm{~m}^{3} / \mathrm{min}(22.5 \mathrm{cfm})$ and time signatures plots (Figure 30) showed slug flow as was visually observed. The noise spike is from the Semiscale computer.

The power spectral density plot (Figure 31) showed that the ultrasonic detector emits a significant portion of its signal in the 10 to $50 \mathrm{~Hz}$ band, whereas both the conductivity detector and gamma densitometer signals of interest emit less than $10 \mathrm{~Hz}$.

Figure 33 shows the probability density function. An offset was introduced into the ultrasonic signal after the time averages were taken. The source of the offset is not known but the offset results in the negative values shown in the probability density functions (PDF) (see Appendix $\mathrm{H}$ ). The offset has no significant effect on the cross correlations or power spectral densities. 


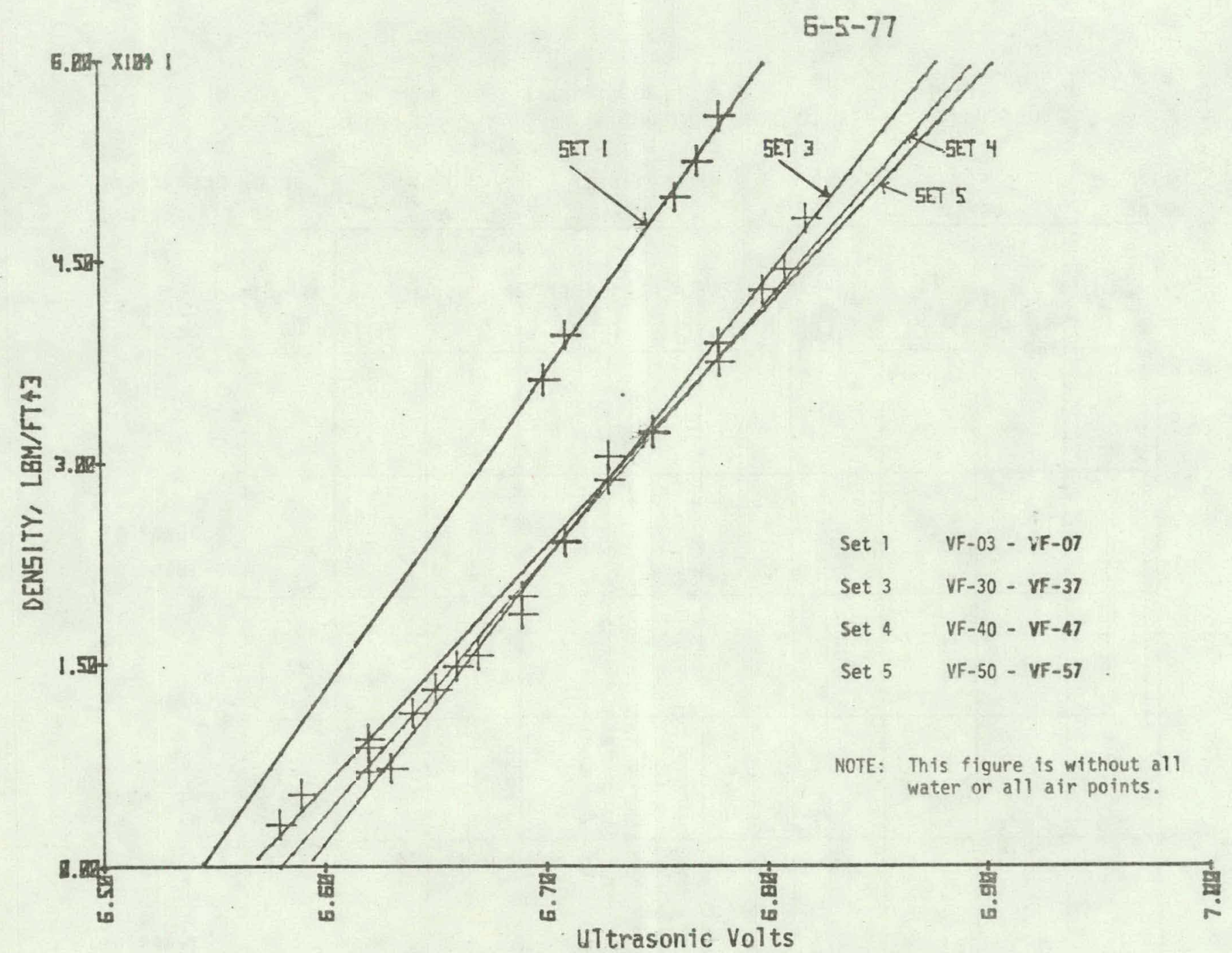

Figure 29: Graph showing time average data for ultrasonic detector in a vertical section (VF series). 


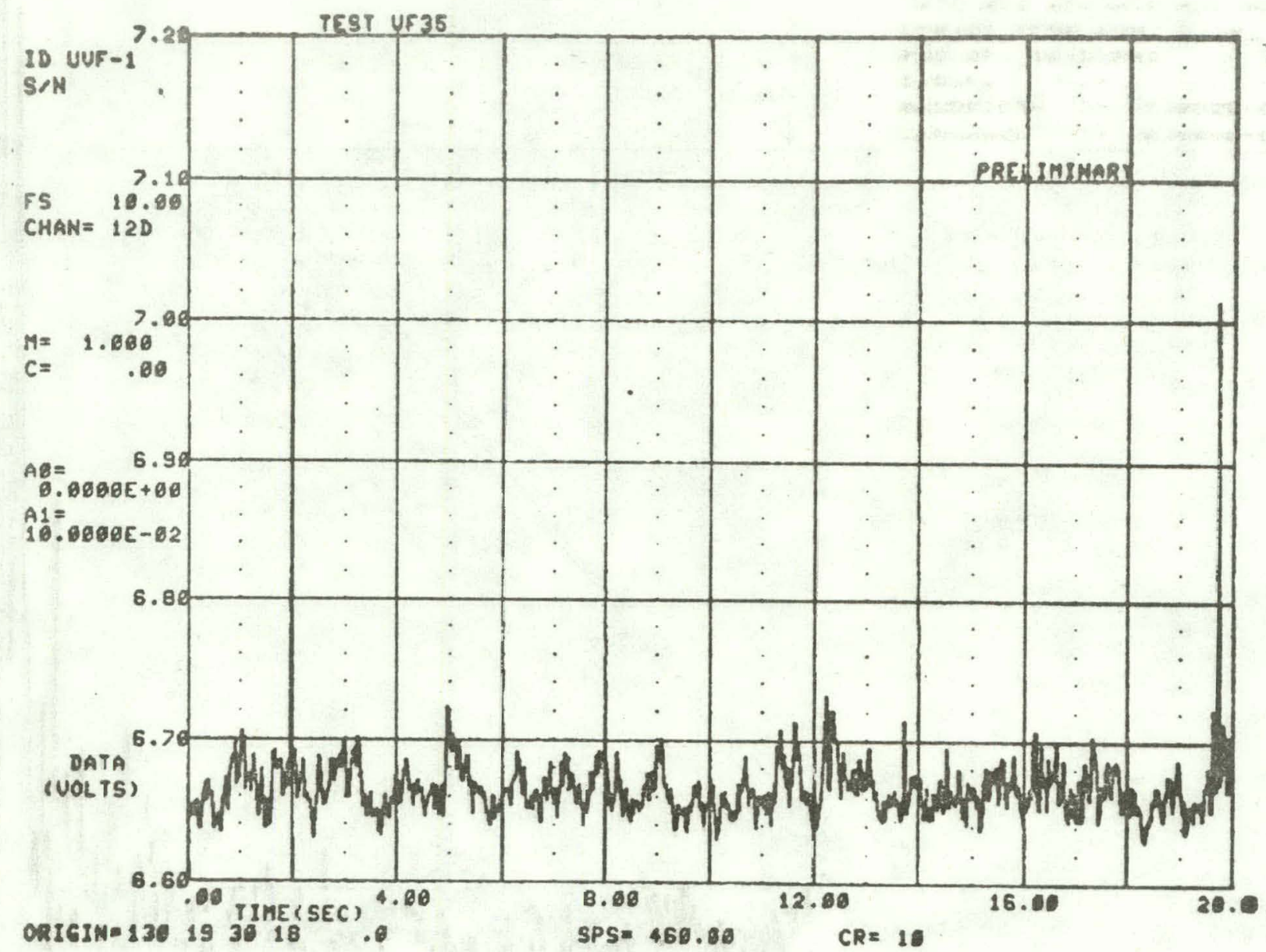

Figure 3JA: Time signature plot of VF-35 (ultrasonic 


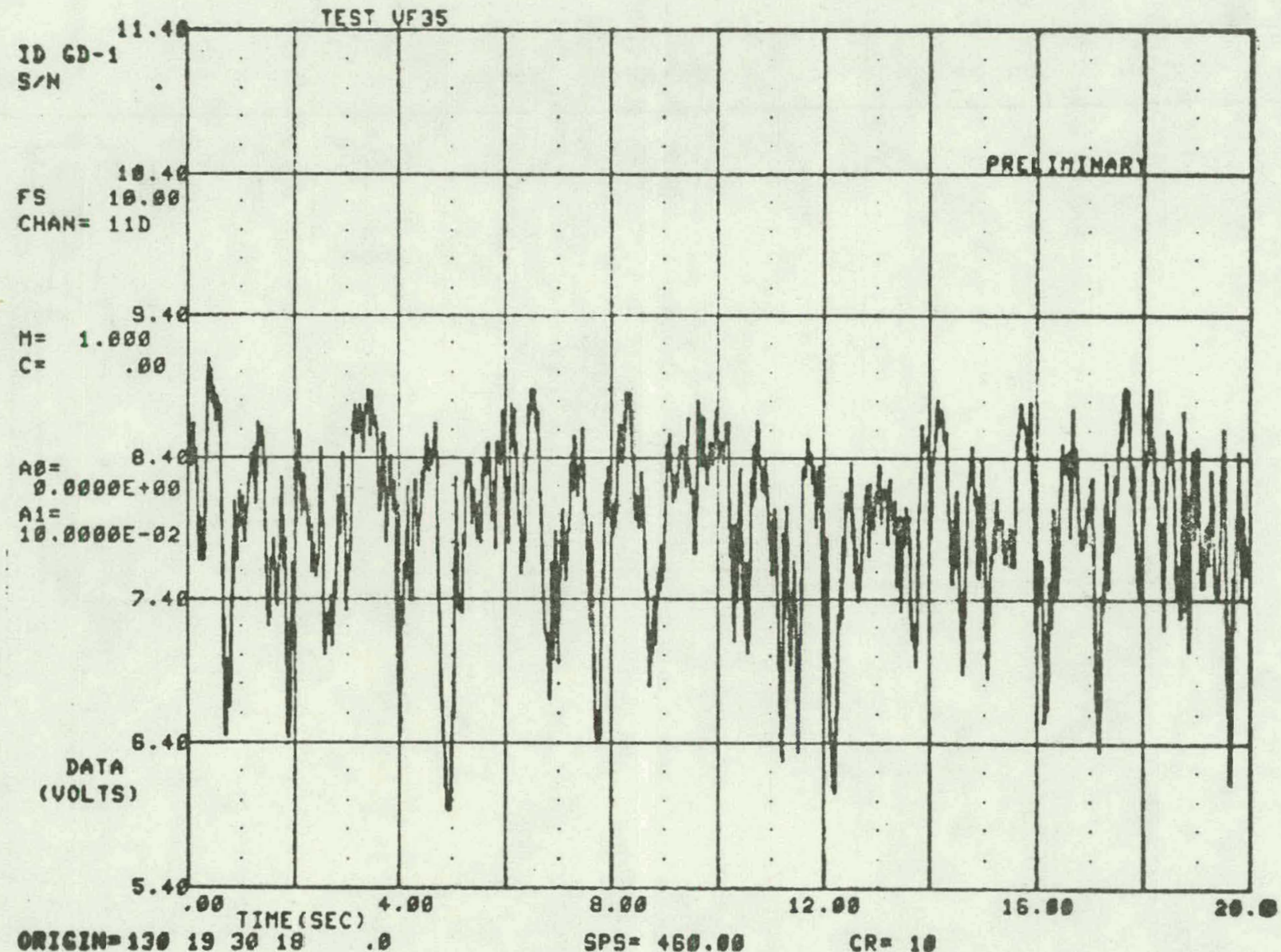

Figure 30B: Time signature plot of VF-35 (densitometer). 


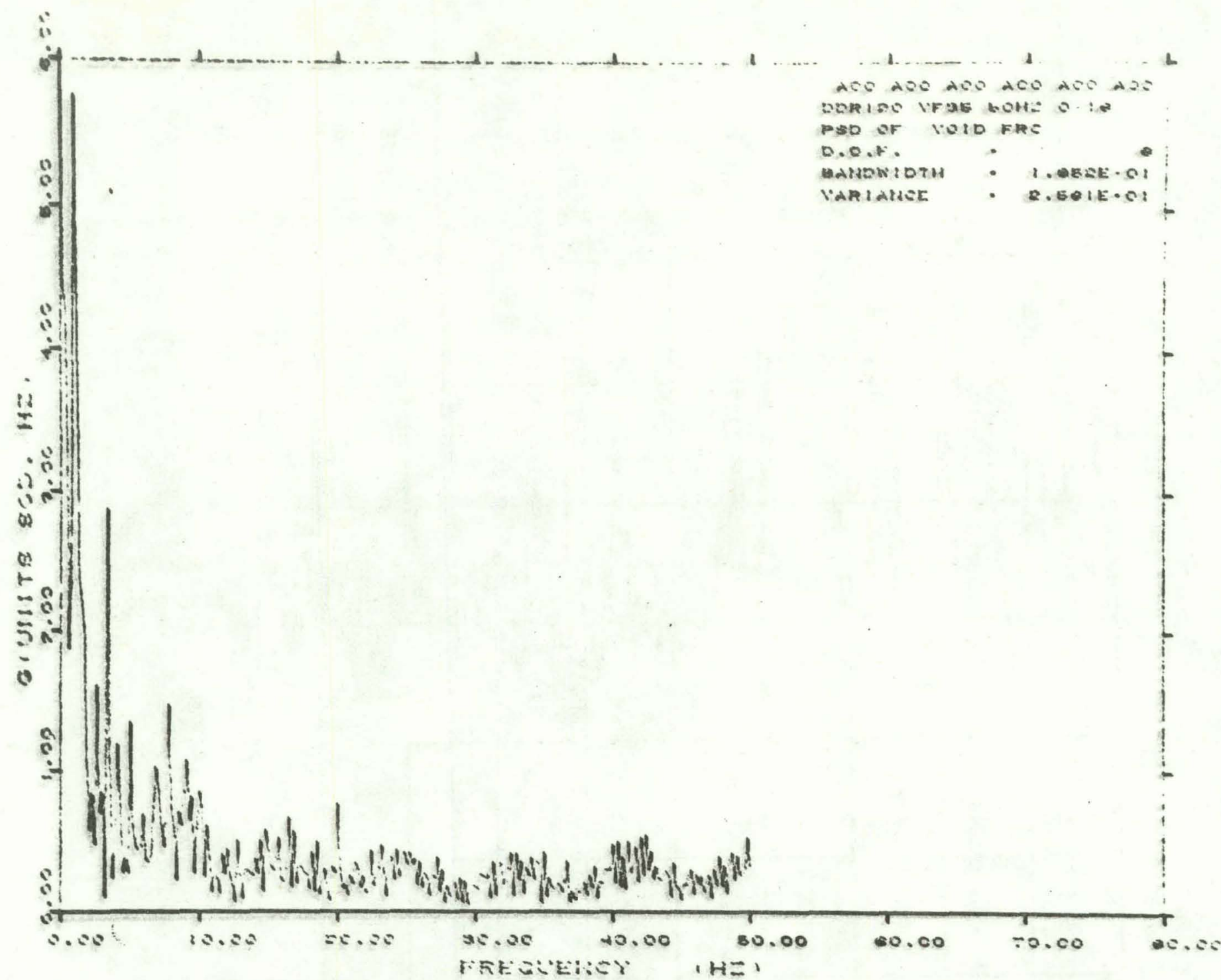

Figure 31A: Power spectral density plot of VF-35 (ultrasonic transducer). 


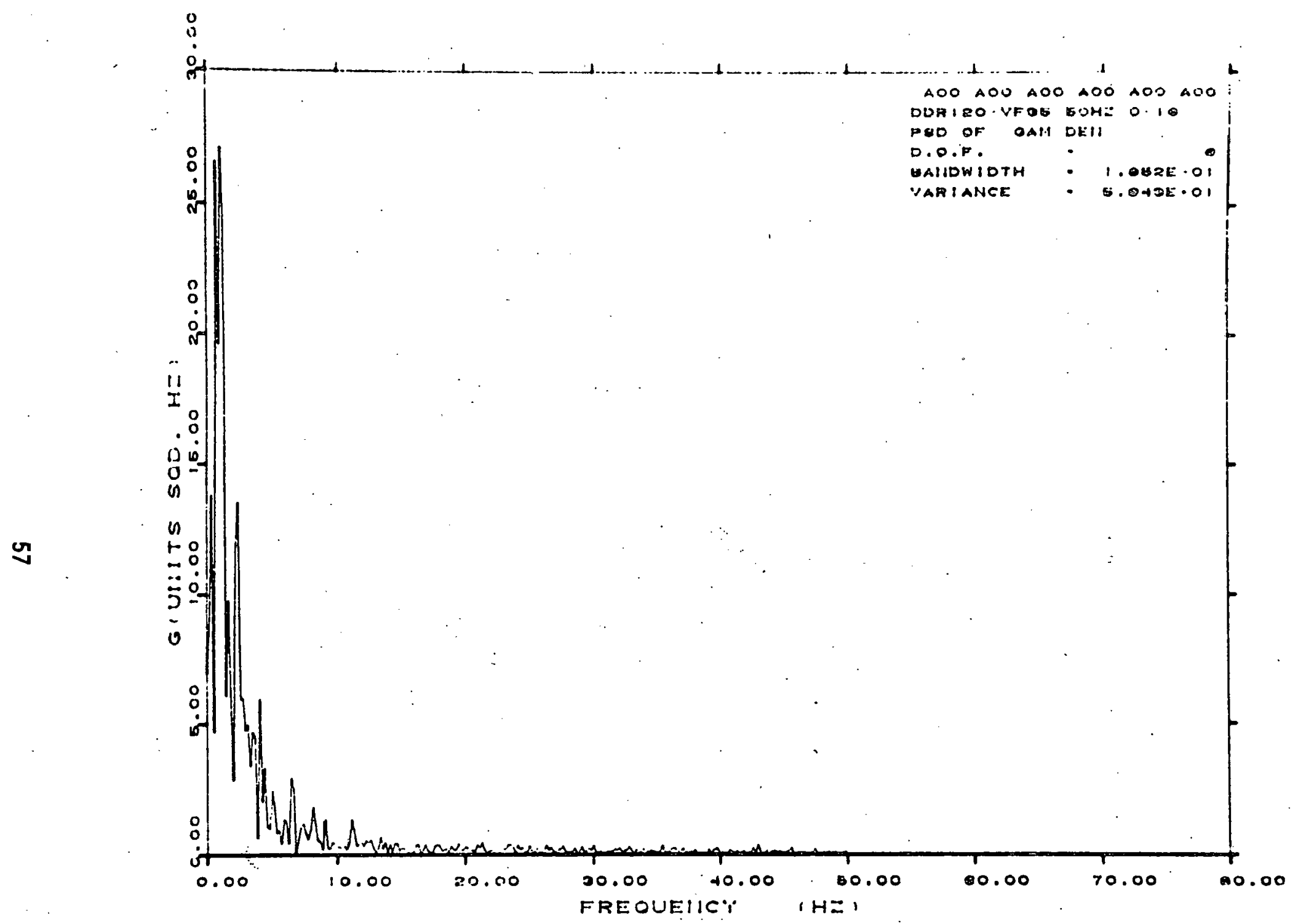

Figure 31B: Power spectral densities plot of VF-35 (densitometer). 


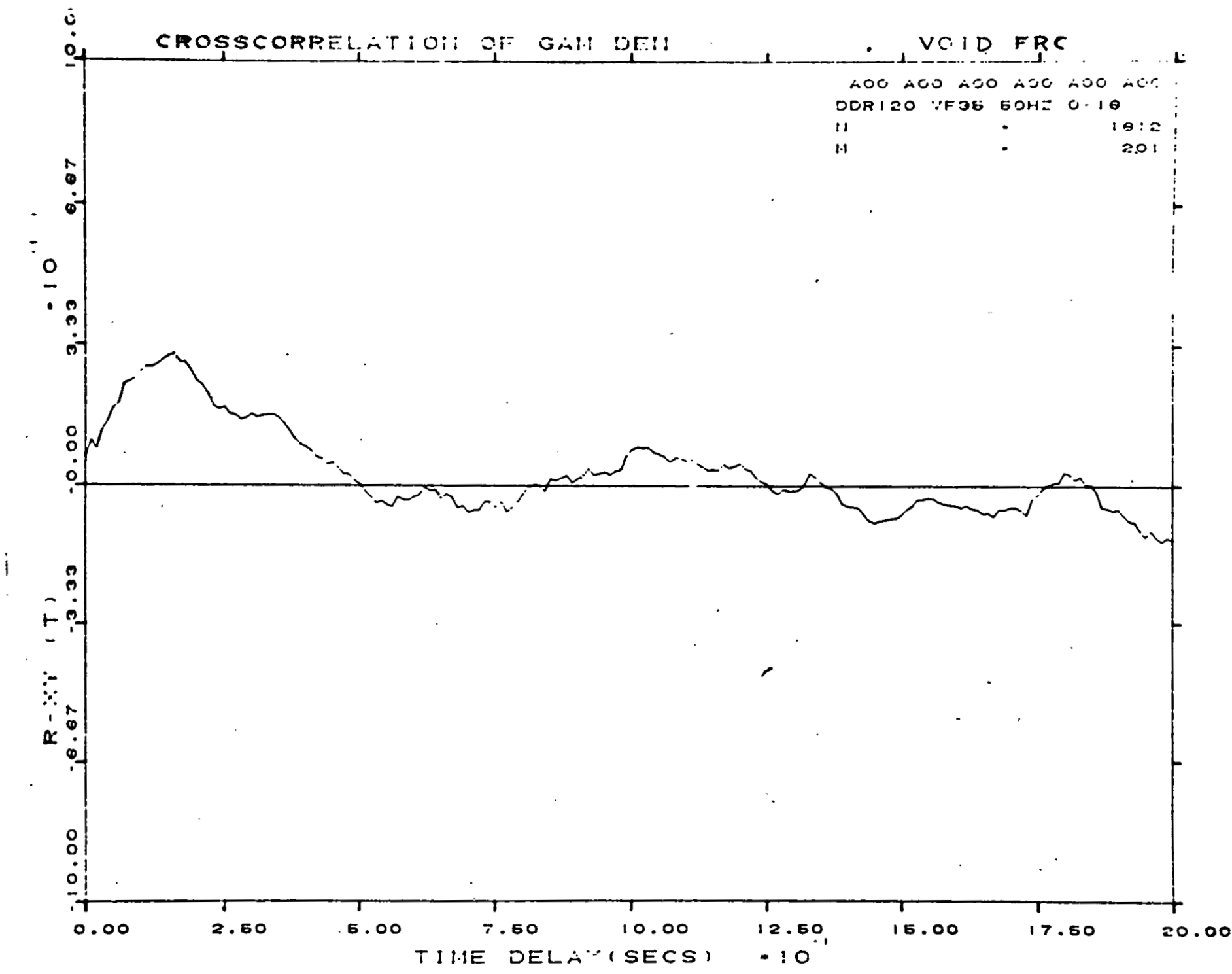

Figure 32: Cross correlation plot of VF-35. 


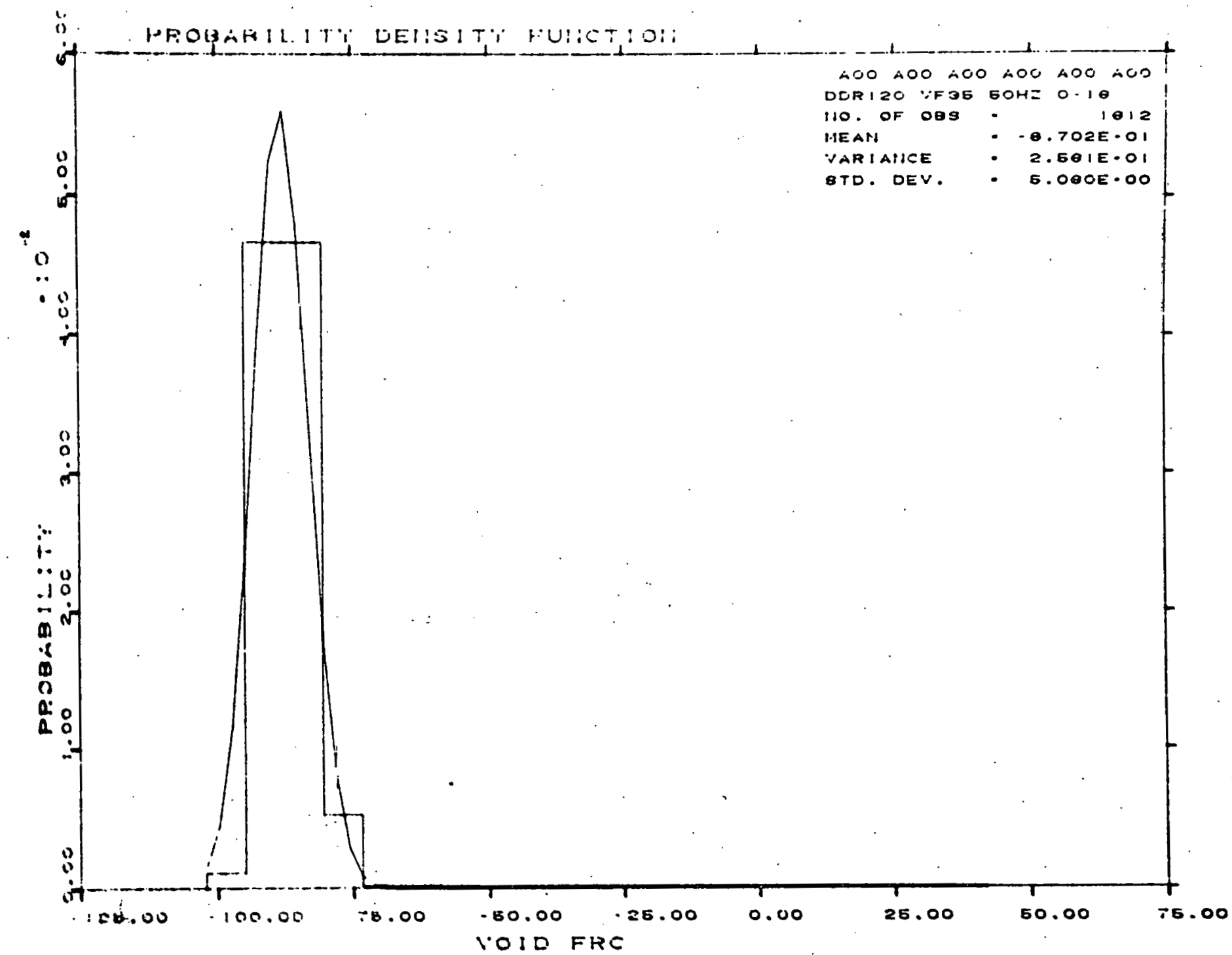

Figure 33A: Probability density function of VF- 35 (ultrasonic transducer). 


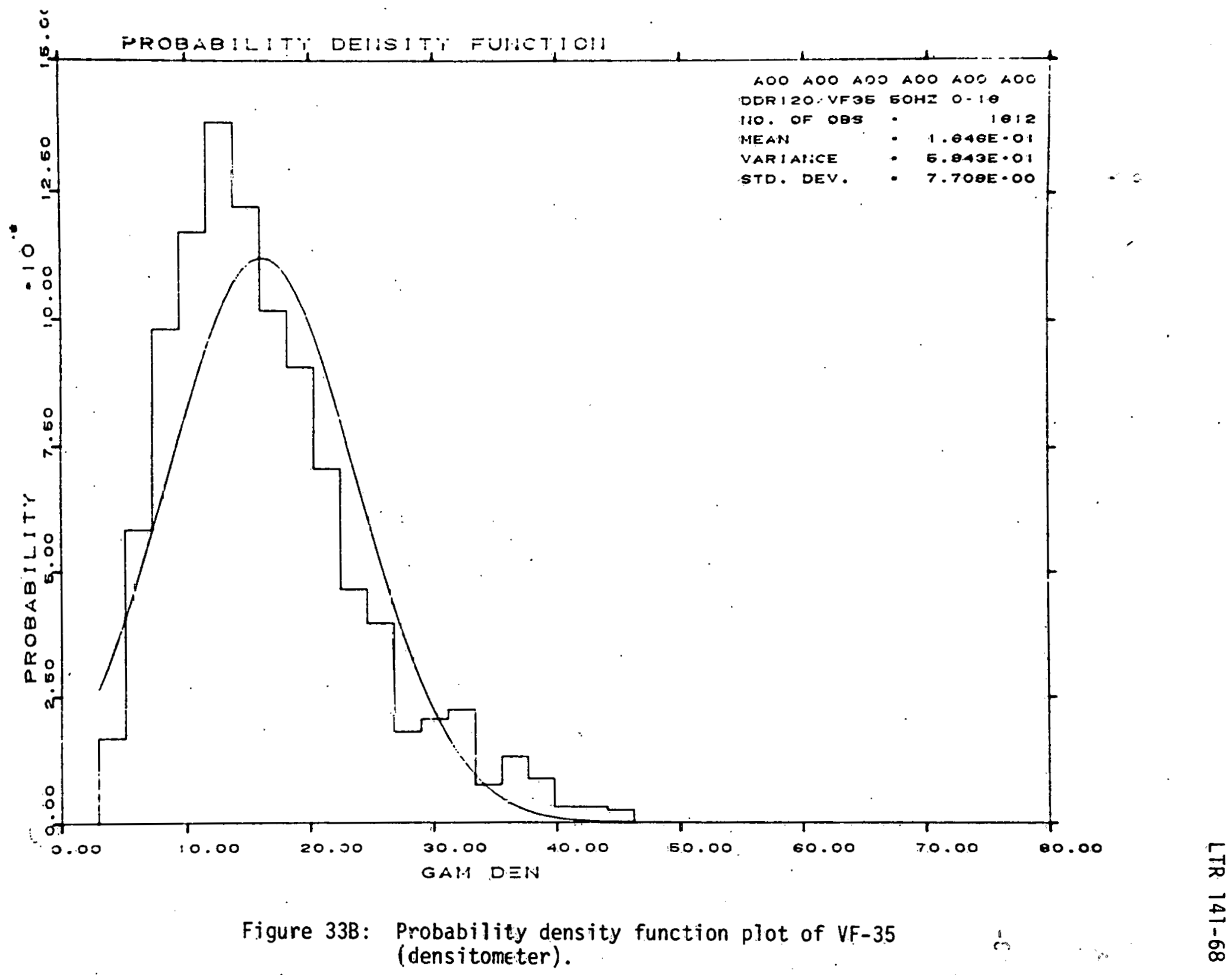




\subsection{Conclusions for Ultrasonic Void Fraction System}

Time averaged data for the ultrasonic detector presented in Figure 29 indicate that the detector signal was a function of void fraction and a weak function of mass flow past the probe. Each line represents a set of data points taken at a constant water flow rate and varying the air flow rate. The goodness of fit $\left(R^{2}\right)$ of each data set is greater than 0.98 , indicating low noise, highly linear data. The difference in the slope and zero offset of each data set indicates the dependence of this measurement on mass flow rate.

The frequency distribution of information in ultrasonic signal could account for the small correlation between the gamma densitometer and ultrasonic signal (Figure 32). The reasons for the frequency distribution of the signals is not currently understood. The results of the data analyses indicate that the ultrasonic detector is capable of measuring a function of void fraction.

The accuracy is approximately $\pm 2 \%$ with a repeatiblity of $\pm 12 \%$ of range yielding an overall accuracy of $\pm 12.17 \%$ of range (Appendix $H$ ).

6.2.1 Detector Modeling. The final report submitted by Panametrics ${ }^{[6]}$ indicates that the ultrasonic detector does not measure void fraction directly, but measures a function of the average density of the two-phase liquid. In the simplest case this would be of the form:

$$
\bar{\rho}=\rho \frac{A \text { wet }}{A \text { sensor }}
$$

where

$$
\begin{aligned}
\rho & =\text { density of liquid portion } \\
\text { A wet } & =\text { wetted area of probe and } \\
\text { A sensor } & =\text { total sensor area. }
\end{aligned}
$$


Also in actual application, the bubble size and distribution will probably complicate the above equation.

The LOFT Measurements Performance Section was requested to mode 1 the ultrasonic detector. The response (Appendix I) indicated that for simplified case the detector measured an effective fluid density, $\rho_{e}$, which is the product of the average density of the two-phase fluid and the fraction of the sensor surface that is wetted by a liquid, i.e.

$$
\rho_{\mathrm{e}} \cong \bar{\rho} \frac{A \text { wet }}{A \text { sensor }}
$$

where

$$
\begin{aligned}
\bar{\rho} & =\text { average density of two-phase fluid } \\
\text { A wet } & =\text { wetted area of probe and, } \\
\text { A sensor } & =\text { total sensor area. }
\end{aligned}
$$

The actual dependence of the sensor response on density, void fraction, and other fluid properties such as flow velocity should be determined by further experimentation. 


\subsection{GENERAL CONCLUSIONS AND RECOMMENDATIONS}

\section{1 Conclusions}

The analyses of the data from the ultrasonic and conductivity vertical tests indicate that both devices are capable of measuring a function of void fraction or void fraction directly in air-water.

Table II lists the results of the performance analysis of the two detectors. The ultrasonic detector system appears to possess the capability for higher accuracy than the conductivity detector if the problem of mass flow sensitivity can be overcome. Both devices appear to be geometrically sensitive. The ultrasonic detector gives a time average over the $66.0 \mathrm{~mm}$ (2.6 inch) active sensing length, while the conductivity detector gives a time average over the length of the $25.4 \mathrm{~mm}$ ( 1 inch) electrode.

\section{TABLE II}

PERFORMANCE CHARACTERISTICS AS INDICATED

BY ANALYSIS OF TEST DATA

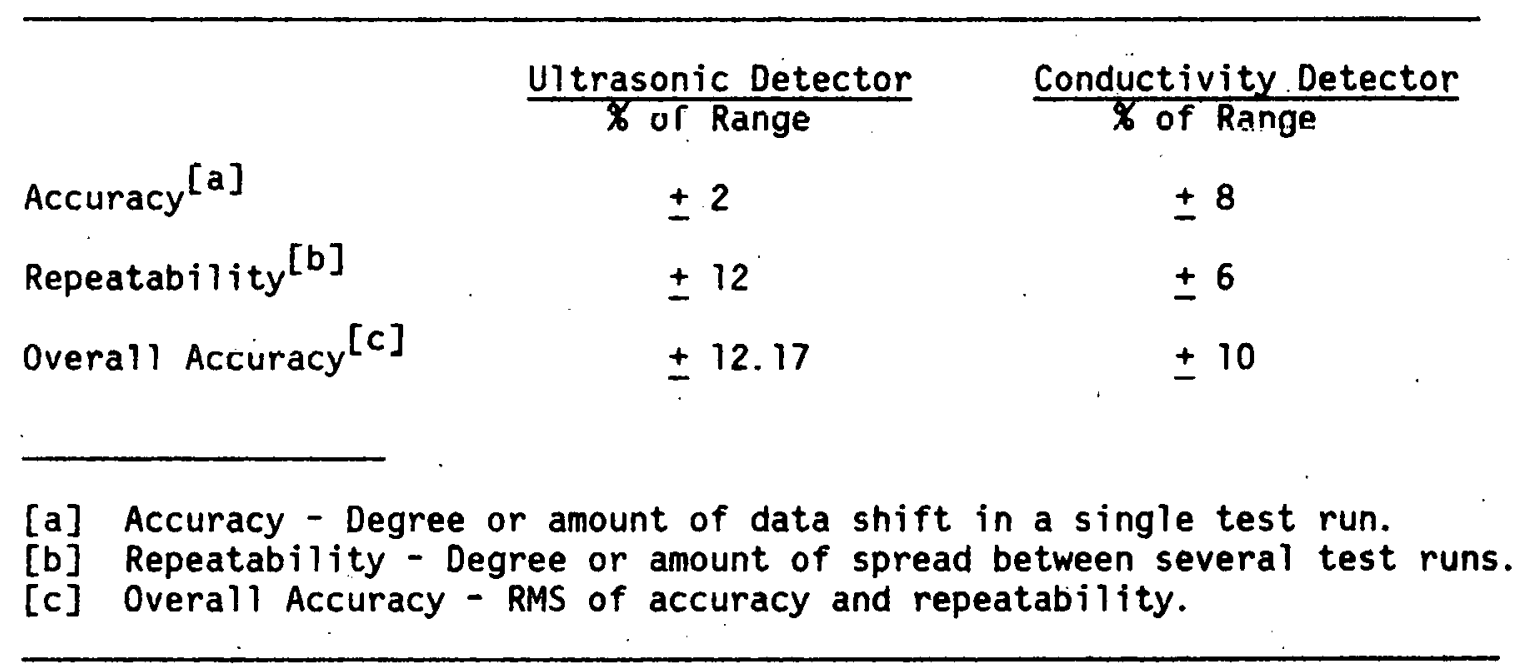


The signature plots of the ultrasonic detector do not show the slug flow regimes with good clarity or air-water definition as depicted by the conductivity detector signature plots. (Reference Figures $30 \mathrm{~A}$ and $16 A$ ).

\subsection{Recommendations}

The mass flow sensitivity of the ultrasonic detector may be improved by using an elliptical shape on the active sensing region instead of the present rectangular shape. A set of electronics that are specificaliy designed for the ultrasonic void fraction detector should be constructed. These recommendations will improve the accuracy of the device.

Development of the conductivity detector should be continued and the electrode redesigned, by removing the shroud and cabling on the LLD and using a smaller electrode, thereby reducing the scatter in these data points. The ceramic seal on the electrode should be improved for longer life in reactor environments. Using a slgnal processing scheme (Appendix $J$ ) will reduce the effect of changing impedance caused by a degenerating ceramic seal. Implementing those recommendations will Improve the life expectancy and acrurary of the device.

A conductivity rake using smaller electrodes should be investigated to provide several point measurements over a long length in the upper core support structure, which will improve average mass flow measurement. 
LTR 141-68

\section{0 REFERENCES}

1. L. P. Leach, Proposal for Additional LOFT Instrumentation Under NRC-Federal Republic of Germany Cooperative Agreement (August 30,1976 ).

2. A. E. Arave, A Conductivity-Sensitive Liquid Level Detector for Reactor Environment, ANCR-1046.' (January 1972).

3. J. D. Schmutz and A. E. Arave, Liquid Leve] Detector Conductivity Study, LTR-144-6 (November 30, 1973).

4. J. L. Morrison, Liquid Level System Redesign, Intermediate Design Review, DR-87-43 (March 14, 1977).

5. A. E. Arave, An Ultrasonic Void Fraction Detector Using Compressional Stress Waves in a Wire Helix, IN-1441 (October 1970).

6. M. E. Buchanan, R. D. McCormick and H. S. Selcho, The Feasibility of Instrumenting LOFT Reload Core Fuel Rods Using Existing Technology, LTR-142-6 (July 1977).

7. G. W. Govier and K. Aziz, The Flow of Complex Mixtures in Pipes, Van Nostrand Reinhold Cuimpany (1372) pp. 503-51?.

8. L. D. Goodrich and R. Crumley, LOFT Gamma Densitometer Uncertainty Analysis, LTR 141-39, Supplement $15 \mathrm{Rev.} \mathrm{A} \mathrm{(August} \mathrm{1977).}$

9. G. W. Govier and K. Aziz, The Flow of Complex Mixtures in Pipes, Van Nostrand Reinhold Company (1972) pp. 322-328. 
LTR 141-68 
APPENDIX A

CORE INLET FLOW AND VOID FRACTION

SENSOR DESIGN REQUIREMENTS 
LTR $\quad 141-68$ 


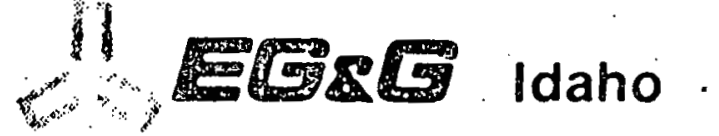

\section{INTEROFFICE CORRESPONDENCE}

date November 3, 1976

10 R. R. Rohrdanz

rom L. J. Ybarrondo off

sUDject CORE INLET FLOW AND VOID FRACTION SENSOR DESIGN REQUIREMENTS Ybr-145 -76

Attachment 1 specifies design requirements fon the core inlet flow and void fraction sensors to be designed under FRG funding.

As we have previously discussed, an early decision as to the type and configuration for the void fraction sensor to be used is required to remain on schedule.

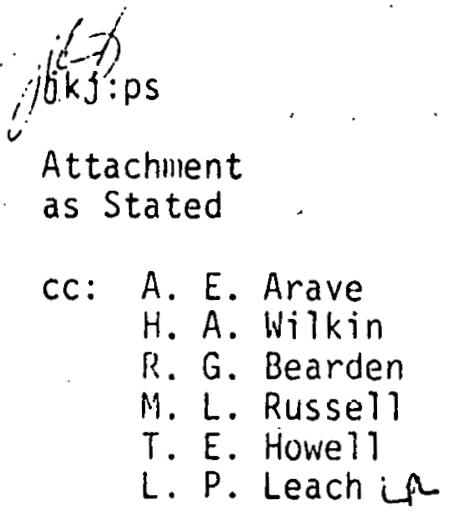




\section{OBJECTIVE}

.- Provide Measurements in LOFT of:

1. Core inlet velocity

2. Core inlet momentum flux

3. Core inlet void fraction 


\section{INTRODUCTION}

The objective of the core flow measurement improvement is to better qualify the flow through the LOFT core during the LOCA transient. This is to be accomplished by providing measurement of velocity, momentum flux, and void fraction at the core inlet. Presently, measurement of core flow is only made at the top of the core (outlet) via three dray disk-turbine units; and at the bottom of the downcomer via two drag disk turbine units. During portions of the LOCA transient, flow is predicted to go out both ends of the core. Also, during greater portions of the transient, the flow in the bottom of the core is significantly different from the outflow at the tols (net accullulation and heat transfer effects). Due to mass accumulation/ depletion in the lower plenum, the flow meters at the bottom of the downcomer do not give a good indication of core inlet flow. 


\section{DESIGN REQUIREMENTS}

\section{A. Location}

The design shall provide for a measurement of velocity, momentum flux and void fraction at the lower tie plate location (inlet) of the center (type A) LOFT fuel assembly. Two DTT units of the present or similar design shall be centered above and within flow holes in the core mounting plate as shown in Figures 1 and 2. The vold fraction. detector shall be located in the general region between the core mounting plate and the lower tin plate. (Modifications to the core mounting plate may be required, i.e., flow hole enlargement at DTT locations.

\section{B. Design Life}

Components shall be designed to meet the 2000 effective full power hour (efph) reactor life requirement. This requirement means that the components must survive for a longer but undefined period of time at reactor vessel temperature, pressure and coolant chemistry environmental conditions. The design objective for these conditions is for 10,000 $\mathrm{hr}$.

\section{Fluid Loading}

$\operatorname{Max} \rho V^{2}=40,200 \mathrm{~kg} / \mathrm{m}-\mathrm{sec}^{2}$

based on a maximum possible steady state PCS flow of $2.27 \times 10^{6}$

$\mathrm{Kg} / \mathrm{hr}$ and a lower core support plate flow area of $0.116 \mathrm{~m}^{2}$

D. Radiation Environment

Cumpunents shall be designed to operate as specified after being subjected to the following radiation environments: 
Flow Measurement Added to Center Fuel Bundle

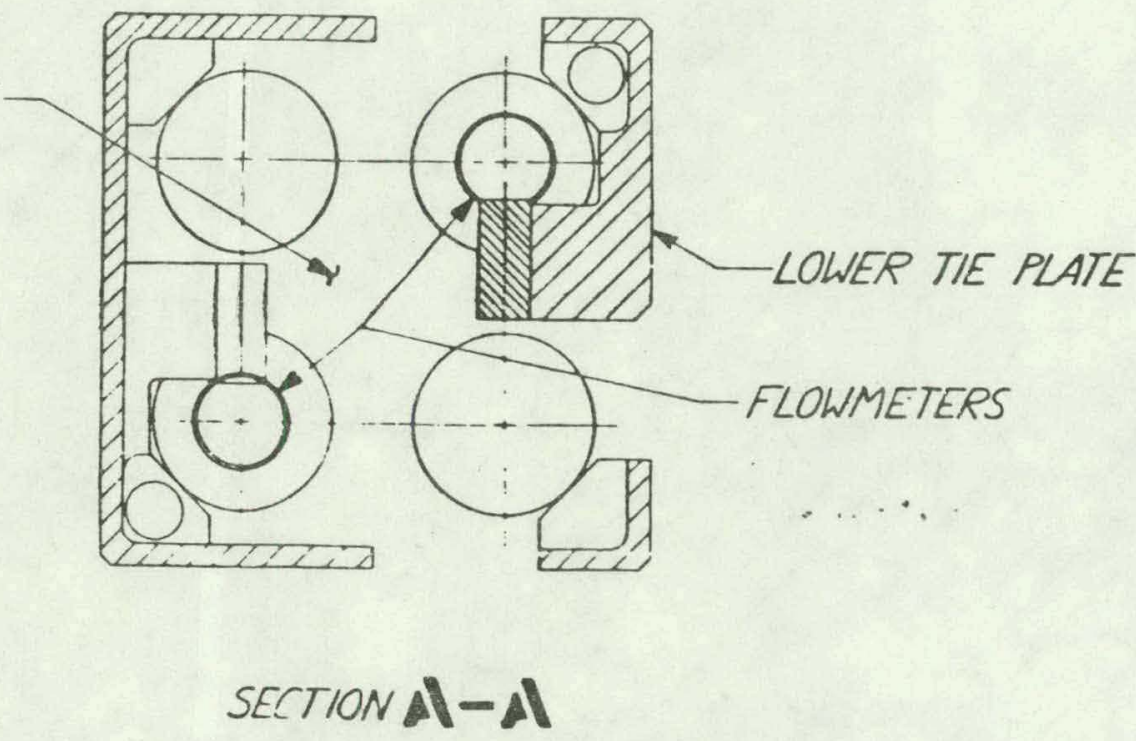

Fig. I Plan view of fiow measurement at fuel module inlet. 
LTR 141-68

fLOWMETER POSIIIONS DENOTED BY

CORE MOUNTING PLATE

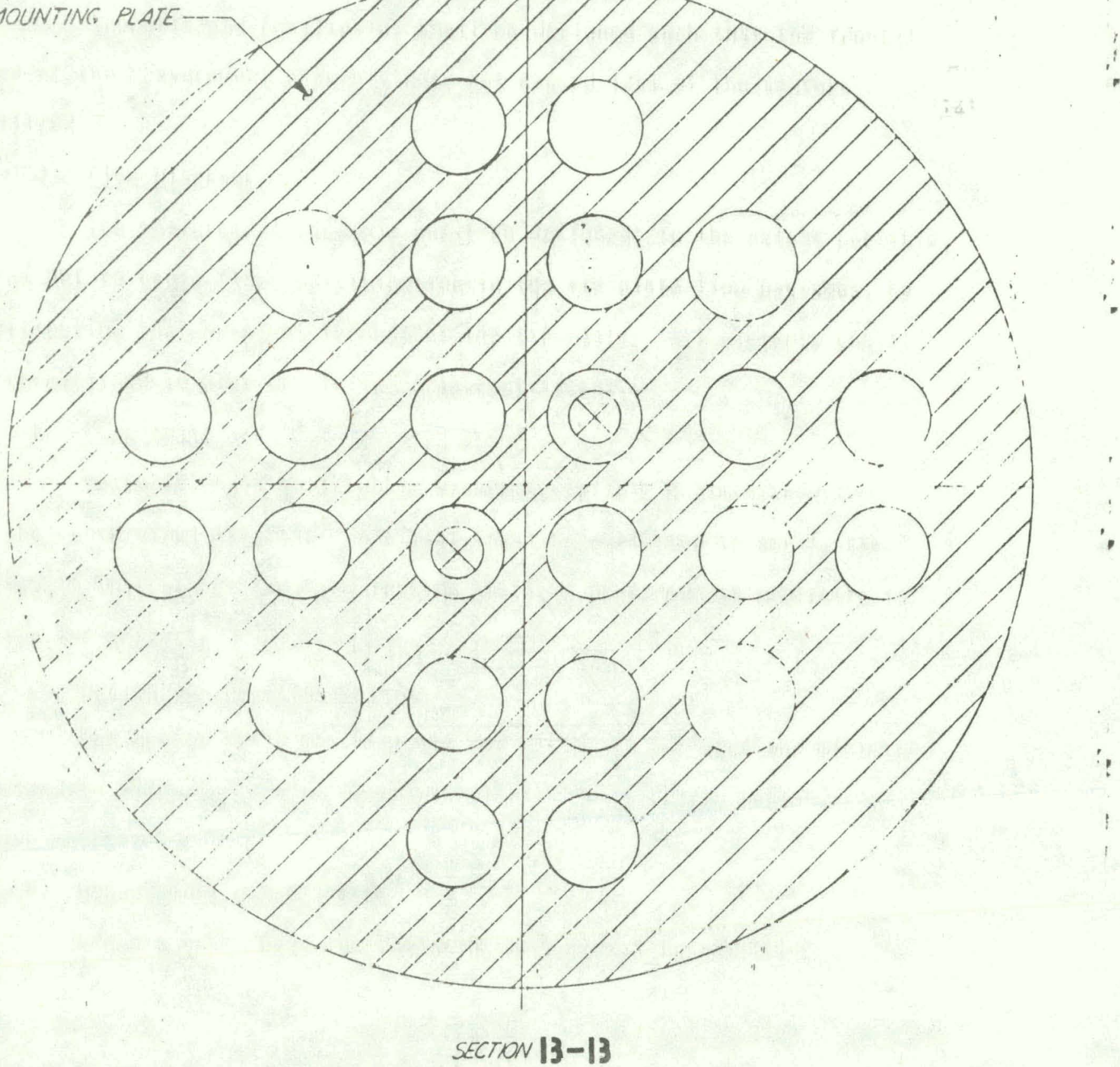

Fig. 2 Flow measurement locations flow measurement added to center fuel bundle 
Heutron flux

$\begin{array}{ll}\text { Normal operation } & 1.0 \times 10^{14} \text { neutrons } / \mathrm{cm}^{2}-\mathrm{sec} \\ \text { Total exposure } & 7.2 \times 10^{20} \text { neutrons } / \mathrm{cm}^{2} \\ \text { Gamma flux } & \end{array}$

Nornal operation $1 \times 10^{9} \mathrm{R} / \mathrm{hr}$

Total exposure $2 \times 10^{12} \mathrm{R}$.

E. Temperature Environment

Components shall be designed to operate as specified for the design life at the primary coolant operating temperature of $327^{\circ} \mathrm{C}$ with maximum temperature transients of short duration during LOCE to $537^{\circ} \mathrm{C}$.

\section{F. Pressure Environment}

Components shall be designed to operate as specified for the design life in the primary coolant pressure environment of 15.51 meganascals (gauge) and transient overpressures to 17.23 megapascals (gauge) hot and 21.55 megapascals (gauge) cold.

G. Coolant Chemistry

Components shall be designed to survive for a design life in the LOFT primary coolant. The primary coolant chemistry is given in Tatir: 2-XXVI of SDD 1.4.1 C.

H. Vibration Resistance

Components and supports shall be designed with sufficient stiffness to preclude premature failure due to the vibration excitation specified in. Interoffice Correspondence, M. W. Dacus to R. L. Crumley, ERRATA-PC-1 Vibration Test Amplitudes, MWD-5-76, dated September 25, 1976. 
I. Frontal Area and Streamlining

Supports and auxiliaries shall be designed such that the frontal

area of the measurement assembly does not exceed $125 \%$ of the sensors utilized.

\section{J. Flow Blockage}

The measurement assembly shall be designed, to the extent possible, so as not to cause flow redistribution in the tie plate flow passages, by distributing the equipment throughout the tie plate. All elements shall be streamlined to provide minimum drag coefficient.

\section{K. Flow Split}

Measures shall be taken to ensure acceptably undiminished fink: to the center fuel assembly. Analysis shall be performed to verify the design in this aspect and flow testing shall be performed as necessory to verify the analysis.

\section{Design for Decontamination}

The design shall maximize the use of smooth surfaces and minimizc crevices to allow for easier decontamination of particulate radioactive material.

M. Measurement Capabilities

Sensors shall have the following measurement capabilities.

\begin{tabular}{|c|c|c|}
\hline Velocity & Void Fraction & Flow Direction \& Monntum! \\
\hline Kange .6 to $6 \mathrm{~m} / \mathrm{sec}$ & $0-100 \%$ & 300 to $3130 \mathrm{~kg} / \mathrm{m}-\mathrm{sec}^{2}$ \\
\hline Accuracy $\pm 5 \%$ of range & $\pm 5 \%$ of range & $\pm 5 \%$ of range \\
\hline $\begin{array}{c}\text { Response } 10 \text { to } 90 \% \text { in } 100 \\
\text { nisec }\end{array}$ & $\begin{array}{l}10 \text { to } 90 \% \text { in } 100 \\
\text { msec }\end{array}$ & $\begin{array}{l}10 \text { to } 90 \% \text { in } 100 \\
\text { msec }\end{array}$ \\
\hline
\end{tabular}


APPENDIX B

SPECIFICATION DENSITY SENSING

SYSTEM FOR LOFT-ES-60188 
THIS PAGE

\section{WAS INTENTIONALLY \\ LEFT BLANK}




\title{
ES - 60188 \\ DATE — December 10, 1976
}

\section{SPECIFICATION}

\author{
DENSITY SENSING SYSTEM \\ FOR \\ LOFT
}

\begin{tabular}{|c|c|}
\hline REV & RELEASE DATE \\
\hline LTR & December 10,1976 \\
\hline & $\ddots$ \\
\hline & \\
\hline & \\
\hline & \\
\hline & \\
\hline & \\
\hline & \\
\hline
\end{tabular}

AUTHORIZED FOR RELEASE

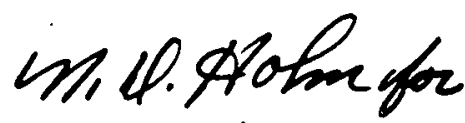

B. L. Freed

LOFT CONFIGURATION-DOCUMENT CONTROL \& SERVICES 
EG\&G Idaho, Inc.

LTR 141-68

DOCUMENT APPROVAL SIGNATURE SHEET

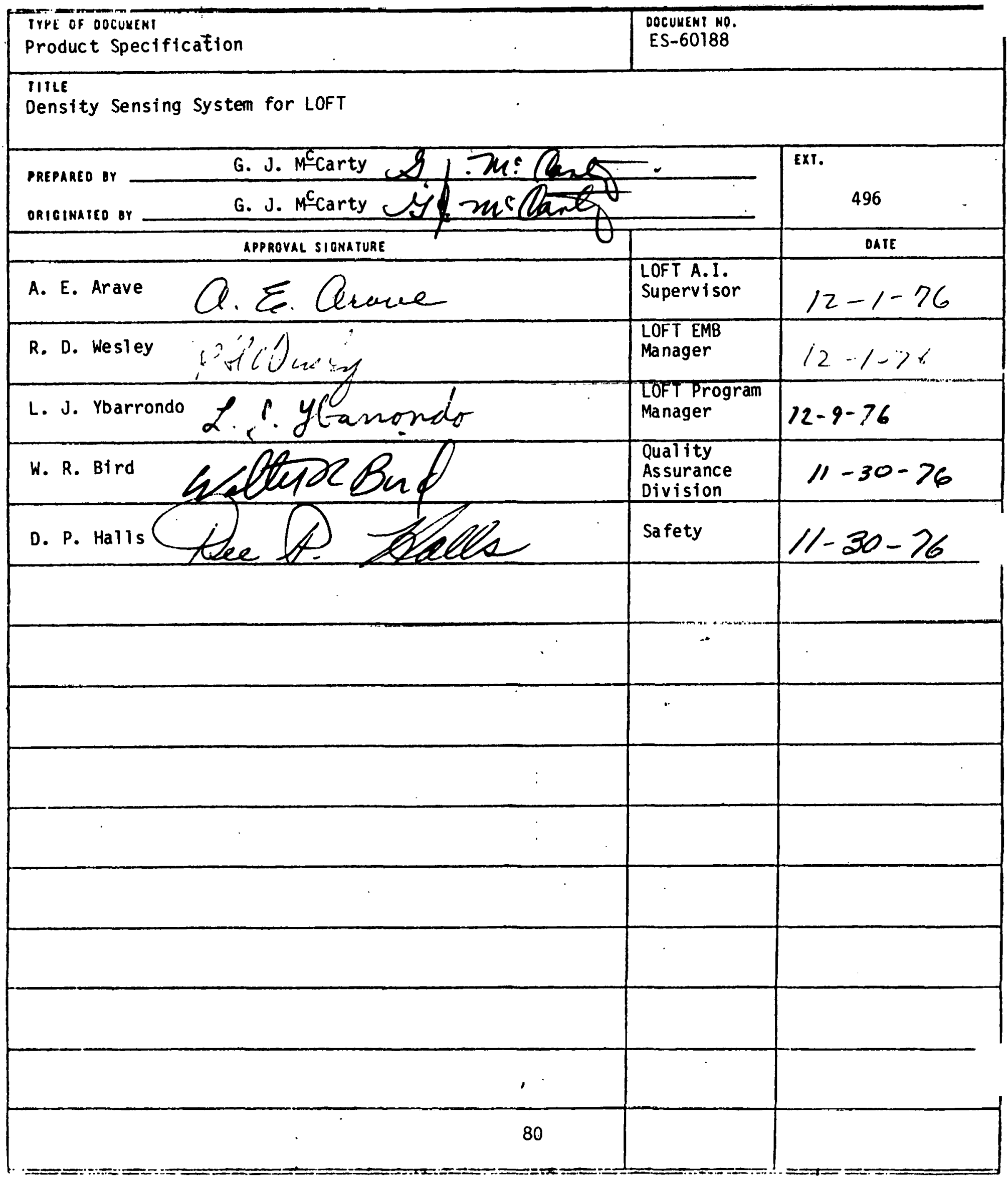


1. SCOPE

1.1. Scope. This specification covers the requirements for the LOFT density sensing system using void fraction sensors and thermocouples. The system will be used to measure density and density profiles in the loss of fluid test (LOFT) reactor pressure vessel during loss of coolant experiment (LOCE) tests.

1.2 Definitions. The following definitions are applicable for this specification.

1.2.1 Mean Time to Fallure (MTTF). Each sensor shall demonstrate a 2,000 hour MTTF at $90 \%$ confidence level. The 2,000 hour MTTF is a product of the number of hours assigned to each LOCE (200 hrs) times the maximum number of LOCEs ( 5 times an operation factor of 2). Peak temperatures occur for a short duration of 30 to 60 seconds during each LOCE, reference 3.3.3a and 3.3.4.

\section{APPLICABLE DOCUMENTS}

The following documents form a part of this specification to the extent specified herein. Unless otherwise specified, the issue in effect on the date of invitation to bid shall apply. In the event of a conflict between the documents referenced herein and the contents of this specification, the contents of this specification shall be considered a superseding requirement.

U.S. Energy Research and Development Administration (ERDA) - Division of Reactor Development and Demonstration

RDT Cl-IT Instrumentation and Control Equipment Grounding and Shielding Practices.

RDT F2-4T Quality Verification Program Requirements

RDT F2-9T Reliability Assurance 
American Society of Mechanical Engineers (ASME)

ASME Boiler and Pressure Vessel Code - Section III

Aerojet Nuclear Company (ANC)

ANC-STD-7006 Marking Methods for Equipment, Components, and Materials

ANC-STD-7020 Preservation and Protection Requirements for Nuclear Reactor Components

ANC-STD-7022 Cleanliness Acceptance Levels for Nuclear or Nonnuclear Service Components

ANC-60092 LOFT Power MTA No. 1 Electrical and Instrumentation and Design Requirements

MRD-2

LOFT Measurement Requirements Document

SOD 1.4.1 LOFT Program Division System Design Description for the Test Assembiy Experimental Measurements System

DWG. 204025 Center Fuel Module Assembly, Type A\&F

DWG. 204390 LOFT-Upper Core Support Structure - Center Fuel Assembly

DWG. 205050 Downcomer Instrumentation Assembly

ANC, LOFT Facility Division Plant Operating Manual, Volume II, Chapter 8

Idaho Nuclear Corporation (INC)

EC-2 LOFT Environmental Conditions 
EXXON Nuclear Company, Inc.

DWG. XN-300, 382 Lower Square THe Plate

DWG. XN-300, 383 Lower Tie Plate

DWG. XN-302, 318 Fuel Bundle Assémbly.

\subsection{REQUIREMENTS}

3.1 General. The density sensing system shall consist of vold fraction sensors, thermocouples (TCS) and mounting hardware, reactor vessel penetrations, junction boxes, test assembly cabling and cable supporting hardware, and signal conditioning and recording equipment.

Void Fraction sensors shall be developed and mounting hardware designed for installing the void fraction sensors and TCS in the following reactor vessel locations:

(1) Two sensors in the lower tie plate of the center fuel module, DWG. $X N-300,383$, located as close as possible to the drag-disc turbine transducers (DTT).

(2) Several sensors in the region of the upper core support structure center fuel assembly, DWG. 204390, covering an area from an elevation near the bottom of the upper core support structure to an elevation approximately two feet above the bottom of the upper core support structure.

(3) Several sensors in the region of the lower plenum starting at the general location of the DTT on one of the downcomer instrumentation assemblies, reference DWG. 205050, to the bottom of the downcomer assembly.

(4) One sensor in the upper core support structure center fuel assembly, DWG. 204390, located as close as possible to the DTT. 
The functions of the density sensing system are to measure the densities at point locations described in (1) and (4) and density profiles at locations noted in (2) and (3). The densities obtained can be used in conjunction with the results from the DTTs to calculate and verify the twophase mass flow rate.

3.2 Performance Characteristics. The following density measurement requirements are, in accordance with MRD-2 and SDD 1.4.1.

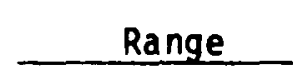

0.05 to $62.4 \mathrm{lb} / \mathrm{ft}^{3}$

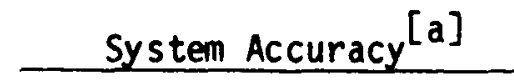

$\pm 5 \%$ of range
Response

$100 \mathrm{msec}(10$ to $90 \%$ rise)

\subsection{Design and Construction}

3.3.1 Items that form part of the primary coolant system (PCS) pressure boundary shall be designed and constructed in accordance with the requirements for Class 1 components of the ASME Boiler and Pressure Vessel Code (the code) Section III.

3.3.2 Items located on the test assembly but not in the PCS or part of the PCS pressure boundary shall be to withstand the applicable onvironmental conditions specified in INC EC-2.

3.3.3 Sensors located in the PCS must be capable of survival in the following environment. Survival is interpreted as operations within specified limits during steady-state operation and withstanding maximum conditions per limited time without affecting calibration. These requirements follow or supplement the requirements specified in MRD-2 or SDD 1.4.1.

a. Temperature - Sensors must survive and demonstrate a mean time to failure (MTTF) of 2,000 hours, refer to 1.2.1, when used in an environment where the temperature under normal operation is $650^{\circ} \mathrm{F}$ and with peak temperatures

[a] System accuracy represents the acceptable error total of all contributory measurement system errors (detection, transmittal, digitizing, etcl. 
for short duration (30 to 60 seconds) in $1000^{\circ} \mathrm{F}$ steam during each loss-ofcoolant experiment (LOCE).

b. Pressure - Sensors must meet the following requirements:

Normal operation

Design maximum (hot)

Design maximum (cold)
2250 psi

2500 psi

3125 psi

Shock resistance - subcooled decompression $\Delta \mathrm{p} / \Delta t=-22,500 \mathrm{psi} / \mathrm{sec}$

c. Corrosion Resistance - Sensors must be capable of operating in a water quality environment specified in Table $I$.

d. Irradiation - Sensors must provide data within the specified accuracies after neutron and gamma exposure equal to the following maximum values:

Neutron Flux

Normal Operation

$1.0 \times 10^{14}$ neutrons $/ \mathrm{cm}^{2}-\mathrm{sec}$

Total Exposure (Maximum)

$7.2 \times 10^{20}$ neutrons $/ \mathrm{cm}^{2}$

Gamma Flux

Normal Operation

$1 \times 10^{9} \mathrm{R} / \mathrm{hr}$.

Total Exposure

$2 \times 10^{12} R$

3.3.4 Sensors attached to the fuel assemblies shall be designed to withstand 10 exposures to the following LOCE environments: 
(1) A differential pressure loading of $50 \mathrm{psi}$ taken in the most adverse direction across each component, instrument, or mounting device, etc. The 50-psi loading requirement shall be evaluated, assuming the same thermal conditions that exist at reactor full power (55 $M W(t))$

(2) Temperature conditions:

Peak

Rate of Change Temperature

(a) Components attached to support tubes $20^{\circ} \mathrm{F} / \mathrm{sec}$

$1450^{\circ} \mathrm{F}$

(b) Components attached to fuel assembly end boxes $20^{\circ} \mathrm{F} / \mathrm{sec}$ $1450^{\circ} \mathrm{F}$

(3) After $5 \mathrm{sec}$ at the maximum temperature, the equipment shall be assumed to be quenched by immersion in saturated steam-water mixture at a pressure of 25 psia.

3.3.5 The attachment and location of the void fraction sensors and thermocouples shall be designed such that (a) reactor operating condition objectives can be achieved and (b) the response of the fuel module during the LOCEs will provide valid core thermal-hydraulic response data.

\subsubsection{Routing of Instrumentation Leads}

(1) Sensor leads from sensors located in the regions described in $3.1(1),(2),(3)$ and (4) shall be routed to connectors on the fuel module and downcomer instrumentation penetration assemblies.

(2). The minimum inside bend radius shall be three cable diameters.

(3) The sensor leads (cable sheath) from the end of the sheath to within four feet of the sensor shall be capable of passing through a ring 
gage that has a hole 0.002 inch diameter over the maximum allowable sheath diameter, and being $0.500+0.001-0.000$ long.

(4) Cable sheath outside diameter shall have a tolerance of $+0.001-0.000$.

3.3.7 Cleanliness. Cleanliness acceptance levels shall be established and specified on all drawings in accordance with ANC-STD-7022.

\subsubsection{Fastener Torquing. Fastener torque values shall be specified on} all assembly and installation drawings.

3.4 Materials. The materials used in the components noted in this specification shall be compatible with the environments and operating conditions specified in $3.3 .1,3.3 .2,3.3 .3,3.3 .4$, and 3.3 .5 and metallurgically compatible with components of the test assembly with which they are in intimate contact.

\subsection{Component Parts}

3.5.1 Junction Boxes. Junction boxes shall be water-tight, air-tight and explosion proof per ANC 60092 .

3.5.2 Cable. Cable from the connectors on the instrumentation penetration assemblies shall provfde circult pruteclion fruiii electrostatic, electromagnetic, and group loop pickup of extraneous signals. Reference RDT CI-IT. Coricin

3.5.3 Signal Conditioning and Recording Equipment. The void fraction sensors and TC signal conditioning and recording equipment and other incircuit items, e.g. cable junction boxes, etc, shall be capable of providing density measurements in accordance with the performance characteristics noted in 3.2 .

3.6 Identification and Marking. Part marking shall be required on all components in accordance with ANC-STD-7006. 


\subsection{Protection and Preservation. Protection and preservation of void} fraction sensors and thermocouples shall be provided in accordance with ANC-STD-7020. ,

\subsection{Interfaces}

(1) The void fraction sensors and thermocouples shall interface with regions in the core center fuel module and downcomer instrumentation assembly specified in the general requirements Section 3.1 .

(2) Instrument leads from sensors located in the area of the center fuel module or downcomer instrumentation assembly shall interface with the connectors on the respective instrumentation penetration assemblies.

(3) Cabling from the connectors on the instrumentation penetration assemblies shall interface with the junction boxes and at Building 650 penetrations. The cabling shall then interface with the signal conditioning equipment in Room 219, Building 650 and then with the patching facility in Room B100, Building 630 .

3.9 Documentation. The documents noted in the design rigor matrix, Table II and those noted in the text shall be supplied.

\subsubsection{Design Verification Analysis Reports. The design verification} analysis reports submitted by the Contractor shall consist of summary descriptions of the computations performed in verifying the density system design and establishing specific design features. The basic criterion for the summary descriptions is that sufficient information is provided so that a knowledgeable reviewer can determine whether or not the analytical technique employed is justified with respect to its application and in relation to alternate techniques available. The format and content of the summary descriptions of the design analysis shall be as follows: 
a. An introduction that states the purpose of the calculation and the results.

b. A description of the analytical technique used showing special equations, working curves, and generally providing enough information to satisfy the reviewer that the method used was justified. When computer codes are used to solve problems, a brief description of the computer code shall be provided. If a reference report is not available, the description shall include the techniques used by the computer code to solve the problems and show that any special correlations used to the computer are justified and accurate.

c. A description of and justification for the assumptions made and the design acceptance criteria and a summary of the data used in the analysis.

d. A detailed presentation of the results.

e. A discussion of the results, describing areas of uncertainty, results of similar design studies, and generally providing enough information to estabiish the authenticity of the results.

f. A list of references.

3.9.2 Design Verification Test Reports. Design verification test reports submitted by the Contractor shall consist of summary descriptions of the tests performed by the Contractor to qualify the density system design for $i$ ts intended use. The basic criteria for the summary description is that sufficient information be provided so that a knowledgeable reviewer can determine whether the test method used is justified with respect to $i$ ts application. The format and content of the summary descriptions of the qualification tests shall be as follows:

a. An introduction that states the purpose of the qualification test and the results. 
b. A description of the test apparatus used and the test procedure. Details of (1) the mechanical interfaces between the test component and the test apparatus and (2) the environment (pressure, temperature, fluid chemistry, flow rates, applied loads) are required.

c. A detailed presentation of the results including a before and after description of the component being tested.

d. A discussion of the test results, describing areas of uncertainty and generally providing enough information to establish that the test method is adequate for qualifying the component for its intended use.

\subsection{QUALITY ASSURANCE PROVISIONS}

4.1 Quality Assurance Program. The Contractor shall maintain a Quality Assurance Program in accordance with the requirements of RDT F2-4T.

4.2 Reliability Assurance. The Cunlractor shall maintain a Reliability Assurance Program in accordance with the requirements of RDT F2-9T.

\subsection{Test Methods and Conditions}

4.3.1 Design Test Plan. A test plan shall be prepared and approved prior to starting fabrication of the sensors. The test plan shall include but not limited to the following items:

(1) Objective of end item development

(2) Description of end item to be tested

(3) Quantity to be tested

(4) Proposed test facility and location

(5) Desired test schedule versus facility availability 
(6) Test equipment required

(7) Support equipment required

(8) Outline of tests to be conducted

(9) Types of data to be acquired

(10) Methods for reporting test results and resolving problems.

4.3.2 Test Procedures. Test procedures shall be prepared and approved prior to starting design testing.

4.3.3 Acceptance Plan. A plan shall be prepared and approved for acceptance of the system.

4.3.4 Qualification Test Plan. A plan shall be prepared and approved for qualifying the system.

\subsection{Acceptance Criteria.}

(1) Acceptance results as documented in reports on the completion of: testing and qualification per 4.3.2, 4.3.3 and 4.3.4.

(2) Completion of all analyses noted in the design rigor matrix. 


\section{T́ÁBLE I \\ LOFT PRIMARY COOLANT SYSTEM CHEMISTRY CONTR̈OL SPECIFÍCATION [a]}

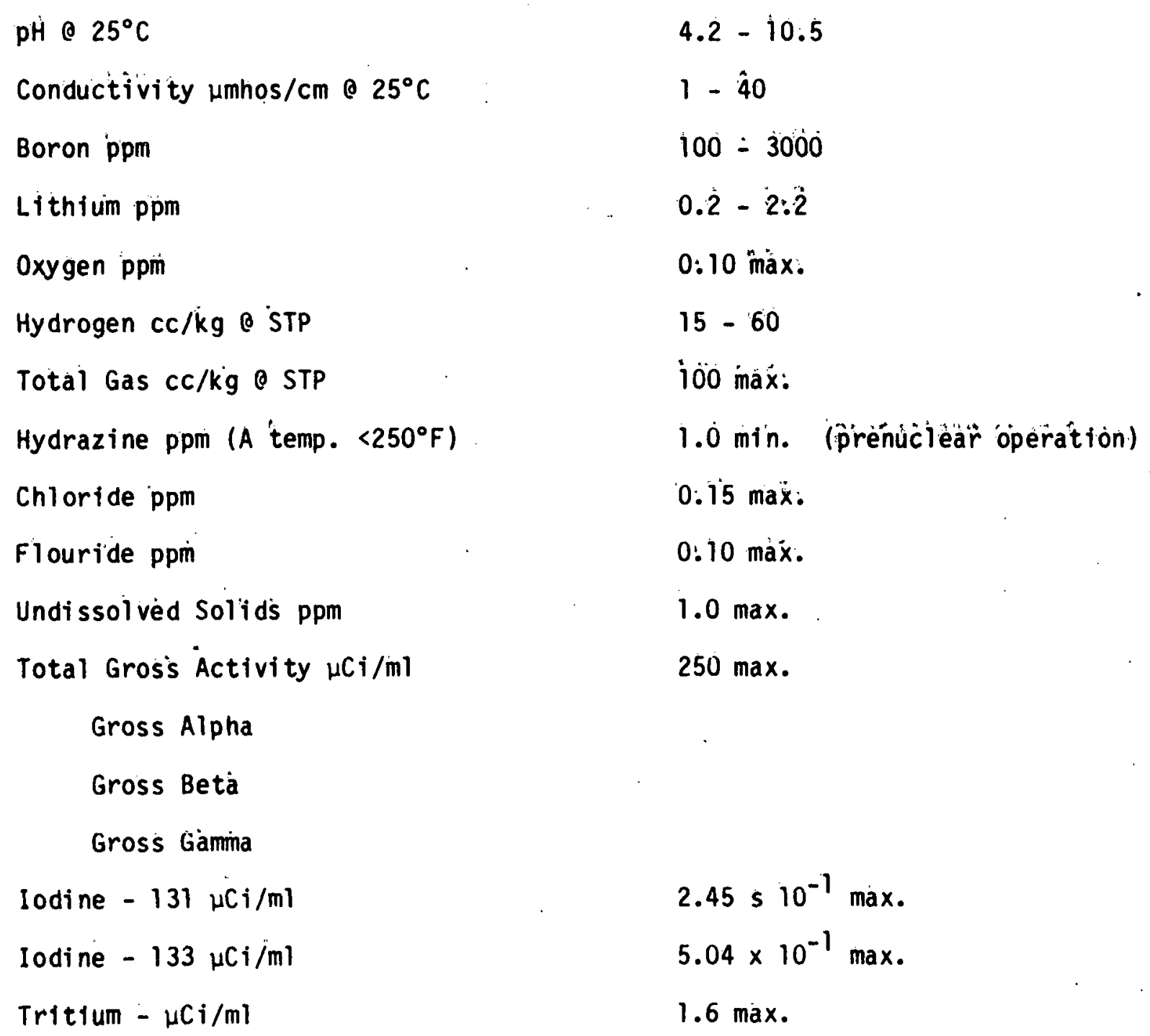

[a] Aerojet Nuclear Company, LOFT Facility Division, Plant Operating Manual, Volume II, Chapter 8. 
TABLE II

DESIGN RIGOR MATRIX

Rigor Matrix

Applicability

\section{DESIGN REQUIREMENTS}

1. Specification ES-60188

1. All components of the system.

DESIGN DOCUMENTATION \& CONFIGURATION CONTROL

2. Layout Drawings

3. Assembly \& Detail Drawings

4. Specifications

5. Reliability Analysis Report

6. Hydraulic Analysis Report

7. Stress Analysis Report

8. Vibration Analysis Report

9. Design Calculations

10. Test Plan

11. Acceptance Plan

12. Qualification Test Plan

13. Test Report

\section{DESIGN REVIEWS}

14. Review Spec. ES- 60188

15. Conceptual Design Review

16. Design Review

17. Final Design Review

QUALITY ASSURANCE PROVISIÖNS

18. Quality Assurance Program RDT F2-4T

19. Reliability per RDT F2-9T

20. Quality Leve1
2. As required to aid design of components, etc.

3. All fabricated items.

4. All purchased items, except of $f$-theshelf items.

5. All components of the system.

6. All components located in the Primary Coolant System (PCS) environment.

7. All components located in the PCS envi ronment.

8. All components located in the PCS environment.

9. All fabricated items.

10. To verify performance of the system.

11. To provide methods for acceptance of the system.

12. To provide qualification criteria for the system.

13. To provide verification that the system meets all the requirement not verifiable by analysis.

14. To spec noted.

15. Upon presentation of design concepts.

16. Prior to starting fabrication of prototypes.

17. Prior to starting fabrication of production items.

18. All components of the system.

19. All components of the system.

20. (a) Development phase through delivery of prototypes shall be to quality Level II.

(b) Production items located in the PCS pressure boundy and all other items shall be to Level II. 
LTR 141-68

. 
LTR 141-68

APPENDIX C

SPECIFICATION - ULTRASONIC

DENSITY SENSING SYSTEM FOR

LOFT-ES-60203 
LTR 141-68 
EE\&S Idaho, Inc.

\section{ES - 60203 \\ DATE - March 24, 1977}

\section{SPECIFICATION}

ULTRASONIC

DENSITY SENSING SYSTEM

FOR

LOFT
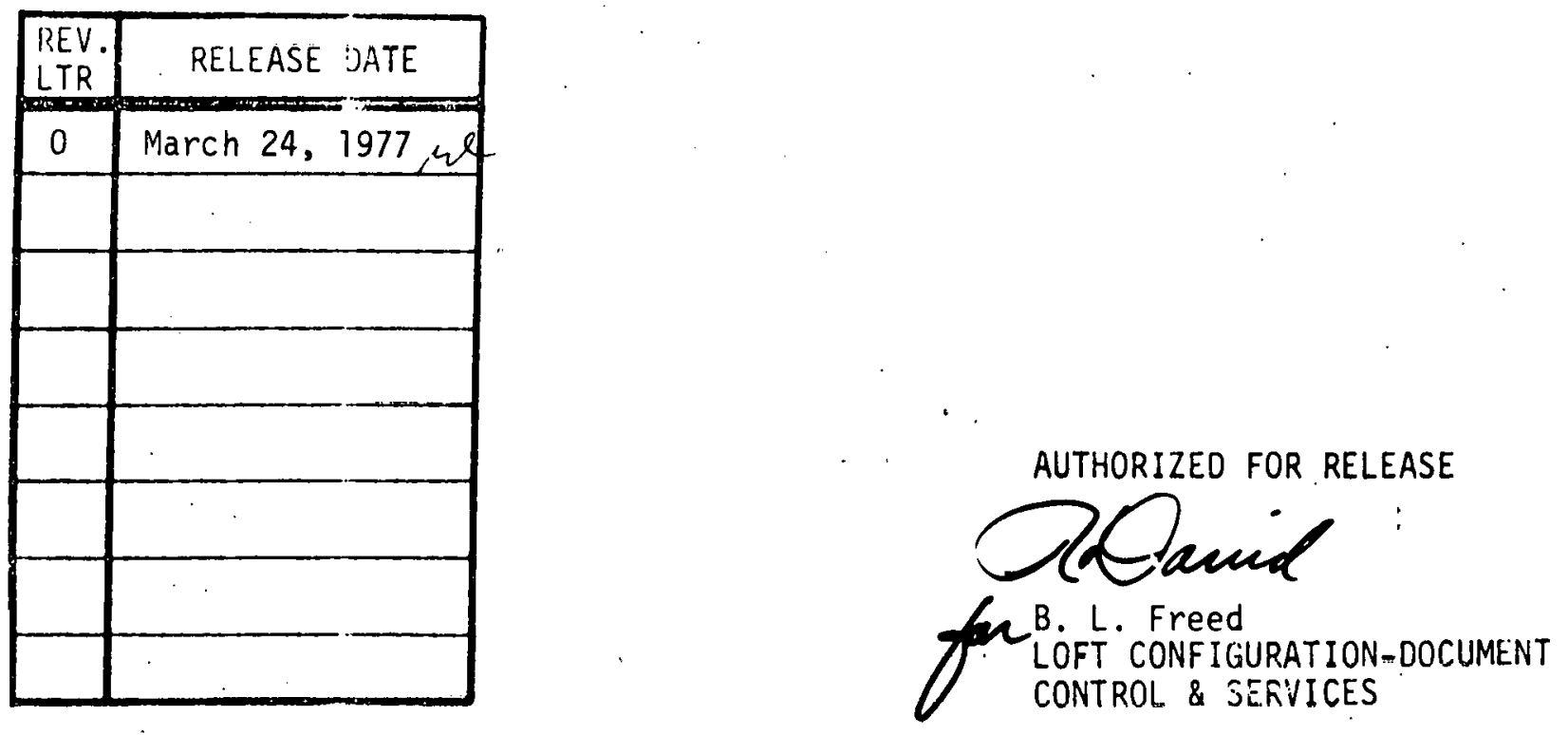


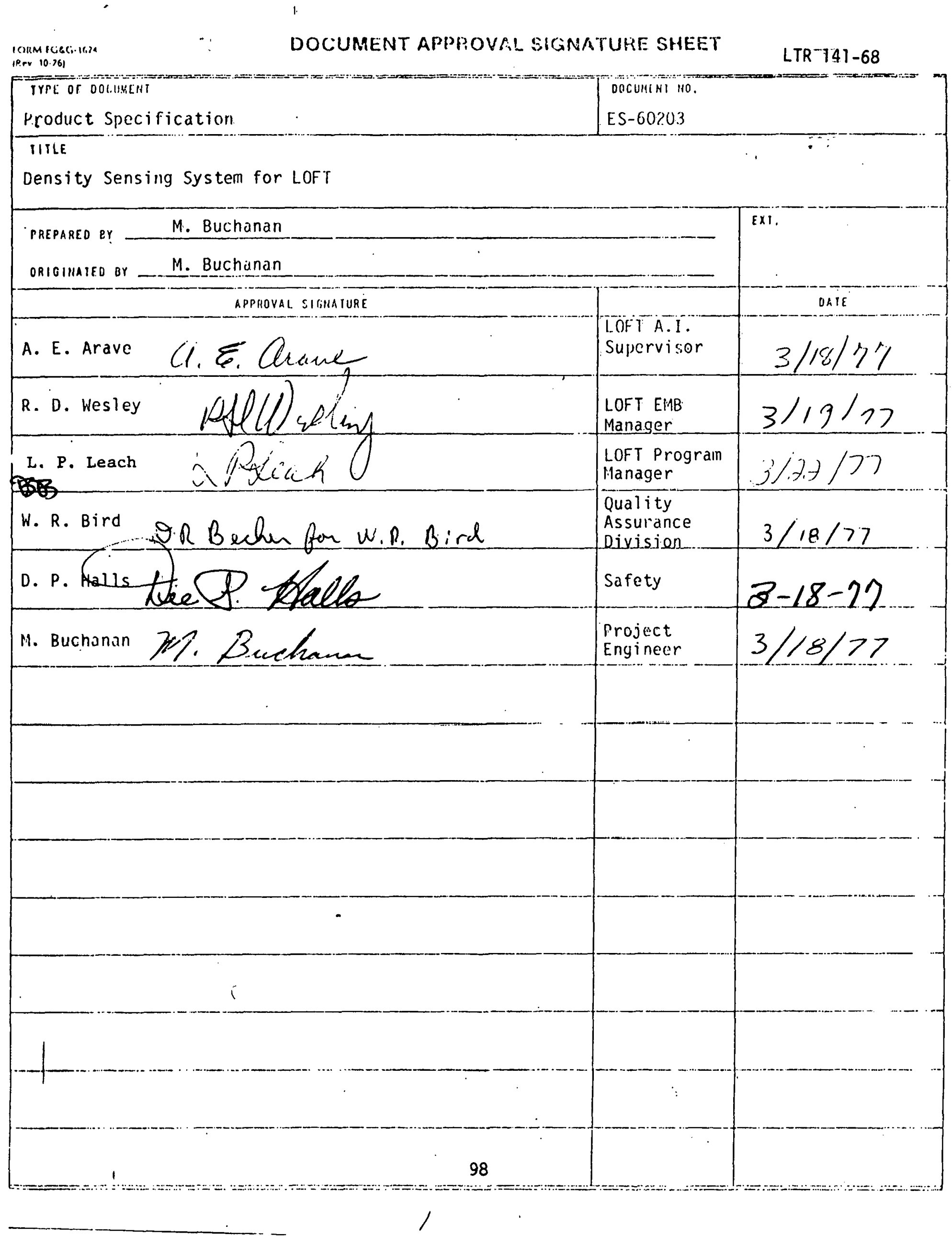


ES-60203

1. SCOPE

1.1 Scope. This specification covers the requirements for the LOFT density sensing system using void fraction sensors and thermocouples. The system will. be used to measure density and density profiles in the loss of fluid test (LOFT) reactor pressure vessel during loss of coolant experiment (LOCE) tests.

\section{APPLICABLE DOCUMENTS}

The following documents form a part of this specification to the extent specified herein. Unless otherwise specified, the issue in effect on the date of invitation to bid shall apply. In the event of a conflict between the documents referenced herein and the contents of this specification, the contents of this specification shall be considered a superseding requirement.

U.S. Energy Research and Development Administration (ERDA) - Division. of Reactor Development and Demonstration

RDT $\mathrm{Cl}-1 \mathrm{~T}$ Instrumentation and Control Equipment Grounding and Shielding Practices.

RDT C17-4T General Instrumentation

RDT F2-4T Quality Verification Program Requirements

Aerojet Nuclear Company (ANC)

ANC-STD-7006 Marking Methods for Equipment, Components, and Materials

ANC-STD-7020 Preservation and Protection Requirements for Nuclear Reactor Components 
ES-60203

ANC-60092 LOFT POwer MTA No. 1 Electrical and Instrumentation and Design Requirements

ANC-E-1 Electrical Construction - Interior

INC-60037 MTA Control and Instrumentation Cable

DWG. 204025 Center Fuel Module Assembly, Type A\&F

DWG. 204390 LOFT-Upper Core Support Structure - Center Fuel Assembly

ANC, LOFT Facility Division Plant Operating Manual, Volume II, Chapter $8^{\circ}$

Idaho Nuclear Corporation (INC)

EC-2 LOFT Environmental Conditions

EXXON Nuclear Company, Inc.

DWG. XN-300, 382 Lower Square Tie Plate

DWG. XN-300, 383 Lower Tie Plate

DWG. XN-302, 318 Fuel Bundle Assembly

EG\&G Idaho

LMP-001 Cleaning and Cleanliness Control Requirements for Nuclear Construction 


\subsection{REQUIREMENTS}

3.1 General. The density sensing system shall consist of void fraction sensors, thermocouples (TCS) and mounting hardware, junction boxes, test assembly cabling and cable supporting hardware, and signal conditioning and recording equipment.

Void. Fraction sensors shall be developed and mounting hardware designed for installing the void fraction sensors and TCS in the following reactor vessel locations:

(1) The lower tie plate of the center fuel module, DWG. XN-300, 383, located such that sensor or sensors spans two holes in the core support plate and averages the density.

(2) The region of the upper core support structure center fuel assembly, OWG. 204390, covering an area from an elevation near the bottom of the upper core support structure to an elevation approximately two feet above the bottom of the upper core support structure.

(3) The upper core support structure center fuel assembly, DWG. 204390, located as close as possible to the DTT.

The functions of the density sensing system are to measure the average densities at locations described in (1) and (3) and density profile at the location noted in (2). The densities obtained can be used in conjunction with the results from the OTTs to calculate and verify the two-phase mass flow rate.

\subsection{Performance Characteristics}


(3) The minimum inside bend radius shall be three cable diameters.

(4) The sensor leads from the end of the sheath to within 6 inches of the sensor shall be capable of passing through a ring gage that has a hole 0.002 inch diameter over the maximum allowable sheath diameter, and being $0.500 \pm 0.02$ inch long.

3.3.6 Cleanliness. Cleanliness acceptance levels shall be established and specified on all drawings in accordance with LMP-001, paragraph 4.2 Class $A$ cleanliness.

3.3.7 Fastener Torquing. Fastener torque values shall be specified on all assembly and installation drawings.

3.4 Materials. The materials used in the components noted in this specification shall be compatible with the environments and operating conditions specified in $3.3 .1,3.3 .2,3.3 .3$, and 3.3 .4 and metallurgically compatible with components of the test assembly with which they are in intimate contact.

\subsection{Component Parts}

3.5.1 Junction Boxes. Junction boxes shall be water-tight, air-tight and explosion proof per ANC 60092 .

3.5.2 Cable. Cable from the connectors on the instrumentation penetration assemblies shall meet the requirements of INC -60037 and provide circuit protection from electrostatic, electromagnetic, and group loop pickup of extraneous signals. Reference RDT Cl-1T.

\subsubsection{Signal Conditioning and Recording Equipment. The void fraction} sensors and TC signal conditioning and recording equipment and other incircuit items, e.g. cable junction boxes, etc, shall be capable of providing density measurements in accordance with the performance characteristics noted in 3.2 . 
etc. The 50-psi loading requirement shall be evaluated, assuming the same thermal conditions that exist at reactor full power ( 55 $\operatorname{MW}(t))$

(2) Temperature conditions:

Peak

Rate of Change Temperature

(a) Components attached to support tubes $20^{\circ} \mathrm{F} / \mathrm{sec}$

$1450^{\circ} \mathrm{F}$

(b) Components attached to fuel assembly end boxes $20^{\circ} \mathrm{F} / \mathrm{sec}$ $1450^{\circ} \mathrm{F}$

(3) After $5 \mathrm{sec}$ at the maximum temperature, the equipment shall be assumed to be quenched by immersion in a saturated steam-water mixture at a pressure of 25 psia.

3.3.4 The attachment and location of the void fraction sensors and thermocouples shall be designed such that (a) reactor operating condition objectives can be achieved and (b) the response of the fuel module during the LOCES will provide valid core thermal-hydraulic response data.

\subsubsection{Routing of Instrumentation Leads}

(1) The sensor leads shall be metal-sheathed cables (304-stainless steel, Mg0 insulated) with an 0.063 inch maximum 0.0 .

(2) Sensor leads from sensors located in the regions described in $3.1(1)$, (2), and (3) shall be routed to connector penetrations on the fuel module instrument stock. 
b. Pressure - Sensors must meet the following requirements: - $s$

Nomal operation

2250 psi

Design maximum (hot)

2500 psi

Design maximum (cold)

3125 psi

Shock resistance - subcooled decompression $p / t=-22,500 \mathrm{psi} / \mathrm{sec}$

c. Corrosion Resistance - Sensors must be capable of operating in a water quality environment specified in Table 1.

d. Irradiation - Sensors must provide data within the specified accuracies after neutron and gamma exposure equal to the following maximum values:

Neutron Flux

Normal Operation

$1.0 \times 10^{14} \mathrm{nv}$

Total Exposure (Maximum)

$7.2 \times 10^{20} \mathrm{nvt}$

Gamma Flux

Normal Operation

$1 \times 10^{9} \mathrm{R} / \mathrm{hr}$

Total Exposure

$2 \times 10^{12} \mathrm{R}$

3.3.3 Sensors attached to the fuel assemblies shall be designed to withstand 10 exposures to the following LOCE environments:

(1) A differential pressure loading of $50 \mathrm{psi}$ taken in the most adverse direction across each component, instrument, or mounting device, 
ES-60203

3.2.1 The following density measurement requirements are:

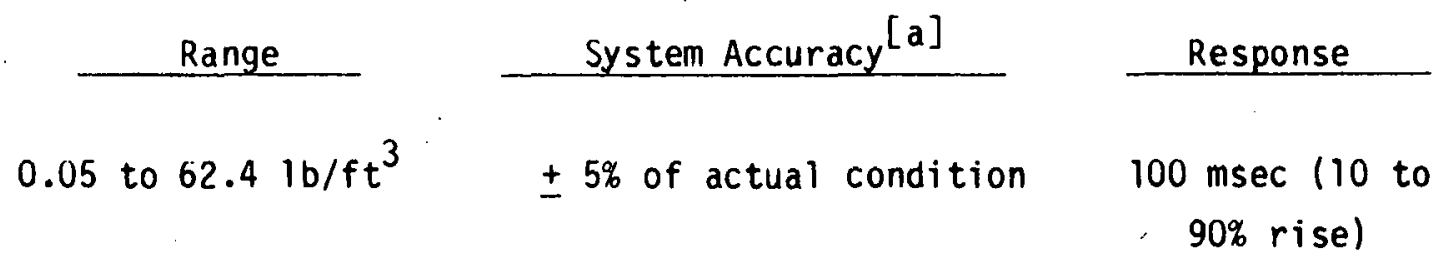

3.2.2 Mean Time to Failure (MTTF). Each sensor shall demonstrate a 2,000 hour MTTF at $90 \%$ confidence level. The 2,000 hour MTTF is a product of the number of hours assigned to each LOCE $(200 \mathrm{hrs})$ times the maximum number of LOCES ( 5 times an operation factor of 2). Peak temperatures occur for a short duration of 30 to 60 seconds during each LOCE, reference $3.3 .2 \mathrm{a}$ and 3.3.3.

\subsection{Design and Construction}

3.3.1 Items located on the test assembly but not in the primary coolant system (PCS) or part of the PCS pressure boundary shall be to withstand the applicable environmental conditions specified in INC EC-2.

3.3.2 Sensors located in the PCS must be capable of survival in the following environment. Survival is interpreted as operations within specified limits during steady-state operation and withstanding maximum conditions per limited time without affecting calibration.

a. Temperature - Sensors must survive and demonstrate a mean time to faiture (MTTF) of 2,000 hours, refer to 3.2.2, when used in an environment where the temperature under normal operation is $650^{\circ} \mathrm{F}$ and with peak temperatures for short duration ( 30 to 60 seconds) in $1000^{\circ} \mathrm{F}$ steam during each loss-of-coolant experiment (LOC.E).

[a] System accuracy represents the acceptable error total of all contributory measurement system errors (detection, cransmittal, digitizing, long term stability, and changing environmental conditions, etc). 


\subsection{Interfaces}

(1) The void fraction sensors and thermocouples shall interface with regions in the core center fuel module specified in the general requirements Section 3.1 .

(2) Instrument leads from sensors located in the area of the center fuel module shall interface with the connectors on the respective instrumentation penetration assemblies.

(3) Cabling from the connectors on the instrumentation penetration assemblies shall interface with the junction boxes and at Building 650 penetrations. The cabling shall then interface with the signal conditioning equipment in Room 219, Building 650 and then with the patching facility in Room B100, Building 630 .

3.7 Documentation. The documents noted in the design rigor matrix, Table II and those noted in the text shall be supplied.

3.7.1 Design Verification Analysis Reports. The design verification analysis reports submitted by the Contractor shall consist of summary descriptions of the computations performed in verifying the density system design and establishing specific design features. The basic criterion for the summary descriptions is that sufficient information is provided so that a knowledgeable reviewer can determine whether or not the analytical technique employed is justified with respect to its application and in relation to alternate techniques available. The format and content of the summary descriptions of the design analysis shall be as follows:

a. An introduction that states the purpose of the calculation and the results. 
b. A description of the analytical technique used showing special equations, working curves, and generally providing enough information to satisfy the reviewer that the method used was justified. When computer codes are used to solve problems, a brief description of the computer code shall be provided. If a reference report is not available, the description shall include the techniques used by the computer code to solve the problems and show that any special correlations used to the computer are justified and accurate.

c. A description of and justification for the assumptions made and the design acceptance criteria and a summary of the data used in the analysis.

d. A detailed presentation of the results.

e. A discussion of the results, describing areas of uncertainty, results of similar design studies; and generally providing enough information to establish the authenticity of the results.

f. A list of references.

\subsubsection{Design Verification Test Reports. Design verification test reports} submitted by the Contractor shall consist of summary descriptions of the tests performed by the contractor to qualify the density system design for its intended use. The basic criteria for the summary description is that sufficient information be provided so that a knowledgeable reviewer can determine whether the test method used is justified with respect to its application. The format and content of the summary descriptions of the qualification tests shall be as follows:

a. An introduction that states the purpose of the qualification test and the results. 
b. A description of the test apparatus used and the test procedure. Details of (1) the mechanical interfaces between the test component and the test apparatus and (2) the environment (pressure, temperature, fluid chemistry, flow rates, applied loads) are required. ..

c: A detailed presentation of the results including a pefore and after description of the component being tested.

d. A discussion of the test results, describing areas of uncertainty and generally providing enough information to establish that the test method is adequate for qualifying the component for its intended use.

\subsection{QUALITY ASSURANCE PROVISIONS}

4.1 Quality Assurance Program. The Contractor shall maintain a Quality ssurance Program in accordance with the requirements of RDT F2-4T.

\subsection{Test Methods and Conditions}

4.2.1 Design Test Plan. A test plan shall be prepared and approved prior to starting fabrication of the sensors. The test plan shall include but not be limited to the following items:

(1) Objective of end item development and acceptance criteria

(2) Description of end item to be tested

(3) Quantity to be tested

(4) Proposed test facility and location

(5) Desired test schedule versus facility availability 
(6) Test equipment required

(7) Support equipment required

(8) Outline of tests to be conducted

(9) Types of data to be acquired

(10) Methods for reporting test results and resolving problems.

4.2.2 Test Procedures. Test procedures shall be prepared and approved prior to starting design testing.

4.2.3 Acceptance Plan. A plan shall be prepared and approved for acceptance of the system.

4.2.4. Qualification Test Plan. A plan shall be prepared and approved for qualifying the system.

\subsection{Acceptance Criteria.}

(1) Acceptance results as documented in reports on the completion of testing per 4.2 .2 and 4.2 .3 .

(2) Completion of all analyses noted in the design rigor matrix.

\subsection{PACKAGING}

5.1 Identification and Marking. Part marking shall be required on all components in accordance with ANC-STD-7006.

5.2 Protection and Preservation. Protection and preservation of void fraction sensors and themocouples shall be provided.in accordance with ANC-STD-7020, Class I. 


\subsection{NOTES}

6.1 Definitions. The following definitions are applicable for this specification.

6.1.1 Void fraction $(\alpha)$ is defined as the time-averaged volumetric fraction of vapor in a two-phase mixture. Careful consideration must be given to the size of a void fraction sensor and the averaging time used particularly with transient flow. In the limit, instantaneous void fraction at a point will always be either zero or one. The void fraction measurement desired herein must be over a large enough volume and provide a suitable averaging time so that combination with measurements of momentum flux or velocity will yield mass flows accurate within $\pm 10 \%$.

6.1.2 Density. Fluid density $(\bar{\rho})$ is defined as:

$$
\bar{\rho} \equiv \alpha \rho g+(1-\alpha) \rho_{F}
$$

where

$$
\left.\begin{array}{l}
\rho_{g}=\text { saturated steam density } \\
\rho_{F}=\text { saturated fluid density }
\end{array}\right\}\left\{\begin{array}{l}
\text { defined from fluid } \\
\text { temperature measurement. }
\end{array}\right.
$$

It should be noted that this average density will not be the same as the homogeneous density, $\rho_{H}$, if slip exists between the phases.

$$
\rho_{H} \quad \frac{\langle G\rangle}{\langle j\rangle}
$$

where $\langle G\rangle=$ mass flux averaged over the sensor and $\langle j\rangle=$ volume flux averaged over the sensor. 


\section{DESIGN REQUIREMENTS}

1. Specification ES-60188

1. All components of the system.

DESIGN DOCLANENTATION \&

CONF IGURATION CONTROL

2. Layout Drawings

3. As sembly \& Detail Drawings

4. Specifications

5. Reliability Analysis Report

6. Hydraulic Analysis Report

7. Stress Analysis Report

8. Vibration Analysis Report

9. Design Calculations

10. Test Plan

11. Acceptance Plan

12. Qualification Test Plan

13. Test Report

\section{DESIGN REVIEWS}

14. Review Spec. ES-60188

15. Conceptual Design Review

16. Design Review

17. Final Design Review

\section{QIIAI ITY ASSURANCE PROVISIONS}

18. Quality Assurance Program RDT F2-4T

19. Reliability per RDT F2-9T.

20. Quality Level
2. As required to aid design of components, etc.

3. All fabricated items.

4. All purchased items, except off-theshelf items.

5. Electronic Components per Mil Handbook 217B.

6. All components located in the Primary Coolant System (PCS) environment.

7. All components located in the PCS environment.

8. A 11 components located in the PCS environment.

9. All fabricated items.

10. To verify performance of the system.

11. To provide methods for acceptance of the system.

12. To provide qualification criteria for the system.

13. To provide verification that the system meets all the requirement not verifiable by analysis.

14. To spec noted.

15. Upon presentation of design concepts.

16. Prior to starting fabrication of prototypes.

17. Prior to starting fabrication of production items.

18. All components of the system.

19. All componenis of the system.

20. (a) Development phase through delivery of prototypes snall be to quality Level II.

(b) Production items located in the PCS pressure boundy and all other

111 items shall be to Level I. 
TABLE I

LOFT PRIMARY COOLANT SYSTEM CHEMISTRY CONTROL SPECIFICATION [a]
$\mathrm{pH} \odot 25^{\circ} \mathrm{C}$
$4.2-10.5$
Conductivity $\mu$ mhos $/ \mathrm{cm}$ \& $25^{\circ} \mathrm{C}$
$1-40$
Boron ppm
$100-3000$
Lithium ppm
$0.2-2.2$
oxygen ppm
$0.10 \max$.
Hydrogen cc/kg STP
$15-60$
Total Gas cc/kg o STP
$100 \max$.
Hydrazine ppm (A temp. $<250^{\circ} \mathrm{F}$ )
$1.0 \mathrm{~min}$. (prenuclear operation)
Chloride ppm
$0.15 \max$.
Flouride ppm
$0.10 \max$.
Undissolved Solids ppm
$1.0 \max$.
Total Gross Activity $\mu \mathrm{C} i / \mathrm{ml}$
$250 \max$.

$$
\begin{aligned}
& \text { Gross Alpha } \\
& \text { Gross Beta } \\
& \text { Gross Gamma }
\end{aligned}
$$
lodine - $131 \mu \mathrm{Ci} / \mathrm{ml}$
2.45 s. $10^{-1} \max$.
Iodine - $133 \mu \mathrm{Ci} / \mathrm{ml}$
$5.04 \times 10^{-1} \max$.
Tritium - $\mu \mathrm{Ci} / \mathrm{ml}$
$1.6 \max$.

La J Aerojet Nuclear Company, LUFT Facility Uivision, Plant Uperating Manual, Volume 11, Chapter 8. 


\author{
APPENDIX D \\ ANALYTIC AND EXPERIMENTAL INVESTIGATION \\ OF ULTRASONIC PROBES FOR APPLICATION \\ IN DENSITY SENSING SYSTEM
}


LTR $141-68$ 


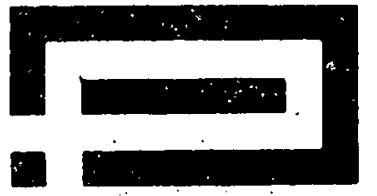

PANAMETRICS

221 CRFSCENT STREET, WAL THAM, MASSACHUSETTS 02154 / $617899-2710$

TELEX: 923400

Final Report

Analytic and Experimental Investigation

of

Ultrasonic Probes for Application

in

Densit; Sensing System as per Spec, ES.60188

Prepared for

EG\&G Idaho, Inc.

550 Second Street.

Idaho Falls, Idaho 83401

Purchase Order No. K-5217, Priority Rating DO-E-2

Buyer: Craig D. Cutler, Tel: (208)522-6640 X1577

TWX 9109775915 ERDA IDAH

Technical Monitor: Alvin E. Arave (208)526-0111 X579

$$
\text { Prepared by }
$$

Law rence C. Lynnworth

Period of Performance: January 24 to February 28, 1977 


\section{TABLE OF CONTENTS}

\section{ABSTRACT}

\section{INT RODUCTION}

LITERAT URE SEARCH AND BACKGROUND TECHNOLOGY

Amplitude Effects

Transit Time Effects

Round Wire

Extensional Waves in Threaded Rod

Tiursional Waves

Flcxural Wa: is

Transverse Shear Waves

Response to $Z$.

Piezoelectric and Magnetostrictive Types

Extensional Waves

Other Guided Waves

Resolution Comparison

TORSIONAL WAVE DENSITOMETER

Background

Reduced Speed

Impedance

Transduction

Density Dependence

Density Profiling

Calibration Procedure

Test Results

Discussion of Torsional Wave Calibration

Dispersion

Electronics

DENSIT Y - CORRELATED VELOCIMETER

CONCLUSIONS 31

REFERENCES ' 33

APPENDIX 1: Reflection Coefficient Probes for Measuring 36 Acoustic Impedance of Liquids

APPENDIX 2: Acuustic Propertics of Selected Liquids - 50

APPENDIX 3: Polar Moment of Inertia of Selected Cross Sections 53 
Analytic and Experimental Investigation

of

Ultrasonic Probes for Application

in

Density Sensing System as per Spec. ES-60188

by

Lawrence $C$. Lynnworth

\section{ABSTRÁCT}

The objective of this study was to define, build and test an ultrasonic densitometer by combining an appropriate wave type, waveguide structure, transduction means and electronic measurement. The sought densitometer was to be responsive to the average density $\bar{\rho}$ in flowing two-phase water at $650^{\circ} \mathrm{F}$ and $2500 \mathrm{psl}$, and ultimately compatible with numerous other requirements of Spec. ES-60188. Based on a review of the Jiterature, a review of Panametrics background technology, theoretical considerations and experimental results with extensional, torsional, flexural and transverse shear waves, It appers that the best approach lies in responding uniquely and linearly to the density. of the liquid in which a probe of suitable shape is immersed, and in which the transit time of the preferred wave type is measured. Suitable probe shapes are noncircular, e.g. , rectangular, of width-to-thickness ratio b/d of about $3: 1$. The preferred wave type is broadband torsional pulse of center frequency $\sim 100 \mathrm{kHz}$. The geometry and temperature of the specified installation presently dictate a mode conversion magnetostrictive transduction means, such as extensional-torsional-extensional. To the extent that the transit time increment $\Delta t$ of the slow torsional wave in an inmersed rectangular waveguide is directly proportional to $\bar{\rho} A_{\text {wet }} / A_{\text {total }}$ (where $A_{\text {wet }}$ is the probe's wetted area, and $A_{\text {total }}$ is the probe's total bensing area) the donoitometer electronico may be a time intervalometer which functionally resembles the Panatherm (B) 5010. For the torsional wave in a $3: 1$ rectangular waveguide, a $15-\mathrm{cm}$ sensor length yields a through-transmission full scale $\Delta t=5 \mu$. Regsolution of $\Delta t$ to $\pm 0.1 \mu \mathrm{s}$ corresponds to $\bar{\rho}$ resolution of $\pm 0.02 \mathrm{~g} / \mathrm{cm}^{3}$. or $\pm 2 \%$ full 8 cale referred to water at ordinary laboratory conditions $(\rho=$ $\overline{1} \mathrm{~g} / \mathrm{cm}^{3}=62.4 \mathrm{lb} / \mathrm{ft}^{3}$ ) based on calibration tests in 8 liquids, of several probes built according to the above principles. The calibration data also show that probe sensitivity increases as $\mathrm{b} / \mathrm{d}$ increases, and in approximate proportion to the sound speed reduction shape factor $K^{-}$, plus a constant. 
LTR 141-68 


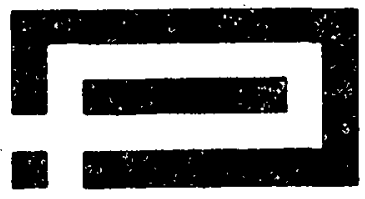

PANAMETRICS 221 CRESCENT STREet, WALTHAM, MASSACHUSETSS 01541617 800-2710 TELEX: 823400

\section{INTRODUCTION}

This report summarizes work done under EG\&G Idaho Purchase Order No. K5217 covering the period \$anuary 24 - February 28, 1977. In general, this work included the following tasks:

Literature search and review of Panametrics' background technology; consideration of the following modes: extensional, torsional, flexural, transverse shear; selection of best techniques; fabrication of laboratory sensors using preferred technique( 8$)$; laboratory testing of prototypes; analysis of test results and determination of how probe responds to density, impedance and wetted area; reporting of analytic and experimental results.

\section{LITERAT URE SEARCH AND BACKGROUND TECHNOLOGY}

Amplitude Effects. To put the present effort in historical perspective, it can be stated that it is clearly a sequel to Arave's experiments reported in 1970 and 1972. 1-3 $^{-3}$ In Arave's work, he demonstrated the interaction between magnetostrictively-generated waves in selected waveguides and surrounding water. The reported interactions were amplitude or attenuation effects. These effects were understood to correlate with void fraction or density $(\rho)$ of the surrounding water. An undesirable oensitivity to flow and temperature was also reportcd.

Transit Time Effects. In conversations with Arave on October 28, 1976, and in more formal discussions at EG\&G Idaho on January 18, 1977, the author identified three different examples of interaction between guided waves and surrounding water, wherein not amplitude but transit time was the principal ultrasonic variable observed. The three examples cited were: mode converted flexural waves in brass strips; piezoelectrically generated flexural waves in an aluminum strip; extensional waves in a thicaled rod. The authoris acquaintance with such phenomena originated with Fam's expcriments conducted at Panametrics in the late sixties 
which led to a patent being issued in 1970. 4 Fam found that the transit time required for flexural waves to traverse a brass strip increased substantially, as the strip was gradually immersed in water. Subsequently the author found that transit time effects already had been predicted by Ageeva, who in 1955 and 1959/1960 reported on immersed flexurally excited plates and ribbon, respectively. 5,6

Round Wire. In the $1960^{\prime} s$ Panametrics demonstrated that the propagation of extensional waves in circular wire," straight or gently curved, was negligibly influenced by immersion. For example, in May 1968, the author and coworkers found that immersion of $\sim 6 \mathrm{~m}(\sim 20 \mathrm{ft})$ lengths of stainles steel waveguides in liquid sodium behaved as expected, producing no observable effects on attenuation. 7 Previously, our tests on $\sim 6 \mathrm{~m}(\sim 20 \mathrm{ft})$ coils of wire immersed in a tub of water similarly showed a lack of interaction.

Extensional Waves in Threaded Rod. At an undetermined date, probably in the late 1960's, the author briefly investigated the propagation of extensional waves in threaded rod. It was found that the speed decreased upon immersion in water, approximately $1 \%$ for threaded steel (size 4-40) and a larger percentage for threaded plastic rod. (These observations were mentioned briefly in a 1975 review. $)^{8}$ But because the threads tend to hold their water, a threaded probe exhibits hysteresis when withdrawn from, say, a beaker of water. Under flowing conditions, or if the threaded probe could be spun or agitated, the hysteresis problem might bo reduced considerably. Furthermore, sensitivity might be increased by using a threaded tube, rather than a threaded wire. Howcver, at this time there appear 8 to be little merit in pursuing thi type waveguide. So far, its principal merit is that it helped clarify a mechanism of interaction different from that utilized in Ref. 1-3. It appears reasonable that the speed of sound is reduced in an immersed threaded rod because the water between the threads contribute $s$ an inertia term, without contributing a compensating elasticity term. (In general, the sound speed in a medium is proportional

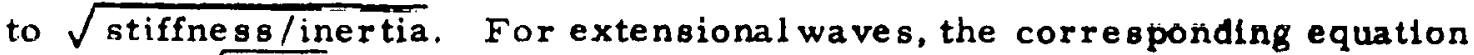
is $c_{\text {ext }}=\sqrt{E / \rho}$ where $E=$ Young's modulus and $\rho=$ density.) See Fig. 1, p. 3 .

Preliminary data for a $15 \mathrm{~cm}$ (6') threaded rod are contained in Table 4 on p. 22, under the Calibration Data. We may note that for extensional waves the threaded rod presents a uniform impedance, and so the threads do not produce noise. This is in marked contrast to the situation for longitudinal waves, in a threaded rod, where the waves interact with the threads. See Fig. 14 a, p. 28. 

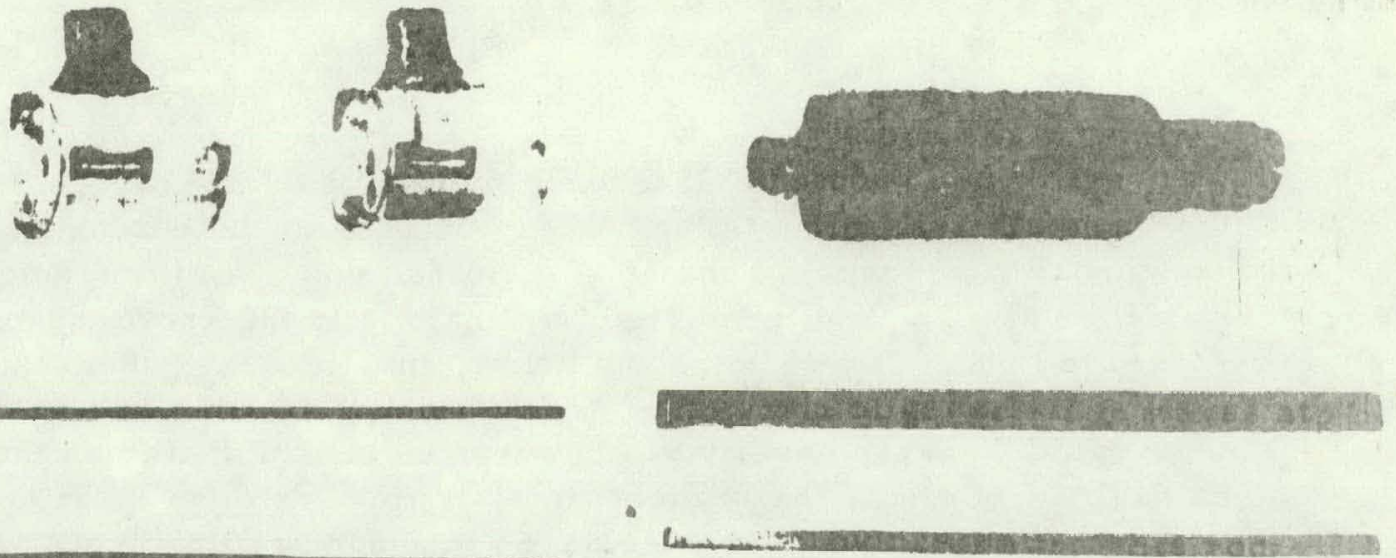

7

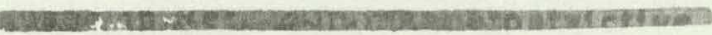

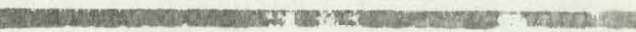

12: : ... -

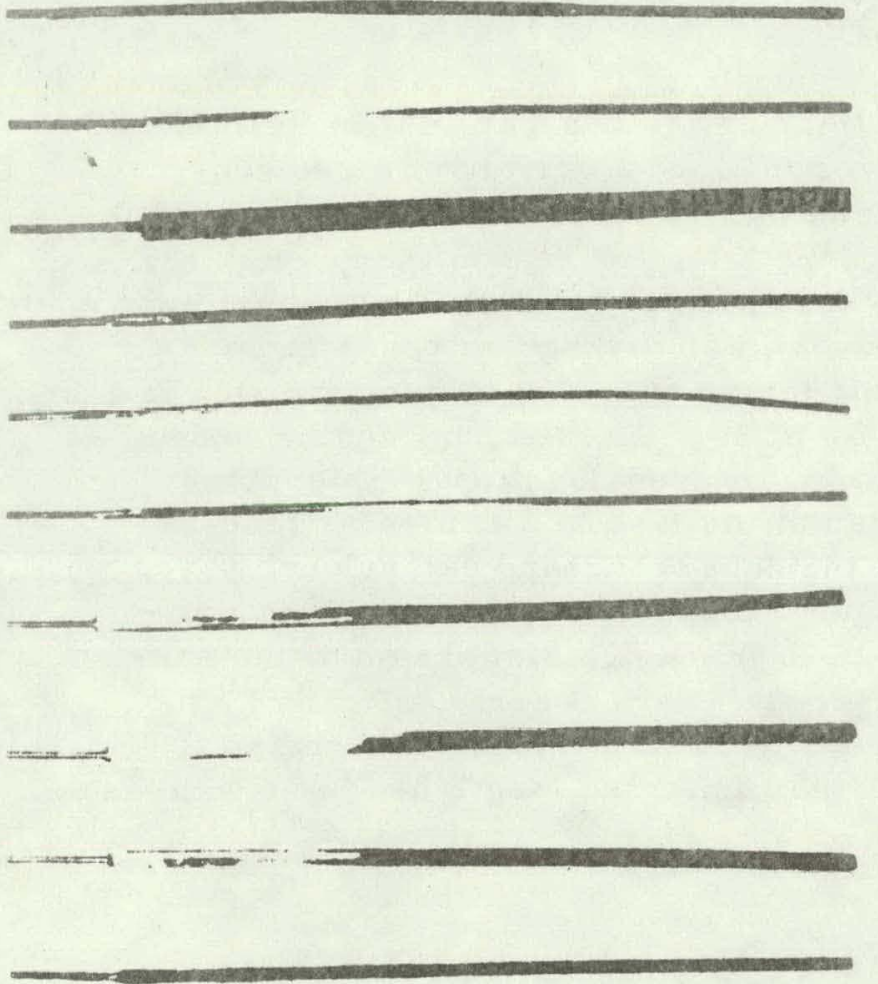

$141-68$

$$
\text { Len. }
$$

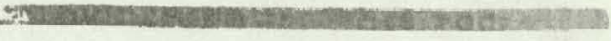

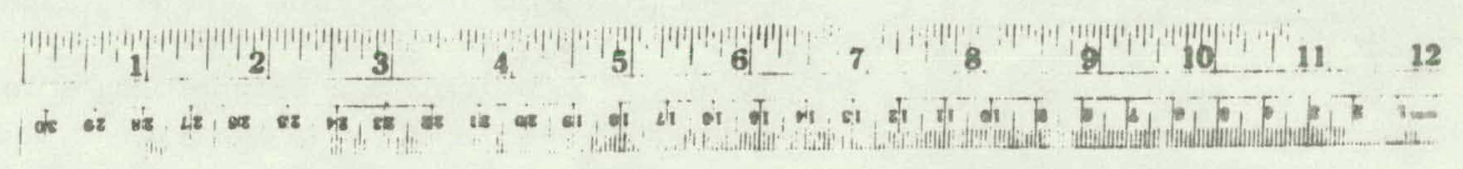

Fig. 1. Photograph of typical candidate densitometer sensors tested in this program. Remendur lead-in lines, typically $\sim 1 \mathrm{~m}$ long for most of the tests, are energized at one end by coils housed as shown at top. 
Torsional Waves. At the EG\&G Idaho meeting on Jan. 18, 1977, the author mentioned that one torsional wave analog of the extensional wave in the threaded rod would consist of a splined rod. An immersiondependence of ctors was predicted, by analogy to the known result for the threaded rod. It will be shown below, in a separate section devoted to the Torsional Wave Densitometer, that $c_{\text {tors }}$ depends on the shape of the waveguide, on the density of the surrounding fluid, and on the wetted area of the probe. At the present time, it appears that, relative to the anticipated application, torsional waves in a noncircular probe will provide the optimum sieasurement of $p$.

Flexural Waves. As mentioned earlier, and in connection with Ref. 4, Fam discovered, investigated and/or utilized a variety of mode conversion processes to generate selected modes in branches to a main trunk line. Analogous to the so-called Scarrott-Naylor design shown on p. 135 of Brockelsby etal., $17 \mathrm{Fam}$ found, for example, that an extensional wave in the trunk could excite flexural waves in an orthogonal brass strip. An example of a right angle probe constructed according to this principle is included in the photograph, Fig. 1 on p. 3. The flexural sensor shown is simply a $15-\mathrm{cm}$ (6"1) flexible SS rule, of cross sectional dimensions $\sim 7 \times .5 \mathrm{~mm}\left(.270 \mathrm{x} .020^{\prime \prime}\right)$ butt-welded on its face to a remendur lead-in of $1.4 \mathrm{~mm}\left(0.056^{\prime \prime}\right)$ diameter. The incident broadband extensional wave, after conversion to flexural, propagated dispersively with a maximum observed velocity of $\sim 1500 \mathrm{~m} / \mathrm{s}(\sim 0.06 \mathrm{in}, / \mu \mathrm{s})$. Immersion of the sensor to a depth of $3 \mathrm{~cm}$ in water caused the earliest arriving transit time to increase by $\Delta t=10 \mu \mathrm{s}$ from $200 \mu \mathrm{s}$ to $210 \mu \mathrm{s}$. To obtain the same $\Delta t=10 \mu \mathrm{s}$ by immersion in acetone, the immersed length had to be increased to $1 \mathrm{~cm}$.

Depending in part on the details of the mechanical connection between lead-in and sensor, a guided wave may be launched such that a significant portion of the incident energy propagates with little dispersion.

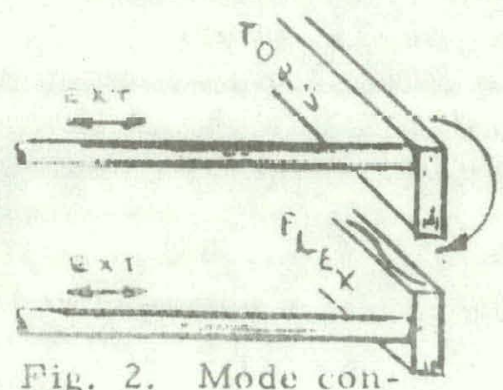

Fig. 2. Mode conversions: $\mathrm{E} / \mathrm{T}, \mathrm{E} / \mathrm{F}$. For example, in tests conducted Feb. 18, 1977, the combination in box at the left produced a distinct video echo corresponding to a torsinnal speed in the SS rectangular cross section $[\sim, 03 \mathrm{x}$ $.09 "(\sim .8 \times 2.3 \mathrm{~mm})]$ of $1.9 \mathrm{~mm} / \mu \mathrm{s}(.075 \mathrm{in.} / \mu \mathrm{s})$ However, centering the extensional source on the end of the same sensor produced a dispersed pulse. Inmersion of this sensor to a depth of $15 \mathrm{crn}\left(6^{\prime \prime}\right)$ procluced $\Delta t^{\prime} s$ of $\sim 15 \mu \mathrm{s}$ in acetone, $\sim 20 \mu \mathrm{s}$ in water and $\sim 32 \mu \mathrm{s}$ in $\mathrm{CCl}_{4}$. Reference to

\footnotetext{
Present address: Thermo Electron Corp. Waltham, MA 02154
} 
Appendix 2 shows the se flexural $\Delta t^{\prime} s$ to be proportional to $\rho$, not $\mathbf{z}$. Thus, flexural sensors provide a potential solution to the present search for a densitometer. Transduction and impedance matching flexural waves is easier than torsional, in some respects. However, dispersion is a drawback. (In Ref. 4 the flexural velocity is given in the form $c_{F}=2 \pi \mathrm{kc}$ ext $/ \lambda$ for $\lambda \gg$ lateral dimensions, and where $k=$ radius of gyration about the neutral axis. $\lambda^{-1}$ implies dispersion. However, with the present geometries and $\lambda^{\prime} s$, this equation is not strictly applicable.)

For the record, we note that other methods of generating flexural waves have been reported in the literature. $5,6,18,19,21$

We conclude this section of flexural waves by presently assigning them a back-up role. Their high sensitivity to depth of immersion is not to be forgotten.

Transverse Shear Waves. This mode was used in Ref. 2 in magnetostrictive probes. Appendix 1 analyzes this mode. Since this mode primarily responds to $Z$, not $\rho$, and because the response is amplitude, not time, we do not recommend it for the intended application, as better alternatives now appear available.

For documentation purposes we include below, two of Fam's oscillograms showing the propagation of broadband transverse shear waves in right angle sensors of brass and SS. The observed velocities in the strips are $10 \%$ lower than AIP handbook values for shear wave velocity in bulk specimens (brass, $70 \mathrm{Cu} / 30 \mathrm{Zn}, 2110 \mathrm{~m} / \mathrm{s} ; \mathrm{SS} 304,2300 \mathrm{~m} / \mathrm{s}$ ).
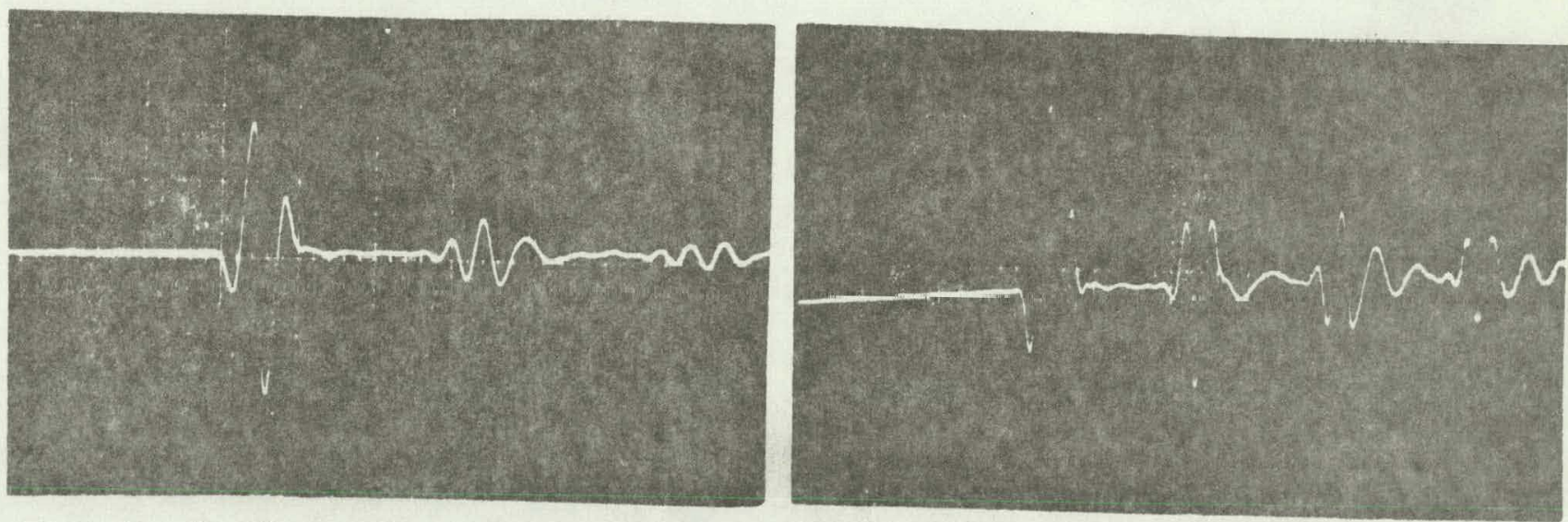

Fig. 3. Oscillograms at $20 \mu \mathrm{s} / \mathrm{div}$ for (left)brass strip, $50 \mathrm{~mm}$ (2"') long $\times 3 \mathrm{~mm}$ $\left(1 / 8^{\prime \prime}\right) \times .75 \mathrm{~mm}\left(1 / 32^{\prime \prime}\right)$, and (right) SS strip, $50 \mathrm{~mm} \times 3 \mathrm{~mm} \times 1.5 \mathrm{~mm}$ or thogonally connected to remendur, $1.4 \mathrm{~mm}$ diameter, after Fam. Transverse shear is pre sumed to be the mode illustrated here, based on the observed velocity, and lack of dipersion in the brass strip of $\mathrm{b} / \mathrm{d}=4$. Fam, however, apparently invertigated torsion too (private communication, Mar. 1, 1977). 


\section{IMPEDOMETER PROBES}

Response to $\mathrm{Z}$. Impedoneter probes are devices which respond primarily to the characteristic impedance $Z$ of the surrounding fluid, where $Z=\rho c$. For a homogeneous fluid of known sound speed $c$, density $\rho$ can readily be calculated from Z: $\rho=Z / c$. Even for a two-phase fluid which is not homogeneous, Arave has pointed nut that empirically one may be able to establish a useful correlation between $\mathrm{Z}$ and $\rho$.

The transmission of ultrasonic energy to a fluid from an immersed probe of any shape, and using any wave type, depends either pattly or totally on the impedance ratio $r$ between fluid and probe. Therefore it appears fairly certain that any existing or conceivable "densitometer" probe utilizing an amplitude or attenuation measurement, in fact responds primarily to $Z$, not $\rho$. To prove this for any specific model in question, one can immerse said model in two liquids of equal $\rho$ but unequal $\mathrm{Z}$, or vice versa. Appendix 2 contains several lists of liquids of known $\rho, c$ and $z$. For example, compare water and carbon tetrachloride, both having $\mathrm{Z} \approx 1.5$, but $\rho=1$ and 1.59 respectively. Or compare carbon disulfide and glycerol both having $\rho=1.26$ but $Z=1.45$ and 2.50 , respectively. Such combinations may be readily selected from the log $-\log$ $\rho$ c graph in Appendix 2. 9

Piezoelectric and Magnetostrictive Types. Impedometer probes have been built using magnetostrictive and piezoelectric transducers. The latter are discussed in Appendix 1. The piezoelectric types are dismissed from further consideration here because the reliability of the most promising candidate (lithium niobate pressure-coupled transducers) has yet to be demonstrated for this application.

Extensional Waves. Let us first consider extensional waves guided in a probe whose end is to be inmersed. As stated in Appendix 1, the sound pressure reflection coefficient for normally incident plane waves is $R=(r-1) /(r+1)$ where $r=$ imperance $r$ atio $z_{2} / z_{1}$. Fur a sleel or remendur $/$ water interface, the ratio of characteristic impedances is about 25 and the corresponding $\mathrm{R} \approx .92$. So one expects, at normal incidence, immersion if the end face to cause a reduction in end echo magnitude of $\sim 8 \%$. But with extensional wave $100 \mathrm{kHz}$ pulses in a $1.4 \mathrm{~mm}$ diameter remendur wavegnire, imulersing one end in water causes a reduction in end echo magnitude of less that $1 \%$. However, immersing the end of thin rods of much lower characteristic inpedance, e.g. , plastics, but of larger cross section, results in a more apparent end echo reduction. In 1973, for example, the author reported a $35 \%$ reduction in end echo magnitude, for the tip of a 20 $\mathrm{Kal}-\mathrm{F}$ thin rod $1 / 8^{\prime \prime} \times 1 / 8^{\prime \prime}$ cross section immersed in liquid nitrogen. 
We now calculate that this corresponded to $R=-.65$ and $r=.21$. For LN-immersed Kel-F, the calculated solid/liquid characteristic impedance ratio is $Z_{\text {uxt }} / Z_{L N}=(2)(1460) /(.81)(850)=4.24$, reciprocally corresponding to $r=.24$. Thus, this thin plastic rod, with immersed tip, behaved as an. extensional wave impedometer. Its observed response was surprisingly only $12 \%$ different from that calculated using equations for plane waves at normal incidence.

Extensional wave $100 \mathrm{kHz}$ pulse echo tests in a dry graphite rod, $4.75 \mathrm{~mm}\left(3 / 16^{\prime 1}\right)$ diameter $\times 260 \mathrm{~mm}$ (9. $\left.8^{\prime \prime}\right)$ long, were reported in Ref. 12 , Chap. 7, and in Panametrics Technical Memo dated Jan. 2, 1973 . On Feb. 16, 1977 this rod was tested again, this time in water. When the free end was immersed, the end echo decreased about $0.6 \mathrm{~dB}$. When $200 \mathrm{~mm}$ was inmersed, the end echo was reduced an additional $3.5 \mathrm{~dB}$. No change in the extensional wave speed was observed, not even in the end portion which had been drilled out to remove half the area, to a depth of $\sim 25 \mathrm{~mm}$ (1'). It is concluded that this probe is not suitable for the present application.

Other Guided Waves. Let us now consider waves guided as in Ref: 1-3.

It is much more difficult to dismiss the magnetostrictive type of impedometer probes. However, as these amplitude-sensing devices are sensitive to temperature and possibly to aging, as they a re of limited range (in ternis of combined effects of attenuation coefficient and wetted length), and as they are individually not as anenable to multizone profiling as are time-responding probes, it appears that the present objectives justify their abandonment in favor of new designs which are now available. It should be stated that the "new" designs fortunately can borrow a good deal from the earlier magnetostrictive design, namely, the transducer concept, and an awareness of orientation and shape relative to flow sensitivity.

Resolution Comparison. To conchule this scction, the following remarks may be helpful. Let us compare a $Z$ probe with a $\rho$ probe. Both $Z$ and $\rho$ may range over at least a 10:1 span. We shall assume that the $Z$ probe yiclds signal anplitudes spanning a $10: 1$ range, or $20 \mathrm{~dB}$, resolvable to $1 \mathrm{dH}$; and we assume the $\rho$ probe yields time-interval changes up to $5 \mu \mathrm{s}$, resolvable to $0.1 \mu s$. Under the stated assumptions on resolution, the $\rho$ probe scnsitivity would be 2.5 times better than the $Z$ probe. To the extent thit these assumed resolutions are representative of the final equipment, one advantage of the $\rho$ probe becomes apparent. Furthermore, the $\rho$ probe's immunity to $c$, and the relative ease of measuring transit time as opposed to. signal ampltiude when in the presence of noise and with $\sim 0.1 \mathrm{~s}$ response, all point toward the sclection of a $\rho$ probe of the type described in the next section. 


\section{TORSIONAL WAVE DENSITOMETER}

Background. Panametrics' work on torsional wave sensors of circular, square, rectangular and other shapes began in the mid-1960's, and was first reported publicly in 1967. 10 These torsional wave guide shapes were initially studied as sensors for temperature or other variables encountered in nuclear reactor lechnology. One patent was issued based on their use in dual-mode sensors. They were also studied as part of Panametrics' general work in determining elastic moduli. For example, on numerous occasions customers requested us to determine Young's and shear moduli ( $E$ and $G$, respectively) in their thin specimens. For circular specimens the equations are simply

and

$$
E=\rho c_{\text {ext }}^{2}
$$

$$
G=\rho c_{\text {tors }}{ }^{2}
$$

But for noncircular specimens such as rectangular strips cut from sheet stock, the $G$ equation needs to be modified. Fam. Papadakis and the author utilized the earlier results of Spinner and Valorell to interpret torsional wave speeds in ribbon in terms of $G$, and also to design impedance-matched or purposely-impedance-mismatched members. 12

Reduced Speed. The reason ( 2 ) is not correct ior non-clrcular shapes is that $c_{\text {tors }}$ is reduced by a factor $K$, this factor increasing as the shape becomes increasingly ribbon-like. That is to say,

$$
c_{\text {tors }}:=K \sqrt{\mathrm{G} / \rho}
$$

where $\mathrm{K}$ is listed in Table 1 and plotted in Fig. 4 for rectangular cross sections of aspect ratio b/d from 1 to $\sim 10$.

The value of $K$ has been calculated exactly only for the square cross section, $b / d=1$. As $b / d$ increases, the uncertainty in $K$ increases, and is nearly $2 \%$ for $b / d=10$. [In passing we may note that a ribbon sensor interrogated in the torsional mode can bc a much more sensitive indicator of temperature than the basue sensor interrogated in the extensinnal mode. Order-of-mignitude enhancement is possible.]

Impedance. The torsional wave impedance is

$$
z_{\text {tors }}=\rho c_{\text {tors }}{ }^{\mathrm{J}}
$$


TE: : : Torsional wave parametez in ribbons ol ross sectional area bd $=1 \mathrm{~mm}^{2}$, including comparison with torsional wave impedance in circular rod of same area (last column). $\mathrm{J}=$ polar moment of inertia = $(1 / 12)\left(b^{3} d+b d^{3}\right)$. $K=$ velocity reduction factor calculated from $A^{2}$ as given in Spinner and Valore $(1958)^{*}$ for aspect ratios $b / d$. The last column shows that for aspect ratios up to 10 , the impedance ratio remains within $4 \%$ of unity for circular ard rectangular cross sections of equal area.

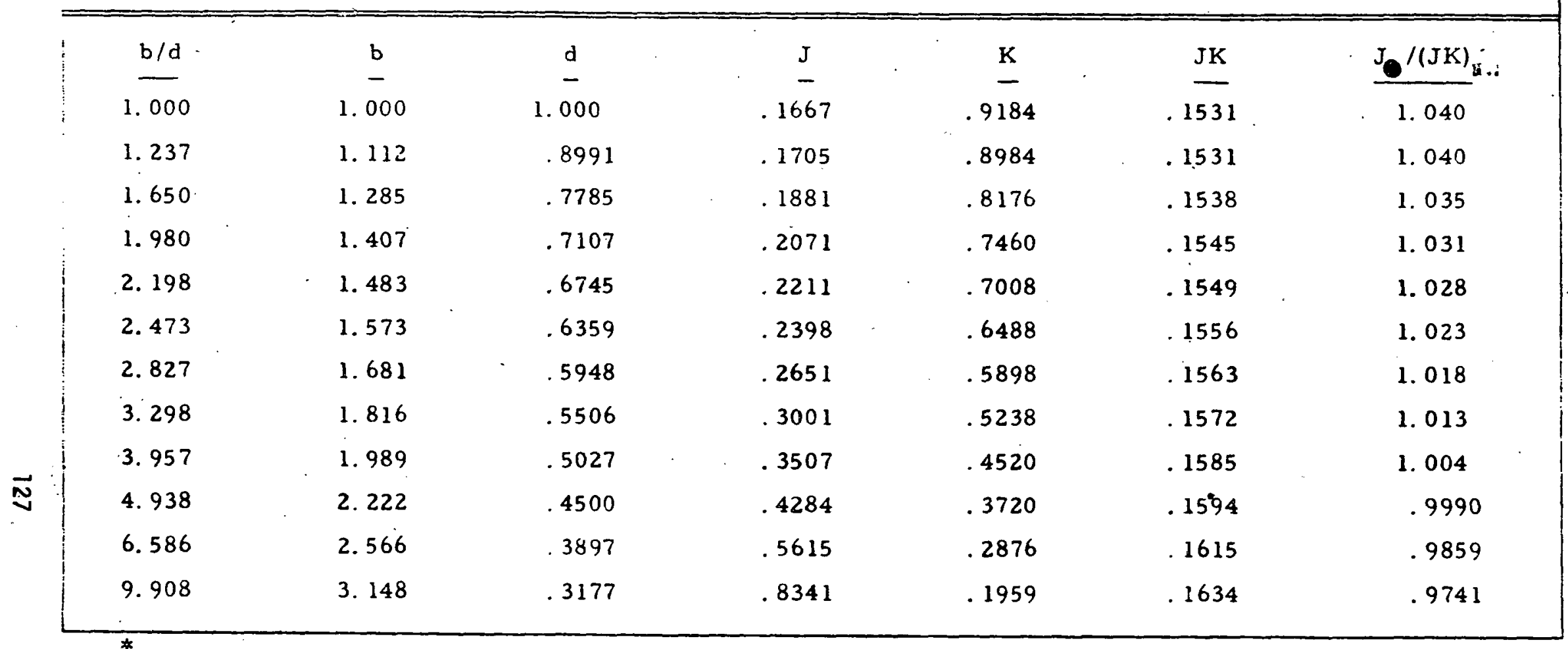

*S. Spinner and R. C. Valore, Jr. , Comparison of Theoretical and Empirical Relations Between the Shear Modulus and Torsional Resonance Frequencies for Bars of Rectangular Cross Section, Journal of Research of the National Bureau of Standards, Research Paper 2861, Vol. 60, No. 5, May 1958, $\mathrm{K}=2 \mathrm{~A} / \sqrt{\left(1+\mathrm{b}^{2} / \mathrm{d}^{2}\right)}$, where $A^{2}=$ shape factor tabulated on p. 462, Table 3, of this reference. 
LTR 14 $\bar{T}-68$

where $J=$ polar moment of inertia. For circular cross section, $J=\pi D^{4} / 32$ where $D=$ diameter. For rectangular cross section, $J=(1 / 12)\left(b d^{3}+b^{3} d\right)$.

It is interesting to note that whereas Spinner and Valor 11 pointed out the extreme difficulty in calculating $K$ for rectangular shape $s$ other than square, Table 1 shows that for rectangular sections of constant area bd $=1 \mathrm{~mm}^{2}$, to a $4 \%$ a proximation or better,

$$
\mathrm{K} \approx 1 / \mathrm{J}
$$

where $J$ is easily calculated by the well-known formula given above. [ $\operatorname{In}^{x}$. passing. we may also note that $J$ is tabulated for all common structural cross sections - see Appendix 3. It would be of interest to measure $c_{\text {tor }}$ in structural cross sections of equal area, egg. $1 \mathrm{~mm}^{2}$, to see if (5) remains a useful approximation for non-rectangular shapes.]

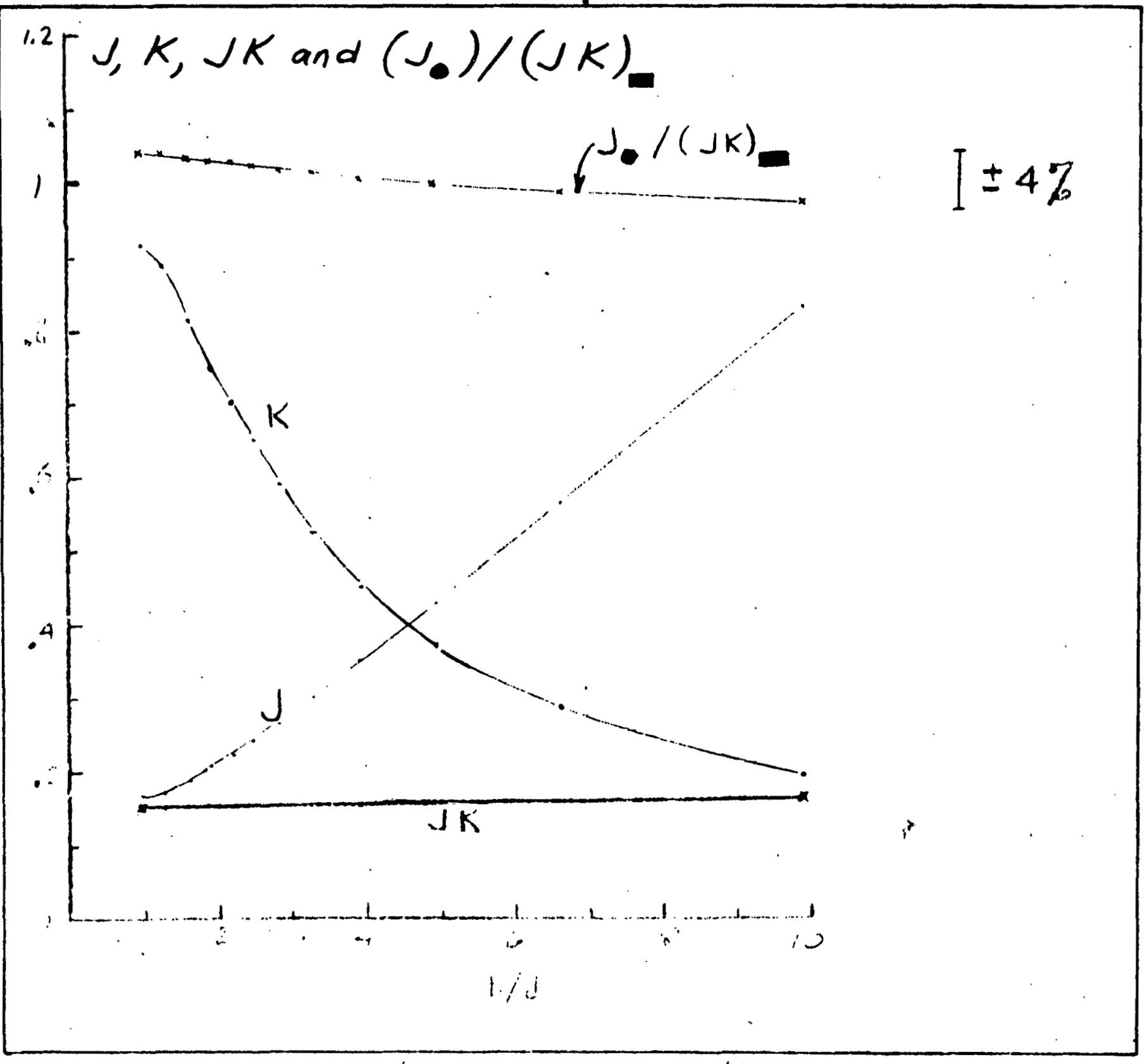

Fig. 4. J, K, JK and $J_{\bullet} /(J K)$ vs aspect ratio bod, based on values in Tulle: 1, p. 9 .

128 
Relative to the present work, the significance of $(5)$ is that the task of impedance matching torsional waves [forordinary materials of comparable Poisson's ratio (including remendur/stainless steel 304)] reduces to substantially the same problem as matching impedances for extensional waves. namely equating areas. That is, if $\left(\rho c^{A}\right)_{-}=\left(\rho c_{\text {ext }} A\right)$ then to a close approximation the same joint will satisfy the requirement $\left(\rho c_{\text {tors }} J\right)_{0}=$ $\left(\rho \mathrm{c}_{\text {tor }} \mathrm{J}\right) \ldots$. In this case, one simply equates bd $=\pi \mathrm{D}^{2} / 4$. See Figs. 4,5 and 6, and Tables 1 and 2 .

Transduction. For completeness we mention here that several earlier ( 1960) workers utilized the Wiedemann effect to generate torsional waves. panametrics' torsional wave transducers now depend on a torsional strain ${ }^{13}$ or twist which is permanent for years, impact-resistant, and believed stable until the remenclur is annealed.

To determine whether the torsional strain of $R$ ef. 13 renains stable at $343^{\circ} \mathrm{C}\left(650^{\circ} \mathrm{F}\right)$, the test of $\mathrm{Fig}$. 7 was conducted. Table 3 shows that the overall transduction efficiency decreased over $7 \mathrm{~dB}$ on heating and soaking for $\sim 2 \mathrm{hr}$ at $\sim 343^{\circ} \mathrm{C}$. Although ample signal remained, the observation that efficiency was decreasing indicates an anneal is in process. Considering the thousands of hours of intended service, it was decided to abandon this otherwise-convenient, direct transduction method.

The obvious alternative is to use a right-angle mode conversion from extensional to torsional, as in Fig. 2. Use of extensional mode takes fullest advantage of the high temperature Curie point of remendur, $980^{\circ} \mathrm{C}$ $\left(\sim 1800^{\circ} \mathrm{F}\right)$. Both Arave and the author have independently verified the use of remender as an efficient extensional wave transducer to temperatures well above $\sim 540^{\circ} \mathrm{C}\left(1000^{\circ} \mathrm{F}\right)$.

Figure 8 represents the use of extensional wave stub transducers mounted off-center at each end of a torsional wave sensor which is to be interrogated in the through-transmission fashion. In a subsequent program it is expecled that optimum parameters for $b / d$, shape of lcading edge, minuting delails, etc. will be worked out relative to Spec. ES-60188.

Density Dependence. The interaction of guided torsional waves and the surrounding liquid may be predicted intuitively by considering the basic equation prescinted carlier, name:ly, sound speed $=\sqrt{\text { stiffness/inertia. }}$ Imagine trying io torsionally accilerate from rest, an immersed stiff strip of steel. Surely the effort will be greater than if the strip were not immersed. The surrounding liquid adds inertia. Intuitively it was thought that the freater thr aspect ratio, wr the greater the $J$, the more pronounced this inertia effect would be on reducing $c_{\text {tors }}$. Preliminary tests using irass strips verified these intuitive concepts. 
The slope or sensitivity $\mathrm{m}$ is nearly proportional to $\mathrm{K}^{-1}$ plus a constant, for b/d from 1 to 4. For these b/d's, and for constant cross sectional area, this means $m$ is nearly proportional to $\mathrm{J}$ plus a constant.

In (7) - (9), tpproximat ly linear response is indicated. But as $\delta$ approaches $\rho_{g}$, due to high $\rho$ and/or large interaction with the shape (due to la rge $b / d)$ then nonlinear response will result.

We may also note in passing that in Ref. 8, pp. $82-83$ describe the use of immersed ribbon-like probes in which the damping of the surrounding liquid is interpreted in terms of $\eta \rho$, where $\eta=$ viscosity. (See also Appendix 1, p. 2.) By combining the present $\rho$ measurement with this previous $\eta \rho$ measurement, $\eta$ may be determined. Ideally, both $\eta$ and $\rho$ would be obtained by interrogating a single sensor in two different ways.

Consider again, (3) on p. 8. For circular cross sections $\mathrm{K}=1 . \rho_{\mathrm{g}}$ the density of the guide material itself. The numerator in the radical, $G, i s$ the shear riodulus. For SS304, G decreases about $12 \%$ as temperature increases from rowm temperature to $343^{\circ} \mathrm{C}\left(650^{\circ} \mathrm{F}\right)$. Correspondingly, ctors lluLusoc $-6 \%$ and approxinuately linearly, or roughtly $1 \%$ per $1000 \mathrm{~F}$. It may be shown that an unconipensated uncertalniy in probo temprature of $\pm 100^{\circ} \mathrm{F}$ corresponds to a liquid density uncertainty of $\pm 20 \%$ full scale, for $\rightarrow$ rectangular cruss section probe: of $b / d \approx 3$ for which the sensitivity $m$ is 5 "ii (sco Table 4, p. 22).

Let the waveguide now be immersed in a liquid of density $\rho$. For a circular cross section, changes in $c_{\text {tors }}$ are neither predicted nor observed. For noncircular cross section, let us assume: that $\rho_{\mathrm{g}}$ is perturbed slightly, becoming in effect $\rho_{\mathrm{g}}{ }^{\prime}=\rho_{\mathrm{g}}+\delta$ where $\delta \ll \rho_{\mathrm{g}}$. Then

$$
c_{\text {turs }} \approx c_{\text {turs }}(1-\delta / 2
$$

and the transit tume over a sensor path length $L$ is correspondingly increased 1.0

$$
1^{\prime} \therefore L / c^{\prime} \approx t_{0}(1+\delta / 2)=t_{0}(1+n p)
$$

The relation butween $\delta$ and $\rho$ depends on probe shape. This is equivalent to saying

$$
\delta=2 \mathrm{~m} \rho \text { ur } \Delta t=\mathrm{m} \rho \mathrm{t}_{\mathrm{o}}
$$


Table 2. Diameters of tubes of cross sectional area equal to circular rod of diameter $0.056^{\prime \prime}$, calculated f rom $D^{2}-d_{a}^{2}=0.056^{2}$, and of equal polar moment of inertia, calculated from $D^{4}-d_{j}^{4}=0.056^{4}$.

\begin{tabular}{|ccc|}
\hline$D$ & $\frac{d_{a}}{d_{j}}$ \\
\hline 0.060 & 0.022 & $\frac{d}{0.042}$ \\
.065 & .033 & .053 \\
.070 & .042 & .061 \\
.075 & .050 & .068 \\
.080 & .057 & .075 \\
.085 & .064 & .081 \\
.090 & .070 & .086 \\
.095 & .077 & .092 \\
.100 & .083 & .097 \\
.125 & .112 & .124 \\
\hline
\end{tabular}

Table 3. Torsional wave echo amplitude vs temperature of straight torsional wave transducer of Ref. 1, , tested as shown in Fig. 7.

\begin{tabular}{|c|c|c|}
\hline$\frac{\text { Tempe }}{{ }^{\circ} \mathrm{C}}$ & $\frac{\frac{\text { rature }}{{ }^{\circ} F}}{}$ & $\begin{array}{c}\text { Echo Amplitude } \\
\text { Volts peak-to-peak }\end{array}$ \\
\hline 27 & 81 & 3.0 \\
\hline 225 & 437 & 3.0 \\
\hline 310 & 590 & 2.9 \\
\hline 350 & 662 & 2. 8 \\
\hline 382 & 720 & 2.5 \\
\hline 354 & 670 & 2. 3 \\
\hline 371 & 700 & 2.0 \\
\hline 332 & 630 & (2 hr soak) \\
\hline 343 & 650 & 1. 3 \\
\hline 149 & 300 & 1.4 \\
\hline
\end{tabular}

Date of test: Feb. 18, 1977 


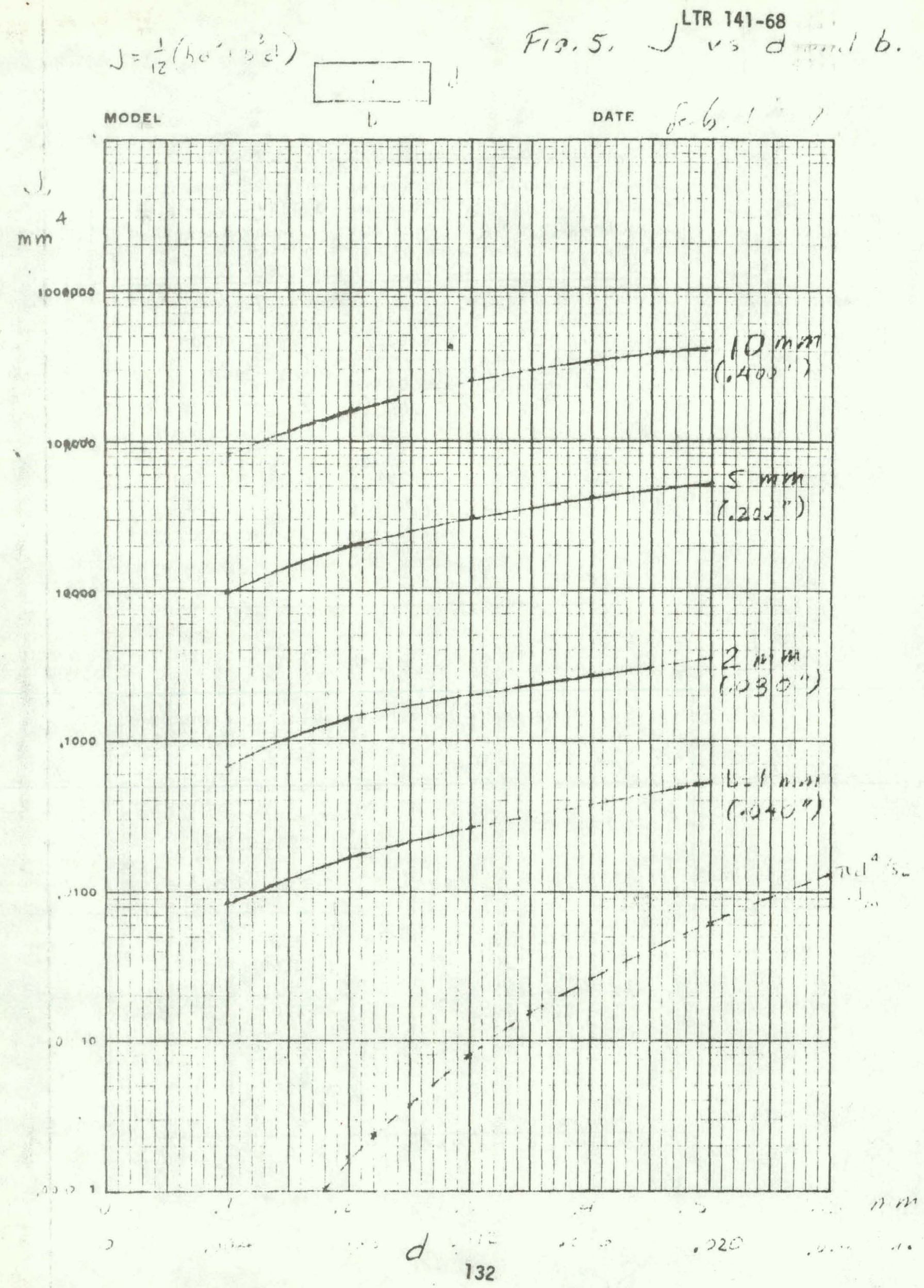




$$
\begin{aligned}
& \text { (TR 147-60 }
\end{aligned}
$$

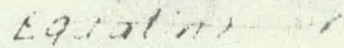

$$
\begin{aligned}
& \left\{b d=\pi D / 4=75 \div D^{2}\right.
\end{aligned}
$$

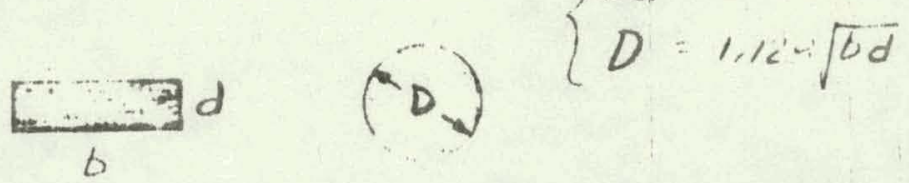

$$
\begin{aligned}
& \text { D. }
\end{aligned}
$$

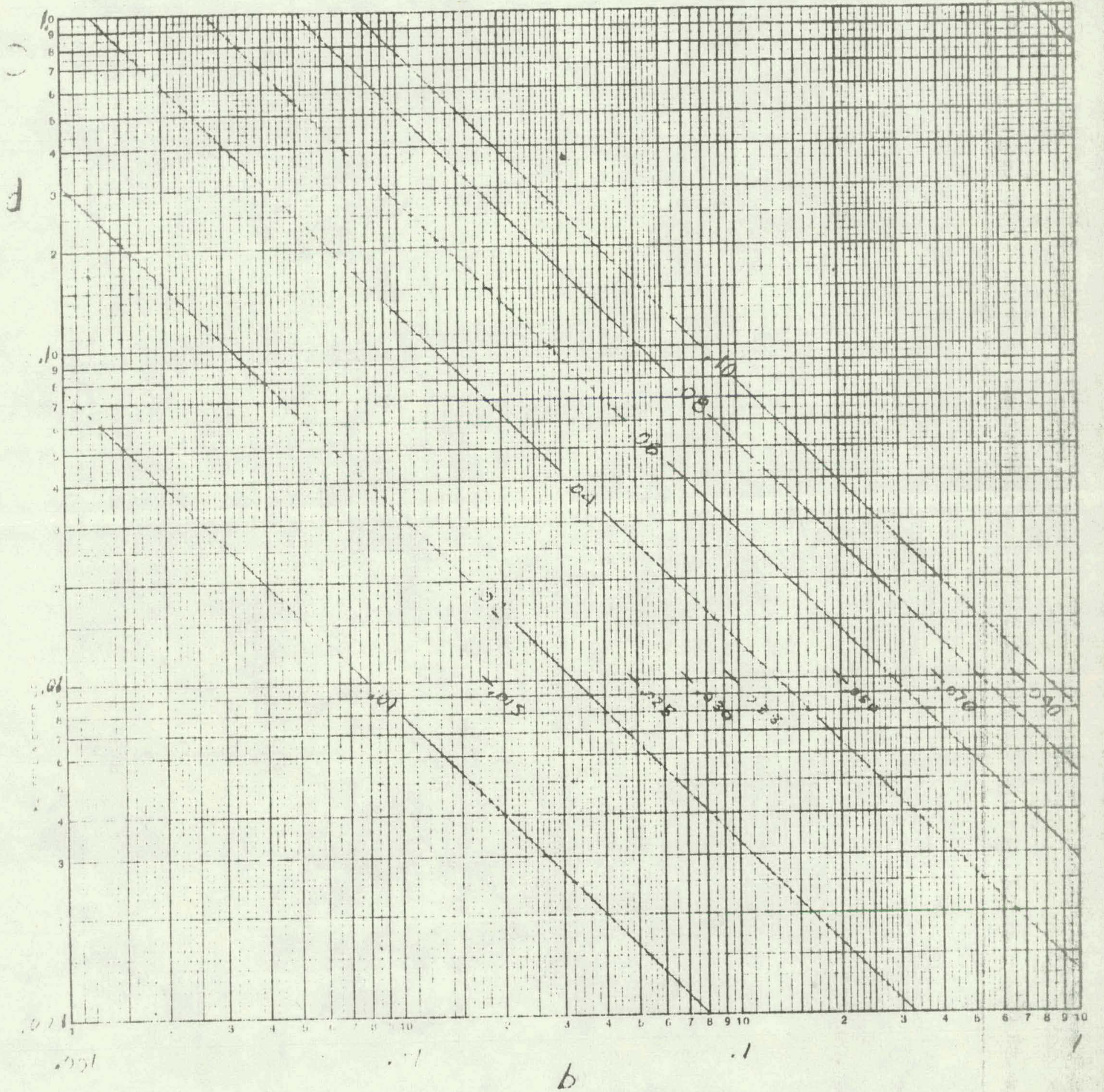

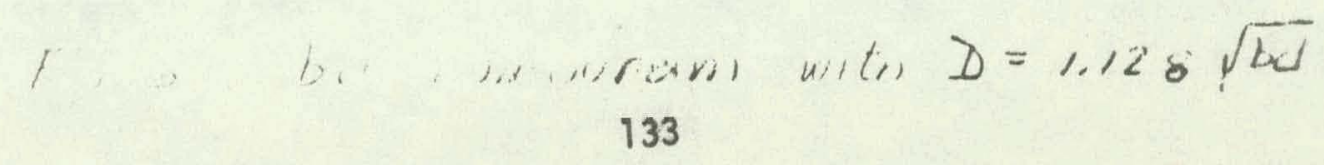




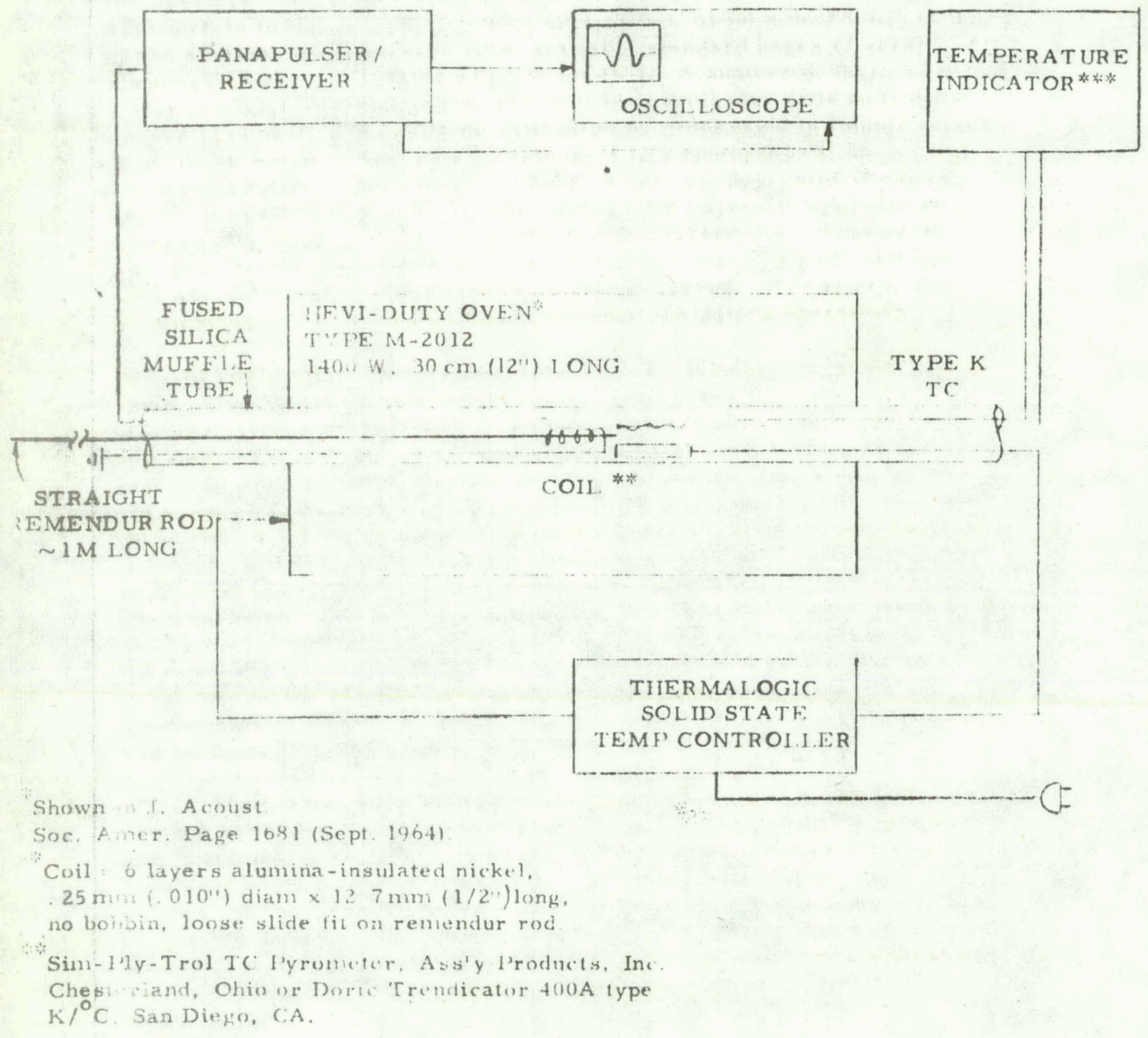

Fig. 7. Thermal test of straight torsional wave transducer. 
(a)

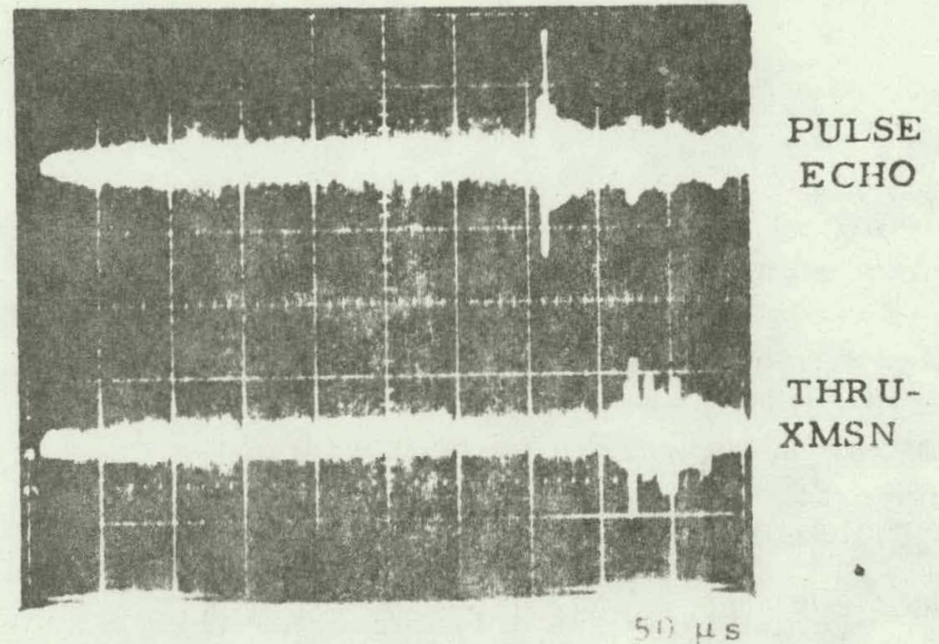

(b)

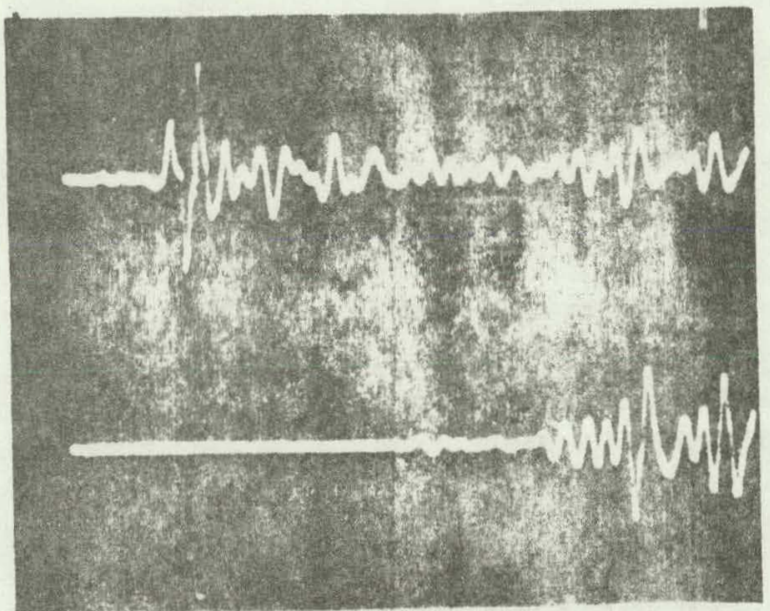

$10 \mu \mathrm{s}$
IIRSION

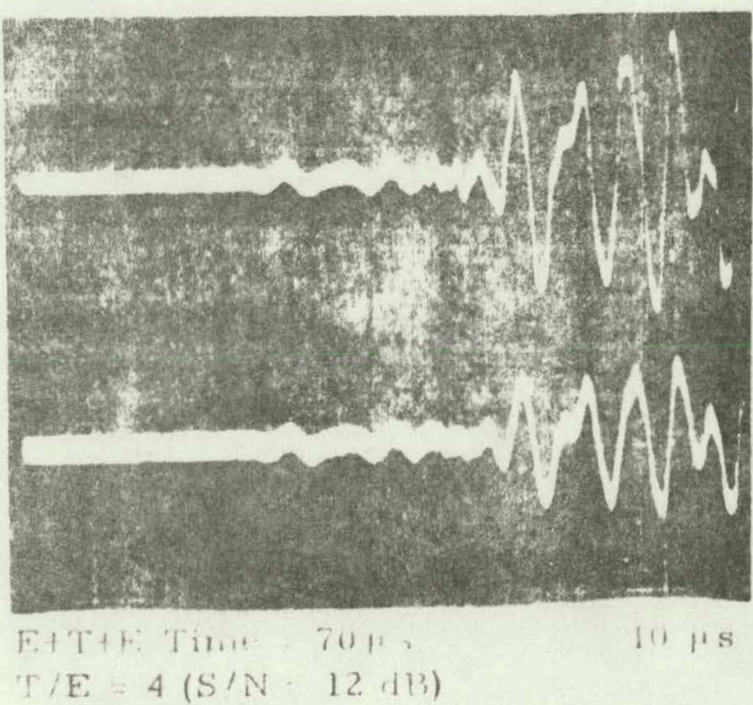

SENSOR, $\mathrm{b} / \mathrm{d} \approx 2$

(. $\left.137^{\prime \prime} \times .060^{\prime \prime}\right)$

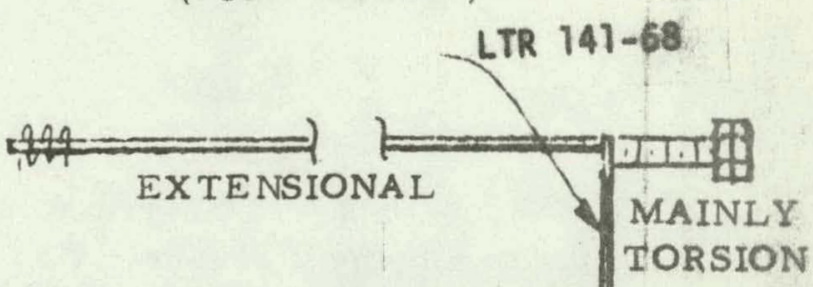

EXTENSIONAL

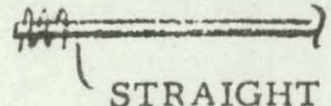

STRAIGHT REMENDUR A NNEA LED

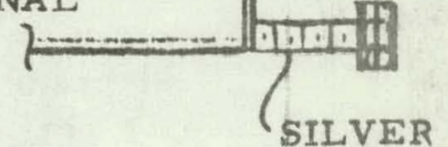

BRAZED MOUNTING ST UD, 4-40 x 1" LONG
SAME AS ABOVE

EXCEPT

SWEEP EXPANDED

(c)

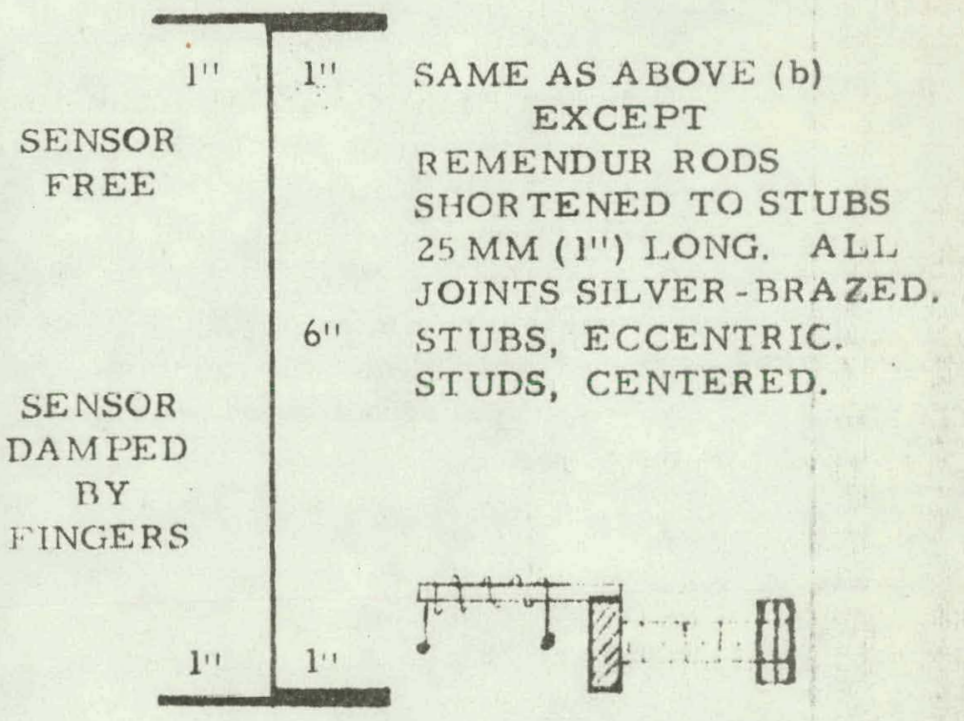

F. Mode-converted forsional waves in sensor with mounting studs. 
To obtain a quantitative picture of the interaction, and to begun the development of fabrication procedures using materials and shapes appropriate to the specific intended application, about a dozen different cross sections were sheared from available standard gages of scrap stainless steel. All lengths were $15 \mathrm{~cm}\left(6^{\prime \prime}\right)$. A number of the se were silver brazed to the end of $1-\mathrm{m}$ (39.37") long remendur rods so that the sensor portions could easily be calibrated by immersion in liquids selected from those listed in Appendix 2. Figure 1 is a photograph illus trating candidate sensor shapes. Table 4 lists the approximate cross section dimensions of those tested. Dimensions are only approximate because in shearing the sensors, the desired rectangular cross section was distorted to a parallelogram; also, the oppnsite sides of some sensors are not parallel. Some twisting also occurred. If required, these deficiencies can be rectified by conventional machining operations.

Density Profiling. In the photograph, Fig. 1, tubular sensors of circular cross section will be recognized. The reader may ask, why circular, since the inertia of this shape cannot be increased upon immersion. The reason for a circular tube is that such a shape is readily deformed over selected portions of the probe length, into a noncircular shape which is as sensitive as a corresponding rectangle. For example, the middle $7.5 \mathrm{~cm}\left(3^{\prime \prime}\right)$ of a thin-walled tubular probe of $\sim 2 \mathrm{~mm}$ OD was flattened, and responded over the flattened portion only, with a local sensitivity simular to a rectaugle of aspect ratin $h / d=2$. Since nnly the flat midsection responded to immersion, it will be understood that a probe of this type could be interrogated in the through-transmissinn mode, and the resulting time increments could be interpreted in terms of $\rho$ adjacent to the flat part only. On pulse-echo, the circular portions could provide a temperature-dependent time shift, to compensate the flat portion for the temperature ( $T$ ) effect, using only the torsional mode.

The transit time shifts along selected zones of a tor sionallyexcited sensor can be related to $p$ profiling. 14 Even if all the zones are "used up" in sensing $\rho$, one can still obtain an ultrasonic $T$ measurement using a second mode, i.e., the extensional mode, over one or more of the $\rho$ profile zones. (cext in immersed ribbon does not depend on $\rho$ of the surrounding liquid.) If both $\rho$ and $T$ vary along the probe, then the combined use of torsional and extensional waves in a multiznned ribbon could provide two sets of profiling echoes, extensional for $T$, torsional for $p$. 
During discussions at EG\&G Jdaho on Jan. 18, 1977 the possibility of 4-zone profiling was discussed. Whether or not $4 \rho$-sensing, $T$-compensated zones can be built into 1 single probe, remains to be seen. In this regard, we make note of $T$ profile probes containing $2,3,4,10,16$ and 22 zones, with representative oscillograms having appeared in the literature over the past decade. $14-16$

A special case of density profiling occurs when one liquid floats on another. This is sometimes categorized as a "liquid level" or "interface location" applicution. Consider first, the situation where both liquids are of known densities $\rho_{1}$ and $\rho_{2}$, as in Fig. $9 a$. As will be understood from the calibration data, for a given probe, $\Delta t$ is proportional to $\rho$. Define the slope of this relationship as $m_{1}$ in probe 1 , and $m_{2}$ in probe 2 . Then

from which

$$
\Delta \mathrm{t}_{1}=\left(\mathrm{m}_{1} \rho_{1}\right) \mathrm{y}_{1}
$$

$$
H_{1}=1-y_{1}=1,-\Delta t_{1} / m_{1} \rho_{1}
$$

Similarly

$$
\Delta t_{2}=\left(m_{2} \rho_{2}\right) y_{2}+\left(m_{2} \rho_{1}\right)\left(L-y_{2}\right)
$$

from which

$$
\begin{aligned}
H_{2} & =2 L-y_{2} \\
& =21,-\left(\Delta t_{2}-m_{2} \rho_{1} L^{L}\right) / m_{2}\left(\rho_{2}-\rho_{1}\right)
\end{aligned}
$$

A graphical equivalent of these equations is sketched in Fig. $9 \mathrm{~b}$.

If densities arc unknown, it is still possible, in principle, to separate the variables $\rho$ and 11 . The separation is based on the slow wave exhibiting a proportionately lower impedance. For example, at a liquid's free surface, the interface introduces an impedance discontinuity proportional to $\Delta t / t_{0}$, where $t_{0}=d r y$ transit time. The interface echo magnitude inay thus be related to $\rho$ in the liquid. In this manmer the probe appears to act like a reflection coefficient impedometer whith responds to the liquid's $\rho$, but not its $Z$. The oscillogram, Fig. 14d, illustrates the interface echn for a probe partly inmersed in water (p. 28). Ilaving determined $\rho$ from the interface echo magnitude, the $\Delta t$ may be interpreted in terms of $H$, as above.

Calihration procedurc. Citlibration of torsinnal wave sensors consisted of measuring the round trip transit time for sensors in air, and then when fully immersed in liquids of known density. Based on preliminary tests on the variety of sensors shown in Fig. 1, four having rectangular cross sections 
LTR $141-68$

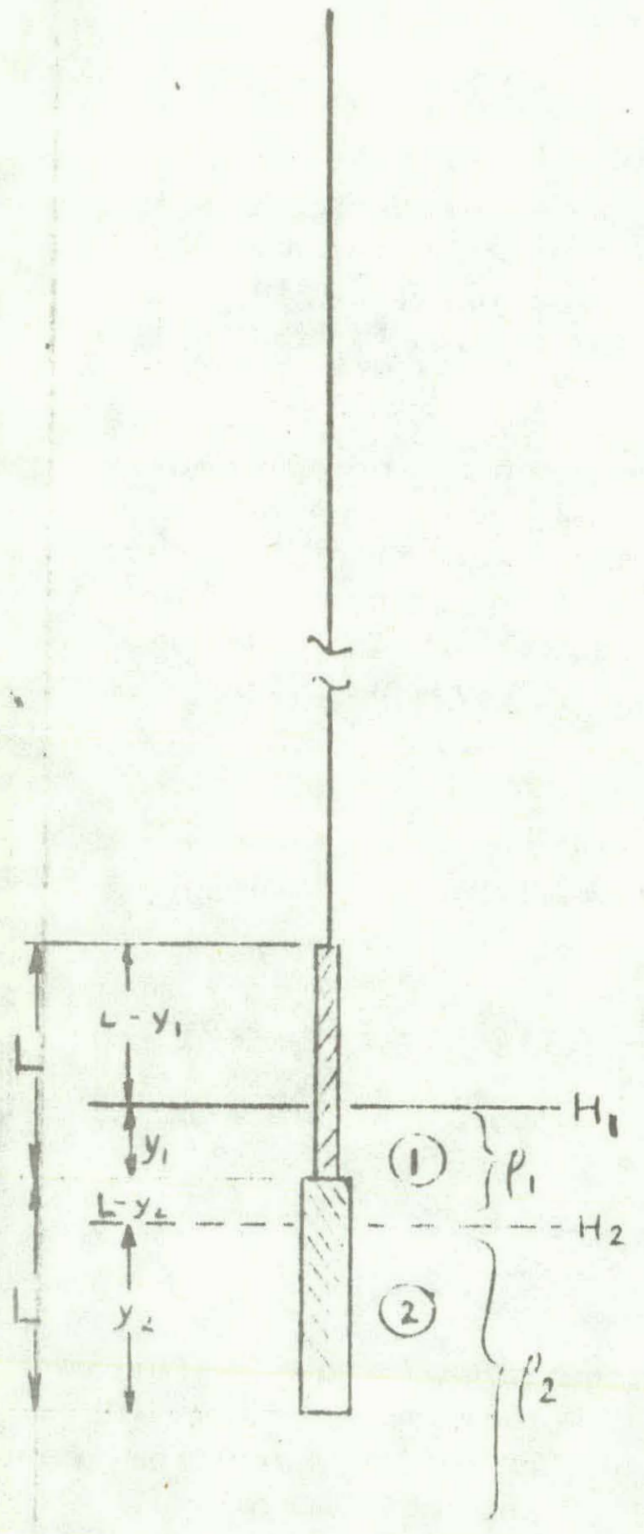

Fig. 9a. Liquid 1 rn 2.

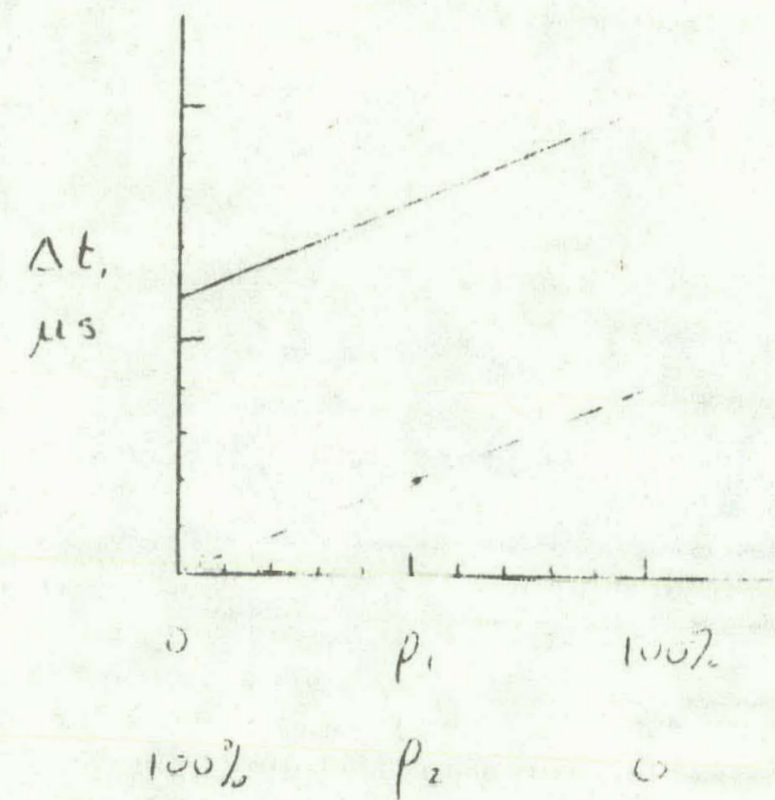

Fig. 9b. $\Delta t$ vs fraction of probe wetted by $\rho_{1}$ and $\rho_{2}$. 
were selected for the calibration test. These four had width-to-thickness ratios of approximately $1: 1,2: 1,3: 1$ and $4: 1$. Each sensor was calibrated using eight liquids ranging in $\rho$ from 0.63 to $2.2 \mathrm{~g} / \mathrm{cm}^{3}$.

The block diagram of Fig. 10 clarifies the set-up procedure. The sensors were oriented vertically for convenience in immersing in $100 \mathrm{ml}$ glass cylinders. These cylinders have an ID of $\sim 25 \mathrm{~mm}\left(\sim\right.$ l") $^{\prime \prime}$. [ Use of cylinders of ID $\leqslant 10 \mathrm{~mm}\left(\sim 0,4^{\prime \prime}\right)$, or accidental contact between the sensors and the cylinder wall increases the observed transit time compared to the correct value which is to be associated with the liquid itself.]

Test Results. Table 4 contains the calibration data obtained on Feb. 19, 1977. All $\rho^{\prime} s$ are taken from the AIP Handbook, Appendix 2. All t's and $\Delta t^{\prime} s$ were measured on the oscilloscope. All $\Delta t^{\prime}$ s were measured at zero crossings. Oscilloscope observation enables one to notice dispersion; waveform changes; attenuation; spurious effects due to probe vibration or contact with the glass container wall or bottom. It was felt that the precision of this calibration (ranging from typically \pm 0.1 but sometimes to $\pm 2 \mu s$, depending on the sensor and liquid) was adequate at this stage of the investigation, and was consistent with the precision in dimensions of "as-sheared" sheet metal sensors, and the use of nominal values for $\rho$.

Recalibration of the final sensors in a subsequent program can incorporate automatic time interval measurements, probably with generally improved precision.

Discussion of Torsional Wave Calibration Test Results. Figures 11 and 12 present the calibration data in raw form, $\Delta t v s \rho$, and in normalized form with "sensitivity" as a function of $\mathrm{K}^{-1}$. Most important, the raw data show that $\Delta t^{\prime} s$ increase essentially in proportion to $\rho$, for each sensor. The normalized graph shows that resolution improves as b/d increases, and approximate in proportion to $\mathrm{K}^{-1}$. For $\mathrm{b} / \mathrm{d}=4$, dispersion was observed. (See oscillograms for four torsional sensors, Figs. 13, 14. See also, pp. 7-42 and 7-43 in Ref, 12, containing Papadakis' results in torsionallytested aluminum ribbons of varying b/d.) To achieve comparably high sensitivity or resolution, yet to avoid dispersion, one may sometimes be able to utilize a multiple echo in a torsional sensor of aspect ratio small enough to avoid dispersion at the frequencies used, namely, b/d $\approx 2$ or 3 at $\sim 100 \mathrm{kHz}$. (The Nthecho is sonetimes used to enhance sensitivity in ultrasonic modulus ineasurements, thermometry and thickness gaging.) However, this appears neither practical nor necessary, in the present application. 
Table 4. Calibration test data for four gtainless steel probes tested at roorn temperature. Date of calibration test: February 19, 1977. Values listed under each liquid are $\Delta t^{2}$ in $\mu \mathrm{s}$, for round-trip propagation of tor sionhl waves in sensors of length $15 \mathrm{~cm}$ (6 $\left.6^{\prime \prime \prime}\right)$.

\begin{tabular}{|c|c|c|c|c|c|c|c|c|c|c|c|c|c|c|}
\hline $\begin{array}{l}\text { Cross } \\
\text { section } \\
\text { inches }(2) \\
\end{array}$ & $\frac{\text { Aspect } \mathrm{Re}}{\text { Nominal }}$ & $\frac{\text { tio } b / d}{\text { Actual }}$ & $K^{(6)}$ & $\begin{array}{c}\text { n-Pentane } \\
(\rho=0.632)^{(1)}\end{array}$ & $\begin{array}{l}\text { Ethyl } \\
\text { Alcohol } \\
(0.79)\end{array}$ & $\begin{array}{l}\text { Acetone } \\
(0.79)\end{array}$ & $\begin{array}{c}\text { Benzene } \\
(0.87) \\
\end{array}$ & $\begin{array}{l}\text { Water } \\
(1.00) \\
\end{array}$ & $\begin{array}{l}\text { Chloro- } \\
\text { benzene } \\
\text { (1.10) }\end{array}$ & $\begin{array}{c}\text { Carbon Tetra- } \\
\text { chloride } \\
\text { (1.59) } \\
\end{array}$ & $\begin{array}{l}\text { Ethylene } \\
\text { Bromide } \\
\text { (2. 178) } \\
\end{array}$ & $\begin{array}{l}\text { Air } \\
t_{0} \mu_{\mathrm{s}} \\
(.001) \\
\end{array}$ & $\begin{array}{r}\mathrm{m}^{(5)} \\
-\%\end{array}$ & $\begin{array}{c}\mathrm{C} \\
\mathrm{m} / \mathrm{s}\end{array}$ \\
\hline $.059 \times .062$ & $1: 1$ & 1. 05 & .91 & 0.9 & 1. 0 & 1. 1 & 1. 2 & 1. 4 & 1. 5 & 1. 9 & 2. 8 & 108 & 1. 30 & 2822 \\
\hline $.057 \times .145$ & $2: 1$ & 2. 46 & .65 & 3. 5 & 4. 0 & 4. 0 & 5.0 & 5. $2^{(3)}$ & 6. 0 & 8.6 & 12. 0 & 140 & 3. 71 & 2177 \\
\hline $.029 \times .085$ & $3: 1$ & 2. 93 & .56 & 5. 8 & 7. 4 & 7. 4 & 8.0 & 9. $0^{(2)}$ & 10.3 & 14.8 & $19.5 \pm .5$ & 170 & 5. 29 & 1793 \\
\hline $.036 \times .135$ & $4: 1$ & 3. 75 & 46 & 10.1 & 13.0 & 13. $\mathrm{C}$ & 14.2 & 15. 2 & 17.5 & 27.0 & $35 \pm 2^{(8)}$ & $200^{(4)}$ & 7.60 & 1524 \\
\hline \multicolumn{15}{|c|}{ Preliminary Test Data $(9-11)$} \\
\hline $4-40$ SS & Threadec & $\operatorname{Rod}^{(9)}$ & - & - & - & 0.5 & - & $.7-.8$ & - & 1.3 & - & 68 & 1.1 & 4482 \\
\hline $.048 \times .049$ & 1:1 & $1.02^{(10)}$ & .92 & - & - & 1. & - & 1.3 & & 2.0 & & 99 & 1. 3 & 3079 \\
\hline $.025 \times .120$ & 5:1 & 4. $80^{(11)}$ & .38 & - & - & 19 & - & 21 & & 35 & & 250 & 8. 4 & 1219 \\
\hline
\end{tabular}

AIP Handbook, $\mathrm{g} / \mathrm{cm}^{3}$.

Two round trips, $18.2 \mu \mathrm{s}$.

3. Three round trips, $14.6 \mu \mathrm{s}$.

4. Group delay $t_{\mathrm{g}}=200 \mu \mathrm{s}$ at period $=7 \mu \mathrm{s}$.

5. Sensitivity $\equiv[i \Delta t$ in water $\left.) / t_{0}\right] \times 100 \%$.

Sound speed reduction factor. See Fig. 4 on p. 10 , or Table 1 on p. 9.

Dimensions only approximate, due to shearing.

Oscilloscope resolution of $\Delta t^{\prime} s$ is $\pm 0.1 \mu s$ unless noted. Repeatability $+0.2 \mu \mathrm{s}$ or better, unless noted.

(thread noise.

0. Square SS, $5-5 / 8$ " long. Raw data multiplied b, $(6 / 5,625)$ to yield values tabulated.

11. Brass, 5-5/8 long. Raw data multiplied as in (10). Values crily approximate, due to dispersion. $B$ pulse width $=100 \mu s$
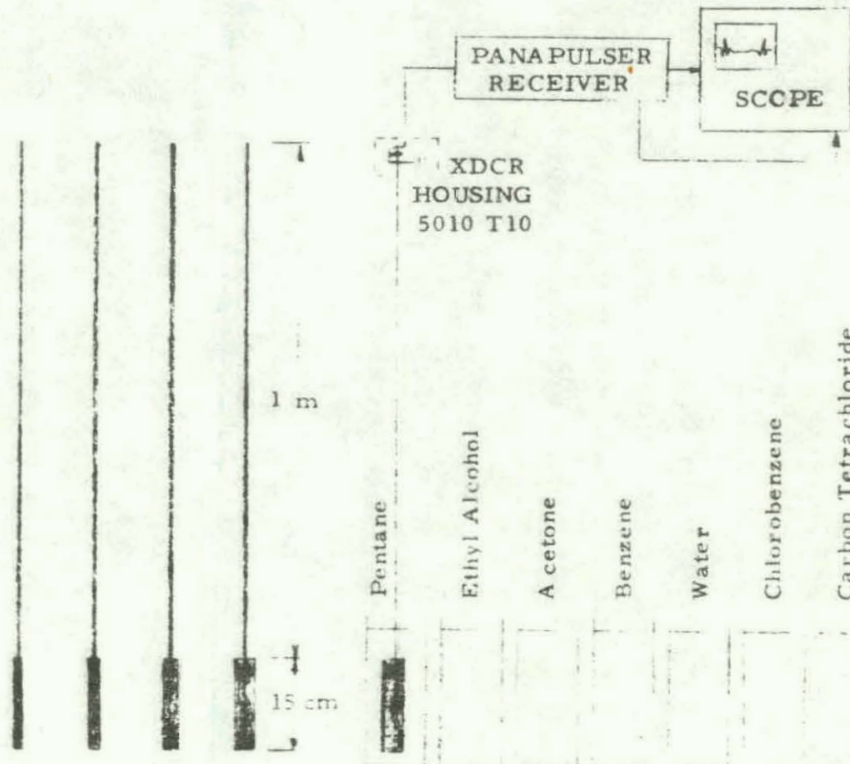
For example consider the possibility of $a b / d=3$ envelope within which an ogive shape is contoured to a relatively sharp leading edge. This shape is likely to exhibit a pulse-echo $\Delta t \approx 10 \mu \mathrm{s}$ for complete immersion into water of a $15 \mathrm{~cm}\left(6^{\prime \prime}\right)$ sensor. On through-transmission this would be halved, to $\Delta \mathrm{t} / 2=5 \mu \mathrm{s}$. Assuming transit time resolution of $\pm 0.1 \mu \mathrm{s}$, the equivalent $\rho$ resolution would be $\pm 2 \%$ full scale, taking full scale to be $1 \mathrm{~g} / \mathrm{cm}^{3}(62.4 \mathrm{lb} / \mathrm{cu} \mathrm{ft})$. For a $66 \mathrm{~mm}\left(2.6^{\prime \prime}\right)$ active length, sensitivity is proportionally degraded, to $\pm 4.6 \%$ or about $\pm 5 \%$ full scale.

This estimate applies for a homogeneous liquid. For a two-phase liquid, some "average" $\bar{\rho}$ will be indicated. In the simplest case this would be of the form $\bar{\rho}=\rho A_{\text {wet }} / A_{\text {sensor' }}$, the $A^{\prime} s$ being wetted area and total sensor area, respectively, and $\rho$ being the density of the liquid portion. In the actual application, the bubble size and distribution will probably complicate the foregoing equation. (See also, Density-Correlated Velocimeter.)

To observe the effects of boiling in a liquid of density lower than water, and at a temperature well removed from room temperature, a $3: 1$ (sensor was tested in and out of a $1 \ell$ dewar of liquid nitrogen ( $\left.L, N_{2}\right)$. Oscillographic results are shown in Fig. 15. When a warm sensor is immersed, two competing effects are observed. The lower temperature, about $-200^{\circ} \mathrm{C}$, increases the sound speed, while the liquid's inertia reduces it. As boiling subsides, noise is reduced, and transit time increases.

When a cryogenically cold sensor is immersed and later removed, a thermally smeared $\Delta t=7.2 \pm 0.4 \mu \mathrm{s}$ is observed (Fig. 15c). Using the calibration data of Fig. 11 without temperature compensation lends to a calculated $\rho_{3}=.78 \pm .05 \mathrm{~g} / \mathrm{cm}^{3}$. This agrees with the nominal value of $0.81 \mathrm{~g} / \mathrm{cm}^{3}$.

When the $\mathrm{LN}_{2}$ was boiling at the warm probe's surface, $\Delta \mathrm{t} \ll<\mu \mathrm{s}$, and so the probe did not correctly sense $\bar{\rho}$ in the dewar. But if the probe and liquid are in thermal equilibrium, the $\bar{\rho}$ corresponding to $\Delta t$ may be acceptably close to the true value. Clearly, more analytic and experimental work is required on this topic.

Dispersion. Dispersion, or the dependence of sound speed upon frequency, is illustrated by chirping in the torsional echoes of Fig. 13e, for an incident broadband pulse of center frequency fo about $100 \mathrm{kHz}$, with $\mathrm{b} / \mathrm{d} \approx 4$. Dispersion can be avoided by using, lower $f$ or smaller $b / d$, tay $\lesssim 3$. However, to take advantage of the higher sensitivity of larger $b / a$, say $b / d \sim 5$ to 10 , and to not sacrifice resolution by using a low $f_{n}$, one can use a narrowband pulse (rf burst) or cw. For example, see Fig. $13 \mathrm{f}, \mathrm{g}$ on p. 27. 
Fig. 11. $\Delta$ t vs $\rho$ calibration data.

LTR 141-68

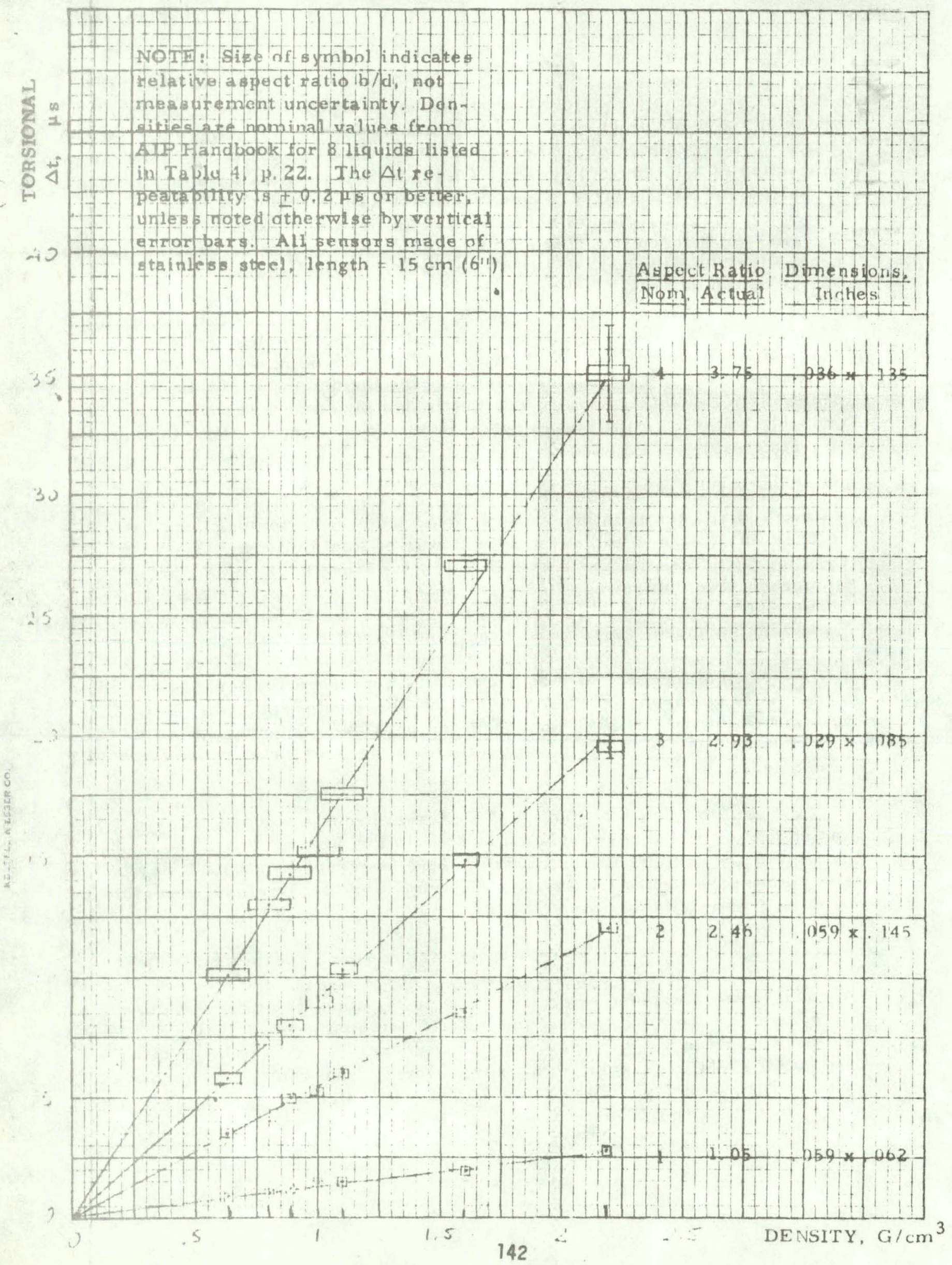




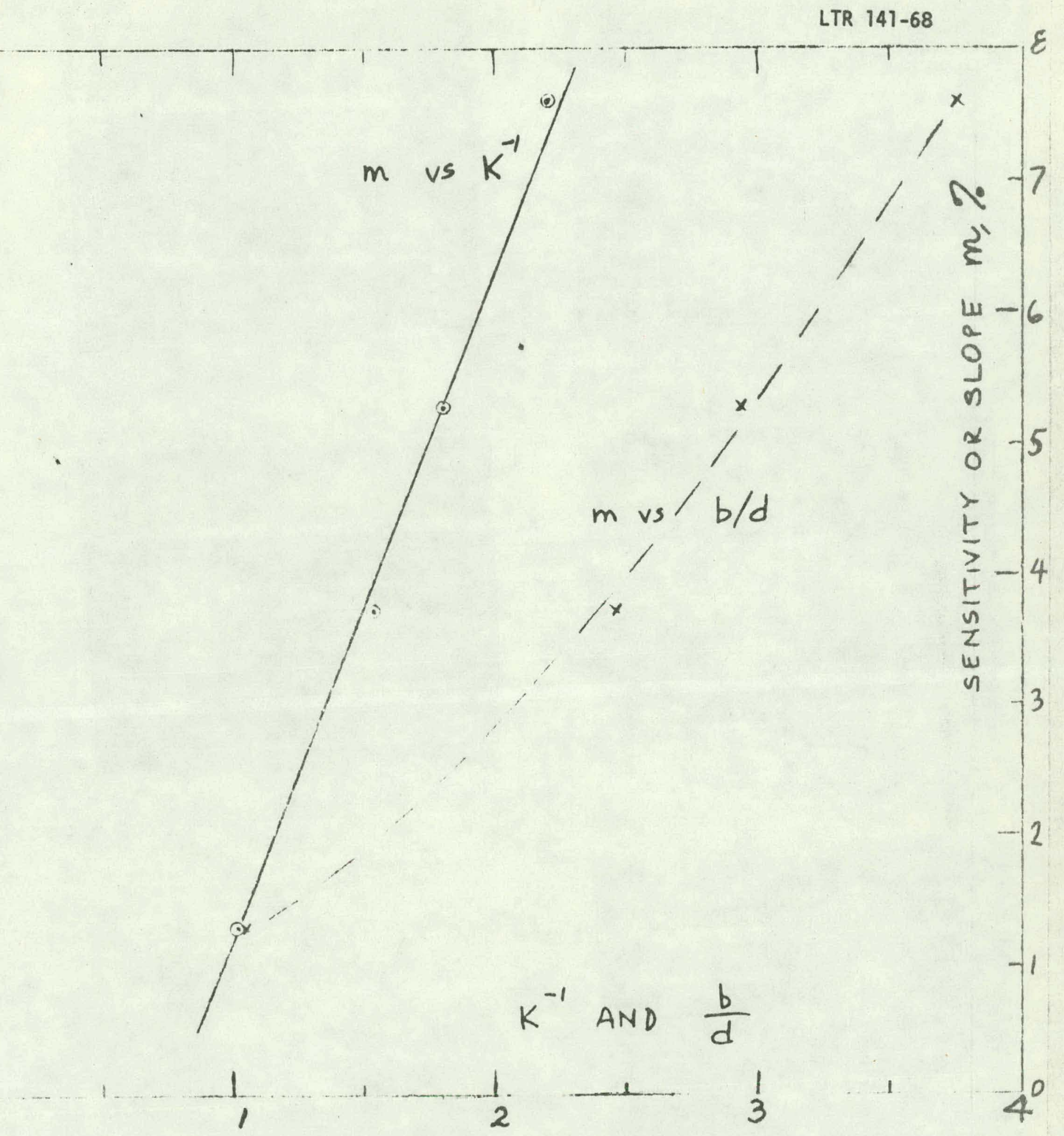

Fig. 12. Sensitivity or slope $\mathrm{m}_{\mathrm{vs}} \mathrm{K}^{-1}$ and $\mathrm{vs} \mathrm{b} / \mathrm{d}$, for calibration test sonsors. 
(a)

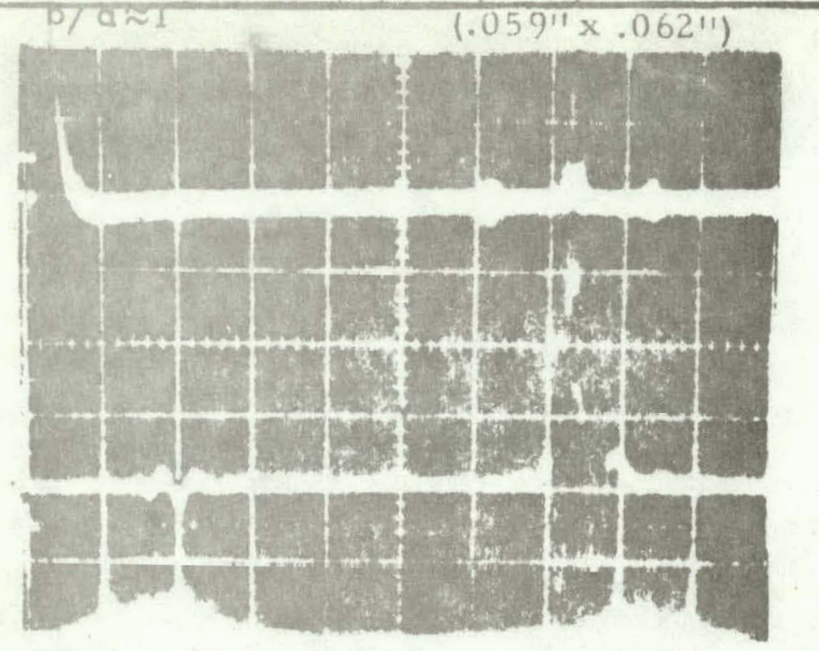

Square; $100 \mu s ; 20 \mu s$

$b / d \approx 2$

(b) 、

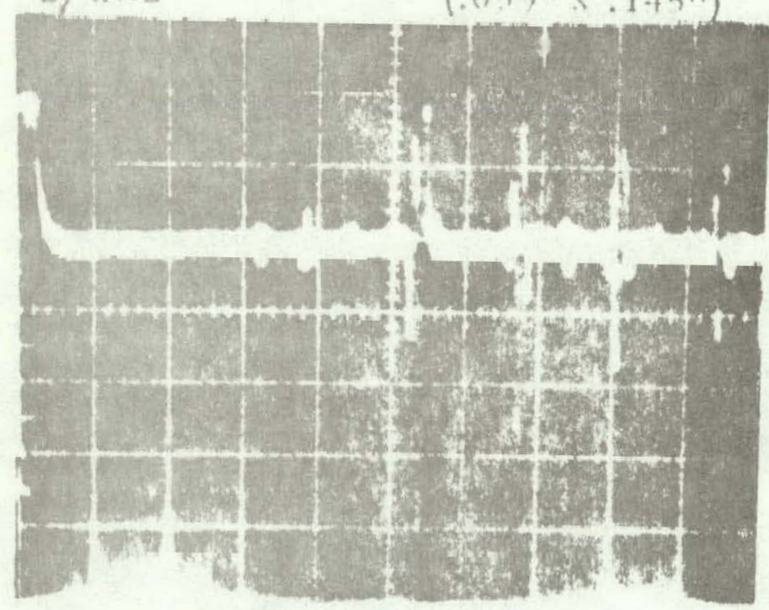

$100 \mu \mathrm{s}$

Ext

$\mathrm{b} / \mathrm{d} \approx 2$

$(.059 \times .14511)$

(c)

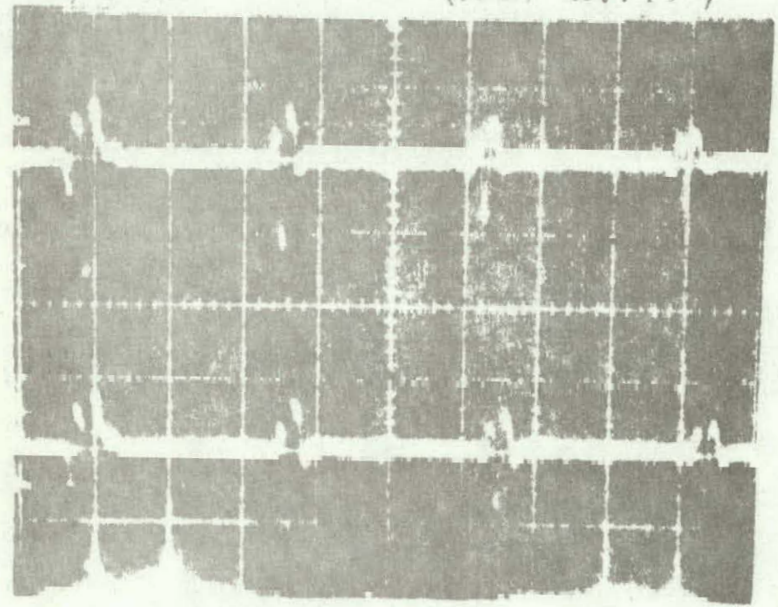

$50 \mu \mathrm{s}$
Triple sensilivaly using

torsional nultiple: cchoes (d)

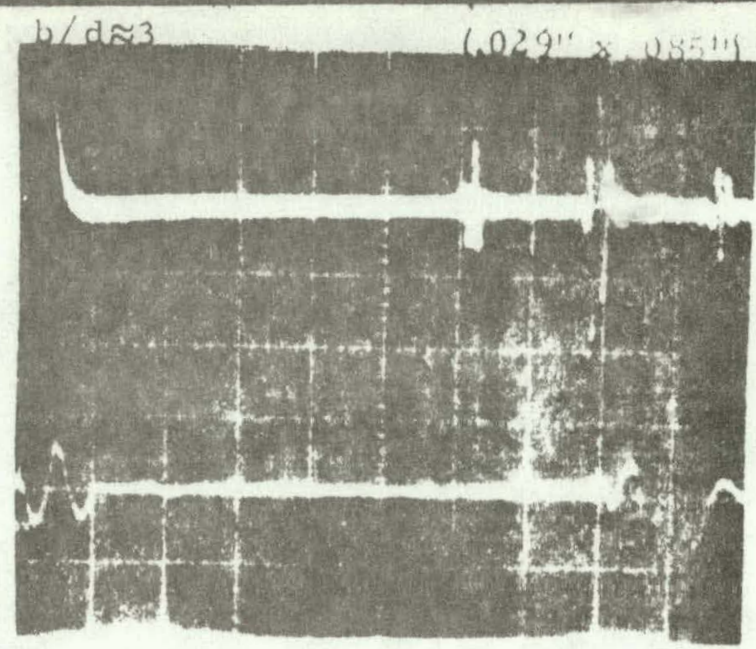

$1011 \mu \mathrm{s} ; 20 \mu \mathrm{s}$

(e)

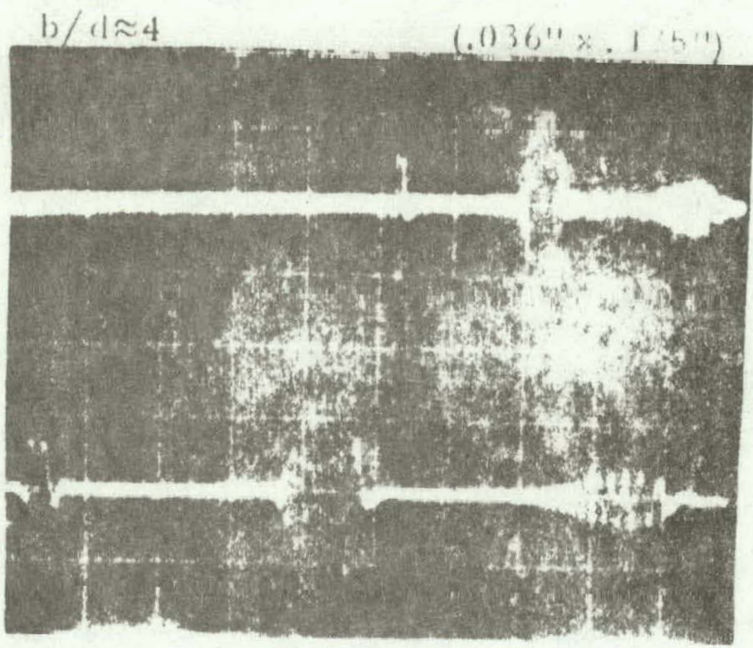

$100 \mu \mathrm{s} ; 50 \mu \mathrm{s}$

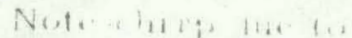

disperstem. He: H

is more pronomare

after serond rumi

trip.

[Comipare wistis it

burst echores un

following page,

Figs. 13f, g]

Fig. 13. Oscillograms for sensors calibrated as in Fig. 10. Conditions for above photos: room temp); dry except as noted in (c). Transducer: torsional mode, straight rod of remendur. 


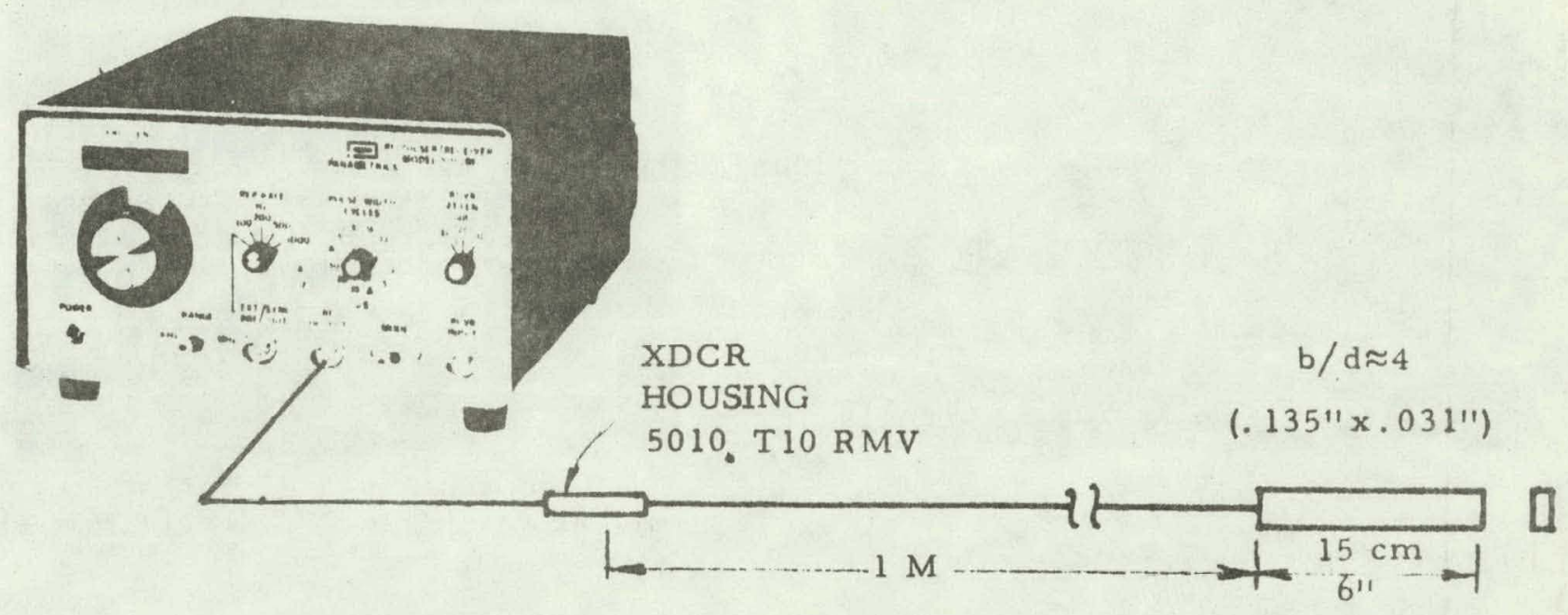

\section{(f)}

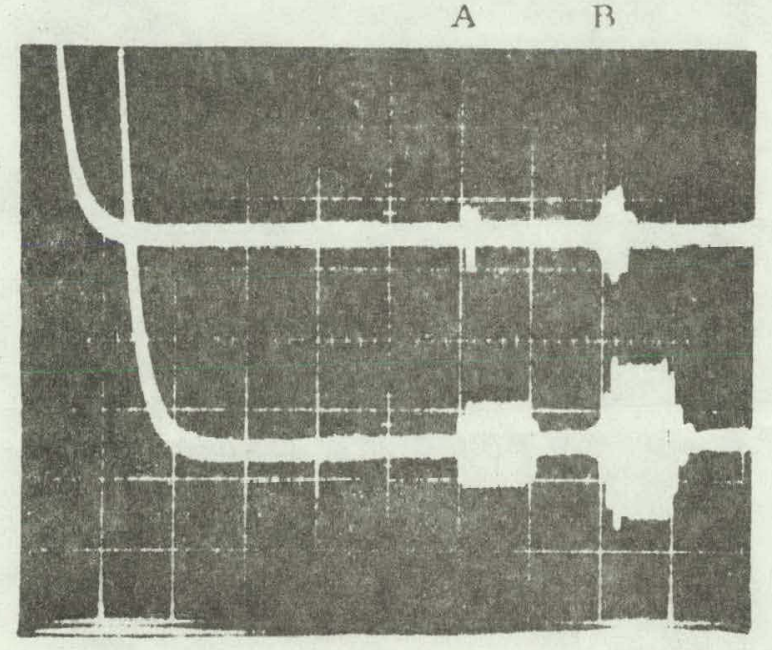

$$
100 \mu \mathrm{s}
$$

Top Trace: Broadband impulse and chirped end echo.

sottom: Narrowband if burst, 10 cycles at $\mathrm{f}_{\mathrm{O}}=100.0 \mathrm{kHz}$.

Observe $t_{0} \approx 200 \mu \mathrm{s}$. (g)

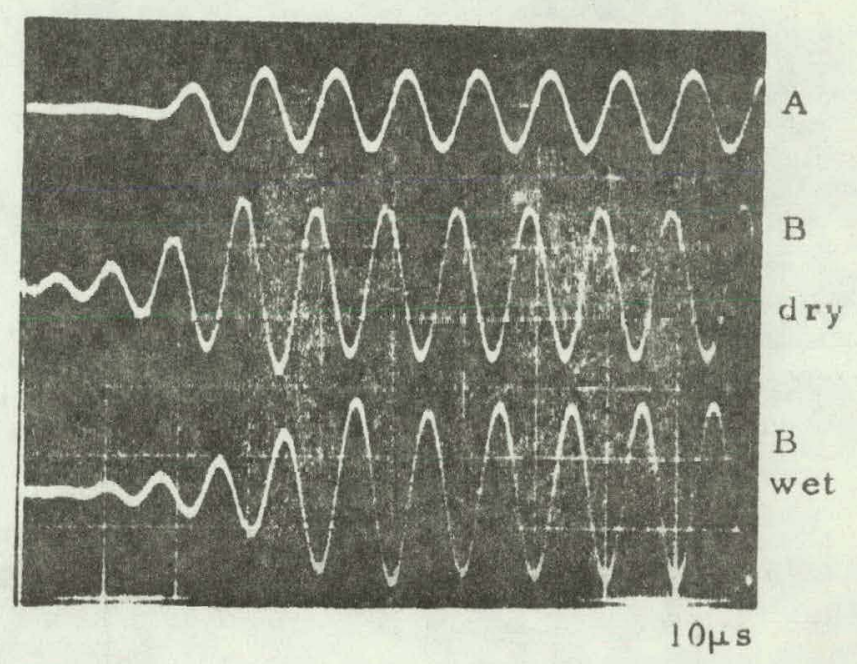

Top Trace: Portion of echo A from silver-brazed joint.

Middle: End echo, dry probe.

Bottom: End echo, probe fully immersed in water. Observe $\Delta t=16 \mu \mathrm{s}$.

ig. 13, cont'd. Comparison of braodband and narrowband echoes in SS sensor of large aspect ratio, b/d $\approx 4$. 
(a)

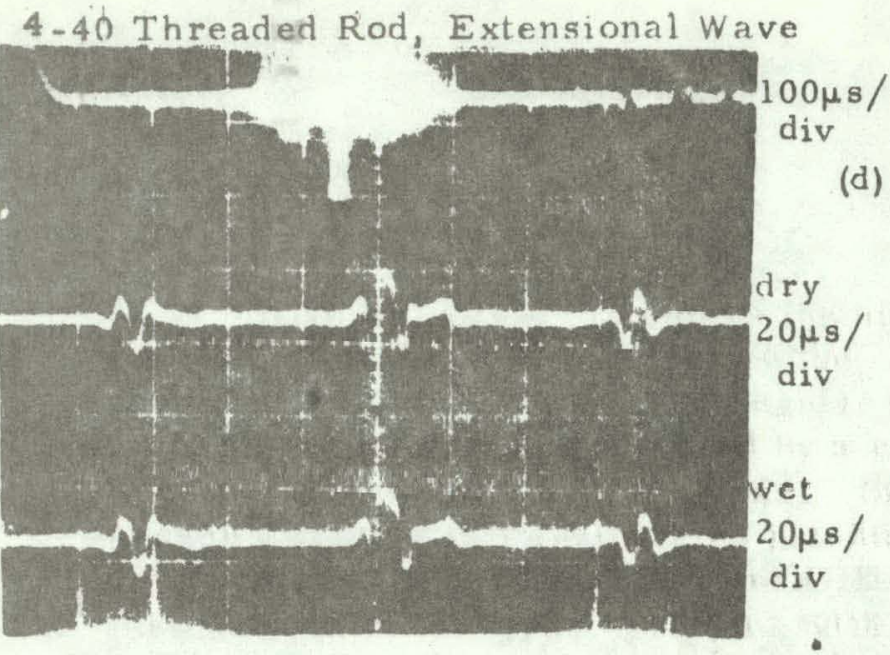

Mid-Squished Tube

(b)

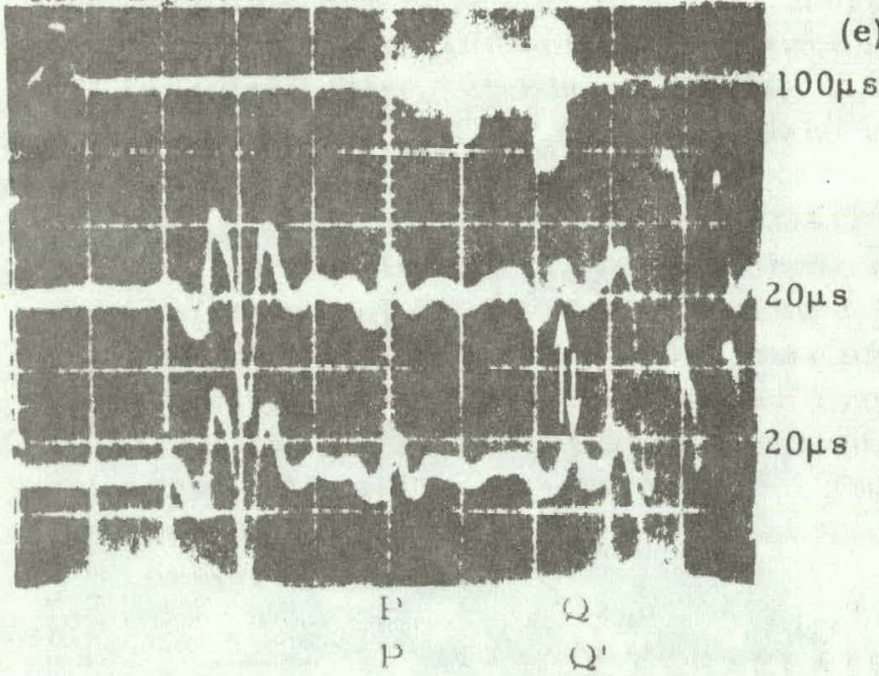

Flexural Wave in $15 \mathrm{~cm}$ (6"') Steel Rule

(c)

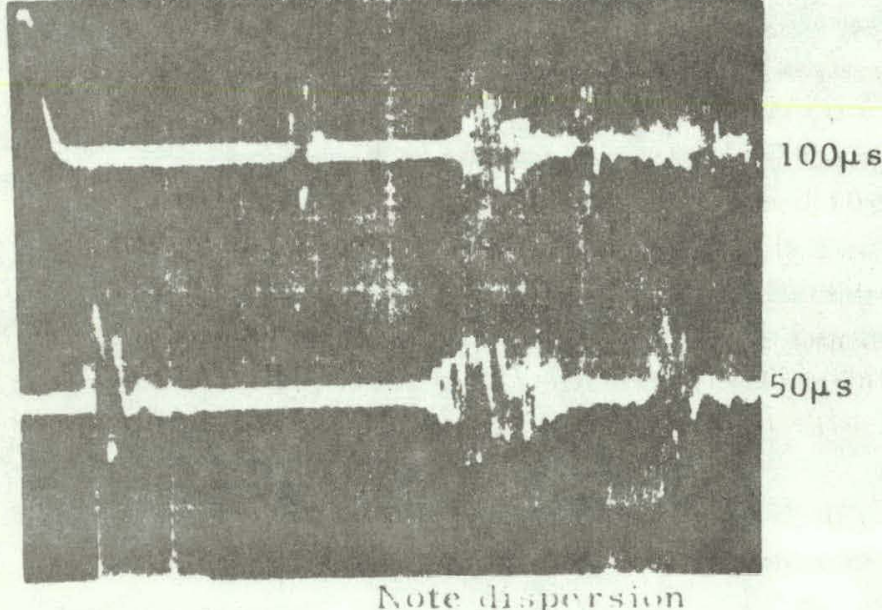

LTR 141-68

$\mathrm{b} / \mathrm{d} \approx 3: 1$

(.024"x. טชs")

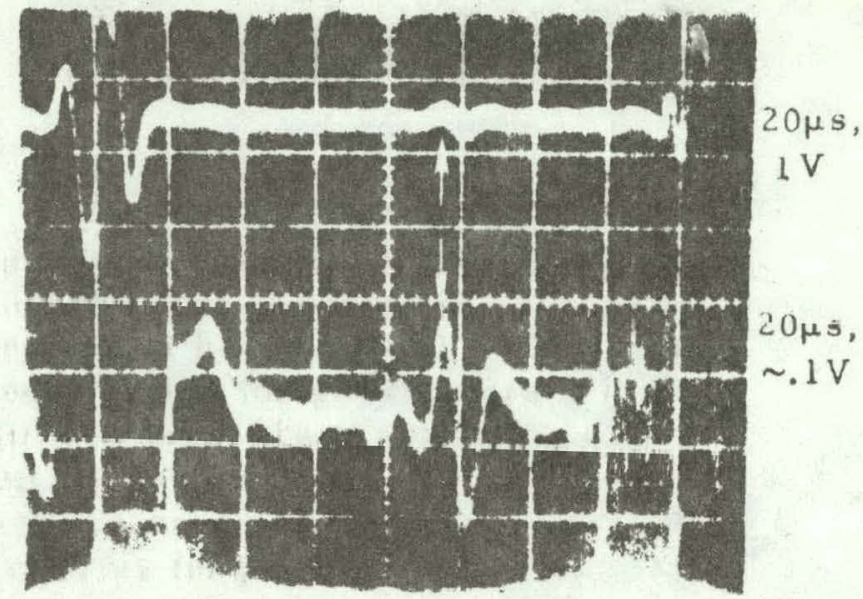

Nearly half-irnmersed. Note small echo al water interface level (a rrows).

e)

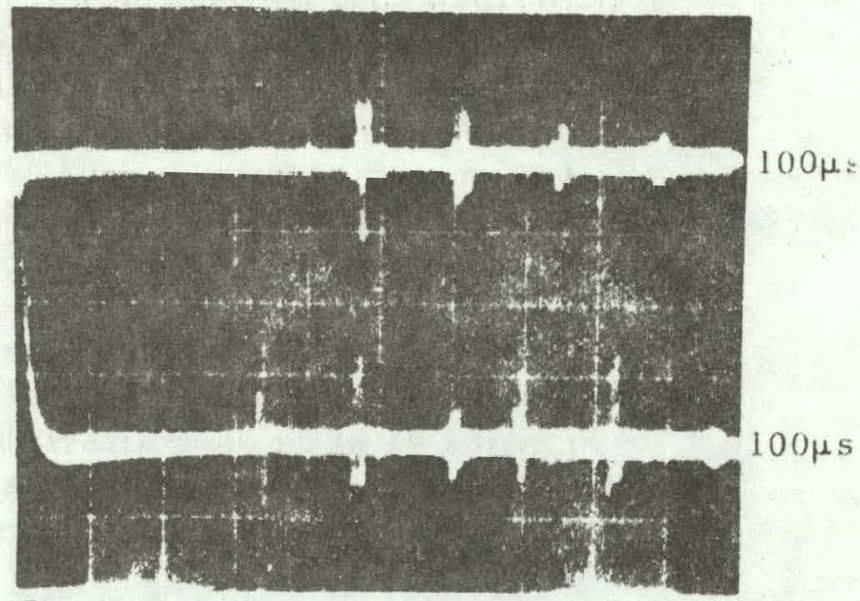

Trip trace: tor sional mode: in strajght line:

Bottom trace: torsional mode in same size sensor but launched by mode conversion from inci dent extensional worte as in Fig. $\angle$ on p. 4 .

Fig. 14. Special cases. (a) shows echoes in $15 \mathrm{~cm}\left(6^{\prime \prime}\right)$ portion of $4-40 \mathrm{SS}$ threaded rod. (b) shows echoes $\mathrm{H}, Q, Q^{\prime}$ from $7.5 \mathrm{~cm}$ (3') sensing portion of SS tube squished in its middle. (c) shows flexural echoes, converted from orthogonally incident extensional waves. (d) shows interface echo. (e) shows equivalence of two different ways of launching torsional wave. 


\section{LTR $141-68$}

(a)

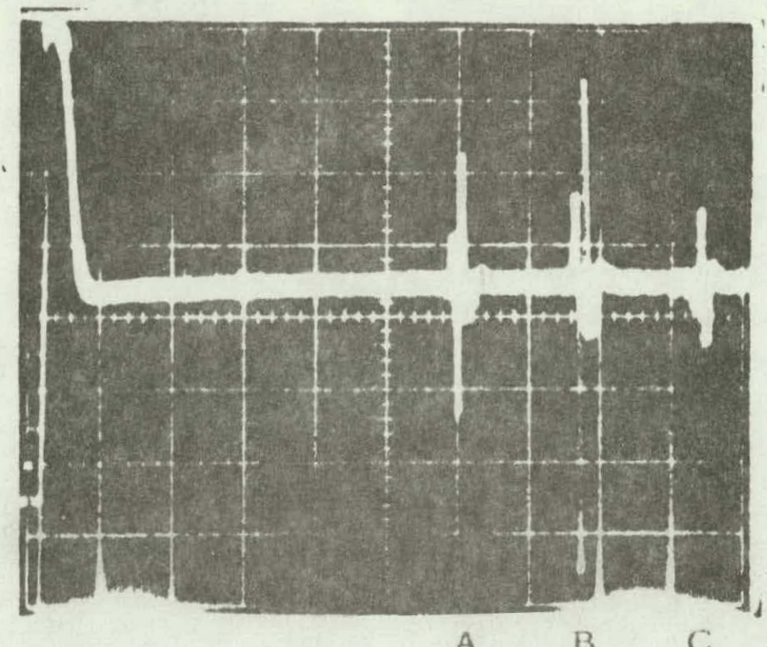

A

(b)

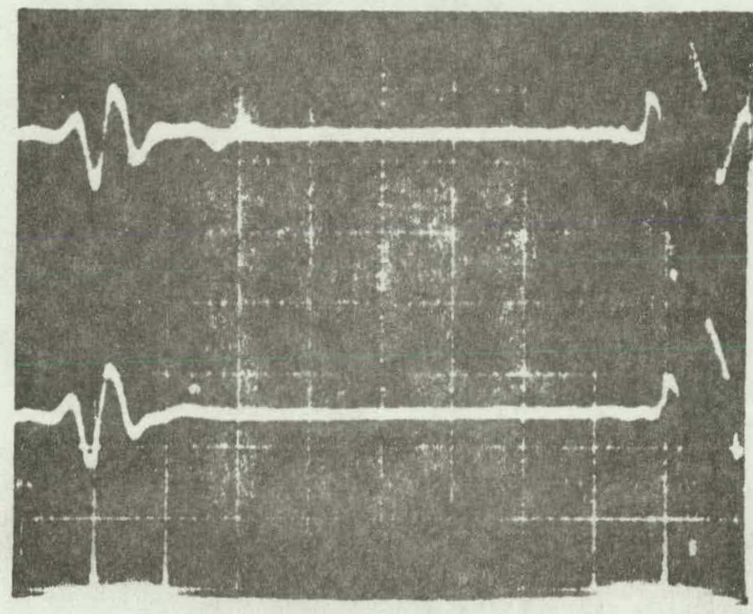

A

13

(c)

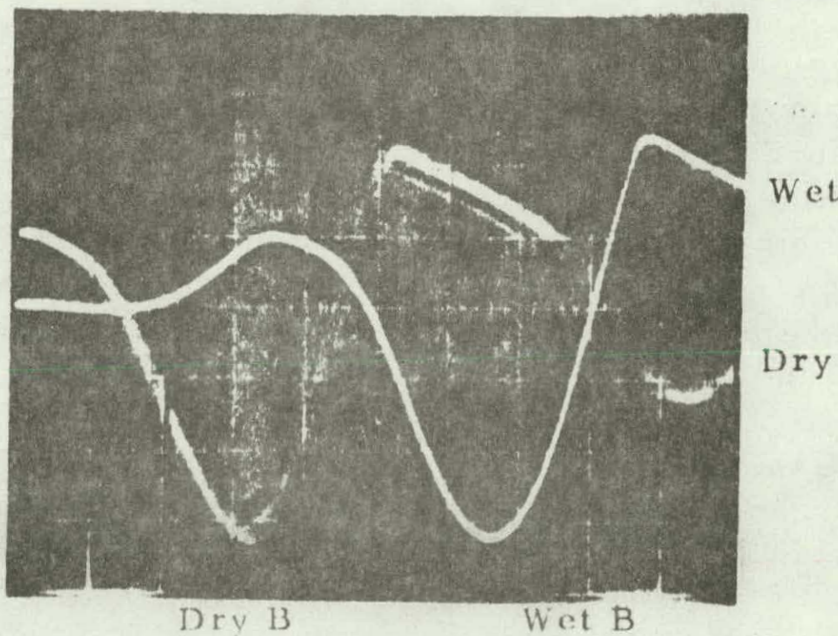

Probe fully immersed.

$100 \mu \mathrm{s} / \mathrm{div}$
Probe dry but nearly at cryogenic temperature of $\mathrm{LN}_{2}$.

$T$ ransit time $=162 \mu \mathrm{s}$.

Probe fully immersed. Note increase in transit time. $20 \mu \mathrm{s} / \mathrm{div}$

Note transit time shift of about $7 \mu \mathrm{s}$

$$
2 \mu \mathrm{s} / \mathrm{div}
$$

Fig. 15. Liquid nitrogen experiments for probe with $b / d \approx 3$. (.029"x $\left..085^{\prime \prime}\right)$. Date of test: Feb. 23, 1977. 
It appears that to achieve the highest accuracy (approaching $0.1 \%$ ) affordable by the slow torsional wave, narrowband $\mathbf{r f}$ bursts or $\mathrm{cw}$ resonance should be combined with a rectangular ribbon of $b / d=5$ to 10 . This combination would also be motivated by a requirement for good accuracy $(\sim 1 \%)$ in a short sensor $\left(<5 \mathrm{~cm}\right.$ or $\left.<2^{\prime \prime}\right)$. Similar narrowband approaches have proven effective in Panametrics patented ultrasonic flowmeter elect ronics developed by N. E. Pedersen and J. E. Bradshaw. Panametrics has built instruments of this type operating with carrier frequencies of $5 \mathrm{MHz}, 1 \mathrm{MHz}$, and most recently, $100 \mathrm{kHz} .23$

Electronics. Given the present requirements on $\rho$ accuracy and sensor length ( 10\% or better in a 2.6" length) it appears that a measurement to $\pm 0.1 \mu \mathrm{s}$ of the time-of-flight between a start pulse and a first received torsional pulse, will be adequate. A straightforward modification of the Panatherm (B) 5010 at EG\&G Idaho can accomplish this measurement.

At a later date, should EG\&G require similar broadband pulse measurements but for many probes, scanned in a multiplexed manner, a variation of Panametrics' patented Transient Temperature Profiler, Panatherm (B) Model 5010B, may provide an optimum solution. The prototype Transient Temperature Profiler, scheduled for delivery in April 1977, has been designed to automatically scan up to 16 zones in each of $M$ probes, where $M \leq 32$. Time of flight resolution is $\pm 0.1 \mu \mathrm{s}$. Scanning rate can be $\sim 5000$ zunes/sccond. (For ardritional technical details, contact W. R. Wade.).

\section{DENSITY - CORRELATED VELOCIMETER}

Correlation flowmeters of numerous types have been described in the literature. These are based on measuring the time for a flow a nomaly to propagate a known distance.

An ultrasonic correlation flowmeter was described in 1973 by Coulthard. 24 Coulthard measured the correlation time between two beams transmitted across nearby pipe diameters. Accuracy of $\sim 5 \%$ was reported The authnr later proposed a noninvasive pulse-echo version of this kind of measurement. 25 Following a suggestion of one of our custunes s at WeEting house, Hanford, the author also proposed two invasive or probe-type ultraennic correlation flowneter designs in this same Ref. 25.

On Jan. 18, 1977 at EG\&G Iclaho, A. E. Arave suggested to the author that the void fraction probes resulting from the present development 
program might also be considered as flow velocimeter (V) probes if operated in a correlation mode. Given the calibration test results, Arave's suggestion may be interpreted in terms of density fluctuation. It appears that if the instantaneous $\bar{\rho}_{i}$ sensed by a probe changes by a few percent, then a correlated $\bar{\rho}_{i}$ would be sensed at a distance $L$ downstream at a time $V / L$ later, where $V=$ average flow velocity in the plane of the probes. However, if $\mathrm{V} \sim 3 \mathrm{~m} / \mathrm{s}(\sim 10 \mathrm{ft} / \mathrm{s})$ a $\mathrm{prf}$ as high as $1000 \mathrm{~Hz}$ may be required in order to not miss $\vec{\rho}_{\text {. fluctuations whose flow-axial }}$ extent is only about $3 \mathrm{~mm}(\sim 1 / 8 ")$. Estimates of the "size" and "lifetime" of $\bar{\rho}_{i}$ fluctuations as a function of $\mathrm{V}$ will be helpful in designing a "double- $\rho$ " probe pair for flow velocimetry according to the above principles, in the event that a development program of this nature appears worthwhile.

It is interesting to contemplate that a pair of ultrasonic noncircular probes could sense the following three parameters:

$$
\begin{aligned}
& \vec{\rho} \quad \text { based on slow torsional sound speed; } \\
& \mathrm{V} \quad \text { based on correlation time between } \rho_{i} \text { fluctuations; } \\
& \mathrm{T} \quad \text { based on temperature-dependence of extensional } \\
& \text { wave speed in either sensor. }
\end{aligned}
$$

\section{CONCIUUSIONS}

The reduced sound speed for extensional, flexural, and most important in the present case, torsional waves, in certain waveguide cross sections, due to immersion in liquids has been explained in terms of the adcled inertia contributed by the density $\rho$ of said liquids. For aspect ratios $b / d$ up to 4 , the slow tor sional wave sensitivity to $\rho$ has been found to increase with b/d and in approximate proportion to the sound specd reductinn shape factor plue a conotant. This meass lhat for a given family of rectangular cross sections of equal area, sensitivity to $\rho$ is approximately proportional to the polar moment of inertia $J$, where $J=\left(b^{3} d+b d^{3}\right) / 12$, plus a constant. It has also been calculated that for this family, the torsional wave impedance remains nearly constant for $b / d$ from 1 to 10 , because the velocily reduction almost exactly offsets the increase in $J$ as $b / d$ increases. An aspect ratio of about 3:1 appears optimum for the present case, conbined with a broadband torsional wave pulse of center frequency $\sim 100 \mathrm{kHz}$. For highesi sensitivity and accuracy, however, it itppears that higher aspect ratios, trom 5 to 10 , and narrowband $r f$ pulses (1) cw technigues, would be preferred. 
Because of geometry and tempcrature constraints, a mode conversion, through transmission measurement is recommended for further development, along with appropriate time intervalometry with \pm 0.1 H resolution.

The calibration work to date, spanning densities from $\sim 0.6$ to over 2, shows that the slow torsional wave yields $\Delta t^{\prime}$ s essentially in direct proportion to the average density sensed by the probe. For a probe length of $15 \mathrm{~cm}$, with $\mathrm{b} / \mathrm{d} \approx 3$, density resolution of $\pm 0.02 \mathrm{~g} / \mathrm{cm}^{3}$ (or $\pm 2 \%$ full scale referred to water at ordinary cơnditions) appears reasonable under laboratory conditions.

It appears that the long-tern objectives discussed at EG\&G Idaho on January 18, 1977 and further defined in Spec. ES-60188 are attainable by a logical continuation of the work reported herein.

\section{ACKNOW LEDGMENT}

J. E. Bradshaw and J. Sieger assisted with the construction and testing of some of the probes that were investigated. R. Morris set up the oven for the high-temperature torsional transducer test. 


\section{REFERENCES}

1. A. E. Arave, IN-1441, "An Ultrasonic Void Fraction Detector Using Compressional Stress Waves in a Wire Helix", (Oct. 1970).

2. A. E. Arave, IN-1442, "An Ultrasonic Liquid Level Detector Using Shear Wave Attenuation in a Bar". (Nov. 1970).

3. A. E. Arave, ANCR-1047, "An Ultrasonic Liquid Level Detector Using Surface Wave Attenuation in a Tobe", (Jan. 1972).

4. S. Fam, "Acoustic Sensing System", U.S. Patent No, 3,540,279 (Nov. 17, 1970).

5: N. S. Ageeva, "Ultrasonic Method for Measuring the Height of the Fluid Level in a Vessel by Means of Flexural Oscillation of a Thin Elastic Strip", Sov. Phys. - Acoustics 6 (1) 116-117 (Jan. -Mar. 1960).

6. N. S. Ageeva, :Ultrasonic Method for Measuring the Height of a Fluid by Means of a Flexurally Oscillating Plale", Reports of the Acoustics Institute of the Academy of Sciences of the USSR [in Russian](1955).

7. E. P. Papadakis, L. C. Lynnworth, D. R. Patch and E. H. Carnevale, "Ultrasonic Thermometry for LMFBR Systems", p. 88, NYO-3906-13 (J une 1972).

8. L. C. Lynnworth, IEEE Trans. Sonics and Ultrasunics SU-22 (2)71-101 (March, 1975).

9. L. C. Lynnworth, ibid, SU-12(2) 37-48 (June 1965).

10. I. C. Lynnworth, "Ultrasonic Probes Using Shear Wave Crystals, Part II - Applications, Proc. Sixth Symposium on Nondestructive Evaluation of Aerospace and Weapons Systems Components and Materials. San Antonio, Texas, 323-361 (April 17-19, 1967). Western Periodicals Co., 13000 Raymer St., N. Hollywood, Calif.; see also K. A. Fowler and L. C. Lynnworth, "Ultrasonic Measurements of Temperature Using Fxtensiond and Torsional Waves", pp. 191-199, in: Proc. Sixth Conf. and Exhibit, Temperature Measurements Society, held April 21, 22 , 1969, Hawthorne, CA.

11. S. Splnner and R. C. Valore. Jr., "Comparison of Theoretical and Empirical Relations Between the Shear Modulus and Torsional Resonance Frequencies for Bars of Rectangular Cross Secion," J. of Res. of the National Bureau of Standards, Research Paper 2861, Vol. 60, No. 5 . (May .1958). 


\section{REFERENCES (cont'd)}

12. L. C. Lynnworth and E. P. Papadakis, (ed.) "Measurement of Elastic Moduli of Materials at Elevated Temperature", Final Report, ONR Contract N00014-73-C-0023 (May 31, 1974).

13. L. C. Lynnworth, Ultrasonics 10 (5) 195-197 (Sept. 1972). Earlier, K. A. Fowler produced torsional waves in a twisted remendur rod.

14. L. C. Lynnworth, D. R. Patch, and E. H. Carnevale, U.S. Patent No. 3, 636, 754 (Jan. 25, 1972); see also: L. C. Lynnworth and D. R. Patch, "New Sensors for Ultrasound: Measuring Temperature Profiles". Materials Research \& Standards, MTRSA, Vol. 10, No. 8, coverpage, 6-11, 40 (Aug. 1970); L. C. Lynnworth and E. H. Carnevale, "Ultrasonic Thermometry Using Pulse Techniques!' presented at the Fifth Symposium on Temperature, Washington, D. C. (June 21-24, 1971), 715-732, Temperature - Its Measurement and Control in Science and Industry. c. Instrument Society of America.

15. L. C. Lynnworth, "Magnetostrictive Ultrasonic Probes", Paper No. 2491, presented at 1976 SESA (Soc. for Exptl. Stress Anal.) Spring Meeting (May 9-14, 1976).

16.- L. C. Lynnworth, "Ultrasonic Reflection from Interfaces Experienciun Static vs Dynamic Friction". Wear 4 l (1) 195-199 (1977).

17. C. F. Brockelsby, J. S. Palfrecman and R. W. Gibson, Ultrasonic Delay Lines, London Ilifie Books Lul. (1963).

18. V. G . Welsby, "The Design of Flexural-Mode Transducers", Ultrasonics International 1975 Conf. Proc., pp. 257-260.

19. Y. Sunthankar, "Directional Ultrasonic Radiators in Air and Water", 1974 Ultrasnnics Symp. Proc., IEEE Cal. \# CHO 896-1SU, pp. 684-687.

20. N. E. Pedersen, L. C. Lynnworth and E. H. Carnevale, NASA CR-112313, "Nonintrusive Dynamic Flowmeter", (R). (June 1973), particularly pages $B-1$ and $B-2$ in its appendix $B$.

21. E. P. Papadakis, "Balanced Resonator for Infrasonic Measurements of Young's Modulus and Darnping in Flexure'", J. of 'Testing and Evaluation, JTEVA, Vol. 1, No. 2, pp. 126-132 (March 1973). 


\section{REFERENCES (cont'd)}

22. R. Thurston, "Tor sional Acoustic Modes in a Clad Rod", IEEE Transactions on Sonics and Ultrasonics, SU-23 (3) 154-161 (May 1977).

23. N. E. Pedersen, L. C. Lynnworth, J. E. Bradshaw and P. R. Morel, "A New Ultrasonic Flowmeter for the Natural Gas Industry", Proc. NBS Flow Measurement Symposium, presented Feb. 23, 1977, NBS Gaithersburg, MD.

24. J. Coulthard, Ultrasonics 11 (2) $83-88$ (March 1973).

25. L. C. Lynnworth, N. E. Pedersen, E. P. Papadakis and J. H. Bradshaw, "Nonintrusive Ultrasonic Measurement of Flow Velocity and Mass Flow Rate", pp. 917-924, FLOW, Its Measurement and Control in Science and Industry. Vol. 1, Rodger B. Dowdell, Ed. in Chief, Part Two, Flow Measuring Devices, Edited by R. E. Wendt, Jr., Presented in part in May, 1971 at Pittsburgh, Pa, at Flow Symp. sponsored by AIP, ASME, ISA and NBS, published by Instrument Society of America (c. 1974). 


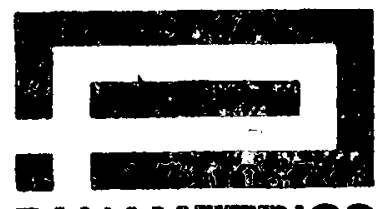

PANAMETRICS

221 CRESCENT STREET, WALTHAM, MASSACHUSETTS 02154/617 899.2719 TELEX: 823408

$$
\text { Reflection Coefficient Probes for }
$$

Measuring Acoustic Impedance of Liquids

\section{INTRODUCTION}

The purpose of this appendix is to describe the design, construction and testing of several types of reflection coefficient probes for measuring the characteristic acoustic impedance $Z$ of liquids. As used here, the term "reflection coefficient probe" includes bulk wave devices in which a received selected echo responds primarily to the energy reflection coefficient $R$ at one or more solid/liquid interfaces.

The need for $Z$-sensing probes stems from scientific and industrial applications such as:

1) Measurement of nass flow rate $\dot{M}$ of liquids such as aircraft fuel. 'T he product of $z$. and the funl Mach number $v / c$ is proportional to $\dot{M}$. The Mach number typically is obtained using either Doppler flowmeters, or upstream/downstream transmission flowneters where the ratio of iransit time differences to sums is proportional to $\mathrm{v} / \mathrm{c}$.

2) Measurement of void fraction ur density $\rho$ of two-phase liquids such as the coolant in nuclear reactors. In a homogeneous fluid, the quotient of $\mathrm{Z}$ divided by $c$, the sound speed in the fluicl, equals $p$. In two-phase fluids where the effective $Z$ sensed by an immersed reflection coefficient probe can be empirically related to average fluid density, some of the designs discussed below may prove useful. 
3) Measurement of liquid level. The liquid's apparent $Z$ is proportional to the depth of immersion of the probe. (Measurements of discrete levels constitute special simpler cases.)

4). General densitometer applications, e.g. , conversion of liquid level data to mas data, conversion of nonacoustic flow velocity data to $\dot{M}$, etc.

The present probes may be thought of as inverses of the classic - impedance tube wherein the unknown impedance of a solid specimen was determined from its reflection coefficient, when it terminated a waterfilled tube. The present probes also bear some resemblance to several carlier ultrasonic reflection probes which have been used to measure the physical properties of liquids. In 1949 Mason etal reported on the use of a trapezoidally-bectioned block of fused silica in which the attenuation of obliquely incidentSII shear waves was interpreted in terms of the viscosity $\eta$ of a viscous liquid specimen contacting the reflecting top surface of the block. $^{1}$ (Some 25 years later, this method still finds use. See, for example, Grigor'evetal., 1974.) $)^{2}$ In 1970 Moore and McSkimin reported on the determination of $\eta$ from measurements of the complex reflection coefficient for shear waves at normal incidence. ${ }^{3}$ The dampening effect of a liquid upon reverberations in a ribbon-like metal sensor (which is not a reflection coefficient probe) is utilized in an instrument introduced in 1968 (Bendix Ultra-Viscoson) to sense the product of density and viscosity, $\eta \rho$. These approaches are illustrated in Ref. 3, Figs. 6b, c and d respectively. Center frequency and band width of calibrated resollant tuning forks have been interpreted in terms of $\eta \rho$ of liquids by Fisch etal. , (1476). 
In 1959 Agecva described the measurement of liquid level by analyzing and demonstrating the retarding effect of water on a flexural wave propagating in an immersed aluminum ribbon. ${ }^{5}$ Fam independently found a sinular effect in his experiments with right-angle sensors (1970). In 1970 and 1972, Arave reported his experiments on the attenuating effects of water at room and elevated temperature $\left(343^{\circ} \mathrm{C}\right)$ on the propagation of surface and shear waves in magnetostrictive probes having sensors of holical form, or circular tube or solid rectangular cross section. ${ }^{7-9}$ In Ref. 5-9,

- the effect of $Z$ on the observed transit time or amplitude was not considered.

In 1974, Papadakis reported on monitoring the moduli of polymers while curing, using reflection cocfficient probes with longitudinal waves in a glass buffer rod, and extensional waves in a metal wire. 10

In 1971 the author introduced a stepped-diameter reflection cocficient probe utilizing normally incident longitudinal waves to sense $Z$ of the liquid adjacent to one end surface of the probe. ${ }^{11}$ Variations of this impedometer probe design, and some test results, were reported in 1975.12 Also in 1975, the author and Chen presentod graphs of energy transmission coefficients at normal and ublique incidence for 20 combinations of liquid/ solid interfaces. ${ }^{13}$ These two 1975 references form the basis of the present. appendix.

Inthis appendix, special simplified cases where $\rho$ (and hence $Z$ ) is proportional to $c$ are not considered. We also omit morc complicated cases where the liquid builds up or leaves deposits on the Eusing ourfacrs, or where absorption losses in the liquid are so large that the well-known lossless equations for reflection coefficients are nut applicable. 


\section{DESIGN OBJECTIVES}

The present study was undertaken to improve the predictability, practicality and other factors relative to the four $Z$ needs listed above. In particular it was desirable to increase the sensitivity and linearity of the probe's response to $Z$; to simplify compensation of changes in probe impedance and liquid temperature; to control the length portion of the probe which is to respond to $Z$, i. e., to obtain either localized or distributed response; to minimize probe cross section and pressure drop for applications

- with flowing liquids; to simplify the design for ease of manufacture and for obtaining reproducible test results.

Naturally no single probe can satisfy all the se objectives, some of which are divergent. Accordingly, the following sections describe several different piezoeletric probe designs. We include a brief discussion of reflection loss at normal and oblique incidence, particularly comparing longitudinal vs shear waves at normal incidence and $45^{\circ}$.

\section{REFLEC'TION COEFFICIENT VS} MODE AND ANGLE OF INCIDENCE

At normal incidence the sound pressure reflection coefficient $R_{p}$ is given by the well-known equations

$$
R_{p}=\left(z_{2}-z_{1}\right) /\left(z_{2}+z_{1}\right)=(r-1) /(r+1)= \pm R^{1 / 2}
$$

where $Z_{1}$ and $Z_{2}$ are the acoustic impedances of the first and second media, and $\mathrm{r}=\mathrm{Z}_{2} / \mathrm{Z}_{1}$. At oblique incidence the corresponding equations for longitudinal and SV shear waves become more complicated. See, for example, Officer ${ }^{14}$, Mayer ${ }^{15}$, Garber ${ }^{16}$, Krautkraemer ${ }^{17}$ or Oliner et al. ${ }^{18}$ The classic mode conversion graphs of Arenberg (1948) ${ }^{19}$ are adso ruluvant to parte of the precent dijeucoion. 
Local $Z$. Consider first, the problem of measuring $Z$ in a limited region such as in the liquid adjacent to a probe along a surface whose axial extent does not exceed about 1 probe diameter. The simplest ultrasonic approach to this problem would appear to be the use of $L$ waves at normal incidence, to measure $Z$ at the end of the probe. Analysis of (1), however, immediately shows that unless $Z$ probe is comparable to $Z$ of the adjacent liquid, $R_{p}$ will be relatively insensitive to $Z$. Except for plastics (which suffer from temperature effects), and graphites and chalcogenide or a few other special glasscs (which are fragile) it is difficult to find a probe material whose $L$ wave impedance is within an order of magnitude of common liquids. Nevertheless, using a fused silica probe, $Z$ measurements have been obtained with a short-term precision of about $1 \%$ using a prototype $10 \mathrm{MHz}$ rf burst peak detector with $0.01 \mathrm{~dB}$ resolution developed mainly by Matec's B. Chick and G. Peterson. ${ }^{12}$ Figure 1 shows that only minor improvement in sensitivity is possible using SV waves at, say, a $45^{\circ}$ angle of incidence in the solid fused silica. Figure 2 shows how much this problem is aggravated by probes of higher impedances.

To obtain a significant increase in scnsitivity, by a factor of $\mathrm{N}$, consider the possibilities of reflecting the incident wave $N$ times at a single wetted face or at a few neighboring wetted faces. This idea led to a sequence of probe designs some of which are illustrated in Fig. 3, and whose characteristics will be described later. But first we return to Fig. 2 to note a few points.

Figure $2 \mathrm{~b}$ is a graph of reflection loss $R_{I}$, vs impedance, for waterimmersed probes, and with the angle of $S V$ incidence within the probe being $45^{\circ}$, and $L$-wave incidence, $0^{\circ}$. The reflection $l o s s$ is defined as

$$
R_{L}=10 \log \left[1 /\left(1-T_{E}\right)\right] \mathrm{dB}=10 \log (1 / R)
$$

where $T_{E}$ is the energy transmission coefficient and $R$ is the energy reflection cuefficient. The values for $R_{L}$ plotted in Fig. $2 b$ were obtained from a number of plots similar to Fig. 1 and contained in 
Ref. 13. In principle, one cannot expect the shear wave points in Fig. 2b to fall on a simple curve, because at oblique incidence $R_{L}$ is not a function of probe impedance alone. ${ }^{13-17}$ However, a a practical matter, it is evident that for ordinary water-immersed elastic materials, $R_{L}$ for $S V$ at $45^{\circ}$ is mainly a function of probe impedance. $R_{L}$ for $L$ waves at $0^{\circ}$ is of course purely a function of probe impedance, for a given $Z$ in the adjacent liquid.

In Ref. 13 it is noted that $T_{E}$ generally can be larger for oblique $S V$ than for $L$ at normal incidence. This may be understood by noting that the shear wave impedance is typically about half the $L$ wave impedance for a given elastic solid. Figure $2 b$ illustrates this point, and also shows another interesting result. The values of $R_{L}$ for $L$ waves at normal incidence, and for SV waves at $45^{\circ}$, all lie approximately on one simple curve. To the extent that this approximation is valid, the task of estimating $R^{\prime} s$ and $\mathrm{T}_{E}{ }^{\prime} \mathrm{s}$ for $\mathrm{SV}$ waves at $45^{\circ}$ rcduces to the use of (1). Furthermore, since $R$ and $T_{E}$ usually do not vary much between $\sim 40$ and $\sim 70^{\circ}$. (1) may be used, to a somewhat coarser approximation for estimating $R$ and $T_{E}$ between these angles too.

We shall immediately dismiss the use of incident $L$ waves (Fig. $3 c$ ) due to the spurious mode conversions along the probe perimeter as well as at the beveled end. 19 Instead we shall consider only shear waves propagating axially or zig-zagging to a local region where sensitivity to $Z$ is enhanced by multiple interaction with the liquid at the wetted face(s). For simplicity of explanation, in Fig. 3 we generally limit the oblique angle 8 to $45^{\circ}$, although angles between a fow degrees of either critical angle are potentially usable.

\footnotetext{
"Measurement of local $Z$ at the end of a buffer rod may be interpreted without undue difficulty, using any $L$-wave echo which has reflected off the end only once, provided only the tip of the buffer is wetted. One application for such a measurement is the determination of the ratio of sound speed in a probe and a liquid, when both are of known densities, e.g. , a fused silica probe and a molten metal. To illustrate this method, one may use a fused silica rod such as shown at the top of the photograph, Fig. 4 . Immersing the tip in water reduces the end teho anplitude about $20 \%$.
} 
Distributed Z. One way to increase $N$, and yet be consistent with the needs inherent in some applications of the listed types (1) to (4), is to sense $Z$ along one or more extended surfaces. For example, note that turning the "local" probe of Fig. 3d end-for-end results in the distributed design of Fig. 3e.

The number of reflections $\mathrm{N}_{-} 20^{\circ} \mathrm{dB}$ required to attenuate a wave $20 \mathrm{~dB}$ is simply $20 / \mathrm{R}_{L}$. Table 1 lists typical values of $R_{L}$ and $20 / R_{L}$ as a function of the impedance ratio $r$, calculated from (1) for normal

- incidence. If we define the acoustic contrast $\mathrm{r}_{\mathrm{sl}}$ to be the ratio of $\mathrm{Z}_{\text {solid }}$ $Z_{\text {liquid, }}$ we draw the conclusion upon comparing columns 2 and 4 in Table 1 . that $\mathrm{N}_{-20 \mathrm{~dB}}$ roughly equals the acoustic contrast:

$$
N_{-20 \mathrm{~dB}} \approx \mathbf{r}_{\mathrm{sl}}
$$

For acoustic contrast between 1.1 and 50, rounding off $r_{s l}$ to the nearest integer gives a reasonably good estimate of the number of normal reflections necessary to attenuate a plane wave by $20 \mathrm{~dB}$. For estimating purposes, (3) may be used for normal incidence provided the differences apparent from Table $I$ are tolerable, and for SV at $\sim 45^{\circ}$ if somewhat larger differences are tolerable.

Distributed But Bounded. This is an intermediate case. Suitably placed ramps or acoustic shields may be used as in Figs. $3 \mathrm{j}, \mathrm{k}$ to limit the wetted zone of interaction to the effective sensor length $\mathrm{L}_{\mathrm{S}}$. 
Table 1. Reflection losa $R_{L}$ at normal incidence $v s r$, and $20 / R_{L}$ vs $r_{8 \ell}$.

\begin{tabular}{|c|c|c|c|c|}
\hline $\mathbf{r}$ & $r_{s l}$ & $R_{L}, d B$ & $20 / R_{L}$ & $\frac{20 / R_{L}-r_{\text {Ol }}}{20 / R_{L}} \times 100 \%$ \\
\hline 0 & - & 0 & - & - \\
\hline .02 & 50 & 0.35 & 57.56 & 13 \\
\hline .03 & 33 & 0.53 & 37.98 & 13 \\
\hline .05 & 20 & 0.87 & 23.01 & 13 \\
\hline .1 & 10 & 1. 74 & 11.49 & 13 \\
\hline .2 & 5.0 & 3.52 & 5.68 & 12 \\
\hline .3 & 3.3 & 5.38 & 3. 72 & 10 \\
\hline .4 & 2.5 & 7. 36 & 2.72 & 8 \\
\hline .5 & 2.0 & 9.54 & 2. 10 & 5 \\
\hline .6 & 1.7 & 12.04 & 1.66 & -1 \\
\hline .7 & 1.4 & 15.07 & 1. 33 & -1 \\
\hline .8 & 1. 3 & 19.09 & 1.05 & -19 \\
\hline .9 & 1.1 & 25.60 & .78 & -42 \\
\hline 1. 0 & 1.0 & - & 0 & - \\
\hline
\end{tabular}




\section{REFERENCES}

1. W. P. Mason etal., Phys. Rev. 75936 (1949).

2. S. B. Grigor'ev, I. G. Mikhailov and O. Sh. Khakimov, "Measuret ment of the Shear Viscoelastic Properties of Certain Liquids". Sov! Phys. - Acoust. 20 (1) 26-28 (July-Aug. 1974). Two trapezoidal blocks were used, one a reference channel, one a working channel.

3. R. S. Moore and H. J. McSkimin, pp. 170-173, in: W. P. Mason and R. N. Thurston, Physical Acoustics, Principles and Methods, Vol. VI (1970).

4. M. R. Fisch, R. P. Moeller and E. F. Carome, "Improved Acoustic Viscosimeter Technique", J. Acoust. Soc. Amer. 60 (3) 623-625 (Sept. 1976).

5. N. S. Ageeva, "Ultrasonic Method for Measuring the Height of the Fluid Level in a Vessel by Means of Flexural Oscillation of a Thin Elastic Strip", Sov. Phys. - Acoustics 6 (1) 116-117(Jan.-Mar. 1960). See also: N. S. Ageeva, "Ultrasonic Method for Measuring the Height of a Fluid Level by Means of a Flexurally Oscillating Plate", Reports of the Acoustics Institute of the Academy of Sciences of the USSR [in Rusian] (1955).

6. S. S. Fam, US Patent No. 3,540, 279 (Nov. 17, 1970).

7. A. E. Arave, IN-1441, "An Ultrasonic Vold Fraction Detector Using Compressional Stress Waves in a Wire Helix". (Oct. 1970).

8. A. E. Arave, IN-1442, "An Ultrasonic Liquid Level Detector Using Shear Wave Attenuation in a Bar", (Nov. 1970).

9. A. E. Arave, ANCR-1047, "Ultrasonic Jiquid Detector Using Surface Wave Attenuation in a Tube", (Jan. 1972).

10, E. P. Papadakis, "Monitoring the Moduli of Polymers with Ultrasound", J. Appl. Phys. 45 (3) 1218-1222 (March 1974).

11. L. C. Lyunworth and N. E. Pedersen, "Ultrasonic Mass Flowmeter," Ultrasonics Symp. Proc., 87-91 (1972), IEEE Cat. \#72 CHO 708-8 SU; presented at Pittsburgh, PA at ASME, AIP, NBS and ISA Joint Sump. on Flow-Its Measurement and Control in Sci. and Industry (May 1971). 


\section{REFERENCES (cont' d)}

12. N. E. Pedersen, L. C. Lynnworth and J. E. Bradshaw, "Improved Ultrasonic Fuel Mass Flowmeter for Army Alrcraft Engine Diagnostics", USAAMRDI, TR-75-8 (June 1975).

13. L. C. Lynnworth and J. N. C. Chen, "Energy Transmission Coefficients at Liquid/Solid Interfaces", Ultrasonic Symp. Proc. 57.5-578 (1975), IEEE Cat. \#CHO 994-4 SU.

14. C. B. Officer, Introduction to the Theory of Sound Transmission, pp. 76-81, McGraw-Hill, N.Y. (1958).

15. W. G. Mayer, "Reflection and Refraction of Mechanical Waves at Solid-Liquid Boundaries," J. Appl. Phys. 34 (4) Part 1, 909-911. (April 1963).

16. J. W . Garber, "Ultrasonic Interactions at Liquid/Solid Boundaries", Union Carbide Rpt. No. Y-1540 (July 1, 1966).

17. J. and H. Krautkraemer, Ultrasonic Testing of Materials, pp. 29-37, 479, Springer-Verlag New York (1969).

18. A. A. Oliner etal., Proc. IEEE 60 (12) 1503-1512 and 1513-1518 (Dec. 1972). See also: A. A. Oliner, H. L. Bertoni and R. C. M. Li, "A Microwave Network Formalism for Acoustic Waves in Isotropic Media," Proc. IEEE 60 (12) 1503-1512 (Dec. 1972); A. A. Oliner, R. C. M. Li and H. L. Bertoni, Catalog of Acoustic Equivalent Networks for Planar Interfaces, ibid. 1513-1518.

19. D. I. Arenberg, "Ultrasonic Solid Delay Lines", J. Acoust. Soc. Amer. 20 (1) 1-26 (Jan. 1948). 


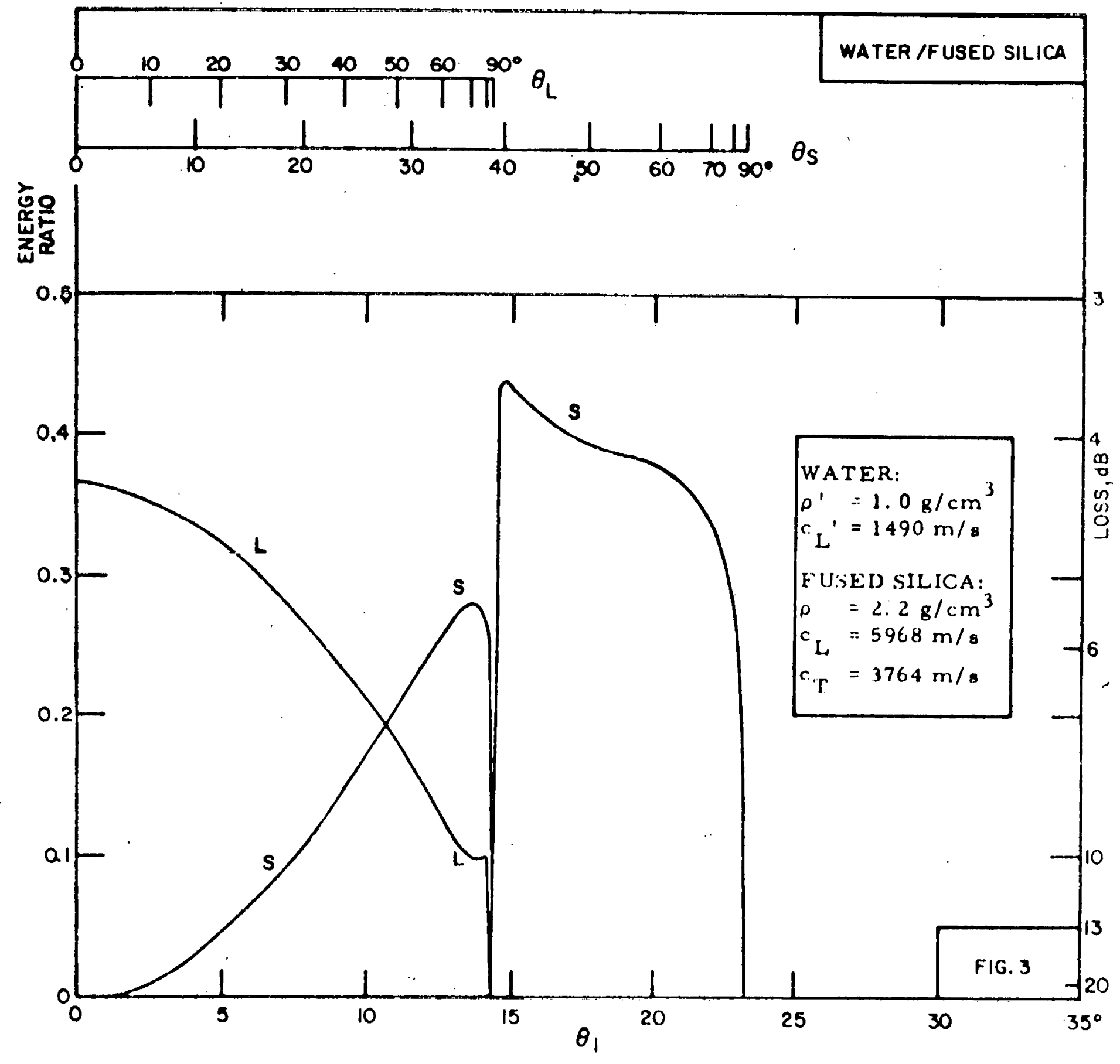

Fig. 1. Energy transmission coefficients for a water/fused silica interface, with incidence from water at $\theta_{i}$. Scales at top, $\theta_{L}, \theta_{S^{\prime}}$ are the refracted angles for $L$ and $S$ modes. 

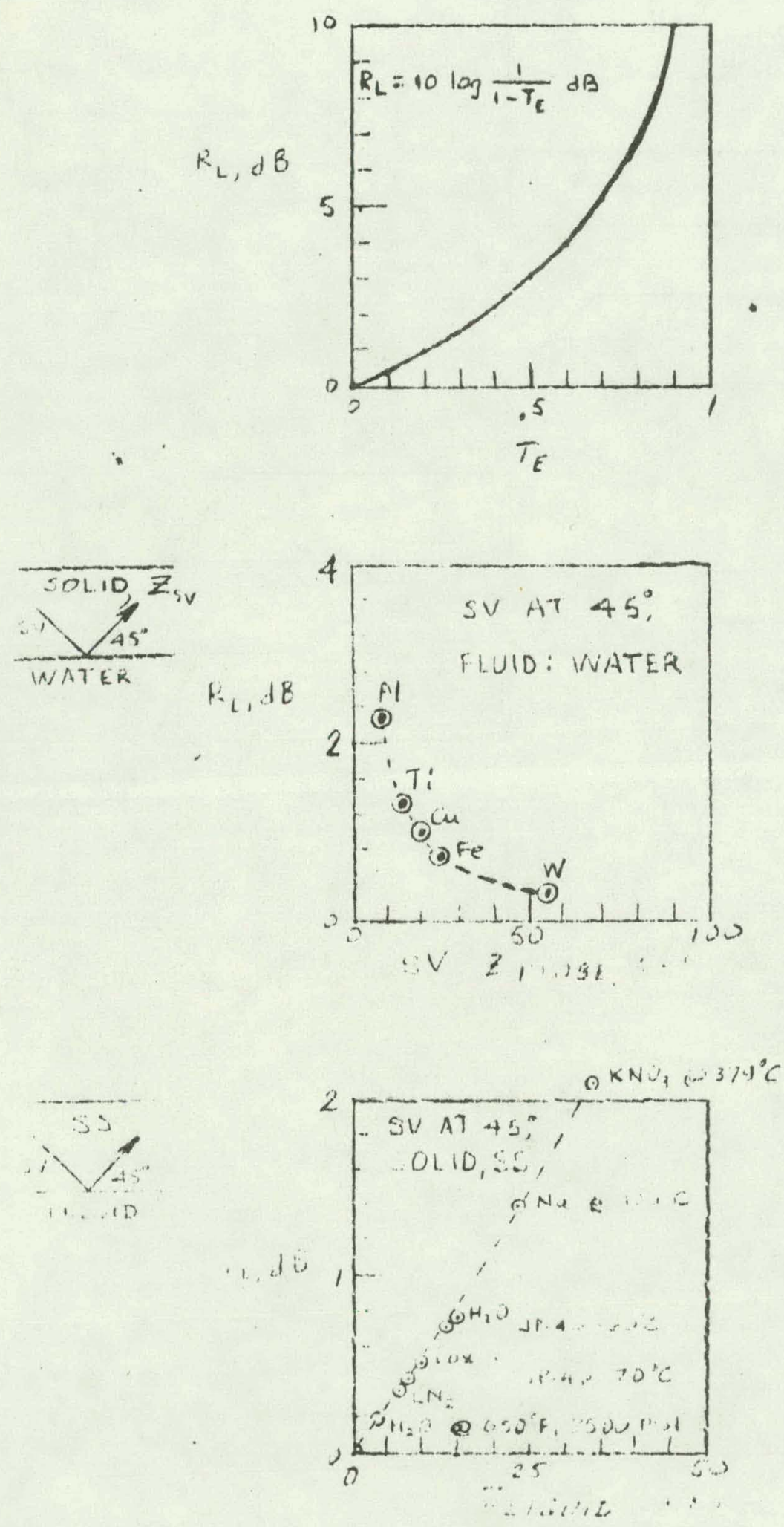

Fig. 2a. $R_{\text {, }}$ v $T_{F}$. Curve show that for amall values of $T_{E}, R_{L}$ in $d B$ ie nearly proportional to $T_{E}$. For a given well-mismatched sensor, $T_{E}$ can be nearly proportional to nuid impedance. In these cases, $R_{\text {L }}$ will be nearly proportional to fluid impedance, for small $T_{E}$.

Fig. 2b. $R_{I}$ vs probe impedance for SV waves. For typical metallic probes (posaibly clad) $R_{L}$ ranges from $\sim 0.4$ to $\sim 2.3$ dB per bounce, for $45^{\circ}$ angle of incidence and water as the adjacent fluid.

Fig. 2c. $R_{\text {L }}$ vs liquid impedance, for a $45^{\circ} \mathrm{SS}$ probe. From room temperature to $650^{\circ} \mathrm{F}\left(343^{\circ} \mathrm{C}\right)$ water's impedance drops by a factur of nearly 4. (See ANC-A-335.) Graph predicts corresponding $R_{1}$. drop from $\sim 0.8$ to $\sim 0.2 \mathrm{~dB}$ per SV bounce at $45^{\circ}$ in SS sensor.

Fig. 2. Reflection loss (dB per bounce) as function of $T_{E}, Z_{\text {probe }}$ and $Z_{\text {liquid }}$ Curves suih as these enable one to calculate the expected performance of immersed sensors of selected designs. 
$101+1 ; 1$

LTR 141-68

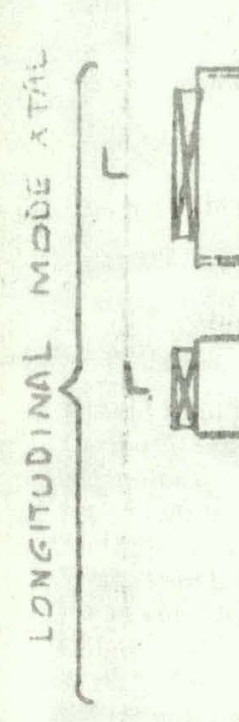

(a)
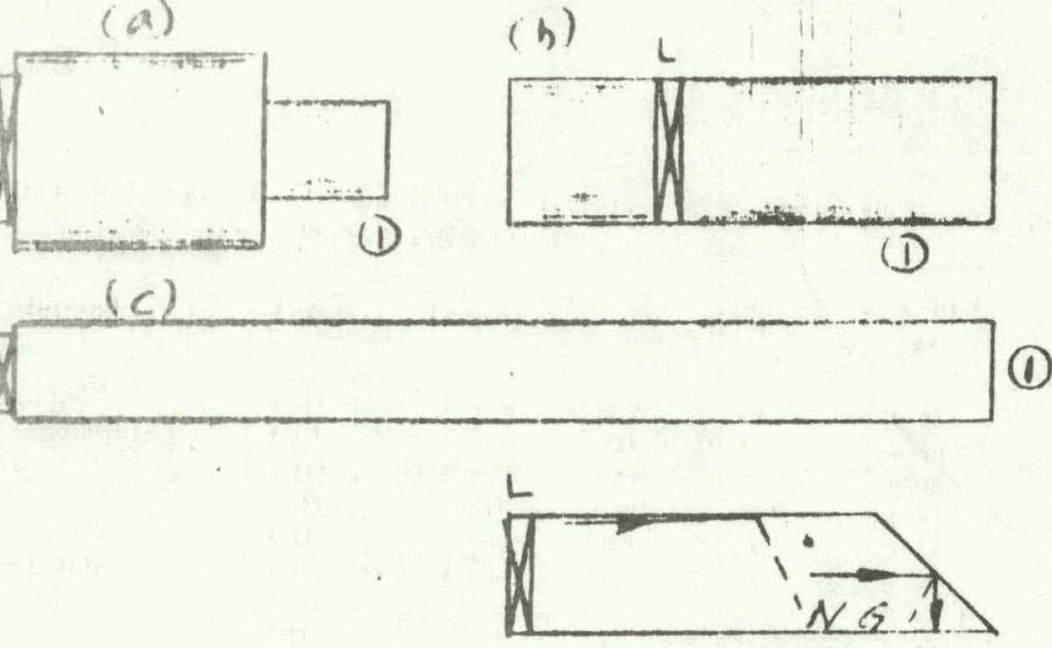

BUT:

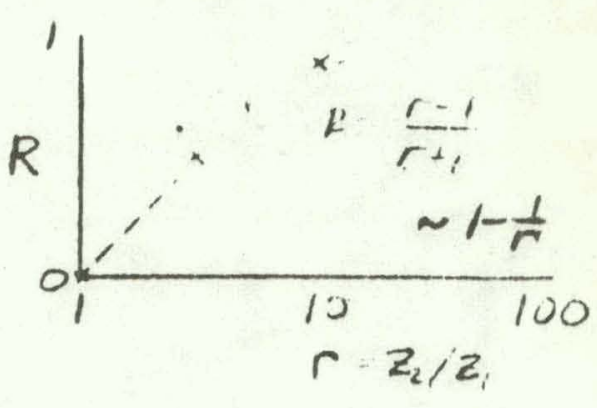

LOCAL

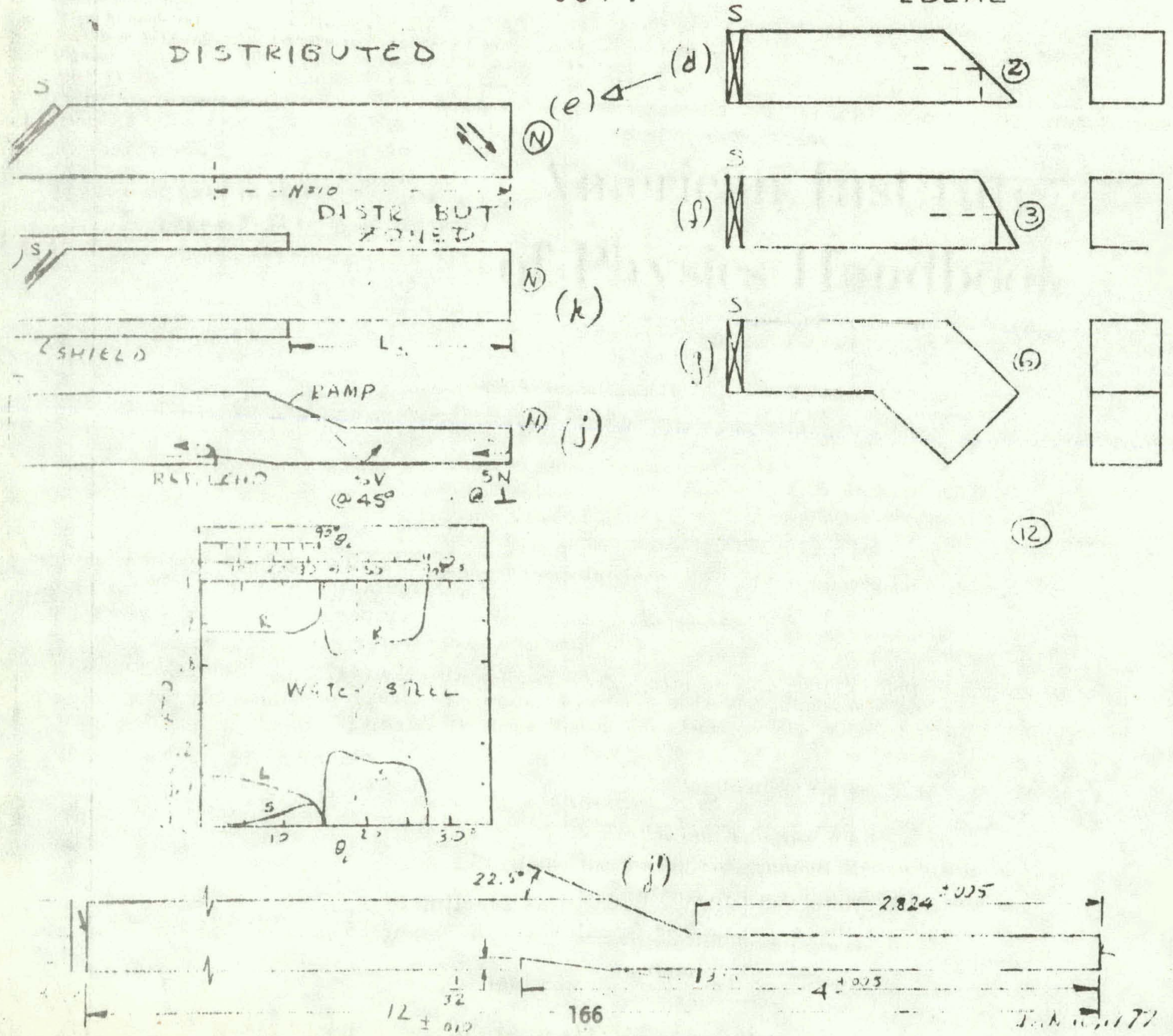



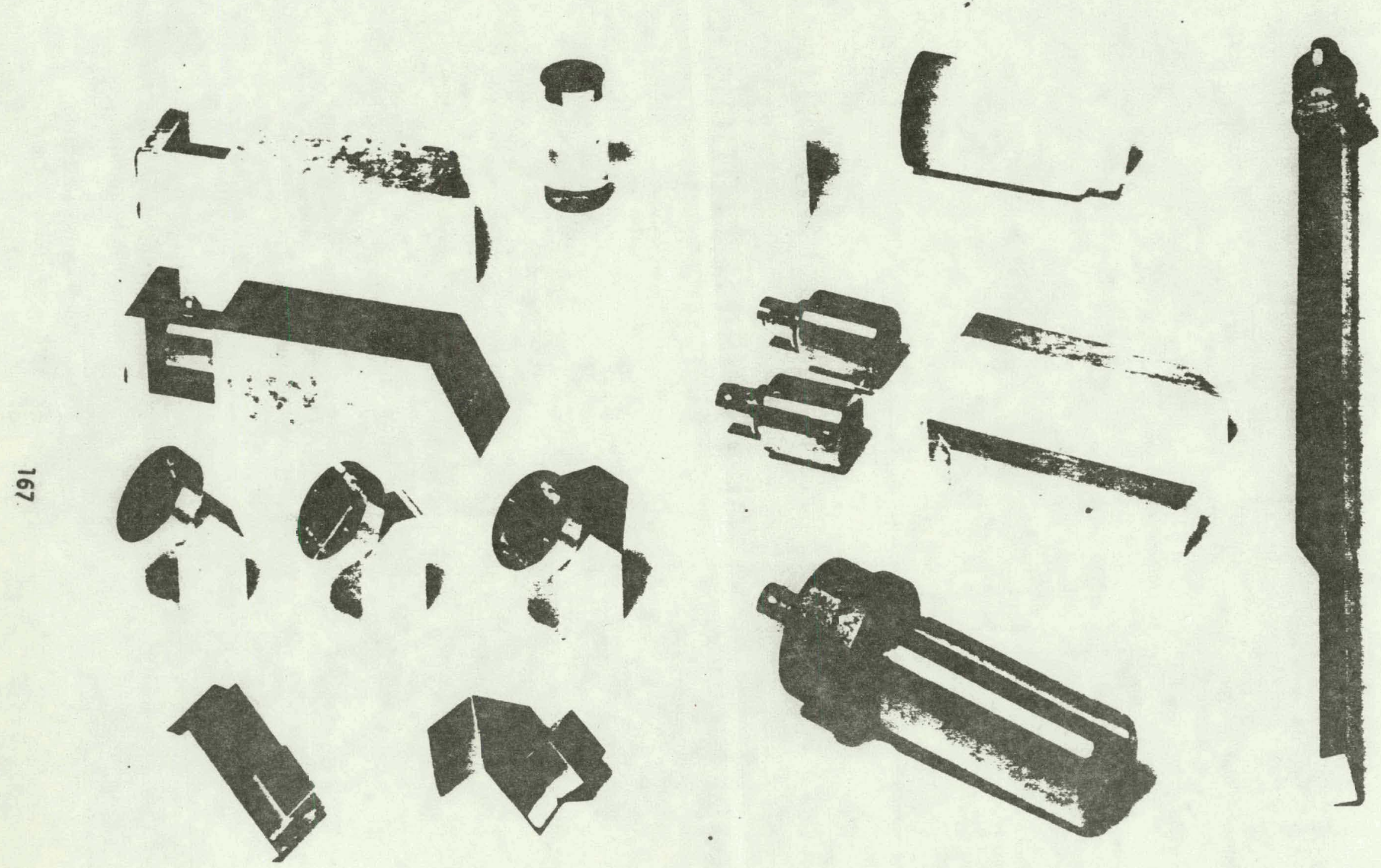

Fig. 4. Photograph of probes responsive locally or in a distributed manner to $\mathrm{Z}$ of adjacent fluid. Probes shown are fabricated of relatively low impedance elastic solids such as fused silica, aluminum and titanium. 


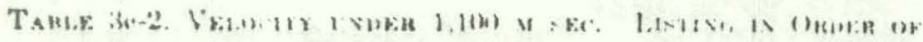

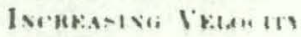

\begin{tabular}{|c|c|c|c|c|c|}
\hline Material & Finmuln & l)ensily & $\begin{array}{c}\text { Vilanits. } \\
\text { mines }\end{array}$ & 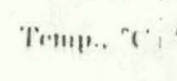 & $\begin{array}{c}p^{0} \times 10^{-6} \\
\operatorname{cg}^{8}\end{array}$ \\
\hline Fthyl hromill, & & & 840 & & \\
\hline $\begin{array}{l}\text { Ethyl hrominle } \\
\text { carluon tetratobloride...... }\end{array}$ & $\begin{array}{l}\mathrm{C}_{2} \mathrm{I}_{b} \mathrm{Hr} \\
\mathrm{C} \mathrm{Cl}_{4}\end{array}$ & $\begin{array}{l}112 x \\
15 ! 46\end{array}$ & $\begin{array}{l}8 \div 12 \\
428.5\end{array}$ & $\begin{array}{l}28 \\
213\end{array}$ & $\begin{array}{l}1.27 \\
1.48\end{array}$ \\
\hline Isronuform . . $\quad \ldots \ldots \ldots$ & $(\mathrm{C} / \mathrm{Br} \mathrm{r}$ & $2 \times s !$ & $(12 !)$ & $2: 3.5$ & 2. (is \\
\hline Hutyl ioutide $(n) \ldots \ldots \ldots$ & $(;, 11,1$ & 1.116 & 9.54 & 28 & 155 \\
\hline Mothyleme bromide. ...... & $\mathrm{CH}: \mathrm{I}_{2} \mathrm{r}_{3}$ & $24.5: 3$ & 17 & - 21 & 238 \\
\hline Metliglesse intiele......... & CH:I, & 3.323 & 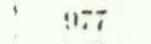 & 21 & 325 \\
\hline Butyl chloride. . . . . . & $C, 11, C 7$ & $11 \times 1$ & $4 \times, 5$ & 25 & 1) $\times 3$ \\
\hline Chloroform . . . . . . . & C $111 \mathrm{C}^{\mathrm{s}}$ & $1+47$ & $1 .|M|)$ & $2,1.5$ & $14 !$ \\
\hline Acetyl tetralirmuile...... & $\mathrm{C}_{2} \mathrm{H}_{2} \mathrm{H}_{\mathrm{r}}$ & $2 \div 4 i 2$ & $1.1 \times 17$ & $2 x$ & 298 \\
\hline Ethylene brumide..... & $\mathrm{C}_{2} \mathrm{H}, \mathrm{BH} \mathrm{r}_{2}$ & 2.178 & 1.1114 & 21 & 2.21 \\
\hline Butyl bromiile $(n) \ldots .$. & $C, 11,13 r$ & 1272 & $1,111 \mathrm{i}$ & $2 x$ & $12 !$ \\
\hline Aretylene dichloride... & $\mathrm{C}, \mathrm{H}, \mathrm{Cl}$ & 1. $2 t i 2$ & 1.1125 & 25 & 1. 29 \\
\hline Puntane. . . . . . . & $\left(, 11_{18}\right.$ & 0.632 & $1,15,02$ & 18 & o lif \\
\hline Allyl , hloristn ........ & $\mathrm{C}, \mathrm{H}, \mathrm{Cl}$ & ก $1: 37$ & $1.08 x$ & 28 & 1,112 \\
\hline
\end{tabular}

Source of data in this appendix: pages $3-71$ to $3-73$ in:

\section{American Institute of Physics Handbook}

\section{Section liditors}

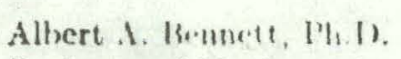

Profenon of Mathemation

llow lis liver:ity.

Bruce II. Billings, I'h.1),

Vice President

Bairi-1tumir, Inc.

1). F. Bhril, Ph. I).

Chiof, Physics Researeh

Department

U.S. Naval (roluance laberatory,

White Oak, Mft

(i. II. Dieke, J'h. I)

Chairman, Department of Physies

The Johns Itopkins I niversity
Fhyd A. Firmene, thot).

Eilitur, Thes b. numbal of tim

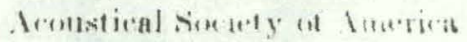

F. . . 1). Kurie, $(\mathrm{h}, \mathrm{l})$

Technical Directerr

L.s. Navy thentrouic laturatury

R. Bruer Limb as , Pis 1)

bean of the firmel tate sithesl

B.,wn Linis.resity

Warh W. Kenait ky, I'h.l.

Prote:sior of Pliy aires

The City College of Niw Furt.

\section{Comrdinating Eddilor}

Dwighte E. (iray, Ph.l)

Program Director for (iovernment Research Information National Science Foundation

Mefiraw

Vew lork Toronto London


3 i:

Arit- in:

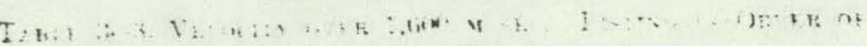
(1). in: $1+1+11$ :

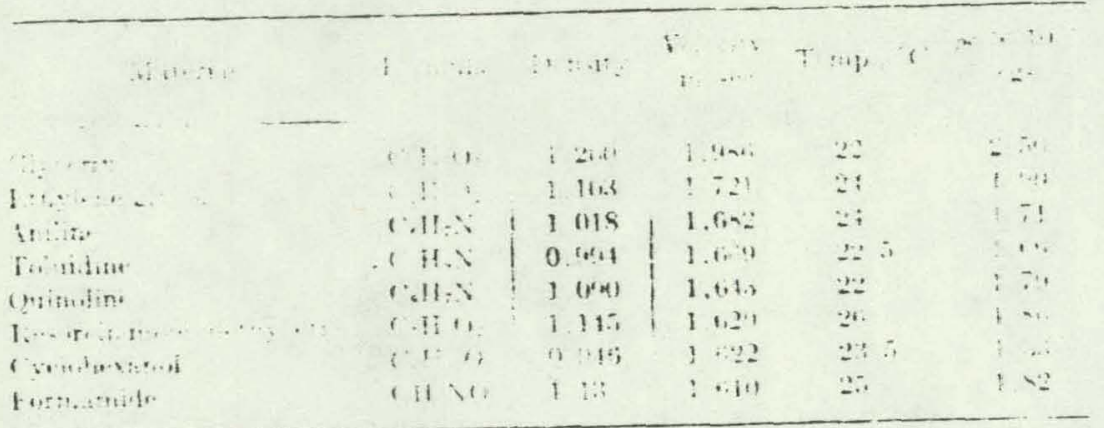

कू

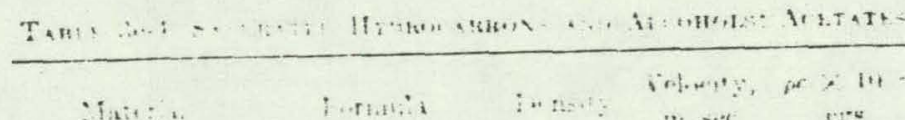

\begin{tabular}{|c|c|c|c|c|}
\hline$i, \ldots+\cdots, n$ & $\therefore \therefore$. & $\| 1, \ldots$ & 1112 & $11: ;$ \\
\hline He ans. & $1:$ & 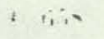 & 1. $1: 2$ & $+\quad \ldots$ \\
\hline ii $\ldots, \ldots: 2,:$ & $+1 !$ & $\cdots i$ & $i \cdots ;$ & \\
\hline Vet:s:. & $i \quad i i$. & 3.112 & 1234 & $11-7$ \\
\hline & $1 \% \therefore \cos$ & Aretais- & 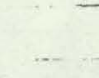 & \\
\hline is + th ! & (:i:!!! & $\because 7$ & i : $: 3 n$ & a. -1 \\
\hline E:s: : & $i \quad i+1 i$ & 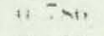 & $24:$ & $\because \overline{7}$ \\
\hline Prop: & $i+\|-1+H$ & 1" - 01 & 1.2.54 & $\omega$ \\
\hline Hats: & ¿ a?+1! & fists & i.313 & i $+\cdots:$ \\
\hline Amyt. & ( $\mathrm{ii} \ldots \mathrm{BH}$ & is sin & 1.347 & $1 \cdot 14$ \\
\hline$\ldots$ & c $\quad 1$ & & & \\
\hline $\begin{array}{l}\text { Mithyi } \\
\text { Ethyl }\end{array}$ & 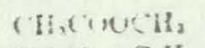 & (1) $\cdots$ & 2.211 & 112 \\
\hline $\begin{array}{l}\text { Ethyl } \\
\text { l'rupyl }\end{array}$ & Cil.coure $\mathrm{H}_{3}$ & (1) $x$ & 1.157 & $10 \%$ \\
\hline l'rupyi & CHirutresit, & $0 \times 91$ & 1.182 & 105 \\
\hline Iutyl & (11), COOK, & 0.851 & 1.1 .9 & 1 H: \\
\hline mol. & (II t uec. If & 0.875 & 1. Ifis & $1+2$ \\
\hline
\end{tabular}

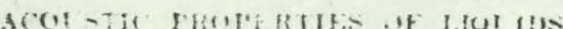

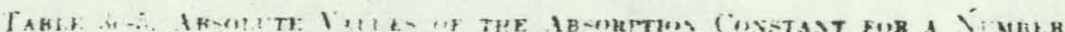

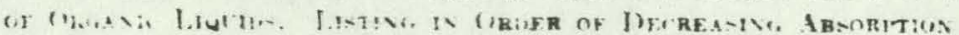
Tempersture intuern 23 and $2 \%$ C,

\begin{tabular}{|c|c|c|c|c|c|c|}
\hline 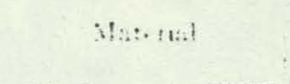 & fortustis & $\begin{array}{l}\text { liment } \\
\Rightarrow f \times\end{array}$ & 10 & Jorisity & $\begin{array}{l}\text { Verterity, } \\
\text { m ree }\end{array}$ & oc $\times 10^{-3}$ \\
\hline 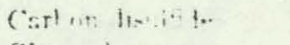 & $\because$ & $\because$ & & 1.26 & 1. It: & 145 \\
\hline filyerel & $\mathrm{C}_{3} \mathrm{Hi}_{1} \mathrm{C}$, & $2 t$ & & 1.26 & 1. $950 \mathrm{i}$ & 2.511 \\
\hline $2, \cdots \beta, 1, \ldots ; \cdots$ & $(\therefore, 1)=$ & 26) & & 10.5 & & \\
\hline Iimtiz: : & $\mathrm{C} . \mathrm{HL}_{2}$ & \& $3 \cdot 9$ & 15 & $0 . x_{i}$ & $1.29511 .316)$ & 113 \\
\hline Corbes intrathersis & $\mathrm{Cri}_{4}$ & $\therefore 7$ & & 1.54 & $930(92 x$ & 145 \\
\hline Cyrlotirat: if & $(: H 1 \cdot 1)$ & 511 & & $0 !+4 ;$ & 1.622 & 186 \\
\hline Aeetringe diefliertite & $1+1 t+1=$ & 10 & & 126 & 1.025 & 124 \\
\hline Cillowifurna & $\mathrm{Clll}_{\mathrm{C}}$ & $3 \times 4$ & it & $14: 1$ & $m=1,1 \mathrm{k}\}$, & $1+x$ \\
\hline \multicolumn{7}{|c|}{ 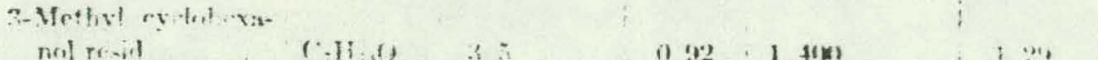 } \\
\hline t- Im: & C:II. 11 & i 3 & & A 81 & 1.204 & $0.5 \%$ \\
\hline Ifesity oxi.j. & r.lints & $\therefore$, & & $11 \times 5$ & 1.3110 & 111 \\
\hline P'romuriorm & $\mathrm{CHOH}_{2}$ & 23 & & $2 \&$ & '4心: & 262 \\
\hline thonty his tide & $C . ! 1.0 !$ & $1: 4$ & - & 0.4 & $\operatorname{tani}$ & $0 \times i$ \\
\hline C"Worn $+4,7$ en & 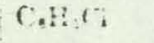 & 17 & & 1. 111 & 1.302 & 143 \\
\hline 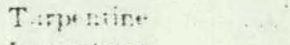 & & 15 & & i: as & $1.25 j$ & i. : \\
\hline I capentane & $(\cdot, 11: 2$ & $1:$ & & 1) 12 & 95:3 & 1" 61 \\
\hline 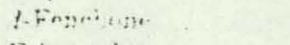 & $(\because, 11, \ldots)$ & 1.4 & & i) 44 & $1: 20$ & 124 \\
\hline$I \cdot$ hw $+1, \cdots$ & $r, 1: \cdots$ & $1.4=$ & $5 i$ & $i \because$ & $2 \times 5$ & (6) \\
\hline Inx:LE. & $(.11,1)=$ & 1.3 & & 1103 & $1.3 \times 0$ & $1+2$ \\
\hline likazenr 13 & $\left(\therefore_{2} ! H_{24}\right.$ & 1.3 & & $0 \mathrm{si}$ & 1.310 & 113 \\
\hline Noruse ne... & & 1.1 & & 11.81 & 1.315 & 166 \\
\hline Vothyl acetate & (.IH.t), & 109 & & (1) 93 & 1.211 & i is \\
\hline Wthy a etste. & $(\mathrm{HI}, \mathrm{O})_{2}$ & $11: 0$ & $\because$ & (1):0 & $1.145 \cdot 127$ & $: 0: 3$ \\
\hline Nisplitha... & & 10 & & 1) $\pi$ & 1.225 & $0+3$ \\
\hline Tuluol & $C: 11$. & i) $6: 8$ & 8.5 & if sf: & 1. $300+1.320$ & i 12 \\
\hline Nitrotwnzene & $\mathrm{C}_{6} \mathrm{H}_{3} \mathrm{NO}=$ & 09 & & 1.20 & 1.490 & $1.7 \mathrm{y}$ \\
\hline \multirow{2}{*}{\multicolumn{7}{|c|}{$\begin{array}{l}\text { 1, 3-1 richleru-inobu- } \\
\text { :ane }\end{array}$}} \\
\hline & $\mathrm{C}_{3} \mathrm{H}_{3} \mathrm{Cl}_{2}$ & o 9 & & 114 & 1.230 & 1.40 \\
\hline Sitrommotiat. & (11. $)$ & $0 \mathrm{y}$ & & 113 & 1.235 & 151 \\
\hline Ethri simet... & $\mathrm{C}_{2} \mathrm{HA}_{\mathrm{A}}$ & 0.7 & & $" \%$ & 1.150 & 1. 91 \\
\hline Mathyl alerital & $\mathrm{CH}, \mathrm{n}$ & 04 & & 1179 & 1. 10511.130 & if 57 \\
\hline Amenitrile & CII, C. & $6 \times$ & & 1178 & $1.20041 .25 \%$ & 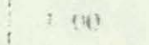 \\
\hline$m$-גyiol ... & C.H1: & (1) -sin & is & 0. 86 & $1.325(1.325)$ & 111 \\
\hline Aretine & $\mathrm{C}_{2} \mathrm{HiO}_{\mathrm{S}}$ & (i) is 5 , & 321 & in & 115001.203 & (1) +25 \\
\hline Alkazene $\mathbf{2 5}$ & $\mathrm{C}_{10} \mathrm{HH}_{12} \mathrm{Cl}_{2}$ & 06 & & $1.2 t$ & 1.200 & $i$ i i \\
\hline Furmsmilv. & $\mathrm{CH}_{3} \mathrm{NO}$ & 0.57 & & $123 \ldots$ & $1 . \sin$ & $1=2$ \\
\hline 2, 5-llexaneulione & $\mathrm{C}_{6} \mathrm{HI}_{10} \mathrm{O}_{2}$ & 0.50 & & 0.36 & 1. +400 & $1: 3$ \\
\hline Water wijutiled & $\left.\mathrm{H}_{3} \mathrm{O}\right)$ & & & & & \\
\hline
\end{tabular}




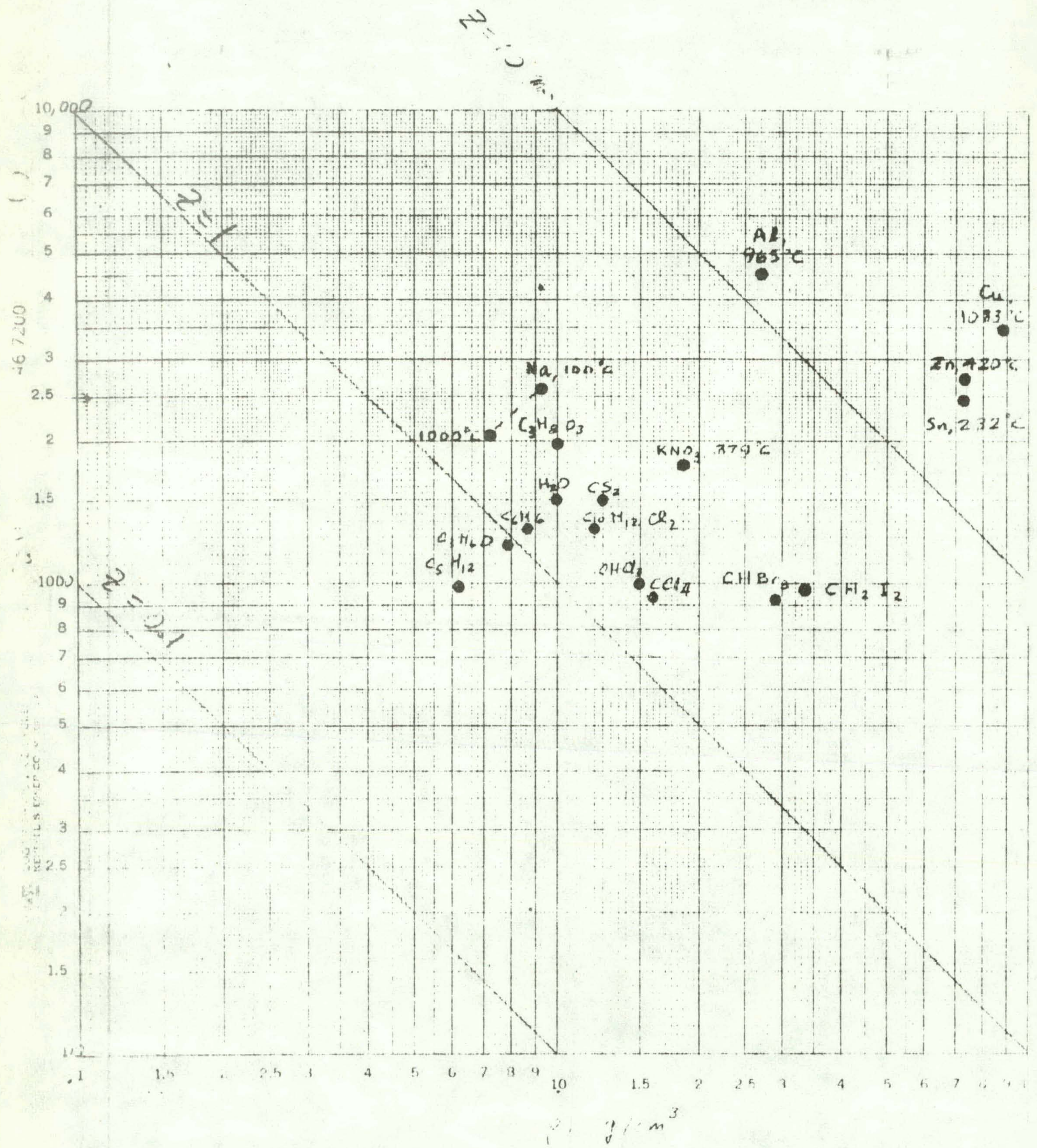




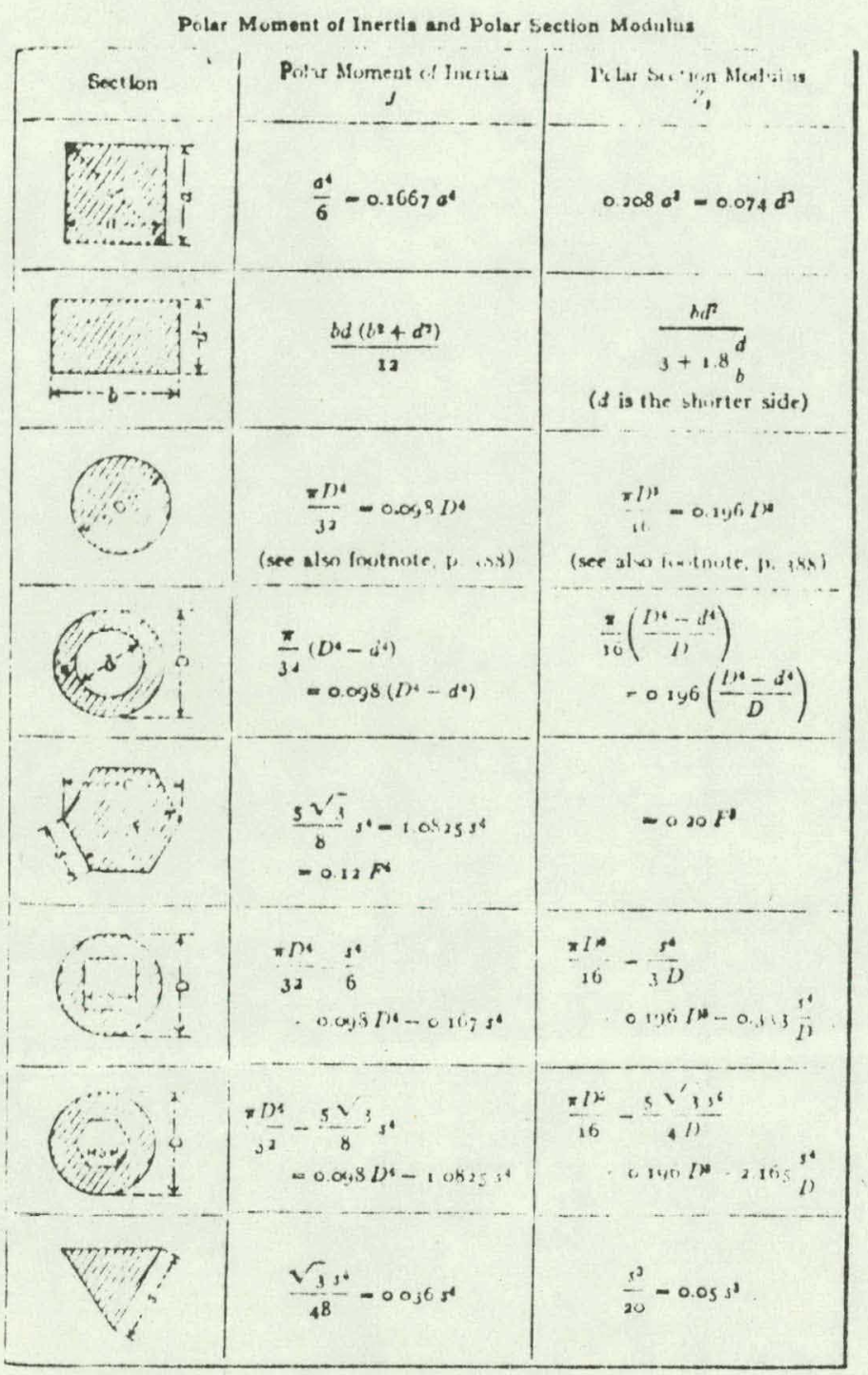

Source: rage: 453 in:

\section{MACHINERY'S HANDBOOK}

\section{A Reference Book for the Mechanical Enginest, \\ Draftoman, Too!mater and Machinist}

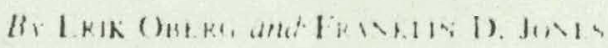

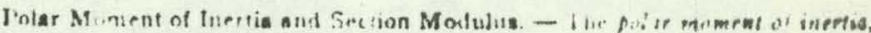

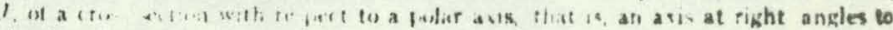

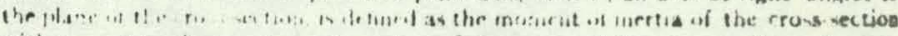

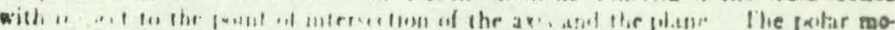

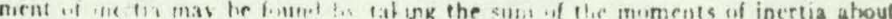

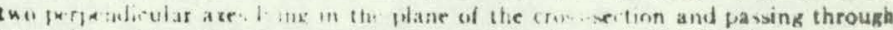
this poiat. Thu fur examph the fralar moment of inertia of a circular or a squeare ares with respect to a fwilst axis th:rough the center of eravity is equal to two sime the moment of imertia with 11 . pret to an axis lyang in the platie of the cruss-section a. I paseing thromgh the conter of kravity.

The pular moment of inettia with resiert in a pular sxis through the center of gravity is teguited for protherns involving the forstenal strength of shafts since this axis 1: usually the axis almat whe h twisting of the haft takes place.

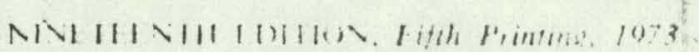

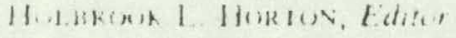

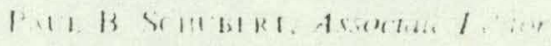

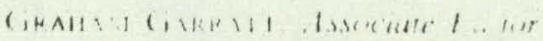

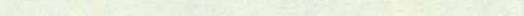

INDUSTRIAL PRFSS, INC: . 00 ifadism Abe. Niw York. N.Y. 10016 
LTR 141-68 


\author{
APPENDIX E \\ TEST PLAN FOR EVALUATION TESTING OF INEL \\ CONDUCTIVITY VOID FRACTION TRANSDUCER \\ AIR-WATER FLOW LOOP
}


LTR 141-68 


\section{TEST PLAN}

Instrument and Control Division

LOFT Experimental Measurements Branch

LOFT-VF-1

For Evaluation Testing

of

INEL Conductivity Void Fraction Transducer

in

Air-Water Flow Loop

Prepared By: \#/. Buchanare $\quad 2-10-77$

Approvals:

U. E. Arave by Hethet 2-10-77 
LTR 141-68 
INEL Conductivity Void Fraction Transducer Air-Water

Flow Loop Test Plan

\section{PURPOSE}

The purpose of the test is to provide data to aid in the evaluation of the INEL Conductivity Void Fraction Transducer as a void fraction detector.

GENERAL

The void fraction detector (Figure 1). will be tested in conjunction with the single beam $r$ densitometer. A 7.5 inch Lexan instrument washer will be installed in the test section of the air-water flow loop with a plexiglass spool piece on each end (Figure 2). This section can be connected on the end of the test section provided for the drag screen air water flow loop tests and run concurrently with these tests. (Reference 1.) The transducer, instrument washer, $\gamma$ densitometer and plexiglass spool pieces will be provided by LOFT Advanced Instrumentation Section.

\section{TEST PARAMETERS}

The test section inlet pressure and temperature shall be maintained the same throughout the test. The flow rates of water and air at the test section shall be varied as indicated in Table 1 . Also attached is a list of parameters to be measured (Table 2).

The data from the void fraction transducer and single beam $\gamma$ densitometer should be taken on FM analog tape and also taken in Mode 4 and processed with Auto 8 and stored on DMT using old tape sequence.

The data points requested in this test correspond to data points in the AV series test for the Drag Screen (Reference 1) except for data points, LV-01, LV-02, LV-03 and LV-04.

Reference 1: J. B. Colson, Air-Water Test Plan for Tests Au, AV, AX and AY-Col-11-76, Dec. 15, 1976 
TABLE 1

\begin{tabular}{|c|c|c|c|}
\hline $\begin{array}{l}\text { Test } \\
\text { Number }\end{array}$ & $\underset{\text { GPM }}{\text { Water Flow }}$ & $\begin{array}{l}\text { Air Flow } \\
\text { CFM }\{\text { Qffs }\end{array}$ & Comments - Observations \\
\hline$A V-05$ & 0 & 0 & Empty Test Section \\
\hline$A V-06$ & 0 & 0 & $\begin{array}{l}\text { Test Section full } \\
\text { water } 55 \text { psiA, zero } \\
\text { flow }\end{array}$ \\
\hline$A V-23$ & 275 & 2.3 & \\
\hline$A V-24$ & 275 & 4.5 & \\
\hline$A V-25$ & 275 & 11.2 & \\
\hline$A V-34$ & 175 & 2.3 & \\
\hline$A V-35$ & 175 & 4.5 & \\
\hline$A V-36$ & 175 & 11.2 & \\
\hline$A V-37$ & 175 & 22.5 & \\
\hline AV -38 & 175 & 45 & \\
\hline AV-39 & 175 & 67.5 & \\
\hline$A V-41$ & 145 & 2.3 & \\
\hline$A V-43$ & 145 & 11.2 & \\
\hline AV -44 & 145 & 22.5 & \\
\hline$A V-45$ & 145 & 15 & \\
\hline$A V-46$ & 145 & 67.5 & \\
\hline AV -47 & 145 & 90 & \\
\hline$A V-4 B$ & 0 & $n$ & $\begin{array}{l}\text { Test Section full } \\
\text { water } 55 \text { psiA, zero } \\
\text { flow }\end{array}$ \\
\hline LV-01 & 85 & 2.3 & \\
\hline LV-02 & 85 & 11.2 & \\
\hline$A V-58$ & 85 & 22.5 & \\
\hline$A V-59$ & 85 & 45 & \\
\hline AV -61 & 85 & 90 & \\
\hline$L V \div 0: 3$ & 60 & 2.3 & \\
\hline$A V-64$ & 60 & 22.5 & \\
\hline$A V-65$ & 60 & 45 & \\
\hline$A V \div 68$ & 60 & 112.5 & \\
\hline$L V=04$ & 34 & 2.3 & \\
\hline$A V \div 70$ & 34 & 22.5 & \\
\hline$A V-73$ & 34 & 90 & \\
\hline$A V=78$ & 17 & 67.5 & \\
\hline \multirow[t]{2}{*}{$A V-80$} & 17 & 112.5 & \\
\hline & & 178 & \\
\hline
\end{tabular}


$A V-81$

AV - 82
0

0
0

0
Test Section full water 55 psiA, zero flow

Empty test section 


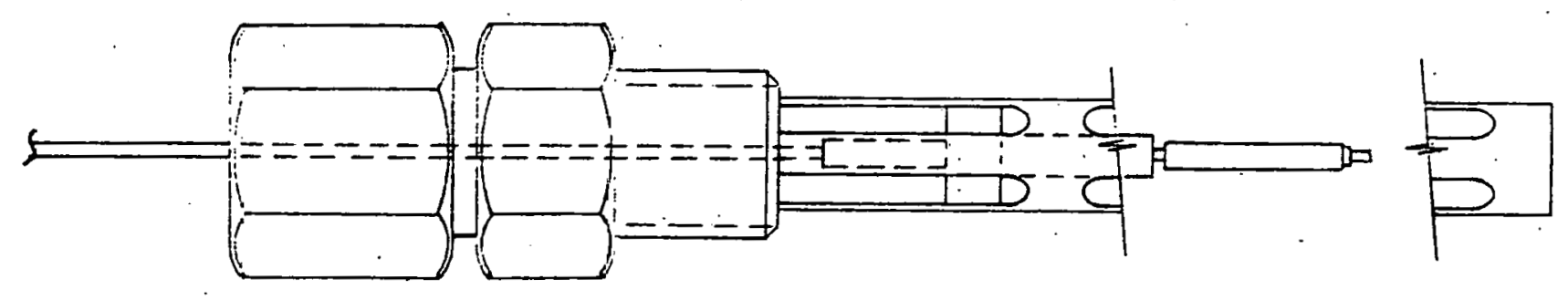

Figure 1: INEL Void Fraction Transducer to be tested in Air-Water Loop. 


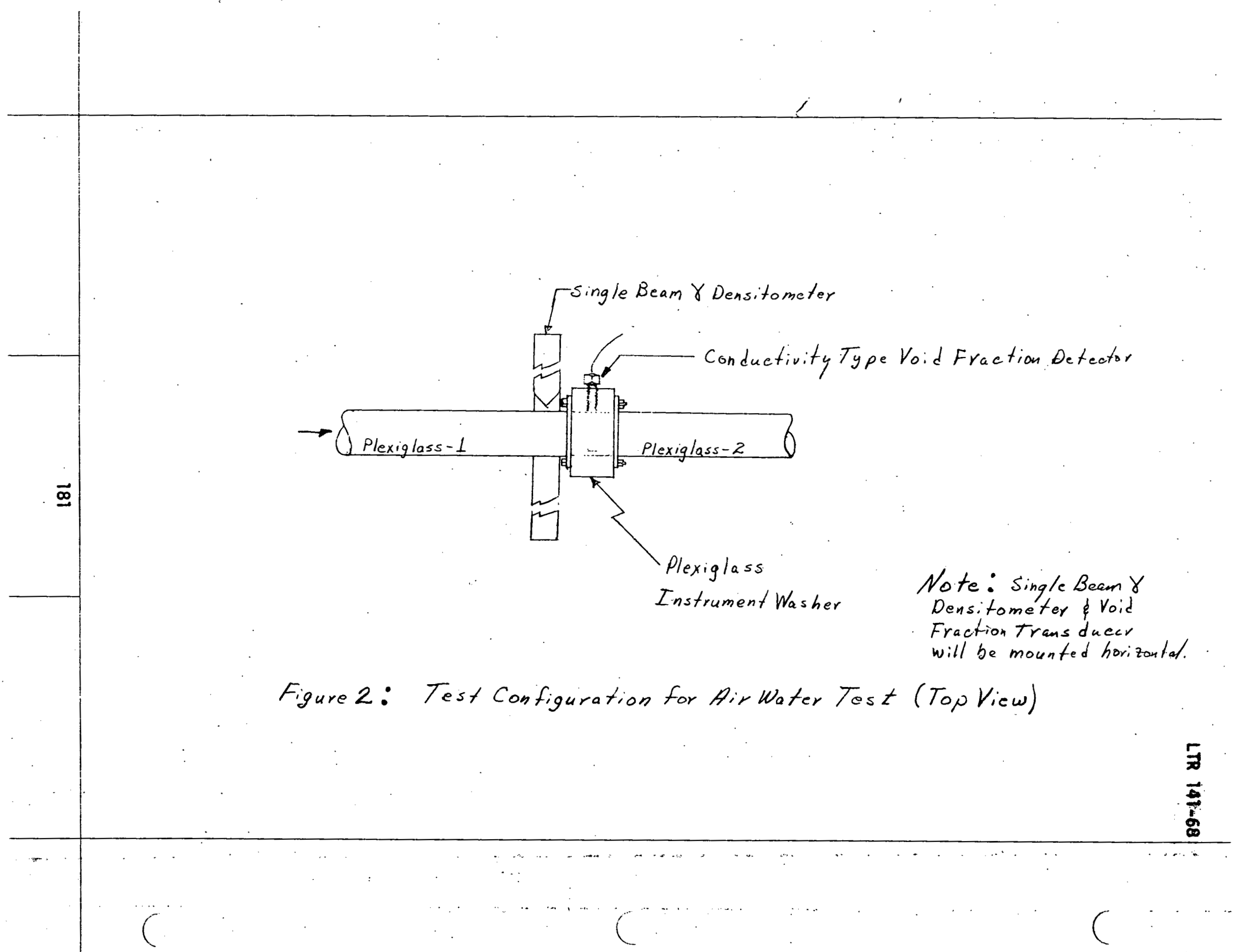


TABLE 2

Air-Water Test

Test Instrumentation

1. Volumetric flowrate of air (dual ranged)

$250 \mathrm{cfm}$

$50 \mathrm{cfm}$

2. Volumetric flowrate of water (dual ranged)

$400 \mathrm{gpm}$

$60 \mathrm{gpm}$

3. Void fraction transducer

$0-5$ volts

4. Pressure at test section inlet

112.5 psia

5. Pressure of air input

212 psia

6. Temperature of air input

$591^{\circ} \mathrm{F}$

7. Temperature of water input

$591^{\circ} \mathrm{F}$

8. Temperature of mixture at test section

$591^{\circ} \mathrm{F}$

9. Single-beam gamma densitometer

$0-1$ volt 


\section{APPENDIX $F$}

TEST PLAN FOR EVALUATION TESTING OF

PANAMETRICS ULTRASONIC VOID FRACTION TRANSDUCER

IN AIR-WATER FLOW LOOP 
LTR 14T-68 
TEST PLAN

Instrumentation Division

Advanced Instrumentation \& Development Branch

LOFT-VF-2

For Evaluation Testing

of

Panametric UItrasonic Void Fraction Transducer

in

Air-Water Flow Loop

Prepared by: Ru Plutf $4-26-7$ 
LTR 141-68 
LOFT-VF-2

\subsection{PURPOSE}

The purpose of the test is to provide data to aid in the evaluation of the Panametric's UItrasonic Void Fraction Transducer as a void fraction detector. The detector will be tested in conjunction with a single beam gamma densitometer in a vertical section at the Semiscale Air-Water Loop. A two-beam gamma densitometer upstream will also be recorded as a back-up unit.

\subsection{REFERENCES}

Drawing SK-MB-001 U1traonic Void Fraction Detector Probe Mounting Concept Manual: U1trasonic Thermometer Operations Manual.

\subsection{FACILITIES AND EQUIPMENT}

3.1 This test shall be performed at the INEL Fluids Laboratory by EG\&G personnel in the Semiscale Air-Water Loop Facility.

\subsection{Equipment}
a. Panametrics U/trasonic Void Fraction Detector (Figure 1)
b. 7.5 inch Lexan instrument washer (Figure 2)
c. Plexiglass spool piece, 3 foot.
d. LOFT single beam gamma densitometer
e. Gamma densitometer signal conditioner
f. Ultrasonic Lhermometer electronics system
g. Oscilloscope Tektronic 321 or equivalent
h. Digital Multimeter Fluke Model $8120 \mathrm{~A}$ or equivalent

\subsection{TEST PROCEDURE}

4.1 Prepare the instrument washer by assembling the ultrasonic void fraction detector into the Lexan instrument washer per Figure 2.

4.2 Install the instrument washer, plexiglass spool piece, and the single beam gamma densitometer into the flow loop with the plexiglass tube up stream of the instrument washer. Refer to Figure 3. It is important to have at least a 2 foot section of pipe after the instrument washer. 
4.3 Connect the electronics up to the ultrasonic transducer and gamma densitometer per directions of John Richardson and Wayne Shurtliff. Refer to Figure 4.

\subsection{Test Measurement Equipment Setup}

4.4.1 Connect the output of the gamma densitometer to the data acquisition system through a X10 amplifier. With the source cast closed, adjust the zero pot on the electronics to obtain zero output. If a zero output is not obtained, record the zero offset.

4.4.2 Connect the output of the ultrasonic electronic to the data acquisition system through a $X 1$ amplifier. Make the necessary adjustments on the electronics as advised by John Richardson.

4.4.3 Connect the FM recorder to record the following information ( 30 icp is the suggested speed):

Channel 1: IRIG A timing

Channel 2: Ultraonic void fraction detector

Channel 3: Single beam gamma densitometer

Channel 4: Thermocouple

Channe1 5: Two beam gamma densitometer

Channel 6: Two beam gamma densitometer

\subsection{Data Acquisition System}

The data taken should be taken on FM analog tape and also taken in Mode 4 and processed with Auto 8 and stored on DMT using old tape sequence. Plots should be made for three channels (single beam gamma densitometer, ultrasonic void fraction detector and temperature) and Program 2 should be run on all channels.

\subsection{FLOW TESTS}

The test section inlet pressure and temperature shall be maintained the same throughout the test. The flow rates of water and air at the test section shall be varied as indicated in Table 1.

At the beginning and end of each day, a calibration test will be run using VF-01 and VF-02. Also any offset in the electronics shall be recorded before and after each day of testing (specifically the electronics for the gamma densitometer). 
LOFT-VF-2

LTR 141-68

DATA SHEET (cont 'd)

FM Analog Tape LOG (cont'd) 


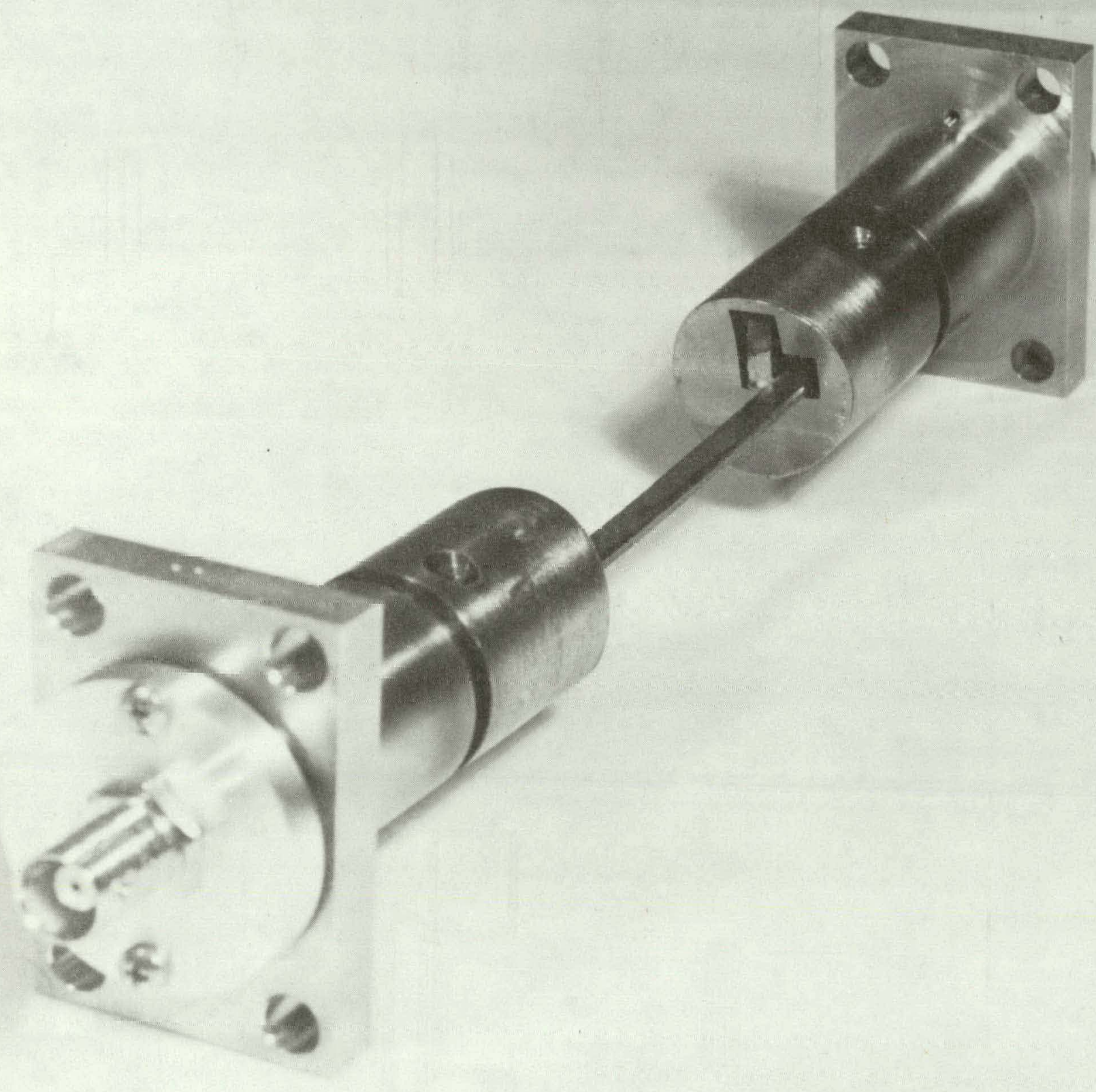




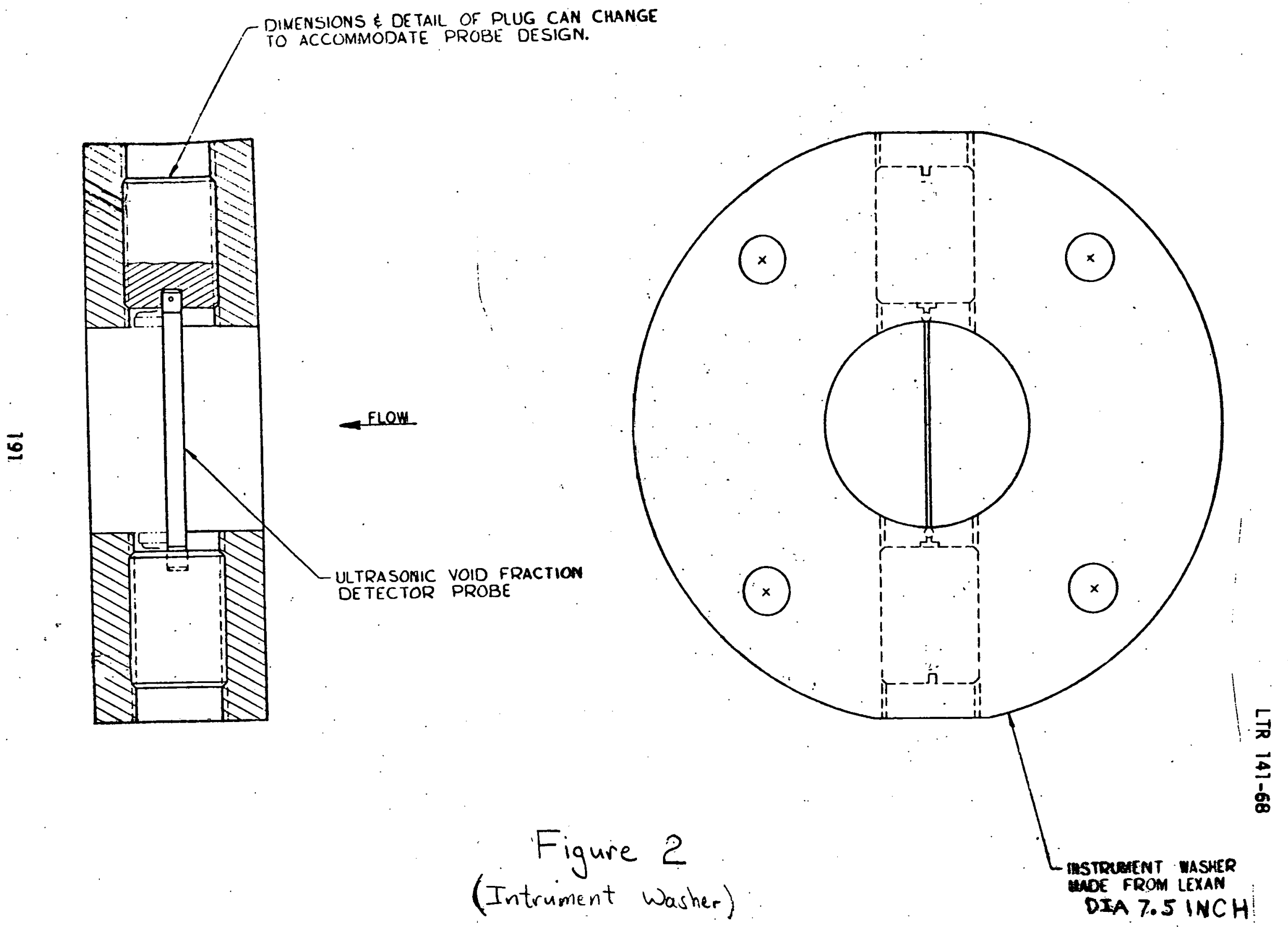




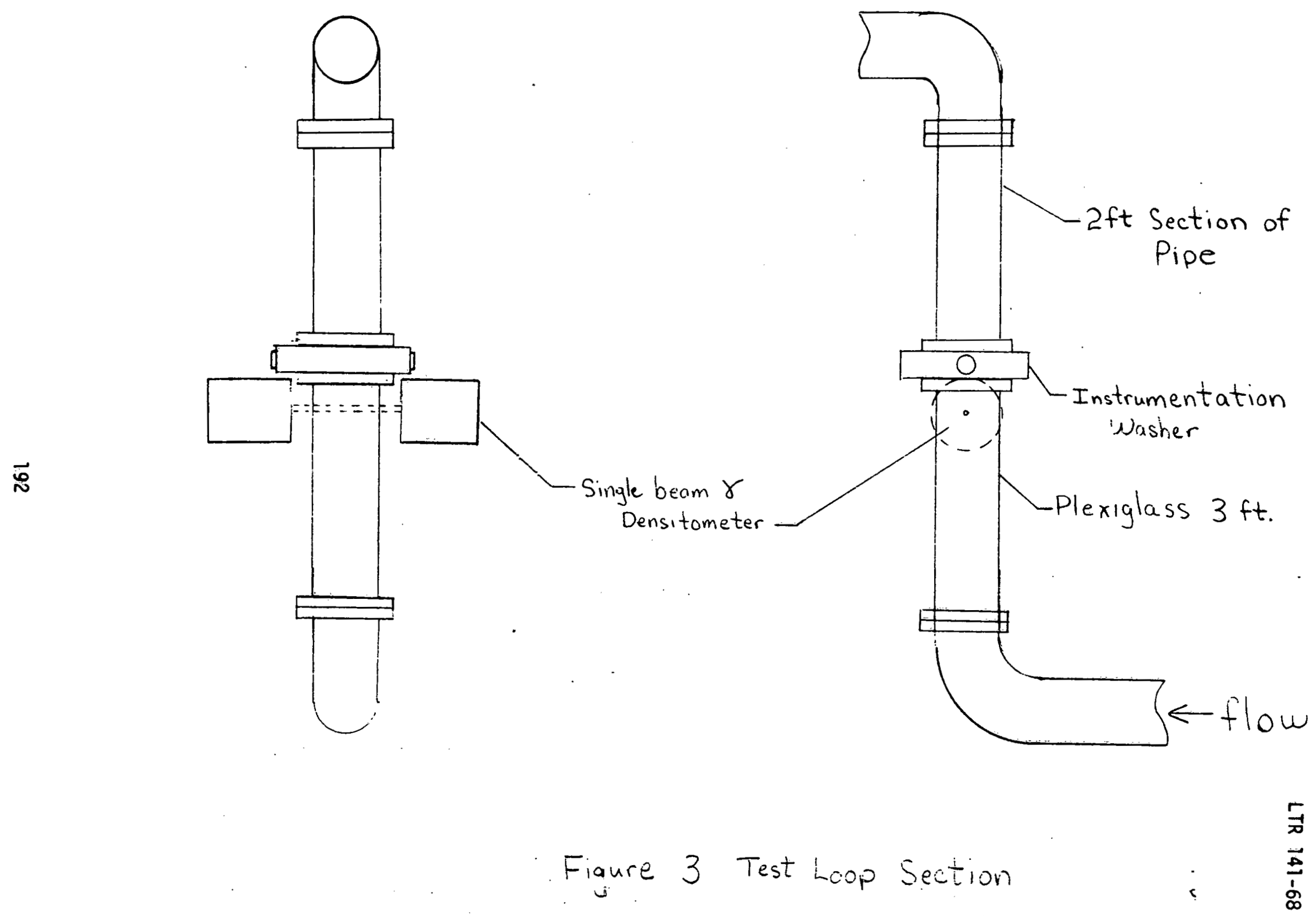




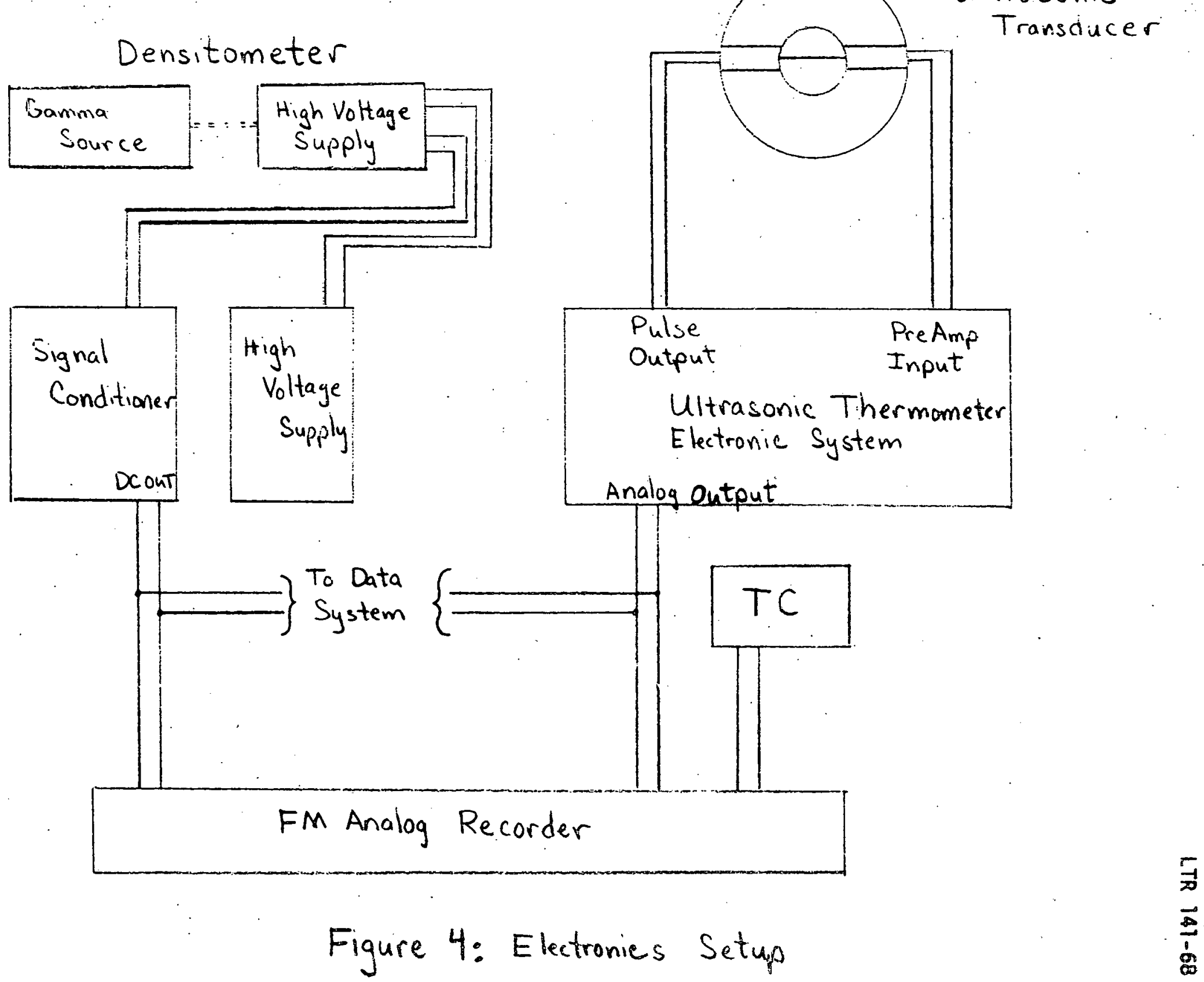


LOFT -VF-2

LTR 141-68

DATA SHEET

"*

Record of offset voltages

Amount

Day

Time

Instrument

Comments

FM Analog Tape Log

Record the beginning IRIG A timing for each recorded data point and any comments to clarify what took place.

Date taken by

Date 
TABLE 1

\section{TEST NUMBER}

VF-01

$V F-02$

VF -03

VF-04

$V F-05$

VF-06

VF-07

VF-08

VF -09

VF-10

VF-11

$V F-12$

VF -13

VF-14

VF -15

VF-16

VF-17

$V F-18$

VF-19

VF -20

VF -21

VF -22

$V F-23$

VF -24

$V F-25$

VF-26

VF -27

VF-28

VF-29

VF -30

VF-31

$V F-32$

$V F-33$

$V F-34$

VF-35

$V F-36$

VF-37

VF-38

VF-39

VF -40

VF-41

VF-42

$V F-43$

VF-44

VF -45

VF-46

VF-47

VF-48

VF -49 . $\underset{\text { WPM }}{\text { WATER FLOW }}$

60

145

145

145

145

145

145

145

60

0

85

85

85

85

85

85

85

60

0

60

60

60

60

60

60

60

60

0

34

34

34

34

34

34

34

34

60

0

17

17

17

17

17

17

17

17

60
AIR FLOW

CFM

0

22.5

1.7

2.3

3.4

8.5

11.2

22.5

45

0

22.5

1.7

2.3

3.4

8.5

11.2

22.5

45

0

22.5

1.7

2.3

3.4

8.5

11.2

22.5

45

0

22.5

1.7

2.3

3.4

8.5

11.2

22.5

45

67

0

22.5

1.7

2. 3

3.4

8.5

11.2

22.5

45

67

0

22.5
COMMENTS

Note 1

Note 2

Note 1

Note 2

Note 1

Note 2

Note 1

Note 2

Note 1

Note 2

Note 1

Note 2 
LTR 141-68

TABLE 1 (cont'd)

TEST NUMEER

$V F-50$

VF-5I

VF -52

$V F-53$

VF- -54

VF -55

VF-56

VF -57

VF -58

VF -59
WATER FLOW

GPM

3.4

3.4

3.4

3.4

3.4

3.4

3.4

3.4

60

0
AIR FLOW

CFM

1.7

2.3

3.4

8.5

11.2

22.5

45

67

0

22.5
COMMENTS

Note 1

Note 2

Note 1: 'Cailbration point for all' Flowing Water

Note 2: Calibration point for all Flowing Air, allow sufficient time to blow transducer dry, before taking data. 
APPENDIX G

ANALYSIS OF CONDUCTIVITY PROBE IN

A HORIZONTAL TEST SECTION 
LTR 141-68 


\section{INTEROFFICE CORRESPONDENCE}

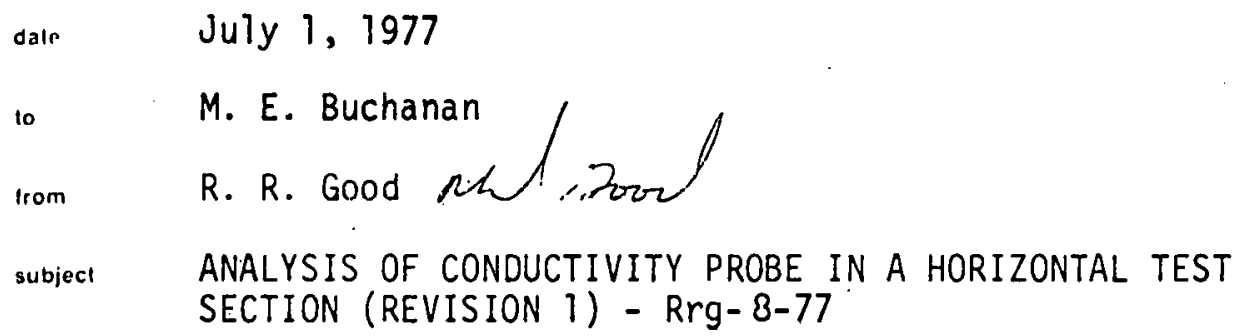

Ref: R. R. Good 1 tr to M. E. Buchanan, Analysis of Conductivity Probe in a. Horizontal Test Section, Rrg-5-77, June 7, 1977

On May 4, a series of tests were conducted at the Air Water Flow Loop. During these tests, data were taken with a conductivity probe in an attempt to measure void fraction. A single-beam densitometer close to the conductivity probe and in the same orientation was used to supply a continuous reference density. A two-beam densitometer ceveral diameters upstream of the conductivity probe was used to

,iy an average density reference. Several data sets at varying . uw rutes were obtained; unfortunately, approximately one-fourth of these data sets were lost due to an error in preprocessing these data. Averages of conductivity probe output were available for all data sets. Data sets AV-64 through AV-69 were examined in detail; all other sets were checked on average value only. Time did not permit a complete analys is of all available data. Data sets AV-64 through AV-69 were chosen as representative data sets, power $: \cdots: \cdots$ ? densities, probability density functions, and auto and cross curreiations were performed on each of these data sets. The in-depth statistical analysis was designed to detect high noise levels, unexpected signal signatures and verify. the analysis conducted on the time averaged data. Figures 6 through 48 present the in-depth statistical analysis. No high noise levels or unexpected signal signatures were detected, and the data was consistent with the time averaged data.

An analysis of the data obtained yielded the following conclusions:

1. The conductivity probe is measuring void fraction

2. The conductivity probe is probably insensitive to tempcrature over the range of tests $\left(70^{\circ}-1000 \mathrm{~F}\right)$

3. The conductivity probe may be sensitive to mass flow rate, however, more data is necessary to verify any correlation

4. The relationship between conductivity probe voltage output and density is of the form: 
M. E. Buchanan

July 1,1977

Rrg- $-5-77$

Page 2

$$
\begin{aligned}
& 1 \\
& \rho=c_{1}-c_{2} \ln V c \\
& \text { where: } \rho=\text { density } \\
& C_{1} C_{2}=\text { are constants } \\
& V c=\text { voltage output of conductivity probe }
\end{aligned}
$$

5. Accuracy of approximately $\pm 10 \%$ RG is possible with the conductivity probe

The conductivity probe measures void fraction. The conductivity probe measures the conductivity of the medium between two closely spaced probes. Conductivity of the medium between the probes is a function of the media. In the case of this test, the media consists of a mixture of air and water. Air and water both have conductivities which remain essentially constant over the range of test conditions employed. Thus, the conductivity of the media is dependent solely on the ratio of air to water, or void fraction.

Experimental prouf of the preceeding conclusion is obtained through a cross correlation of the gamma densitometer output and the condurtivity probe output. The gamma densitometer output is well know to be a function of the density of the media. The media employed, air and water, have essentially constant densities over the range of test condition thus, gamma densitometer output is a function only of the ratio of these fluids, a function of void fraction. Flgures $8,12,16,20,28,32,36,40,44$, and 48 present the cross correlation of the conductivity probe and gamma densitometer. Lag times of less than .I second indicate correlation coefficient of approximately 1, clearly proving that both the gamma densitometer and conductivity probes are measuring the same thing, void fraction.

The conductivity probe is probably insensitive to changes in temperature over the range of test condition (700F $\rightarrow 1000 \mathrm{~F})$. This conclusion is based on assumptions on what the conductivity probe measures. It is known that the conductivity of denineralized water and air do not change appreciably over the range of $700 \mathrm{~F} \rightarrow$ $100^{\circ} \mathrm{F}$; thus, the conductivity probe should be insensitive to temperature. An experiment was conducted to test the preceeding hypothesis. Results of this test are presented in Figure .5. These data seem to indicate a temperature sensitivity, however, the experiment was not performed under sufficiently controlled conditions. The change in conductivity volts is believed to be due to $\mathrm{CO}_{2}$ dissolving into the deionized water which was the media of the experiment. 
M. E. Buchanan

July 1, 1977

Rrg-8-77

Page 3

Shifts in the coefficients $C_{1}$ and $C_{2}$ were obtained each time a different data set was analyzed. These shifts appear to have some correlation with mass flow rate. These data are presented in Table 1 and Figures 1 and 2. The limited amount of data available makes impossible the task of correctly assigning the effect mass flow rate has on the calibration coefficients. Vortex shedding is suggested as a possible mechanism whereby mass flow rate could effect the output of the conductivity probe.

Density as a function of conductivity probe voltage output is a logarithmic function of the form:

$$
p=c_{1}-c_{2} \ln V c
$$

This function was arrived at through consideration of the signal conditioning network and experiment. The signal conditioning network outputs a voltage which is a function of the impedance across the conductivity probe. Voltage is a linear function of conductivity whencurrent is held constant. Figure 4 is a graph of input impedance vs output voltage. The voltage output as a function of impedance is:

$$
V=C_{1}+C_{2} \ln Z
$$

This functional relationship is demonstrated in Figures 1 and 2 , a graph of voltage vs density. Figure 3 shows attempts to fit Polynomials to the data. In all cases, equations of the form $C_{1}-C_{2}$ InVe gave better fits to the data. Table 1 presents coefficients determined for different test series.

The data always appears to fit the logarithmic equations well; hence, it is expected that reasonable accuracy, within $5 \%$, may be obtained. A prerequisite of obtaining this accuracy will be to conclusively determine the effects of temperature and mass flow rate on the conductivity probe output.

pS

Attachments: As Stated

cC: L. D. Goodrichpr

R. R. Good File

Central File 


\section{TABLE 1}

Table of $C_{1}$ and $C_{2}$ Coefficients

Test Series

AV 22 - AV 27

AV 27 - AV 33

AV 33 - AV 40

AV 40 - AV 48

AV 48 - AV 57

AV 57 - AV 63

AV 63 - AV 69

AV 69 - AV 75

AV $75-$ AV 81 $c_{1}$

148.9

159.3

153.0

147.1

137.8

197.8

105.1

163.9

228.1 $c_{2}$

68.6

76.9

69.2

68.5

59.9

87.7

72.0

71.3

102.0
$R^{2 \star}$ .96

.96

.98

.99

.99

.91

.98

.96

.89

$\star R^{2}$ is the correlation coefficient, a measure of the goodness of fit. 


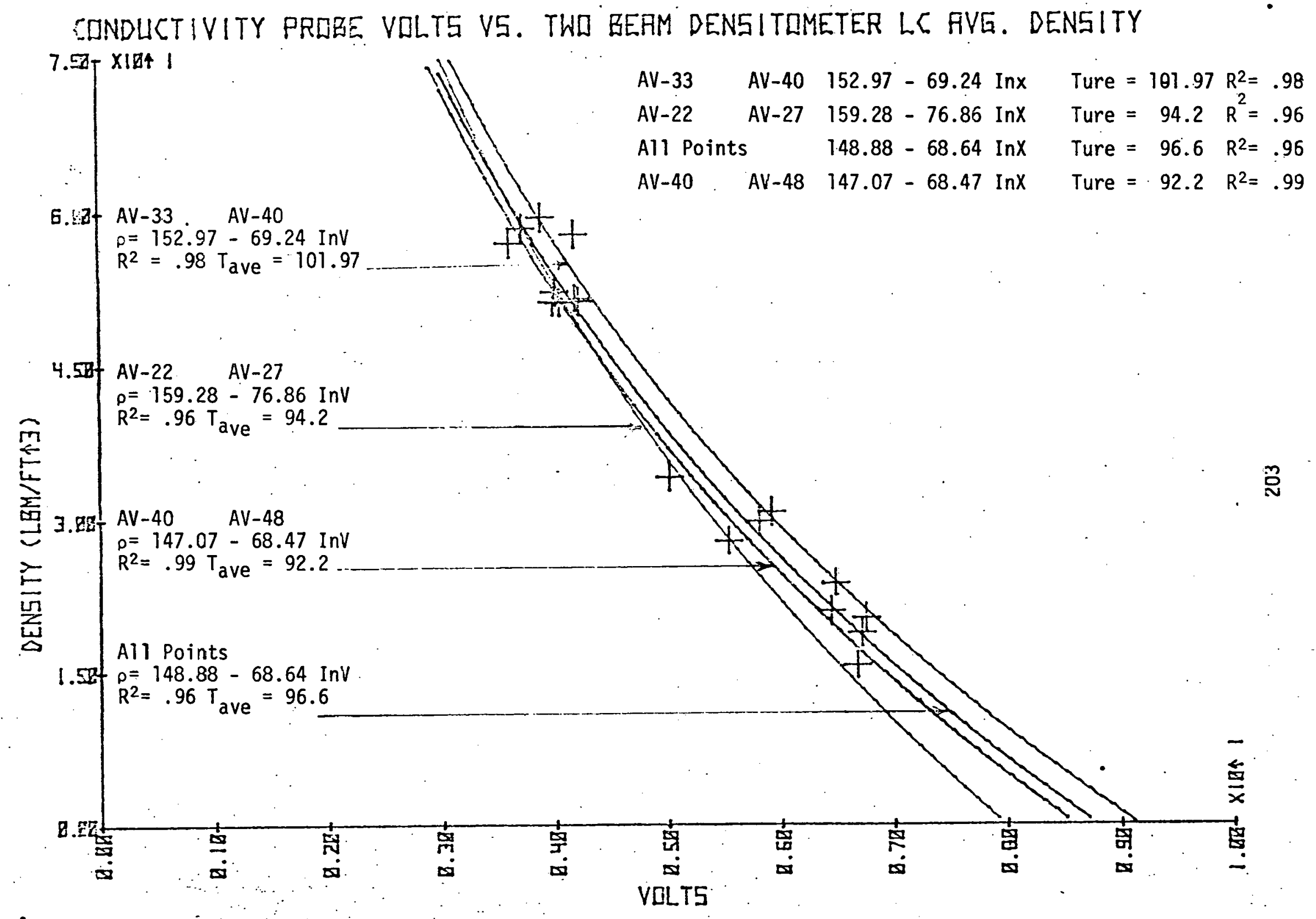




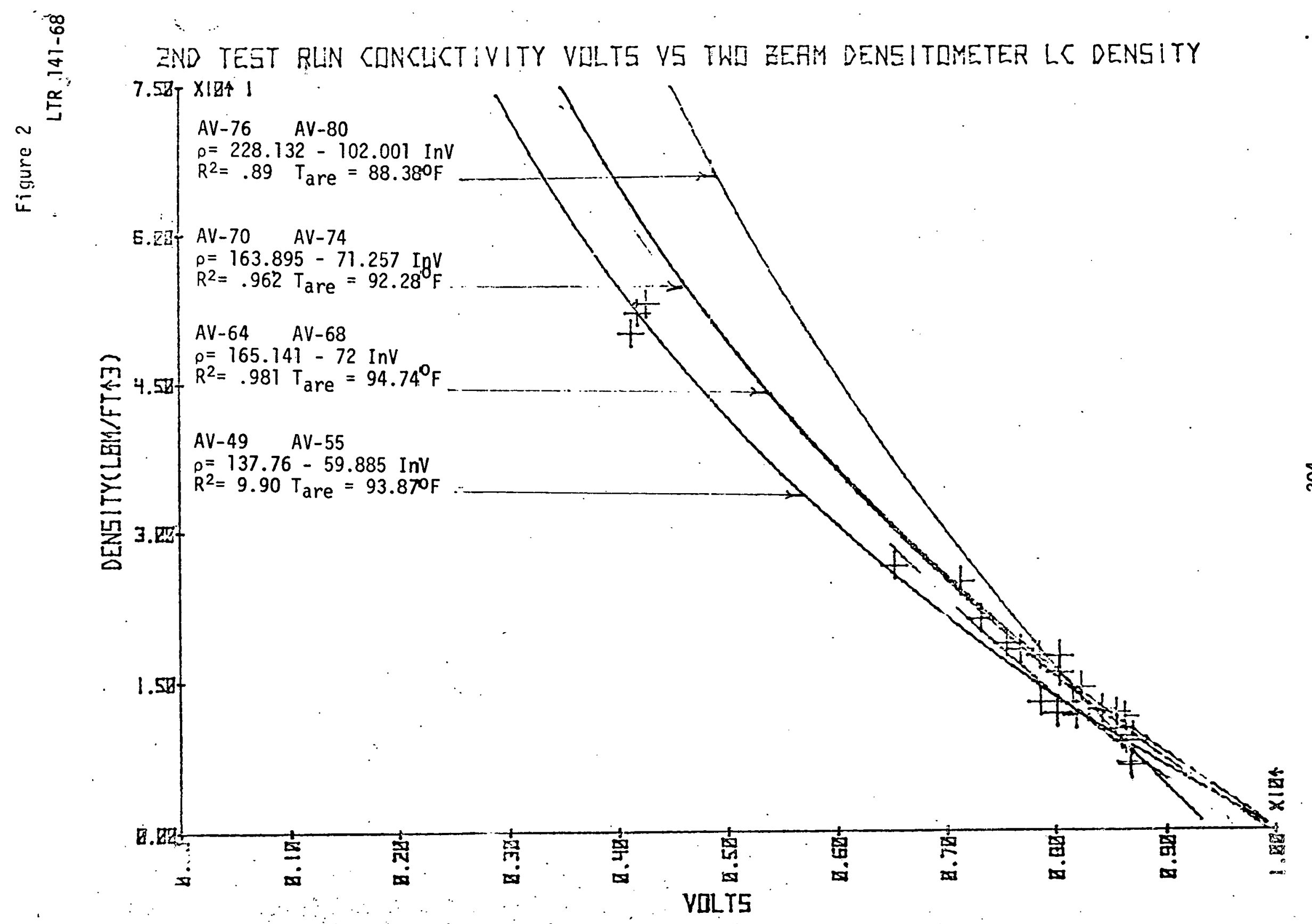




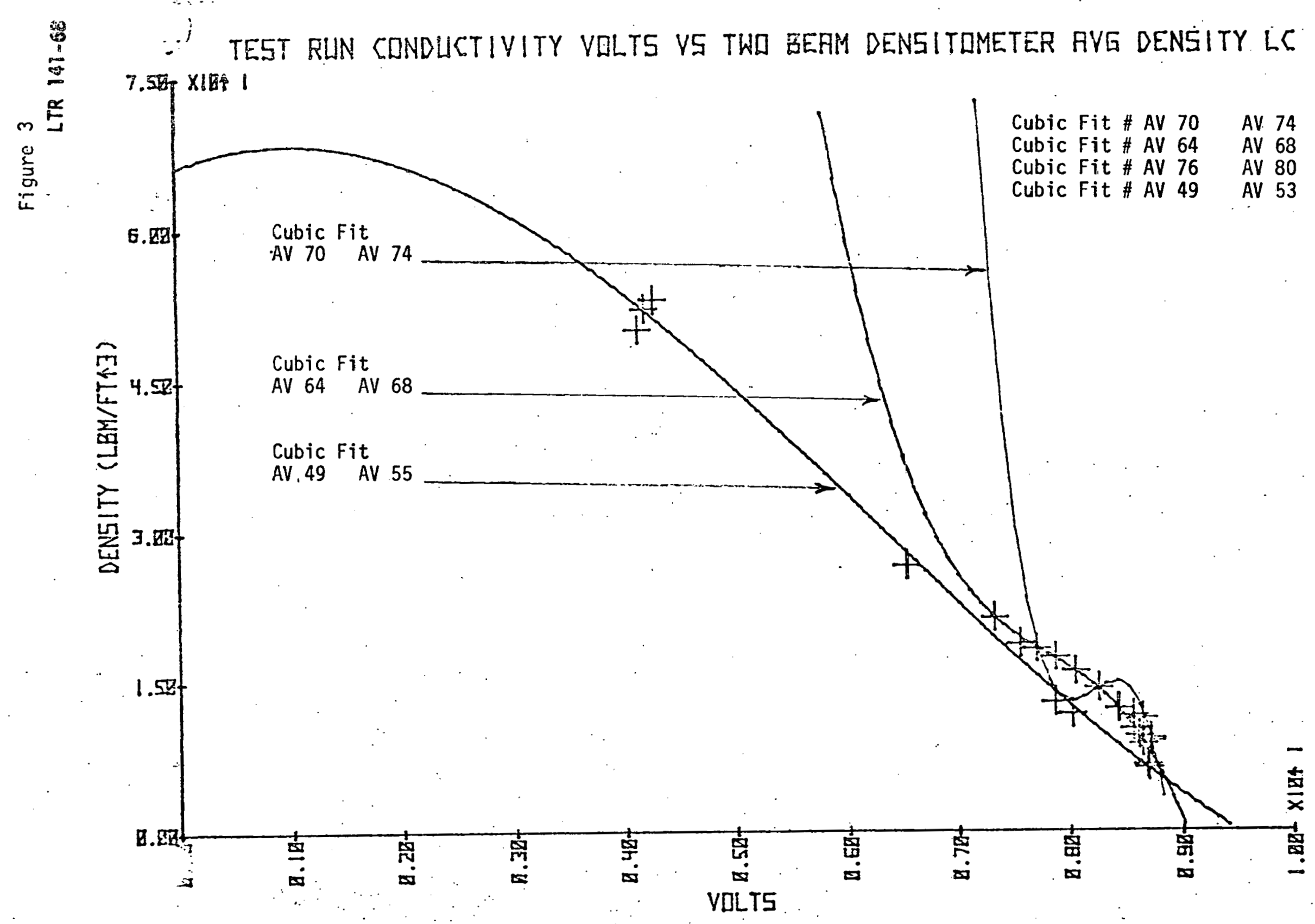




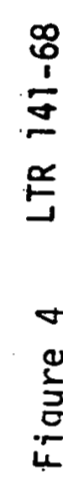

VILTS DUTPUT VS CONDUCTIVITY

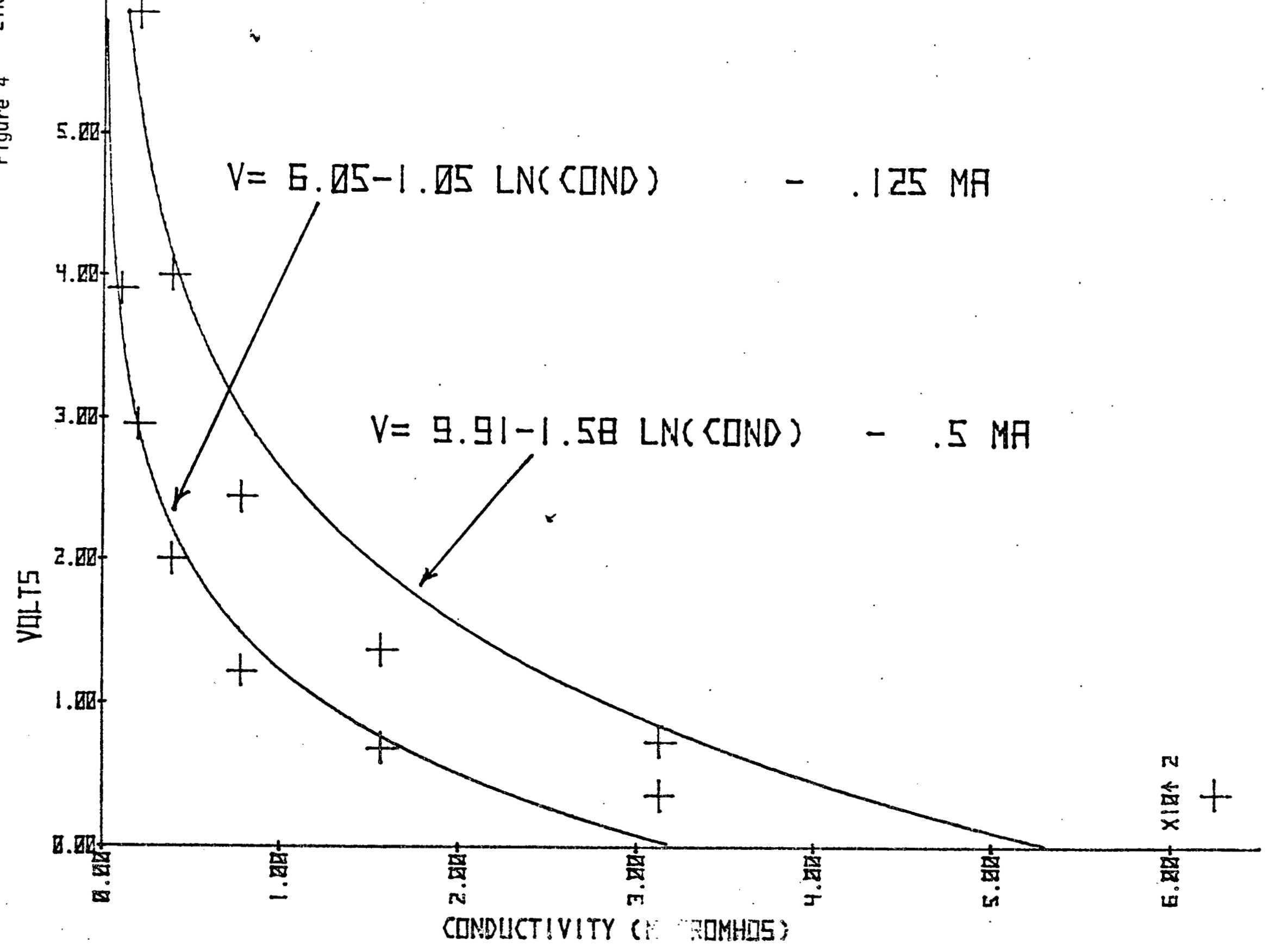




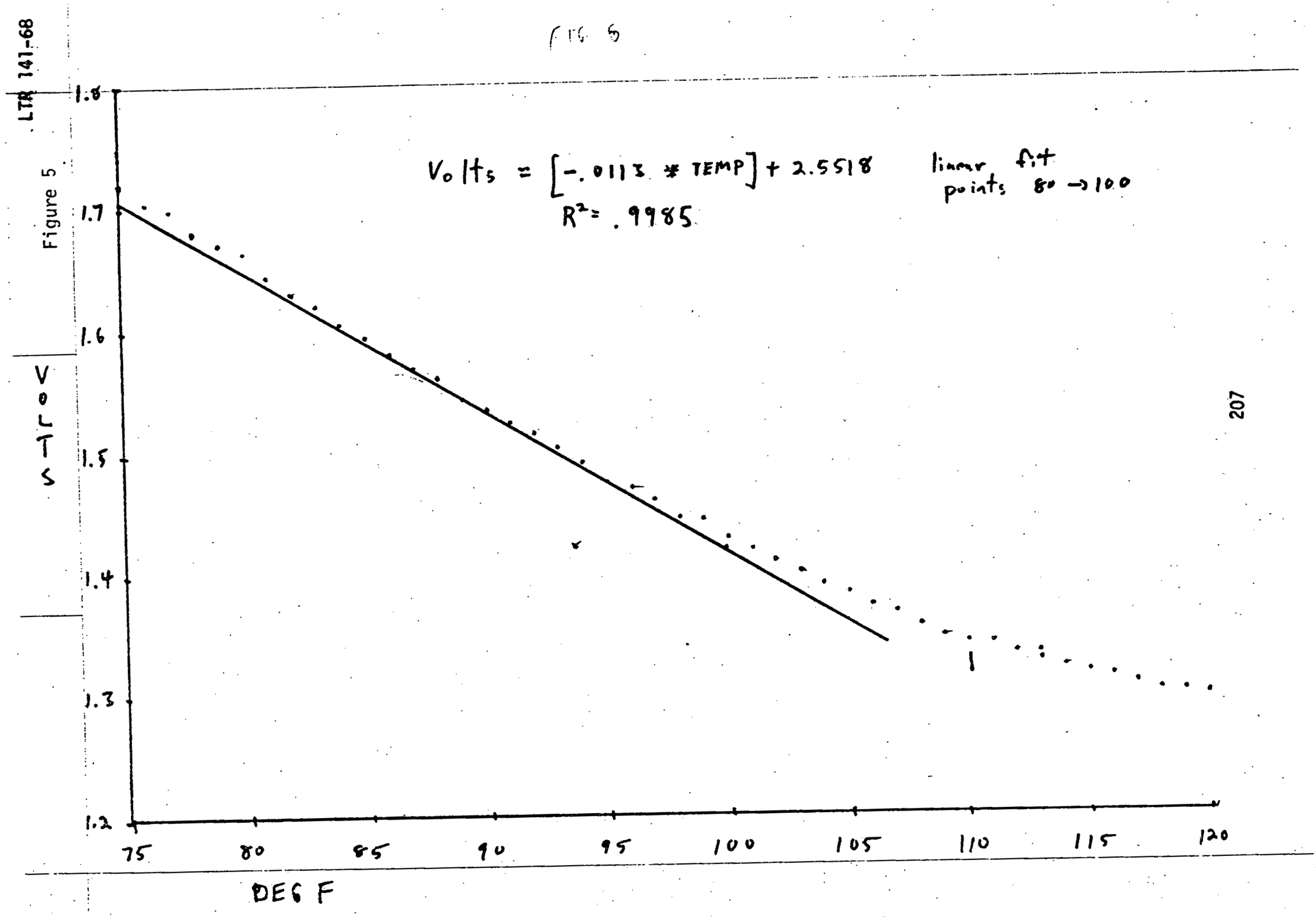




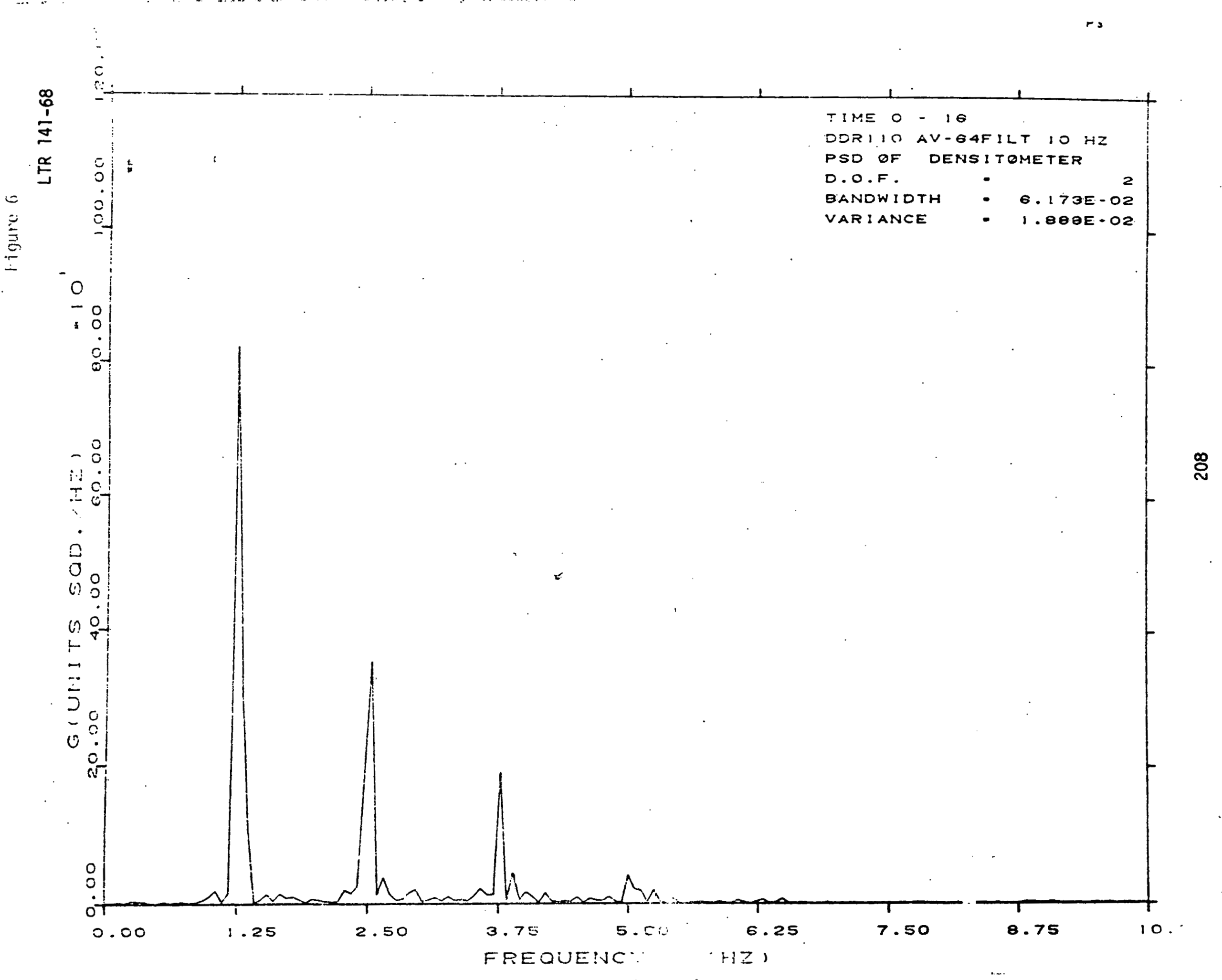




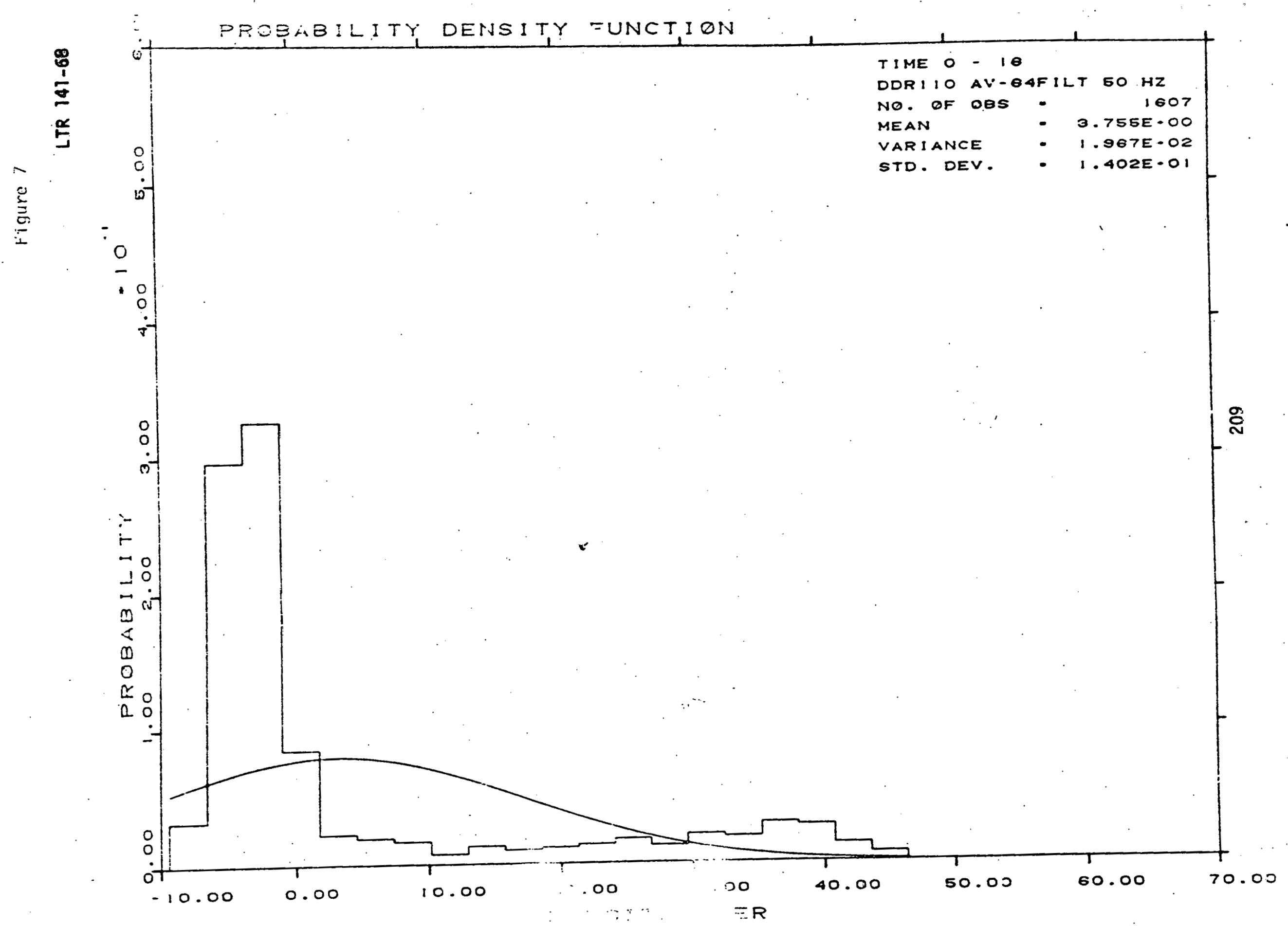




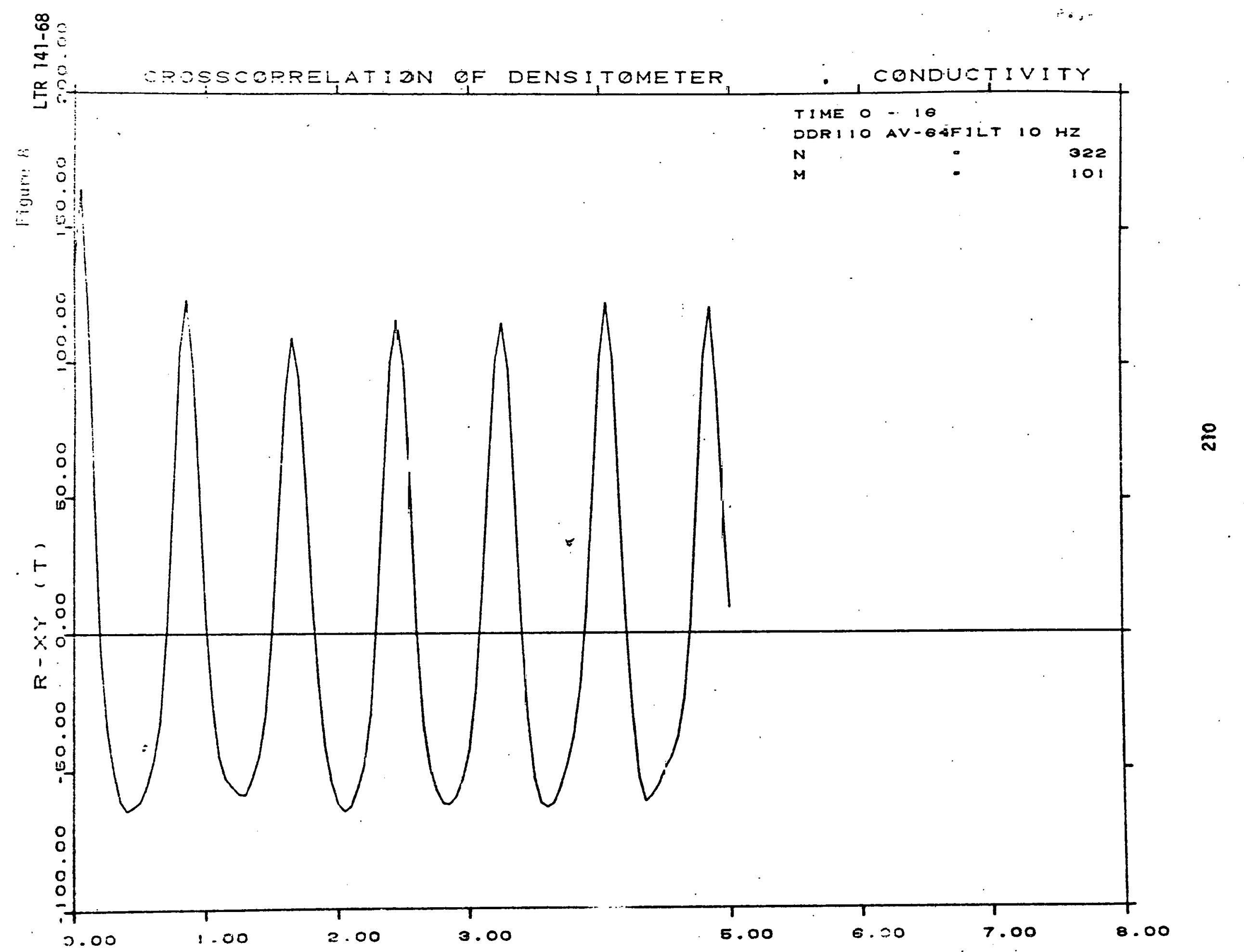


$P \bullet Q \bullet 1$

mo

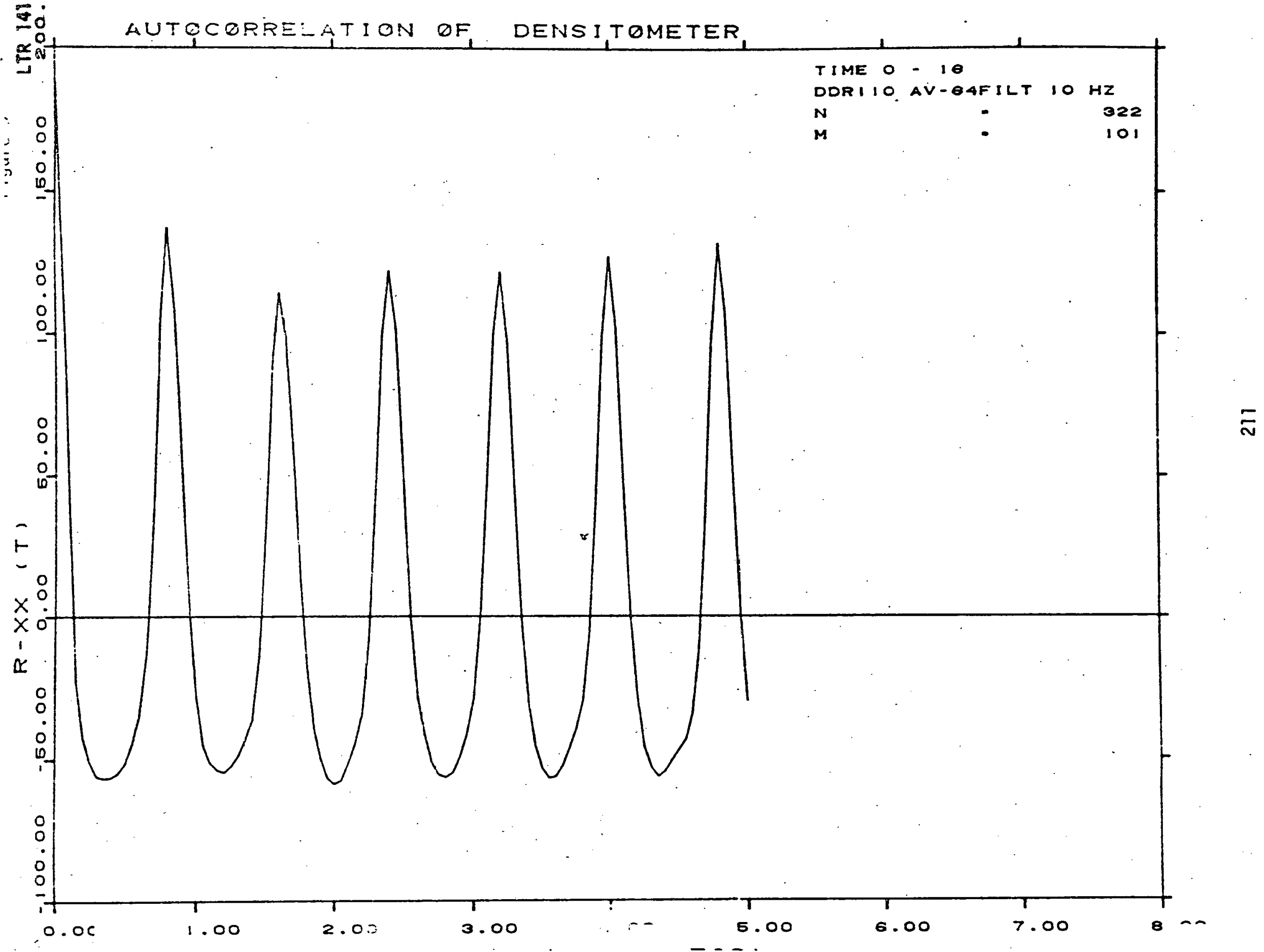




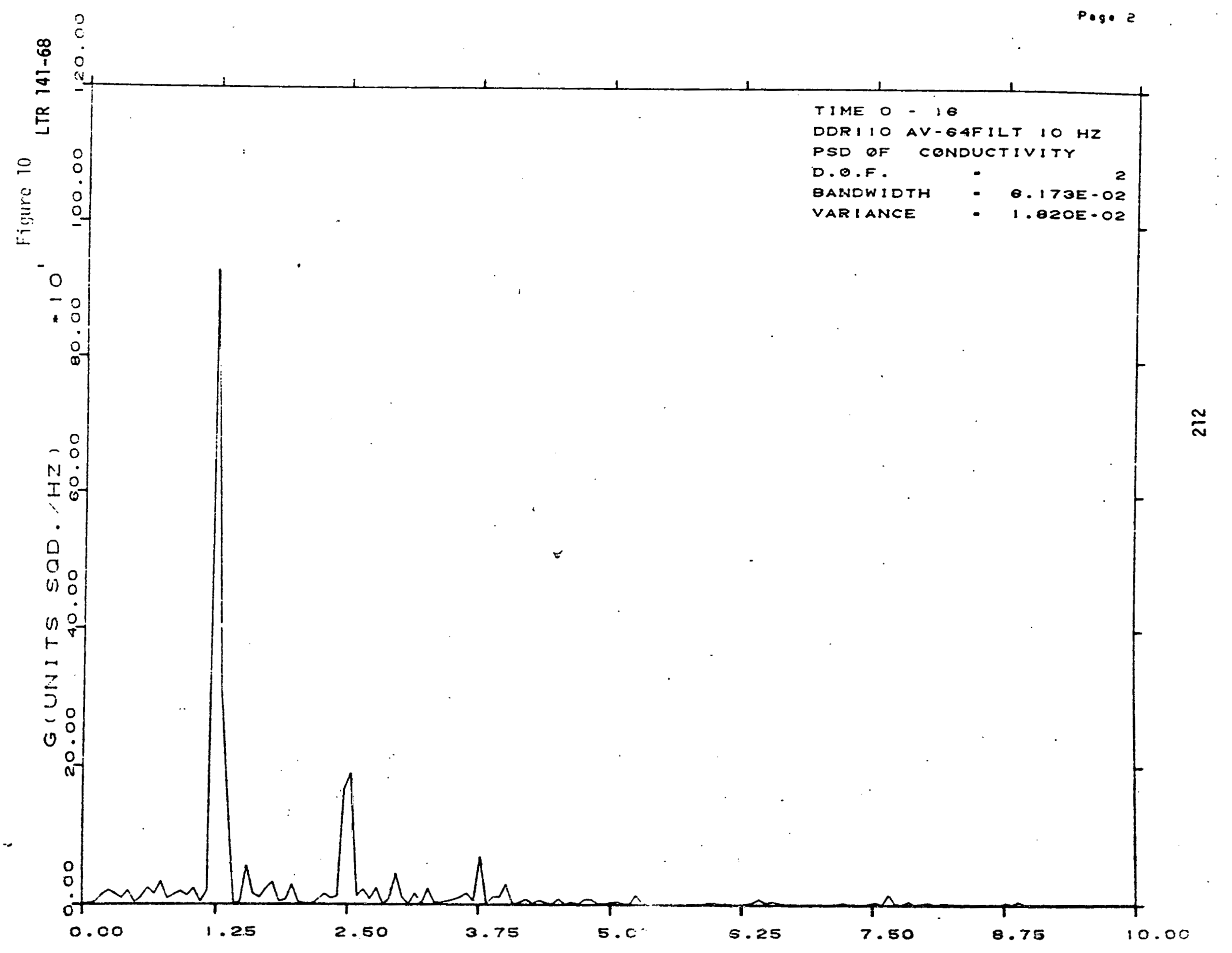




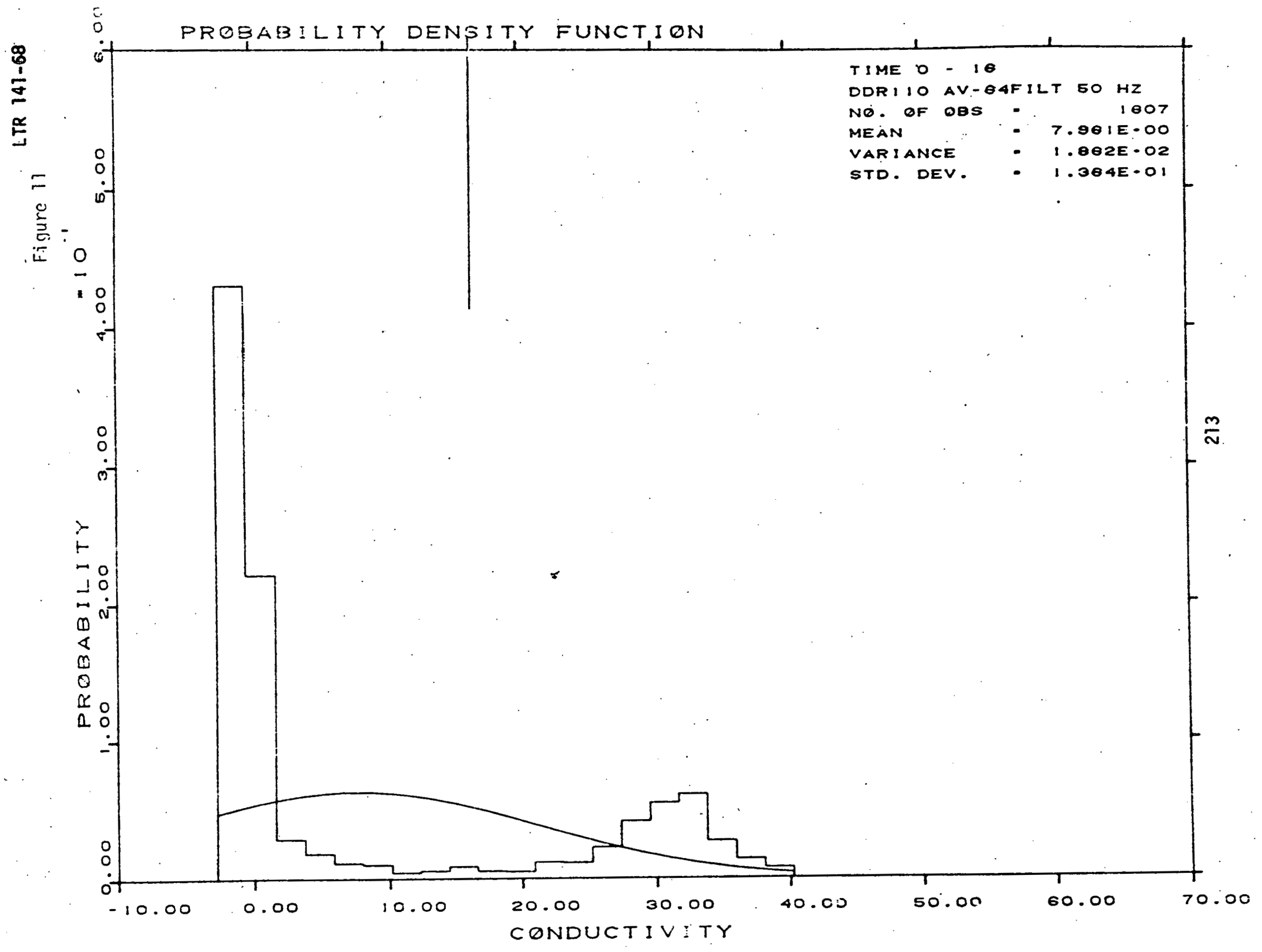




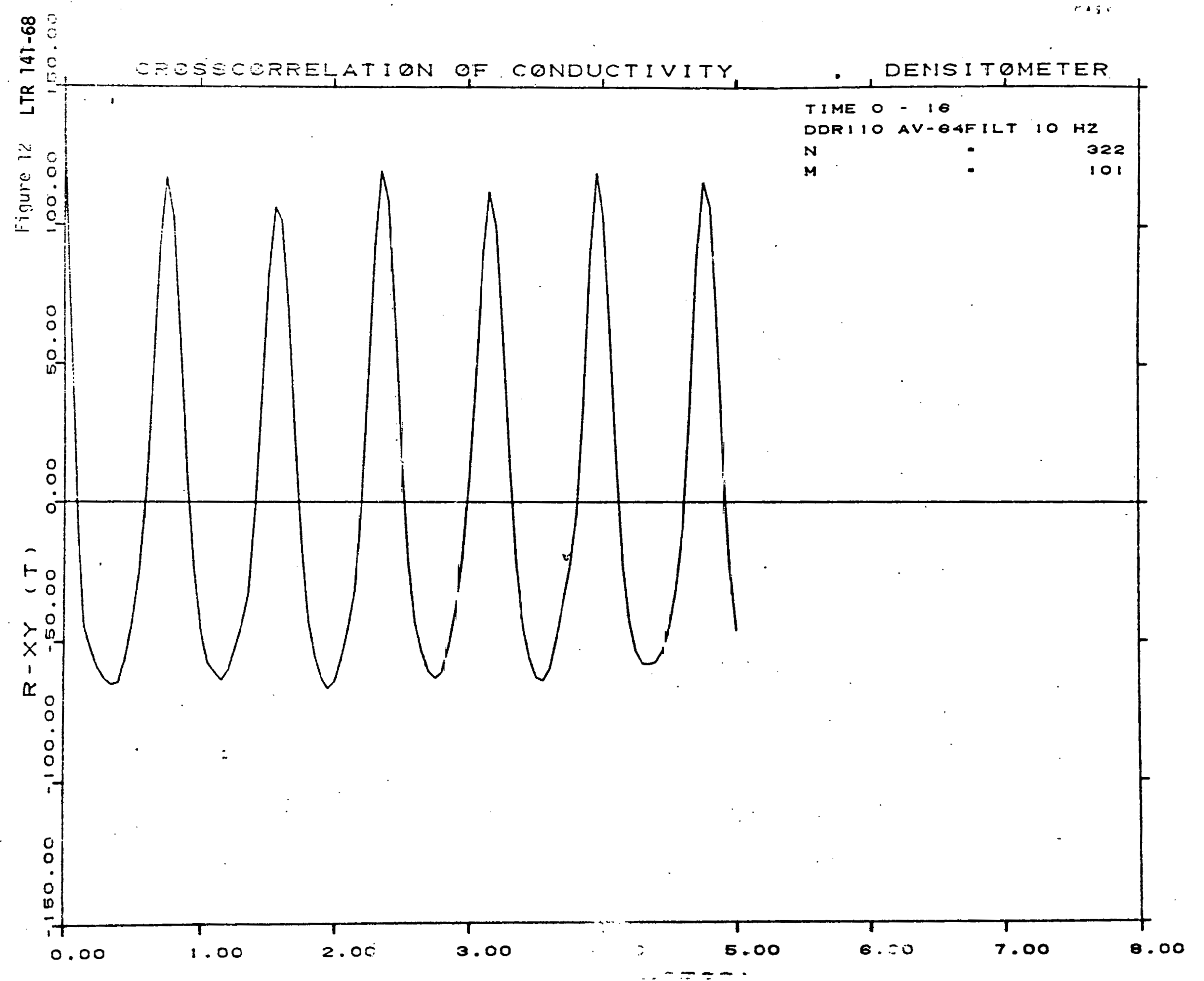




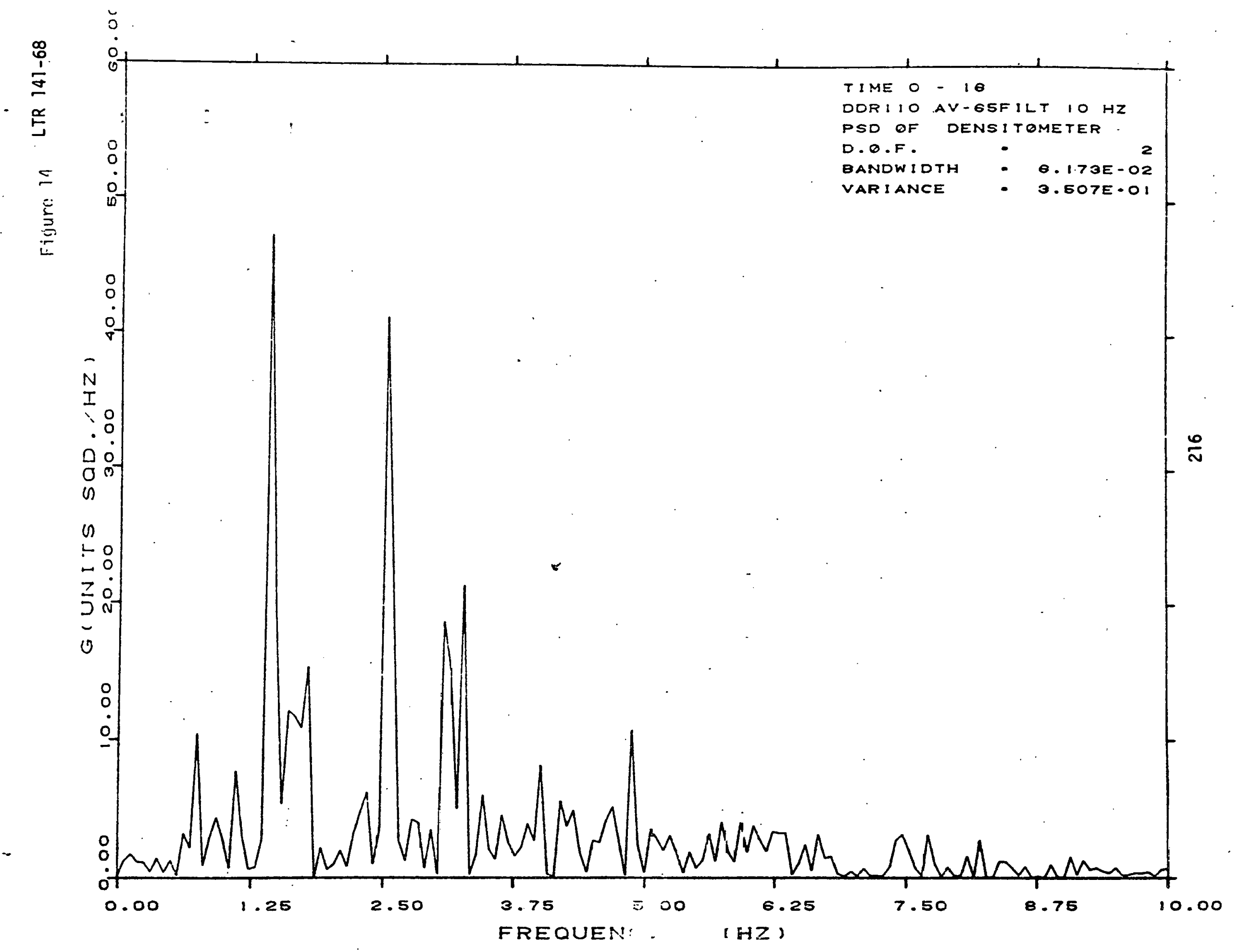




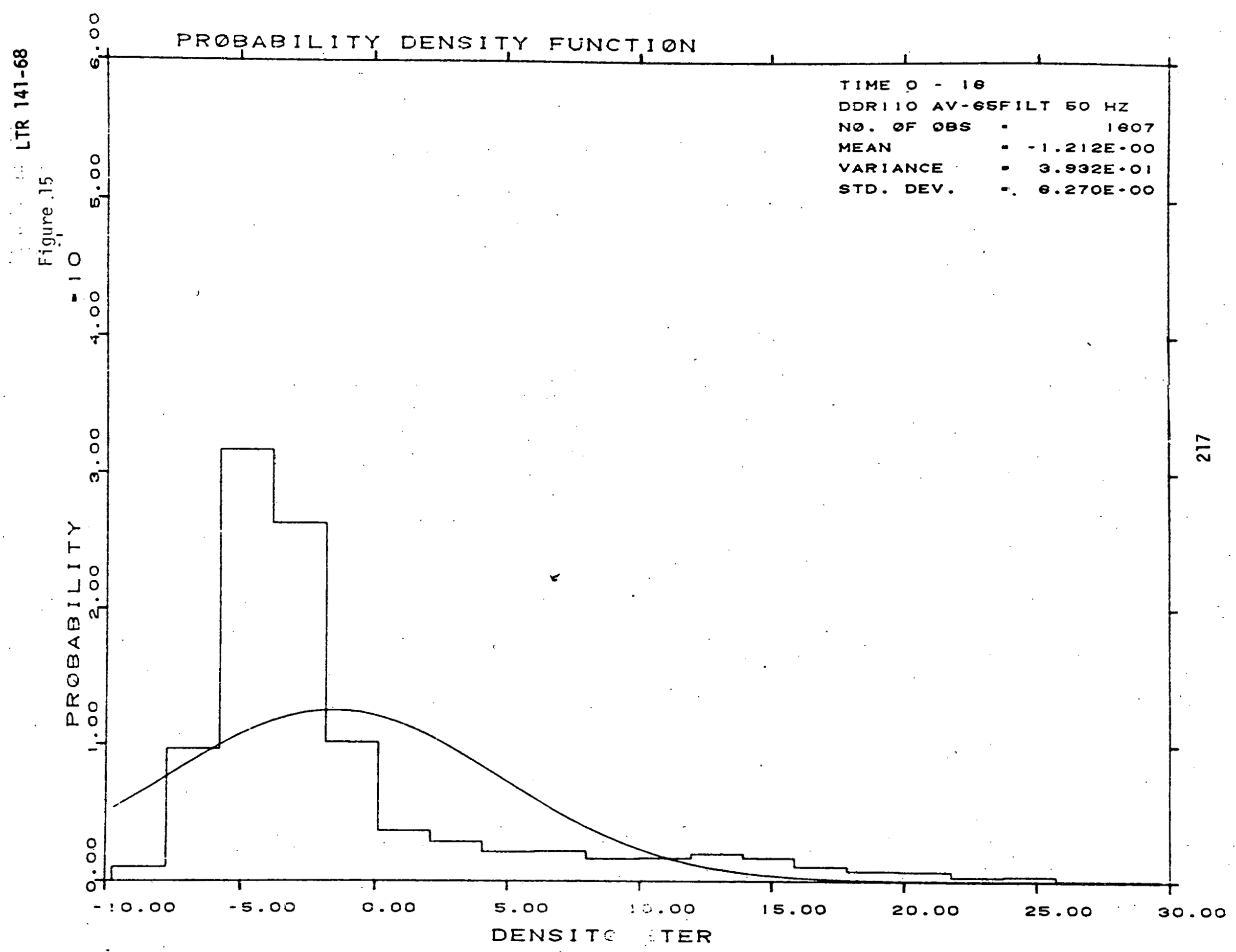




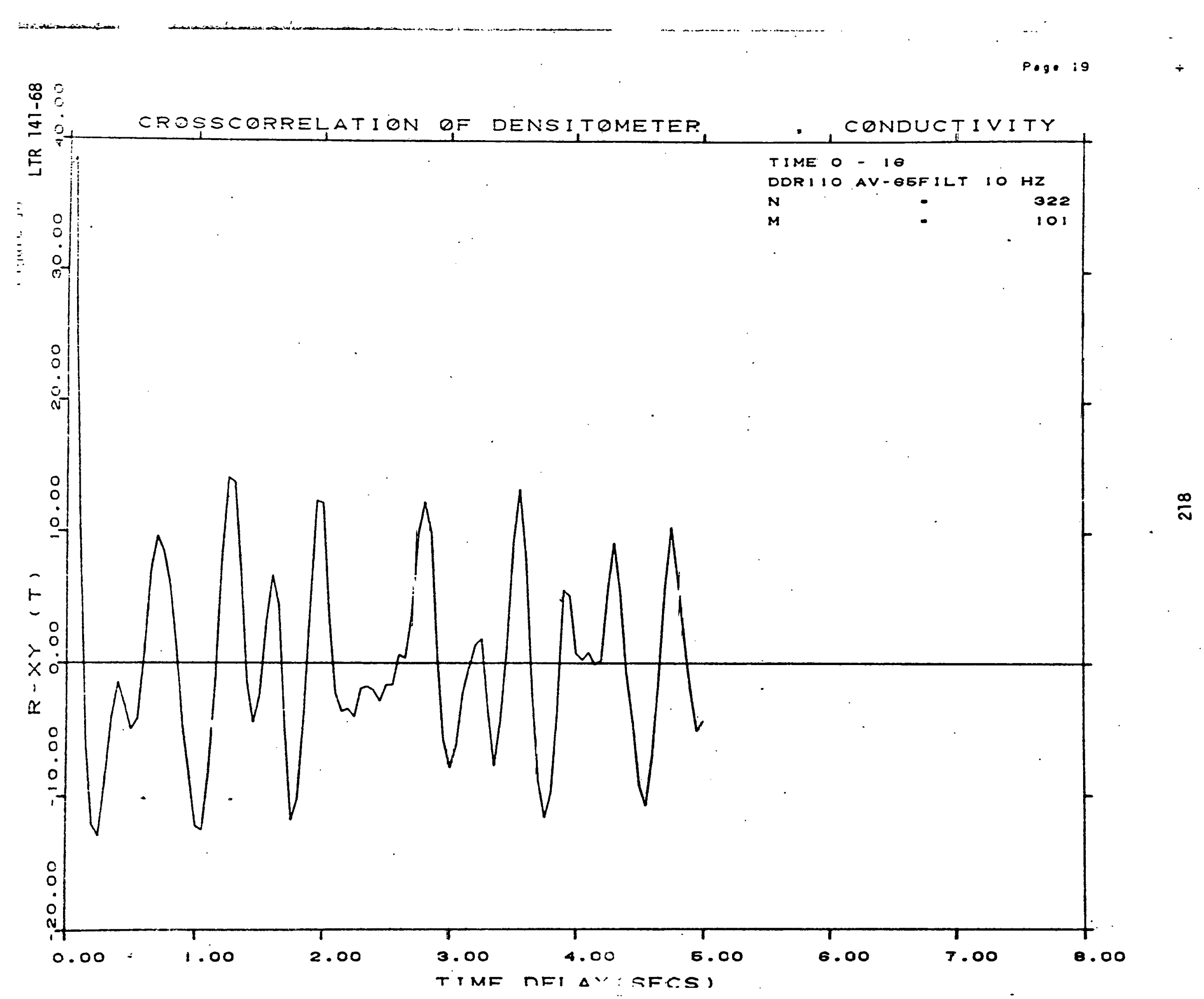




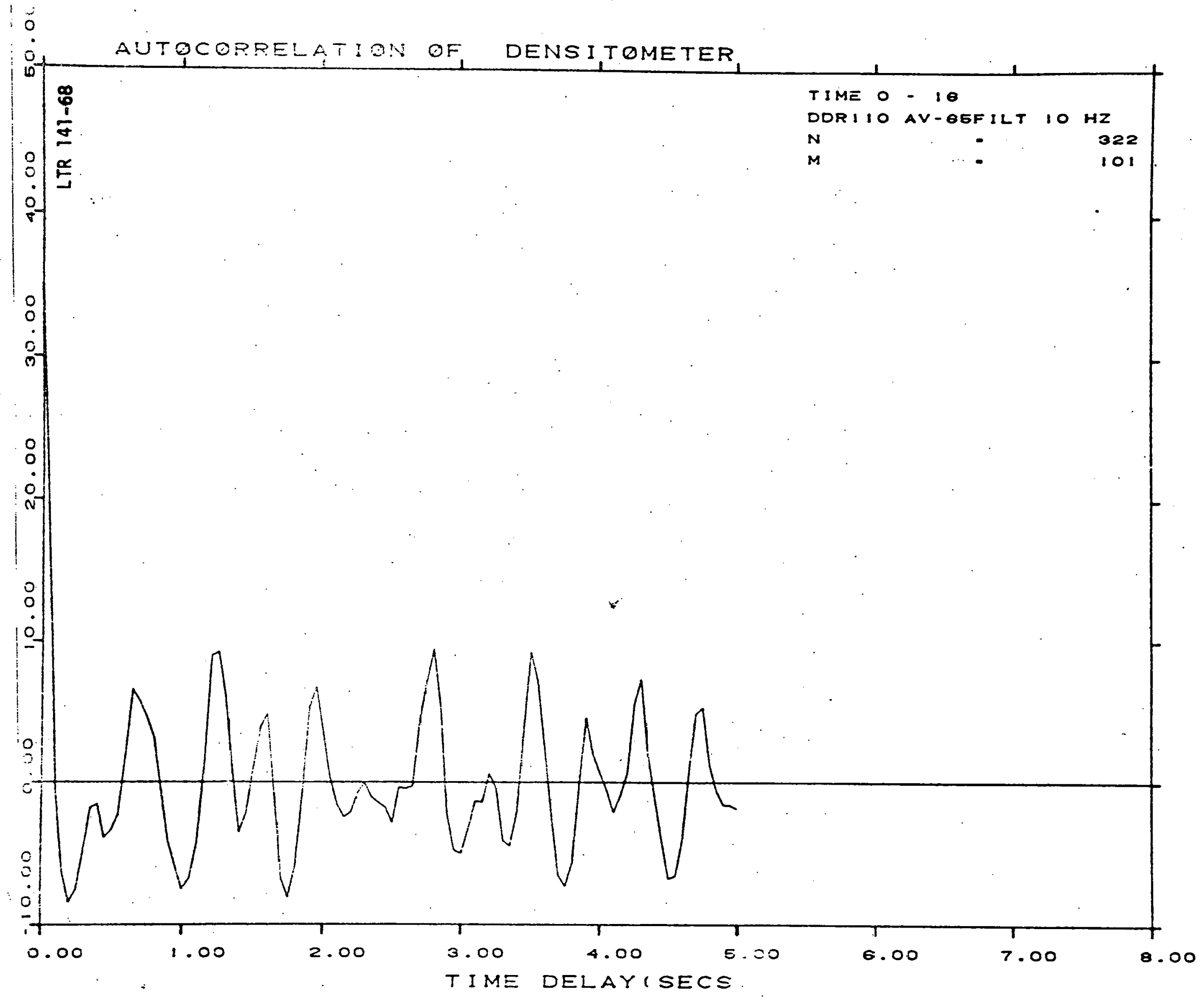




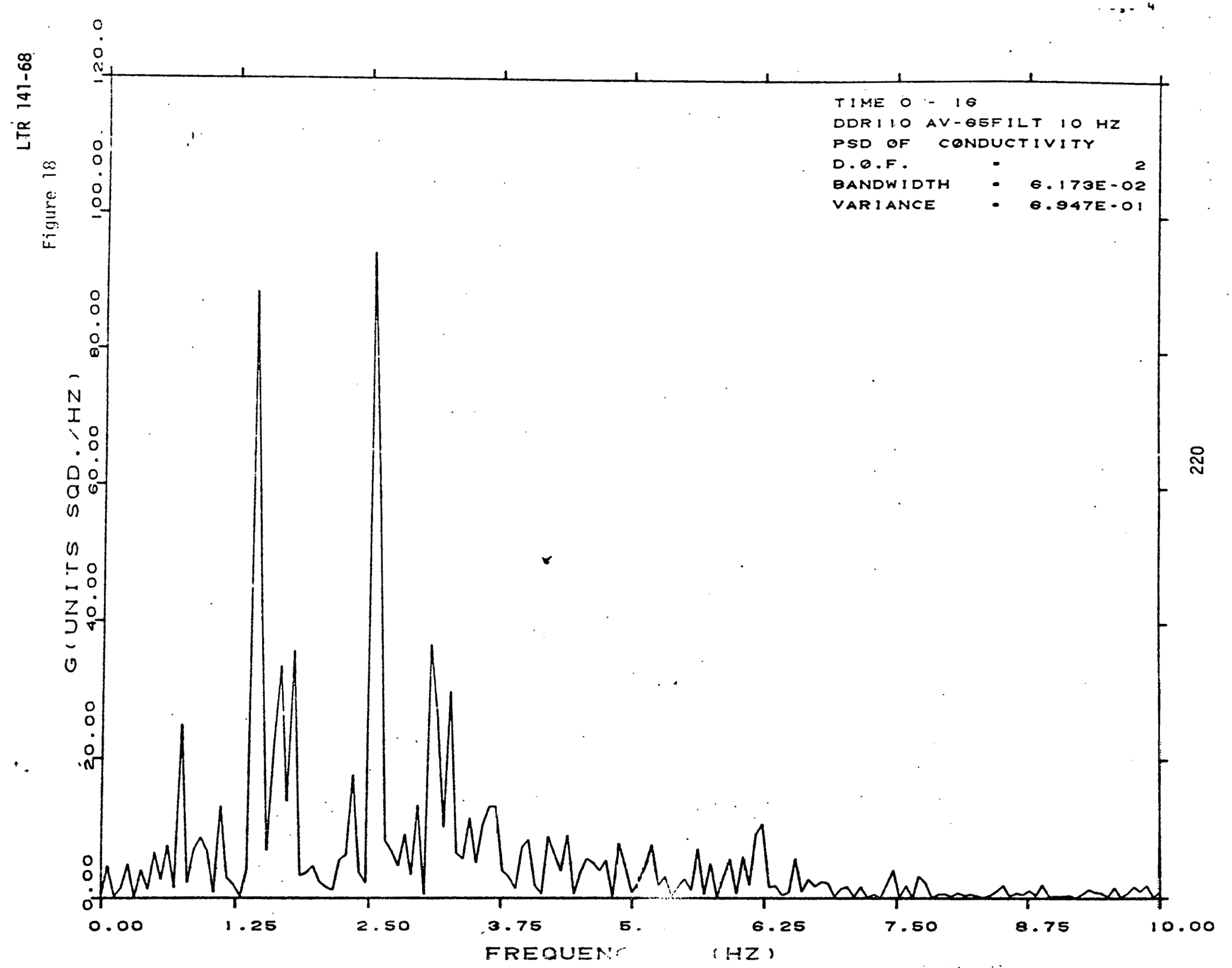




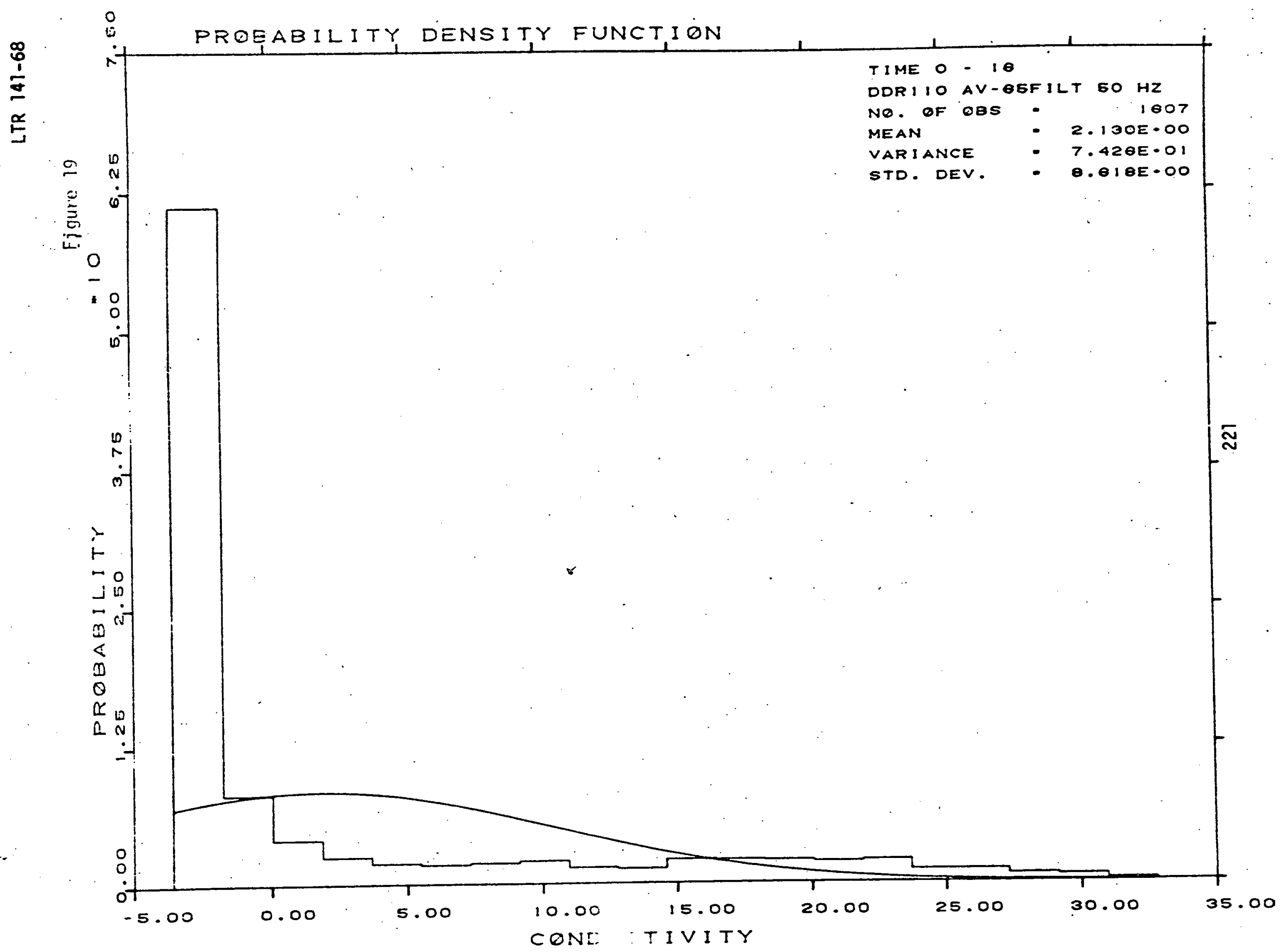




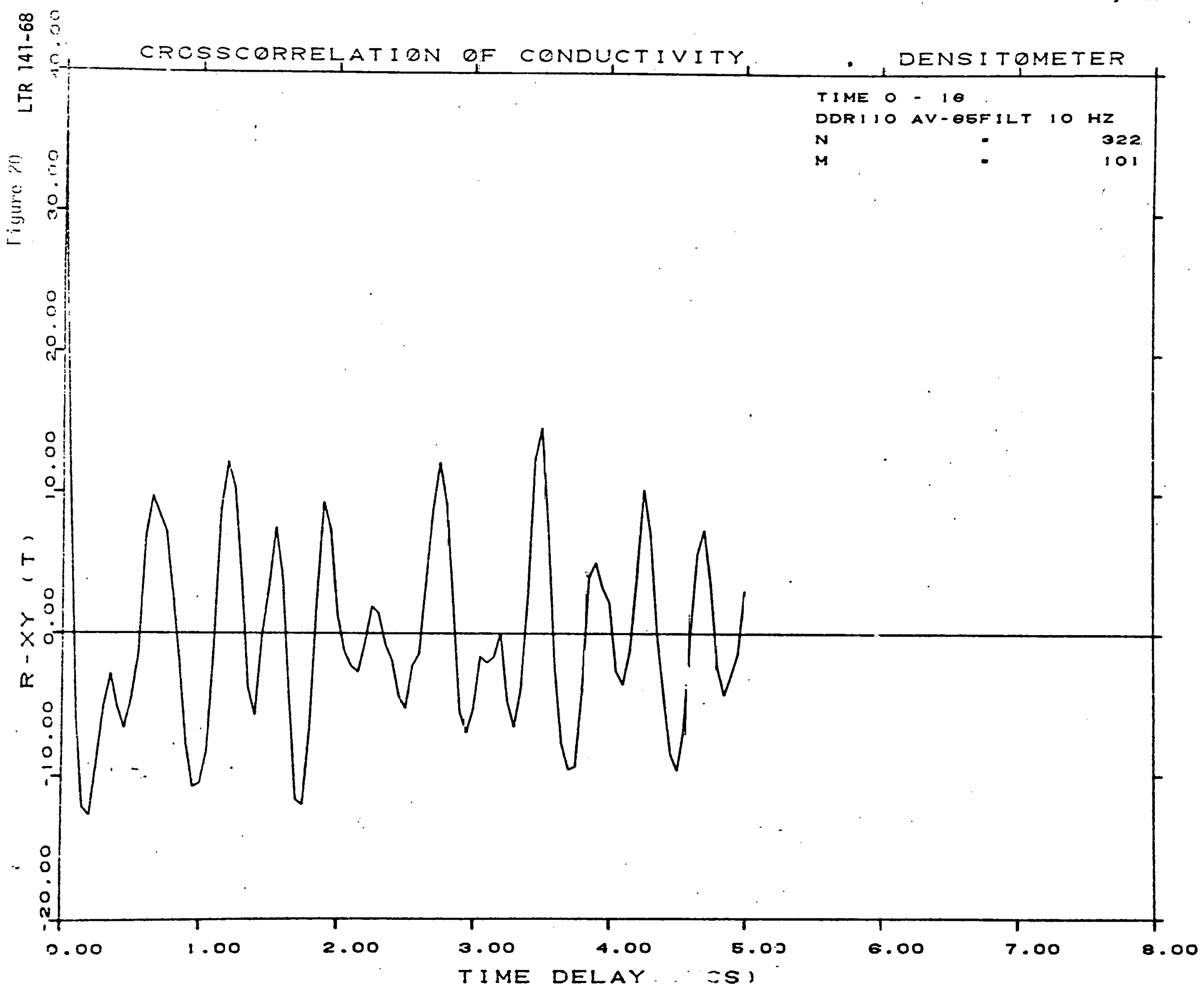


Pog. 12

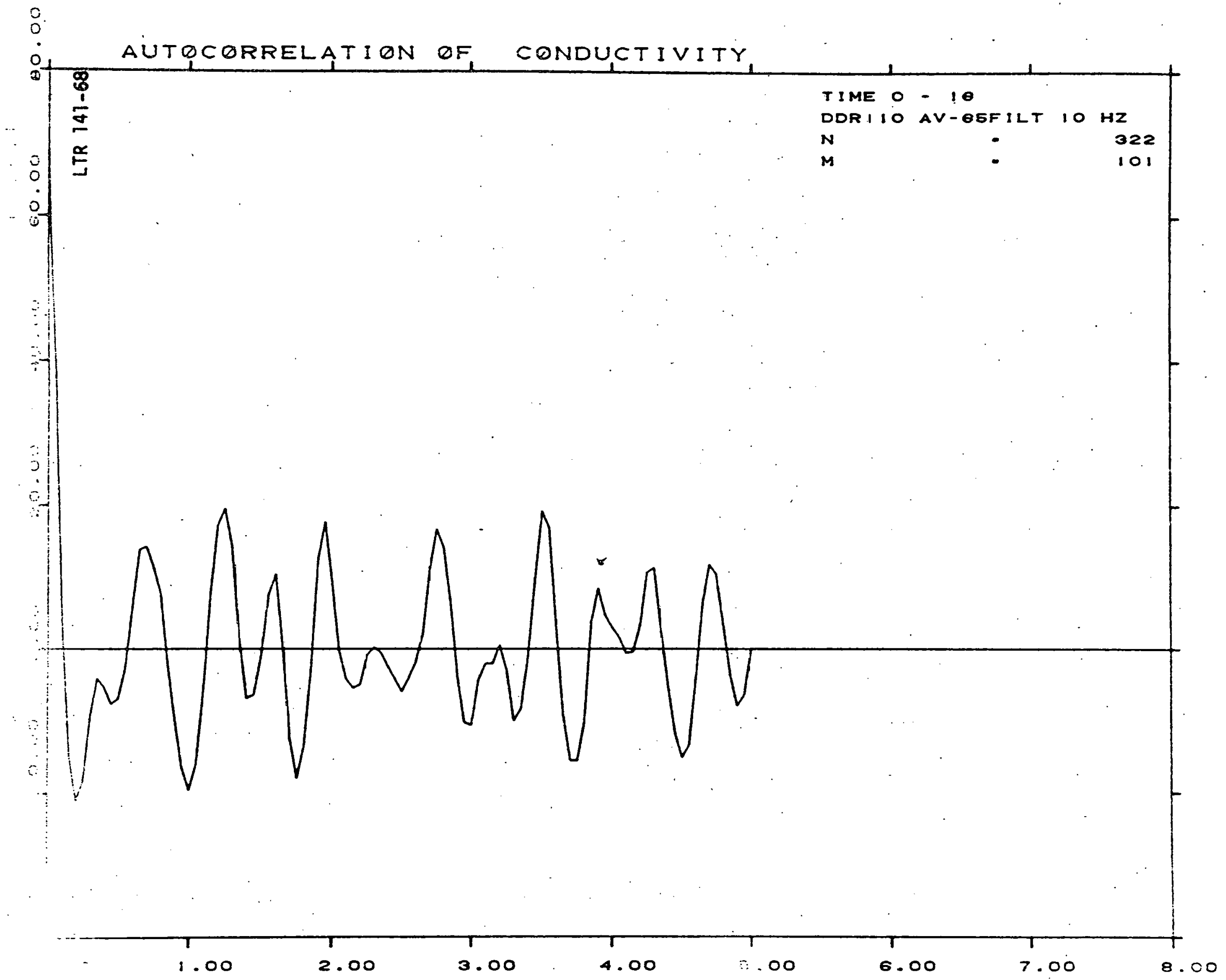




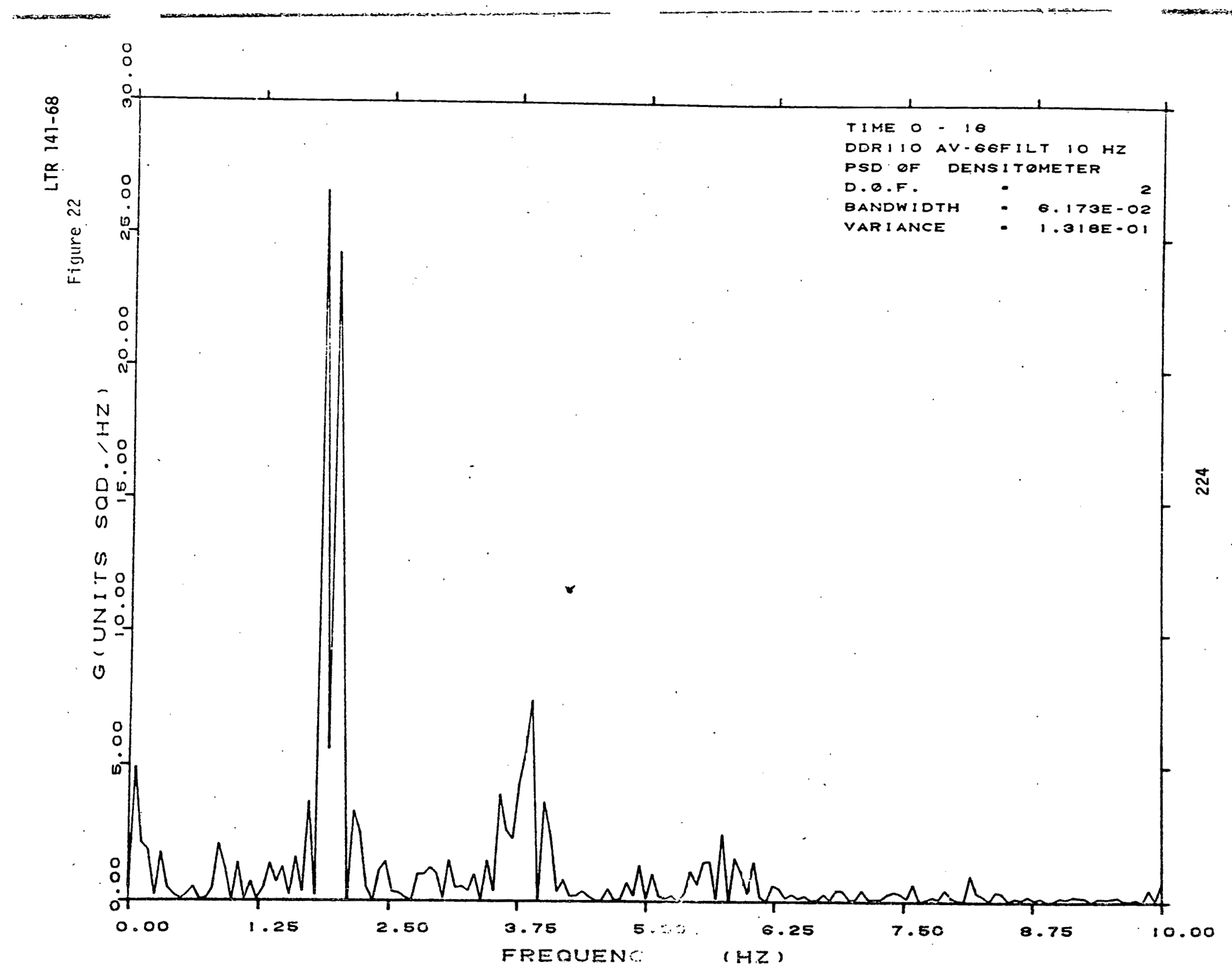




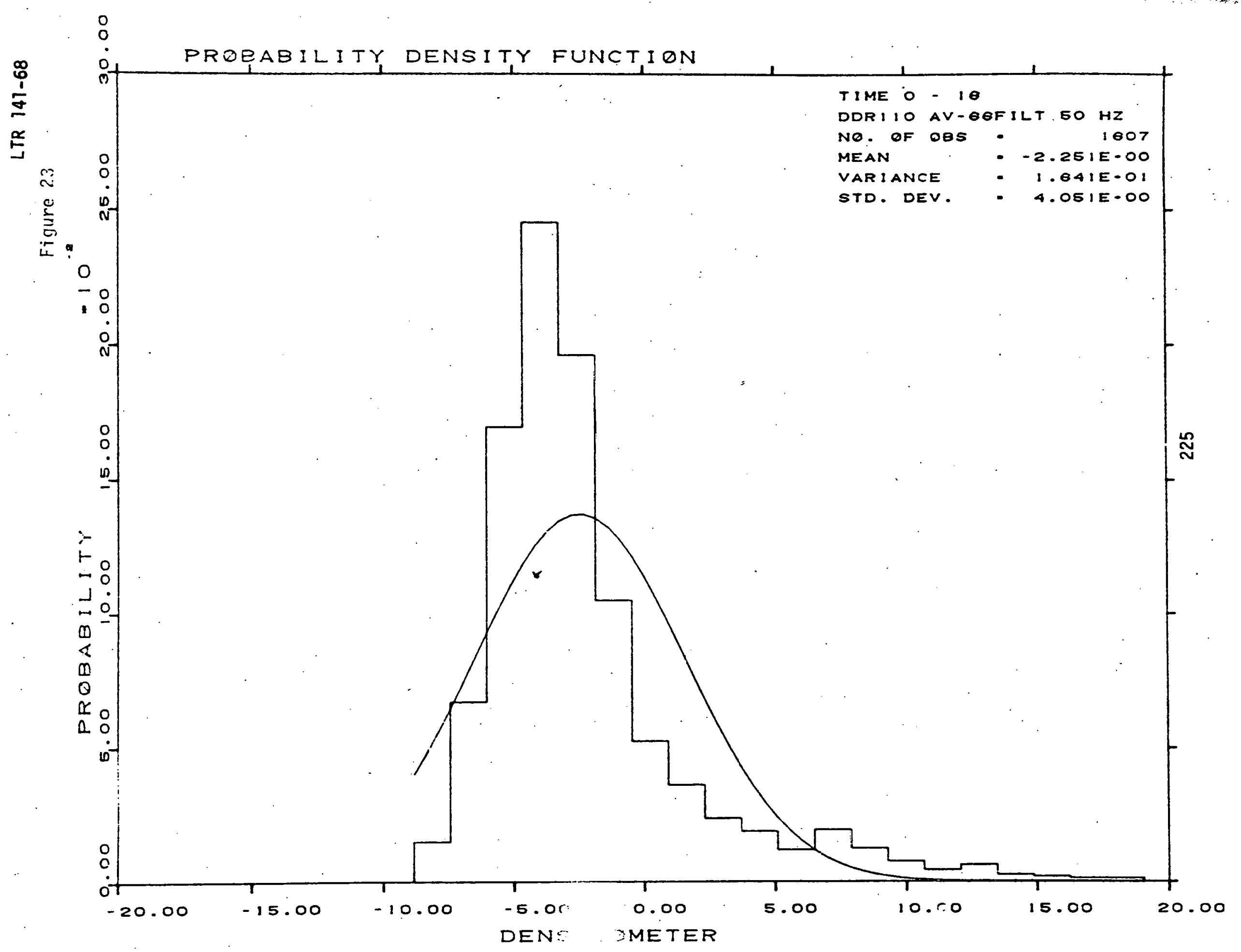




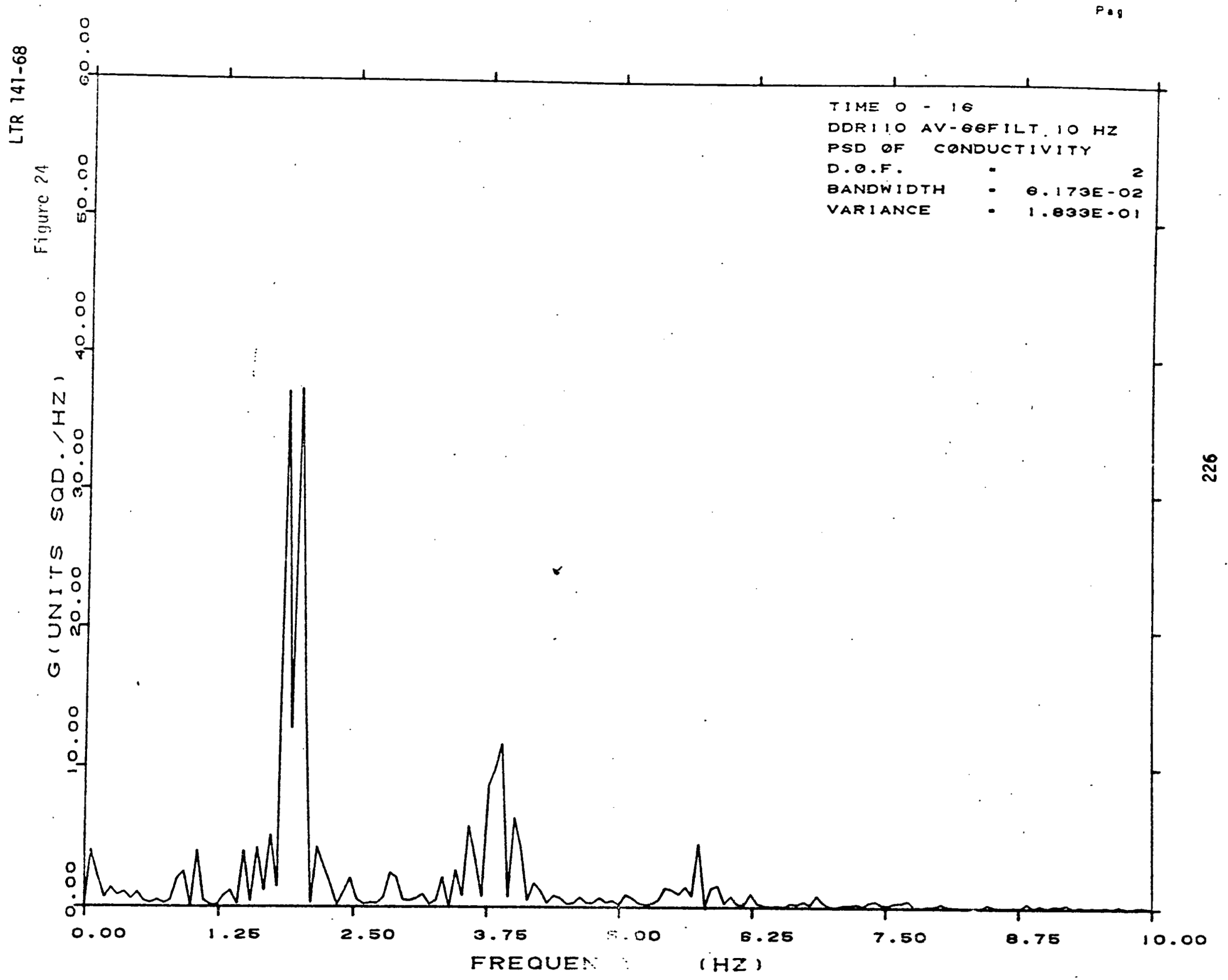




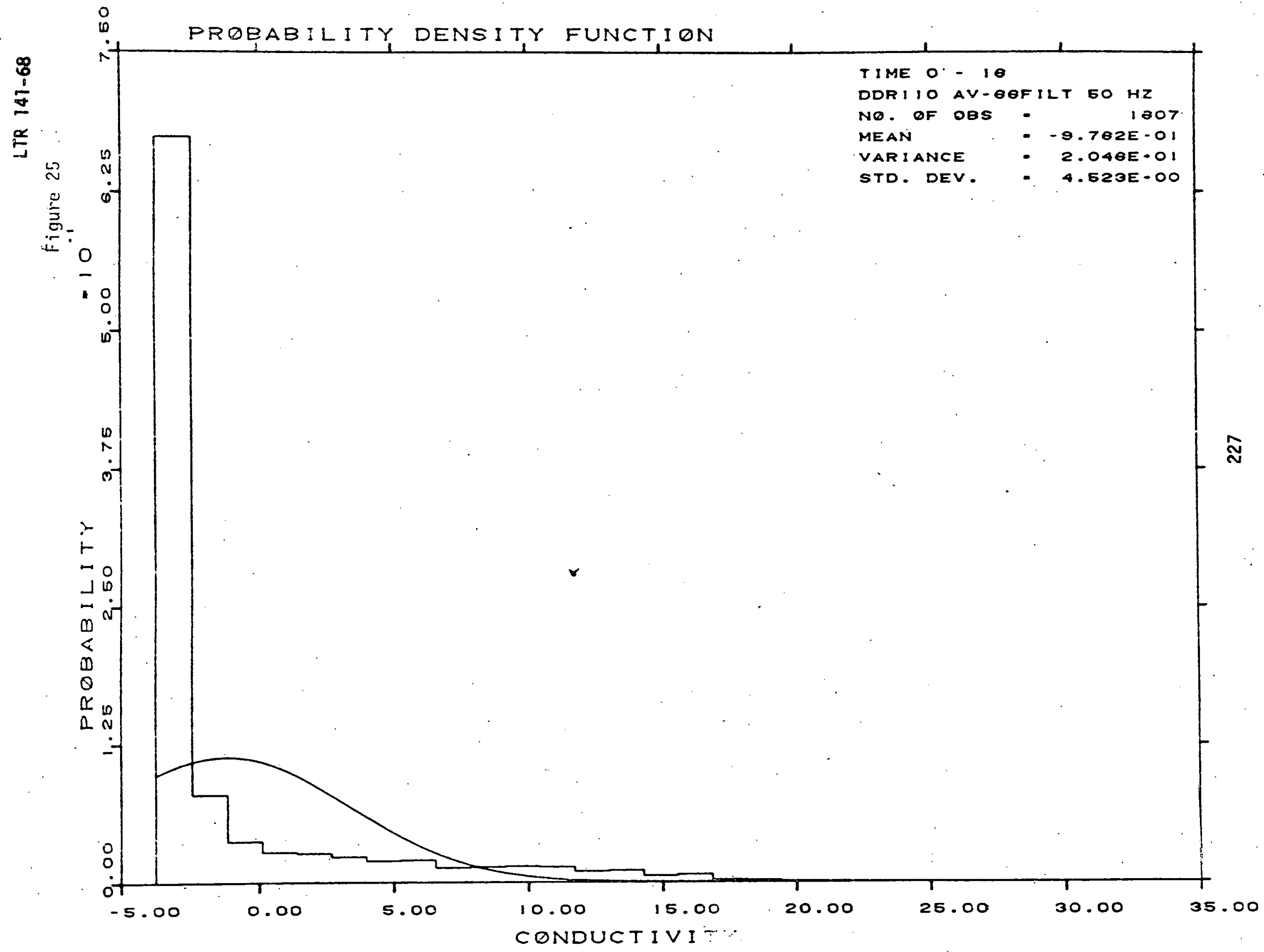




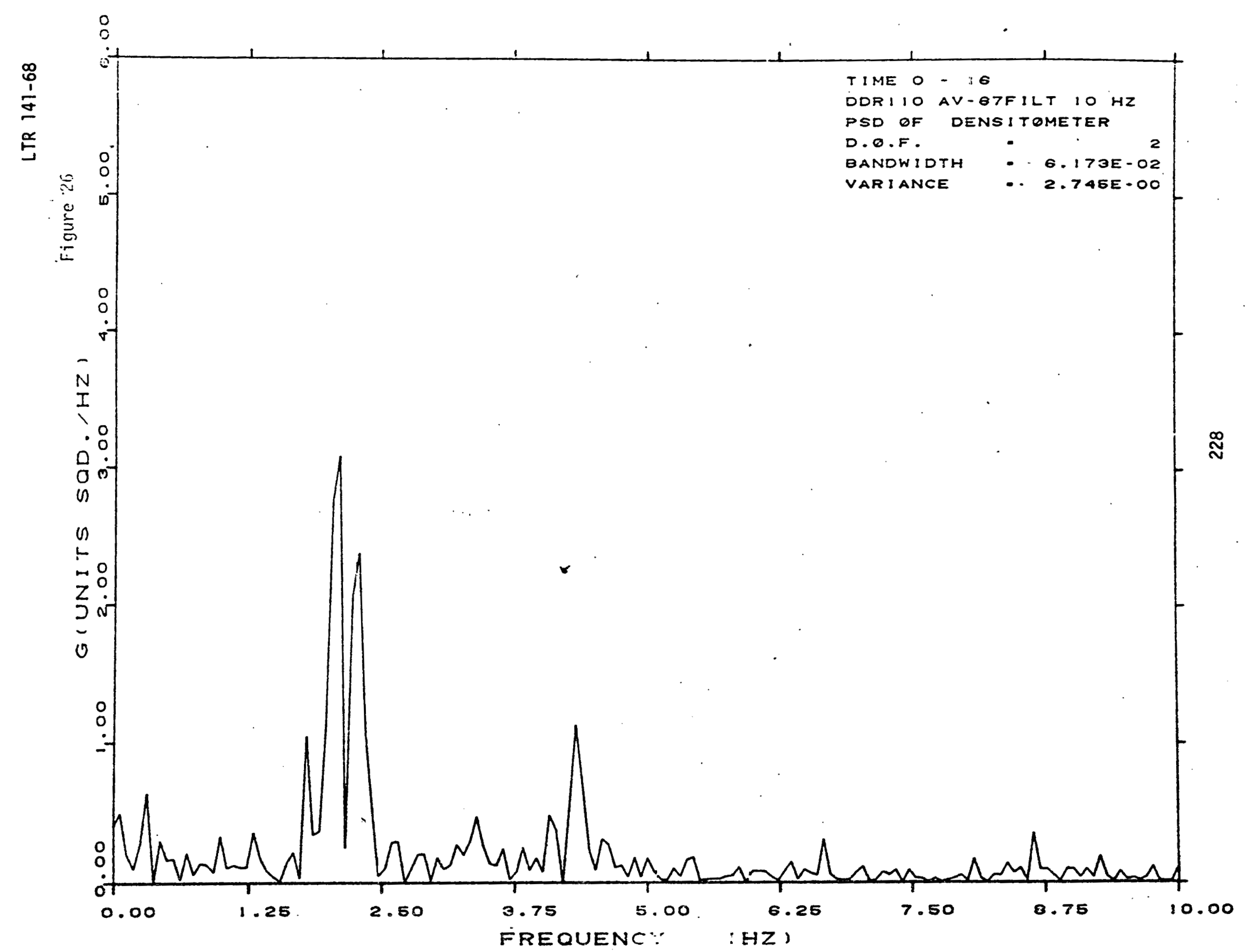




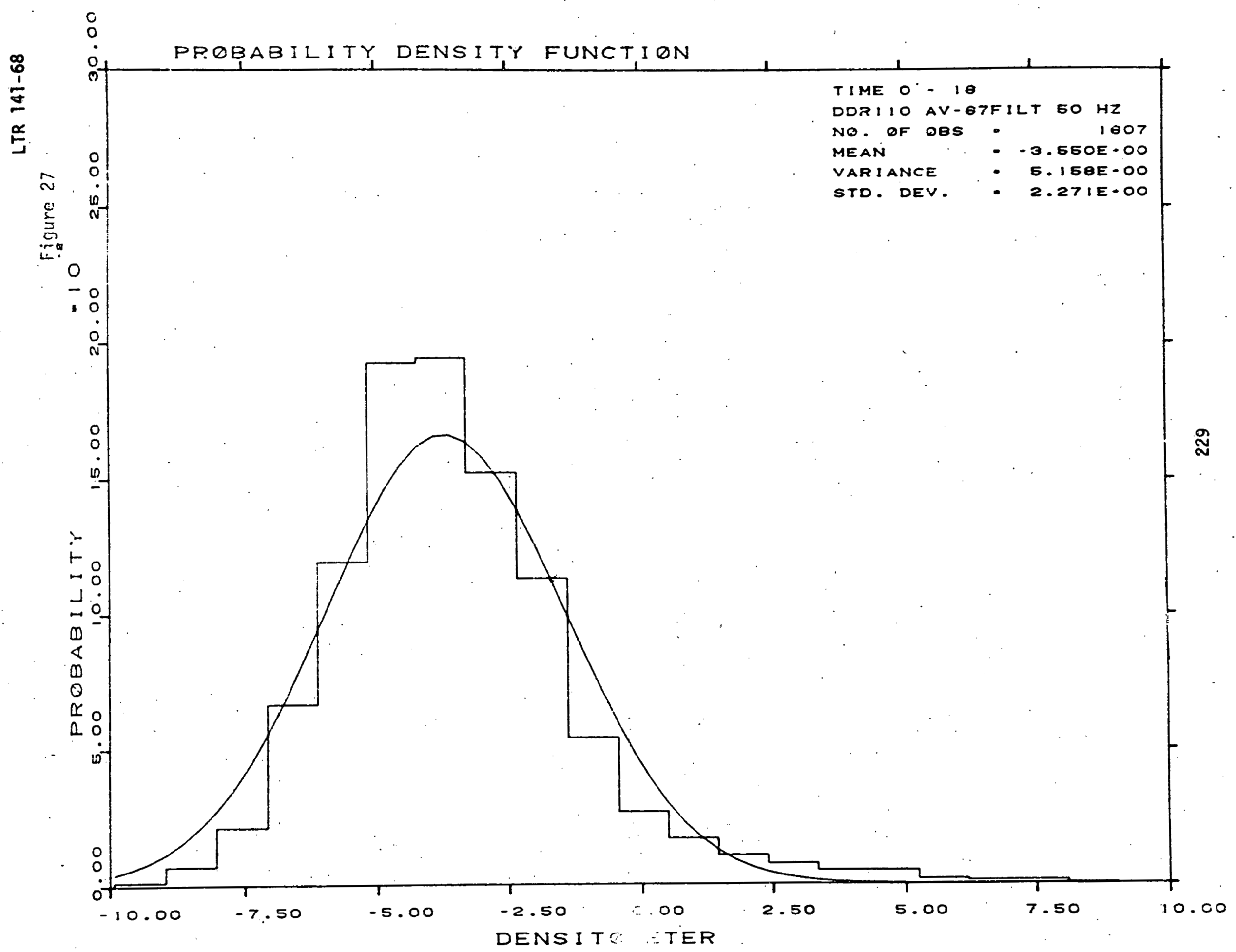




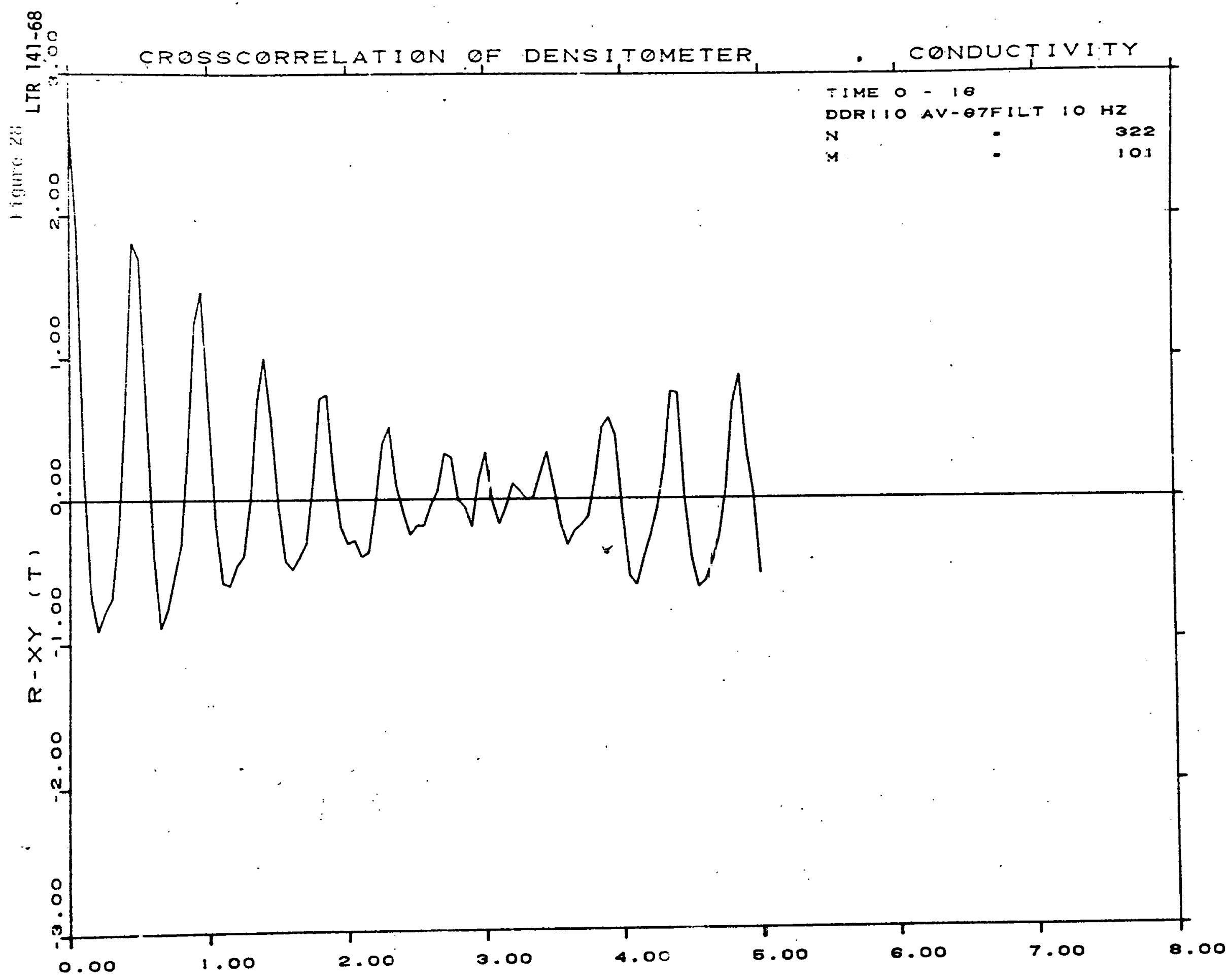




HWMAnMM




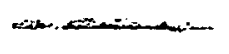

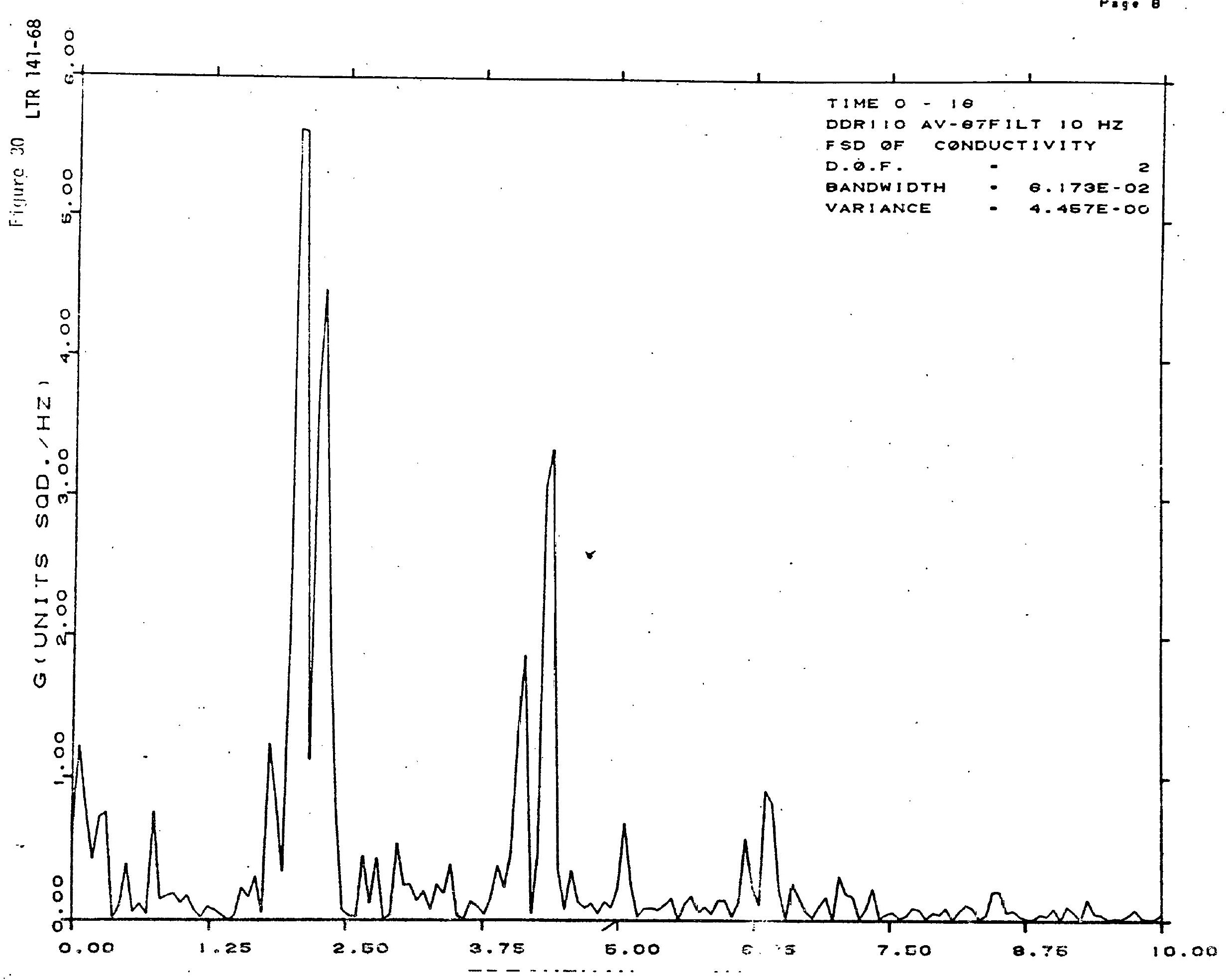




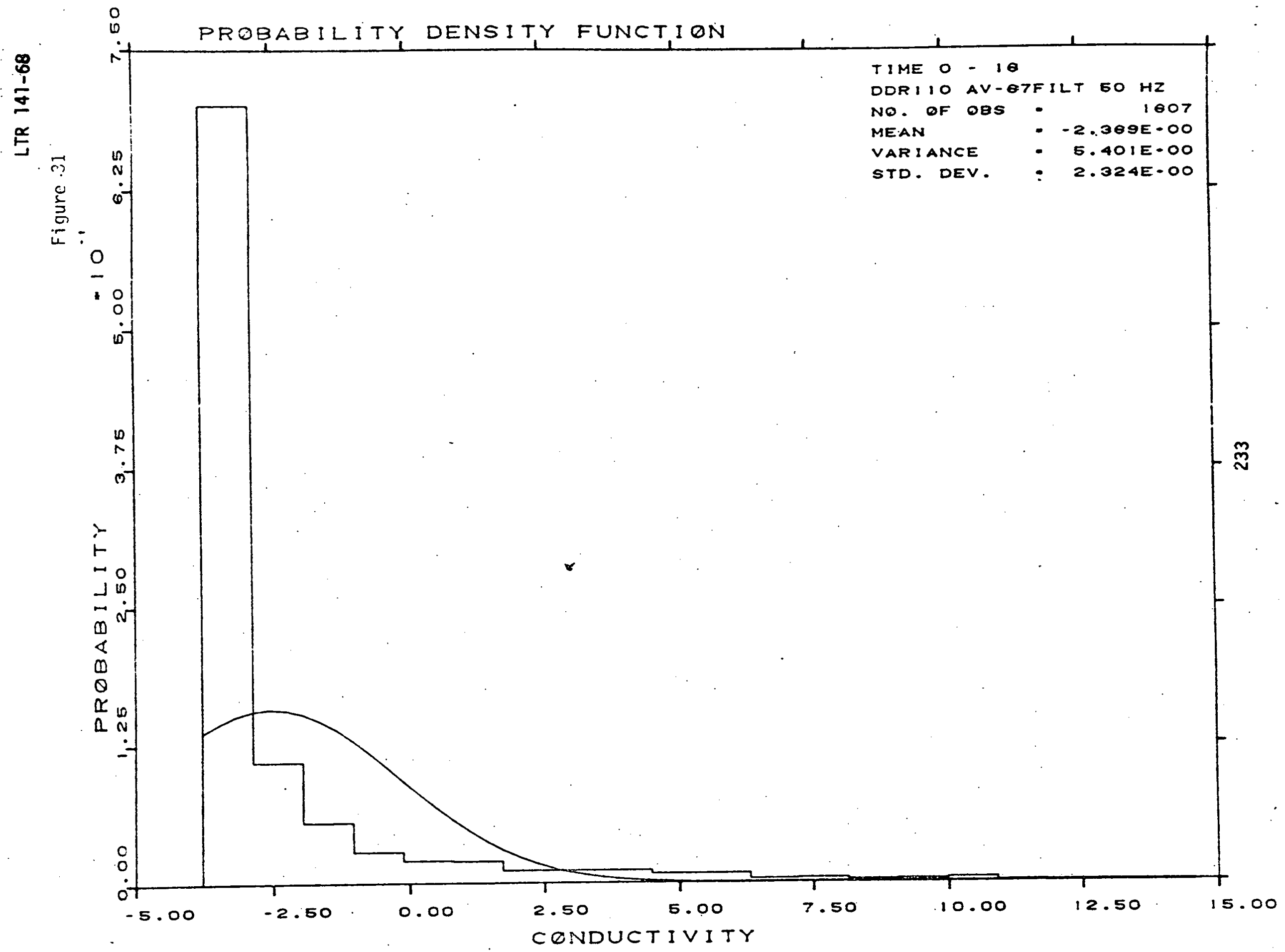




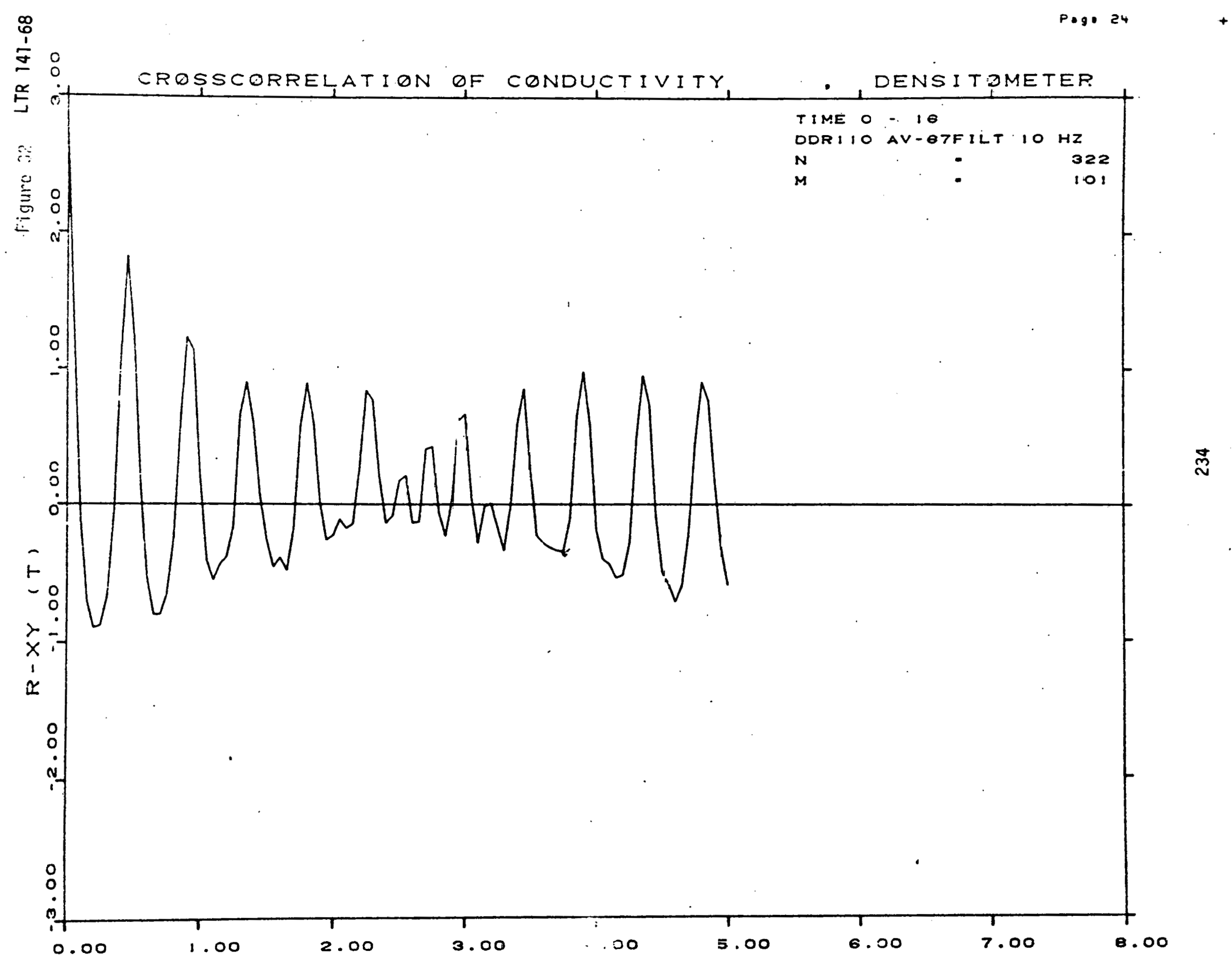




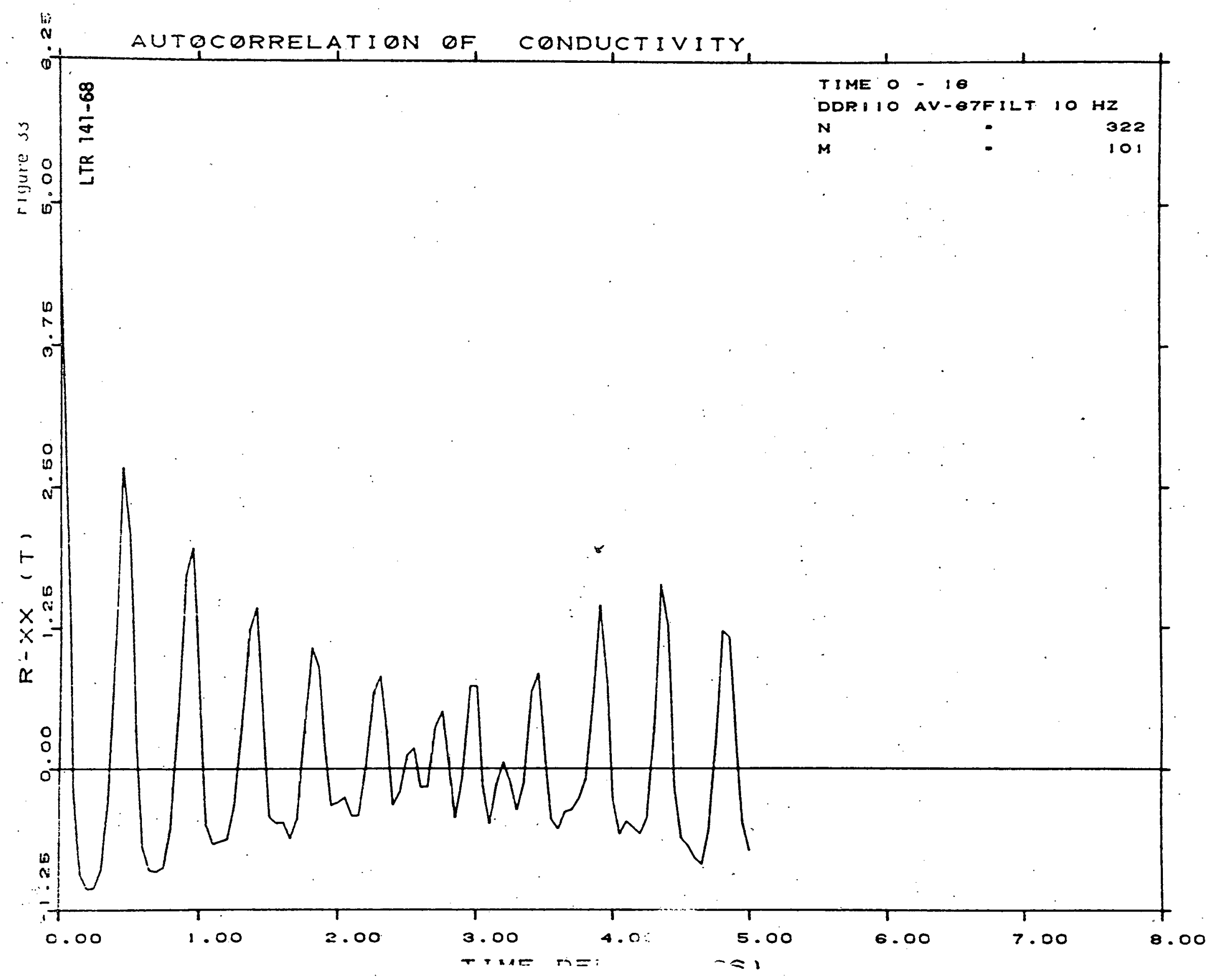




$$
\text { Whane }
$$




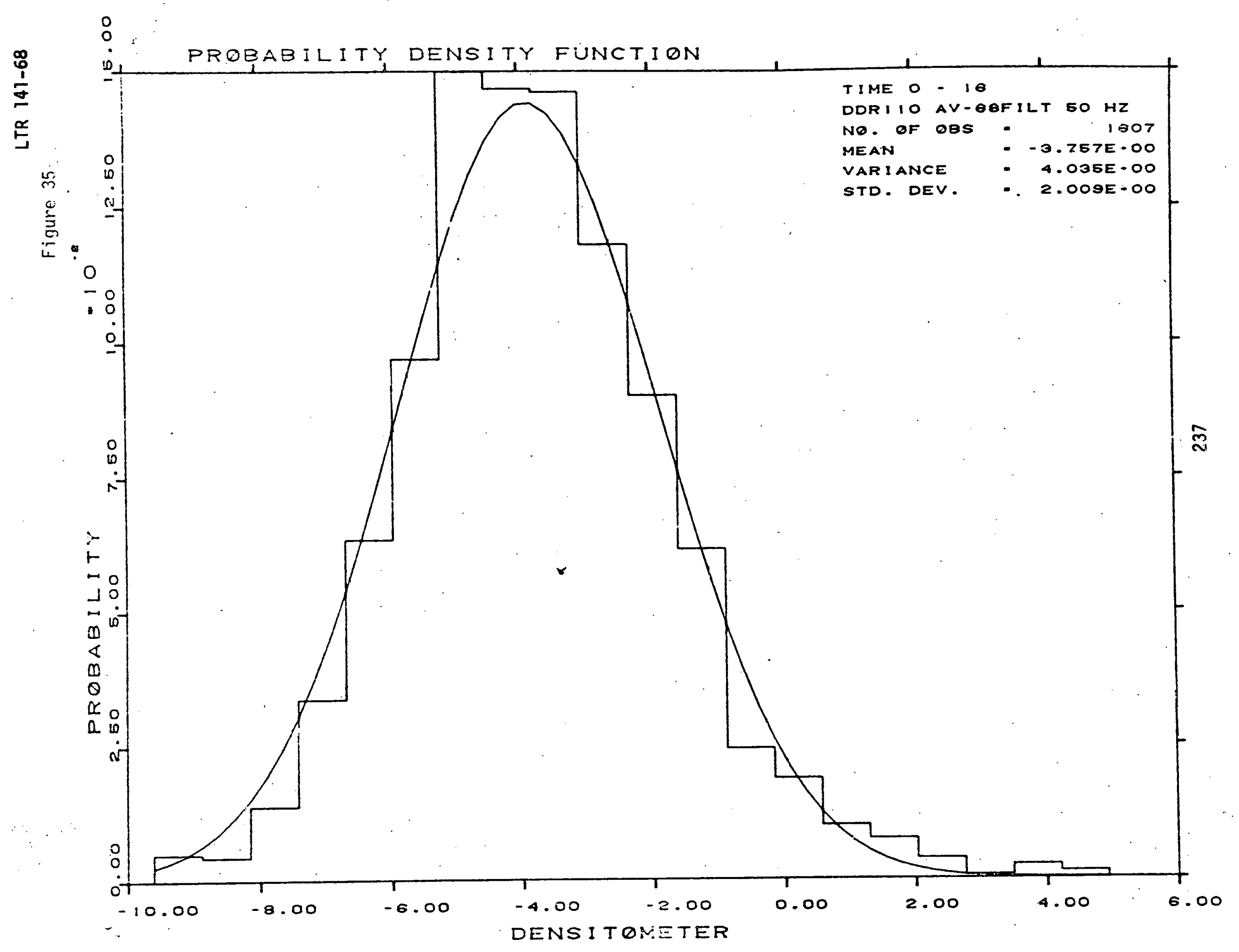




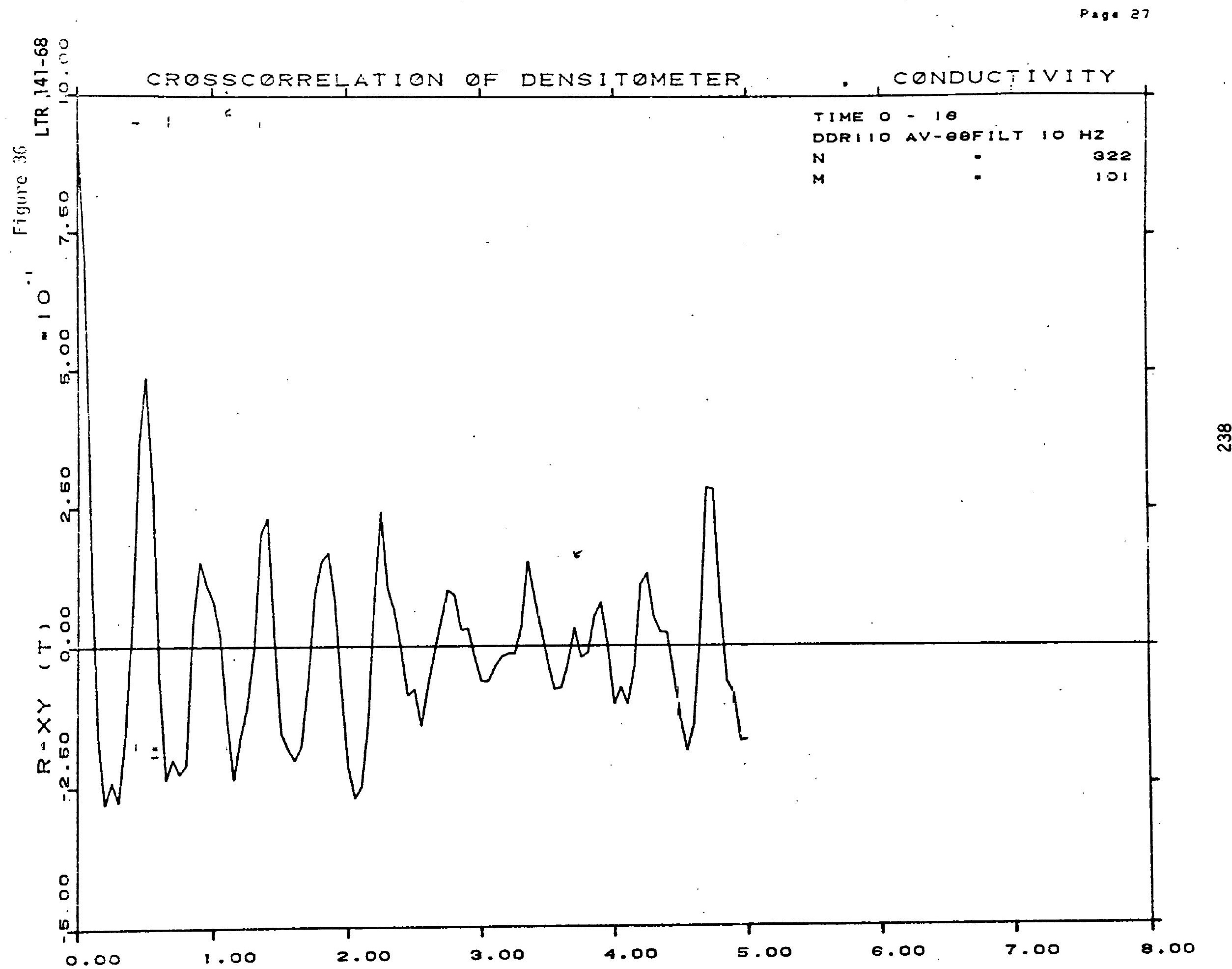




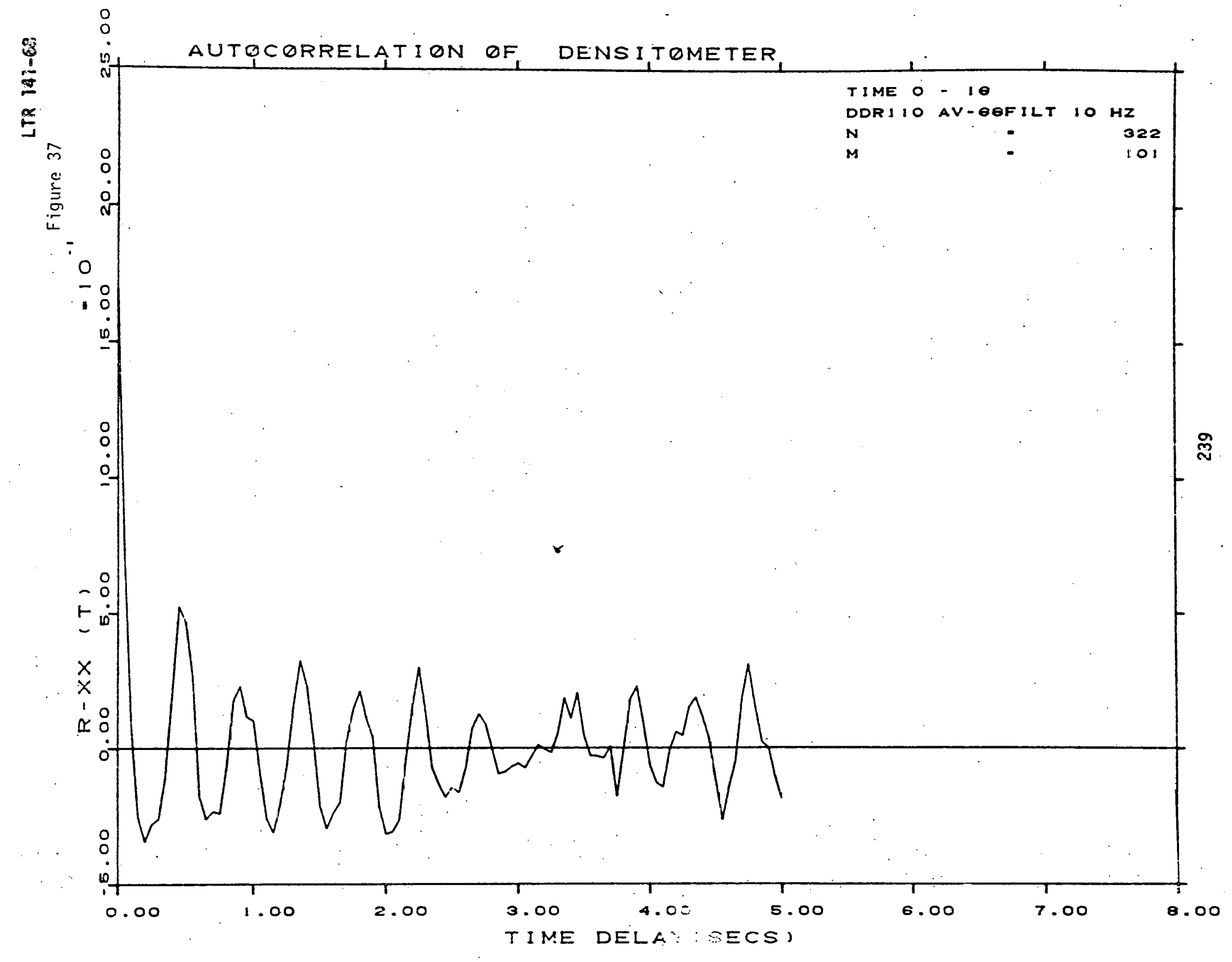




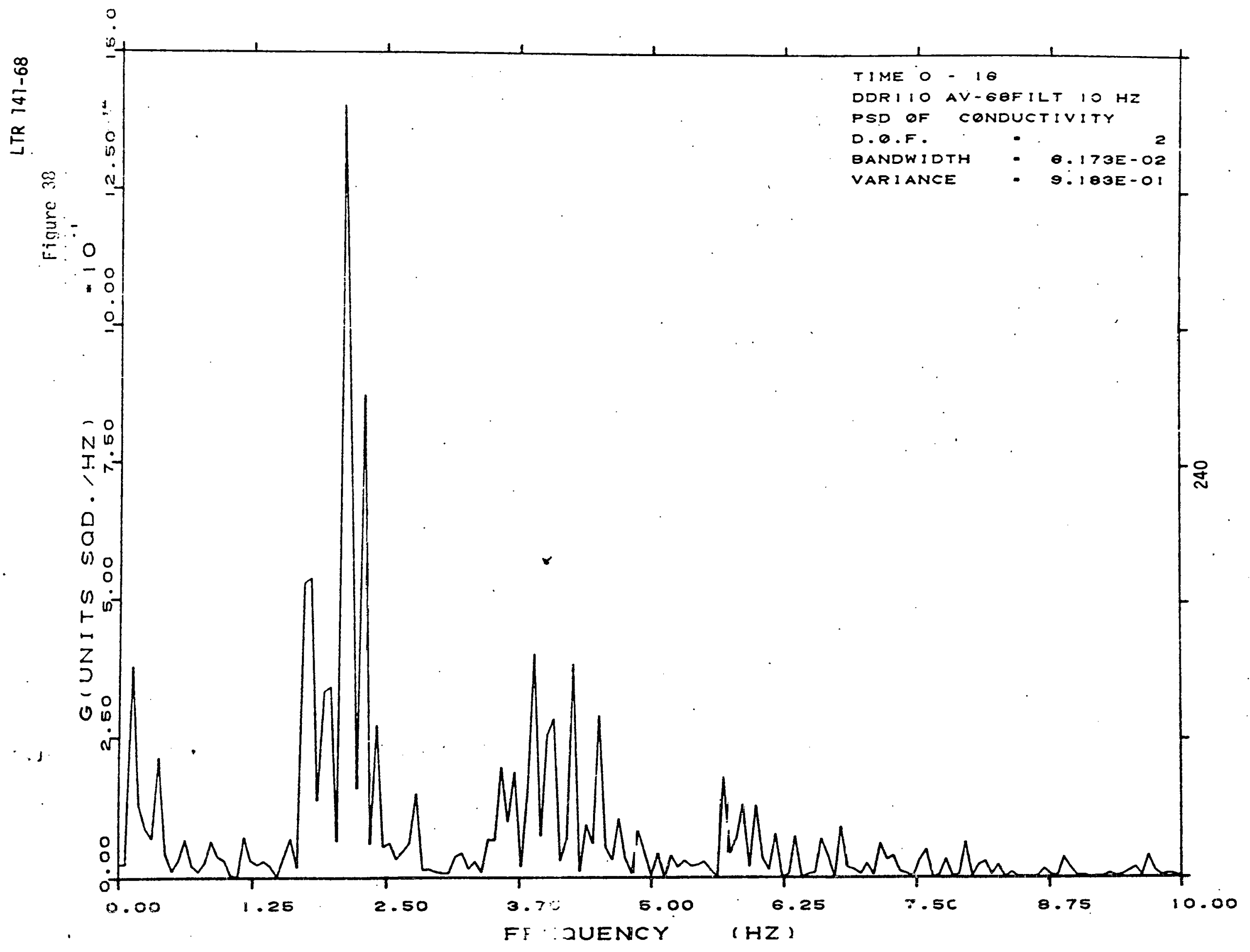




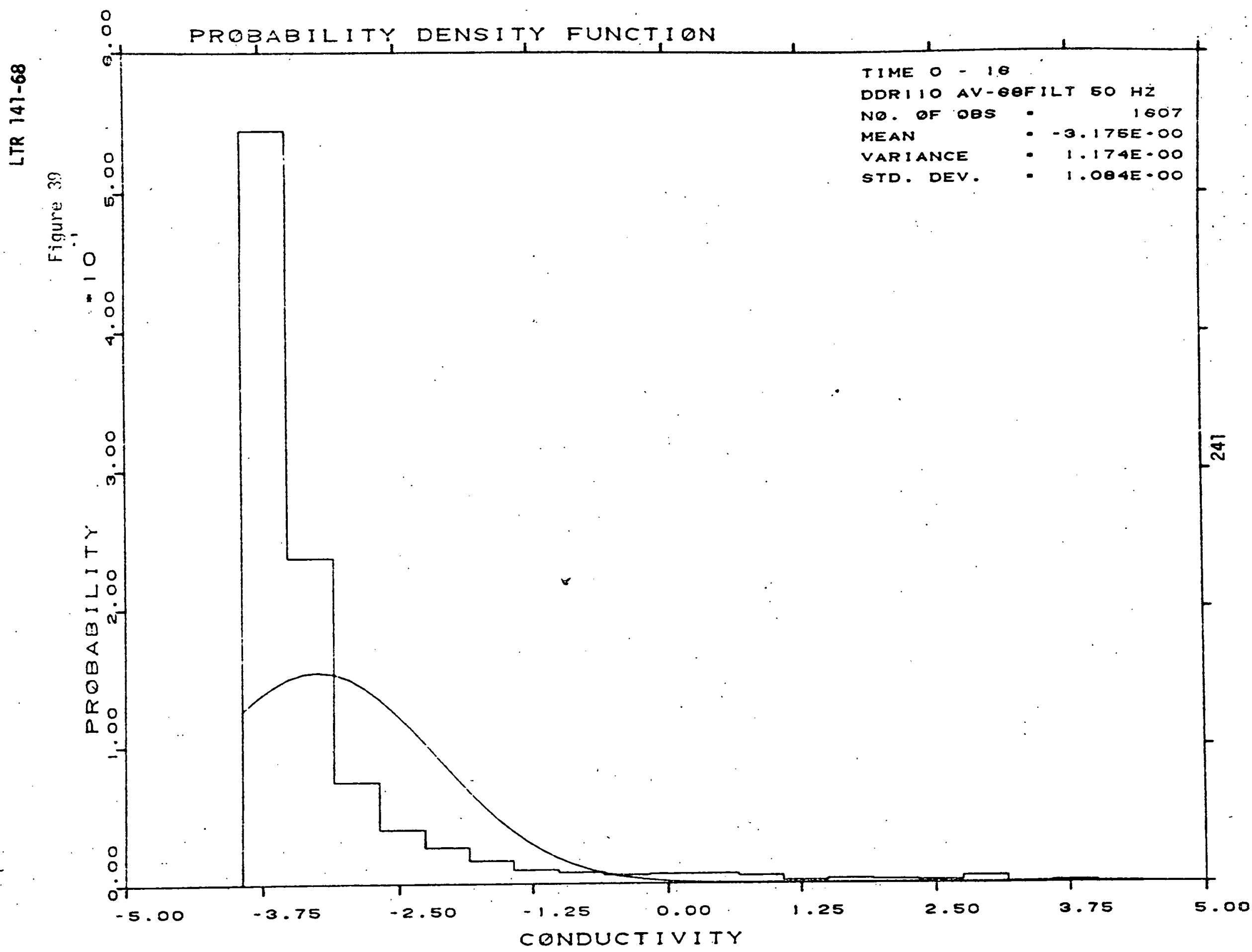




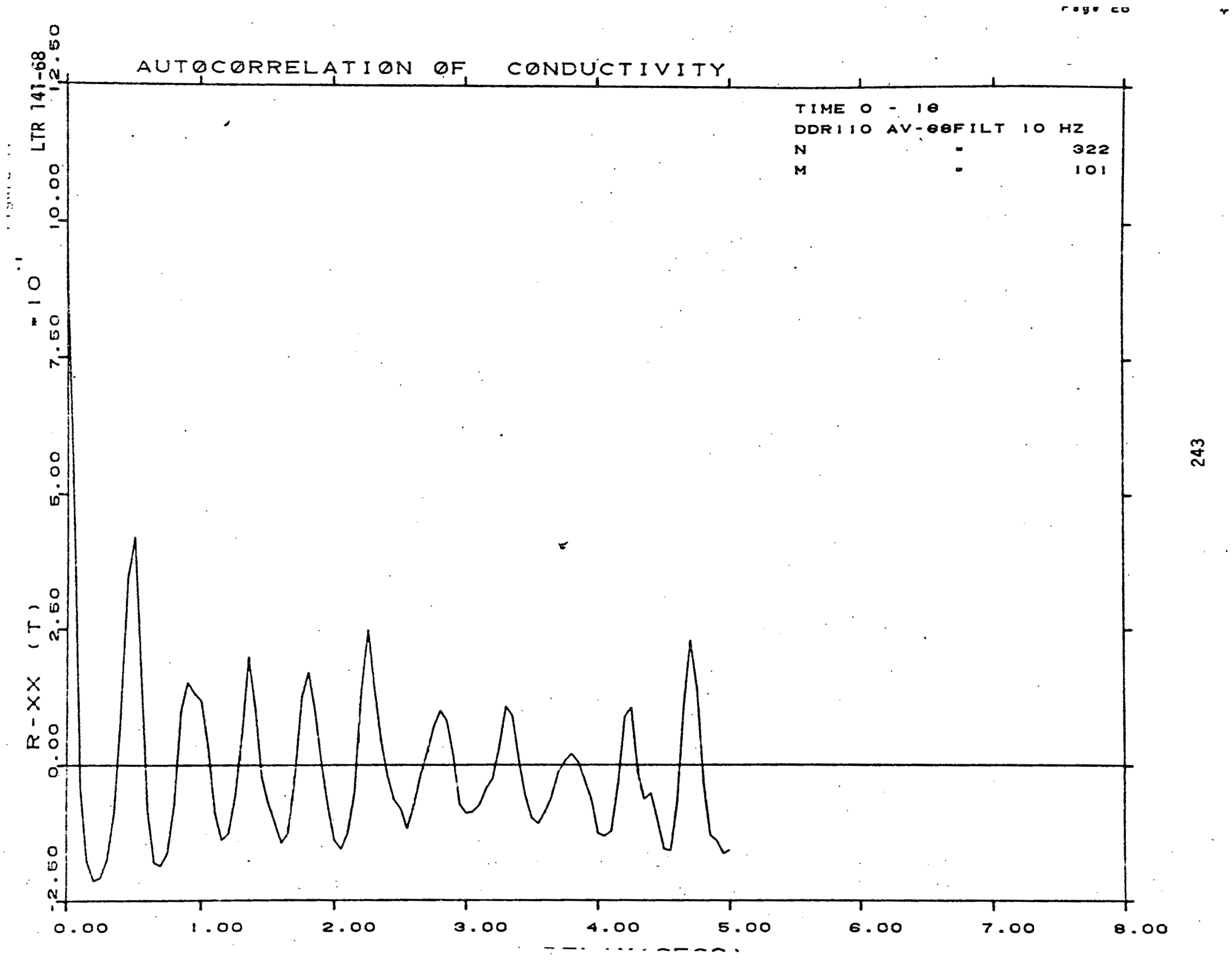




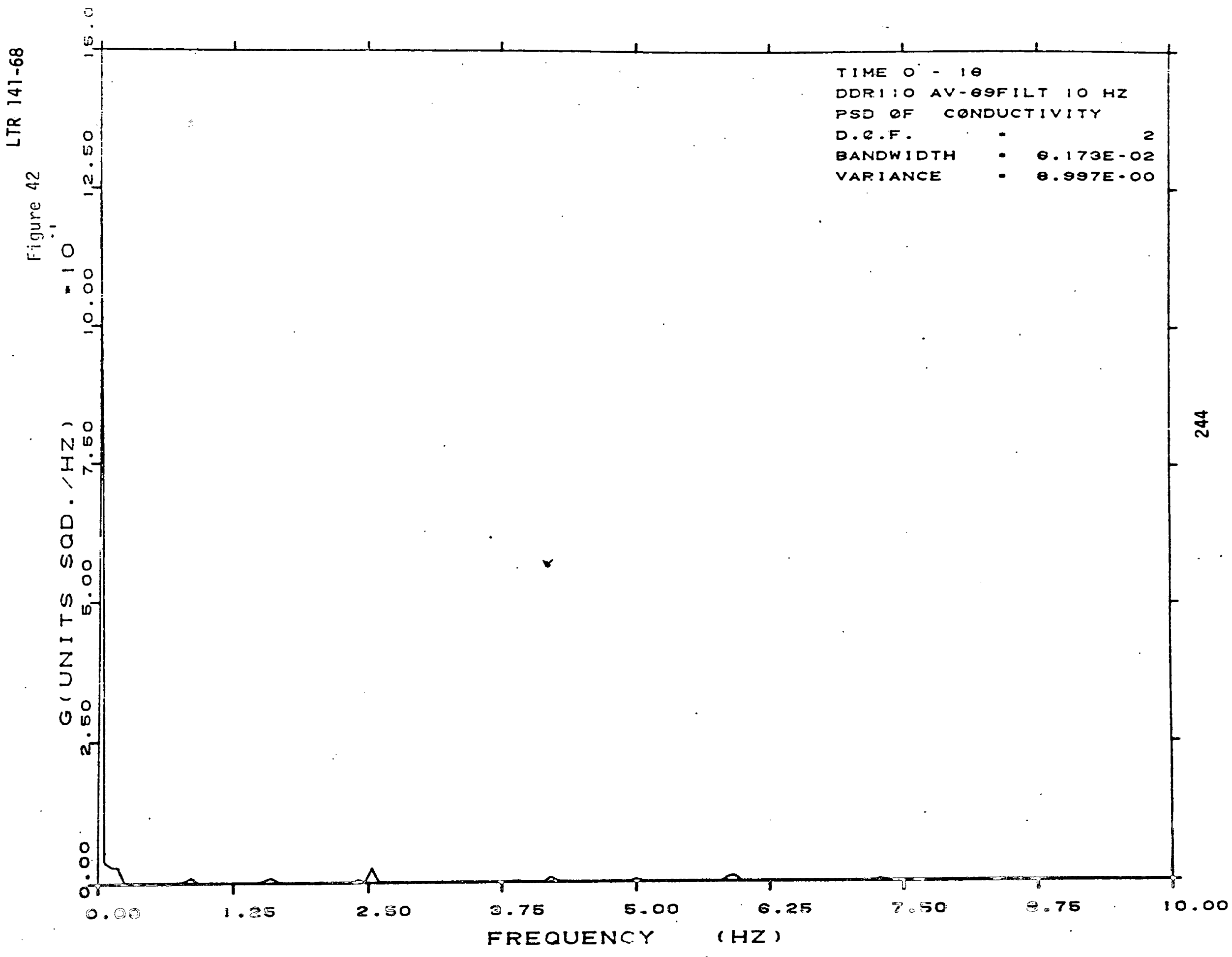




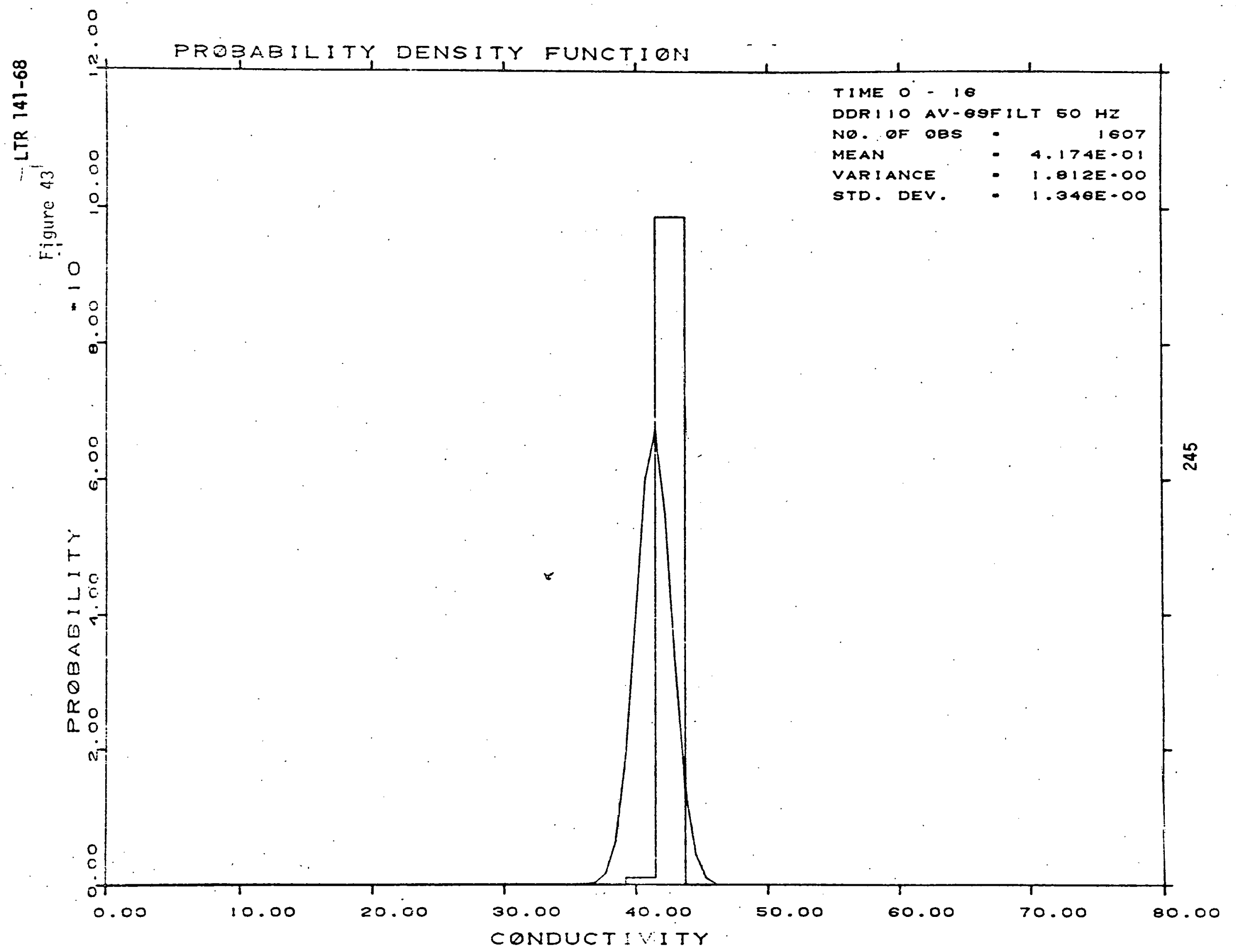




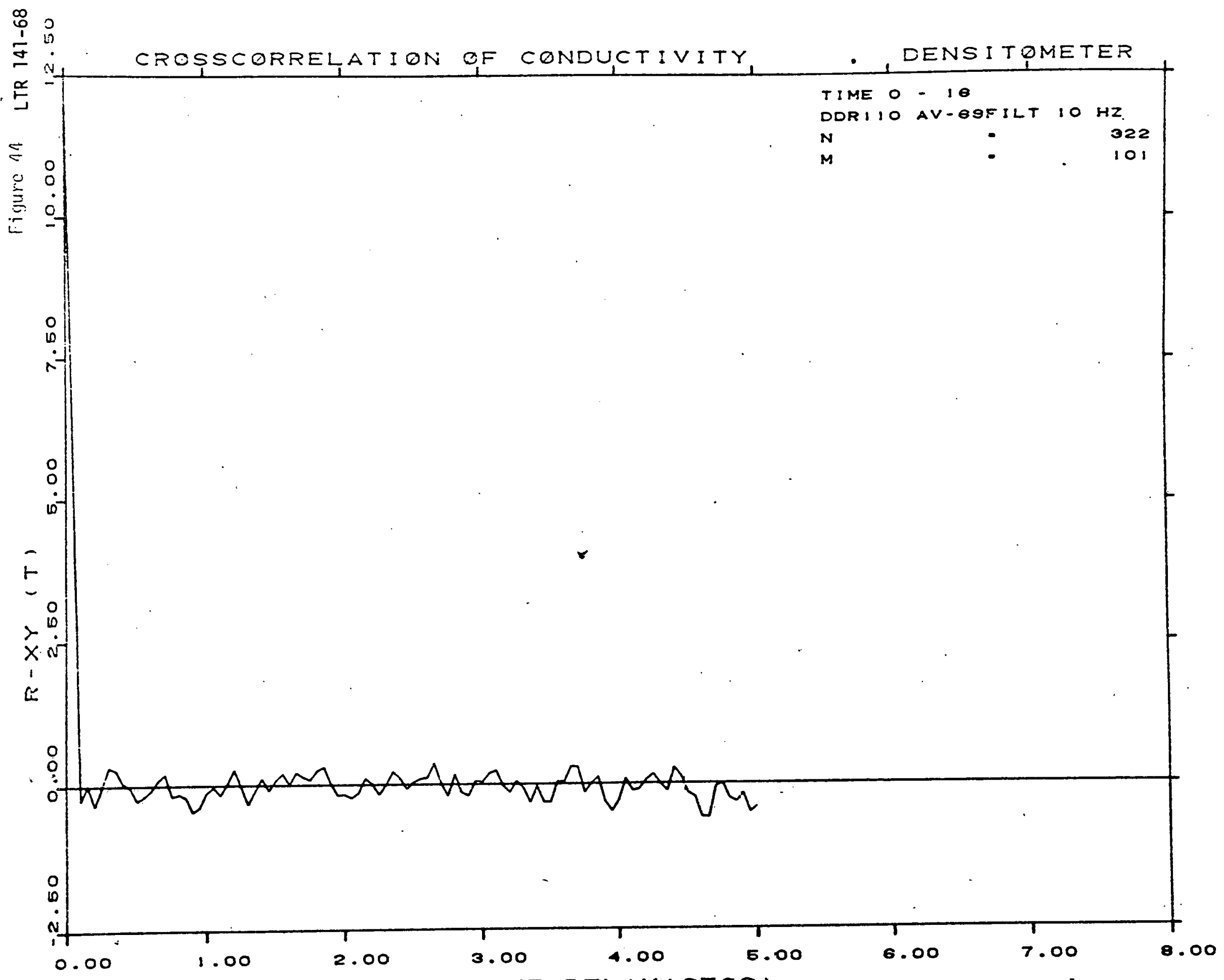




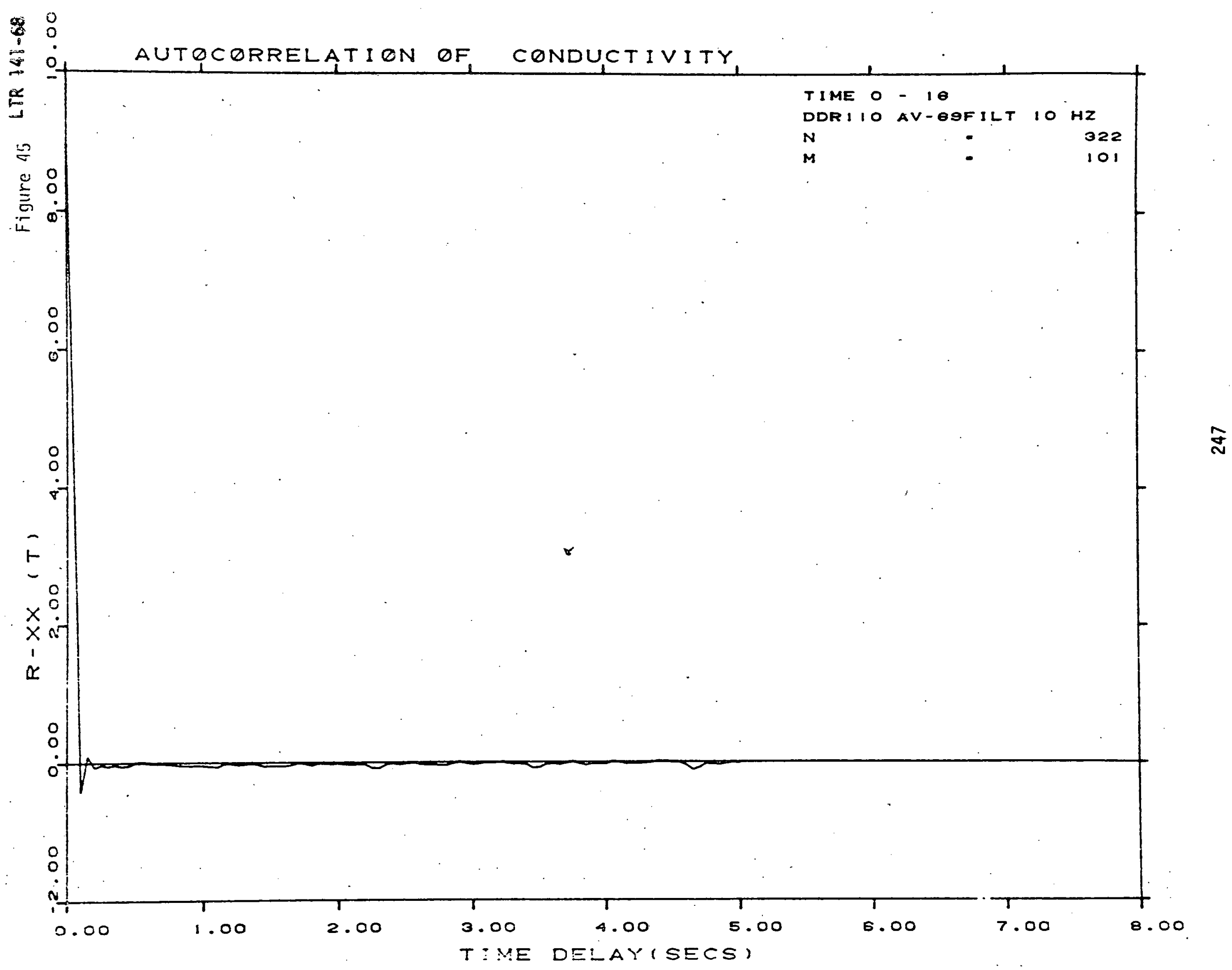




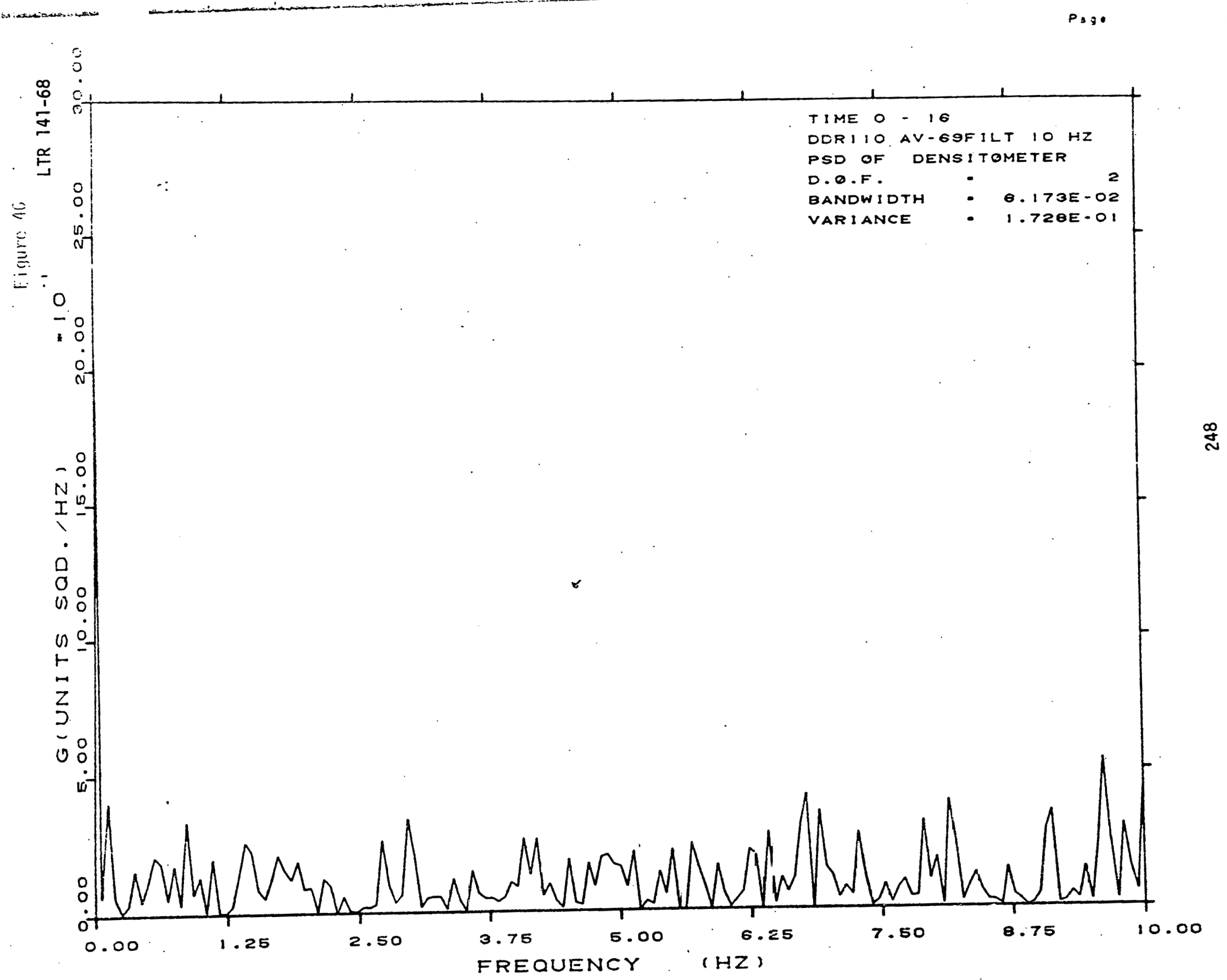




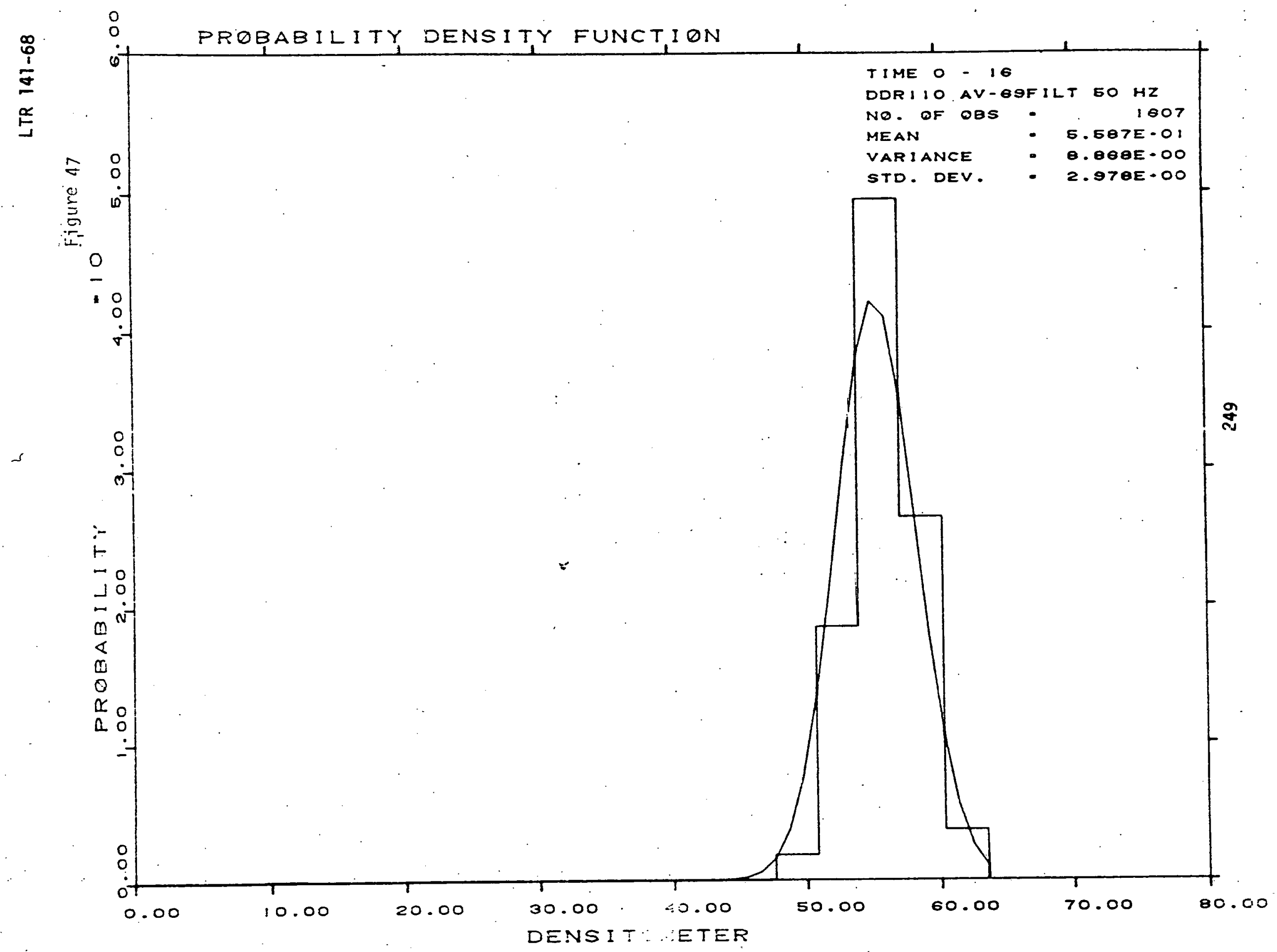




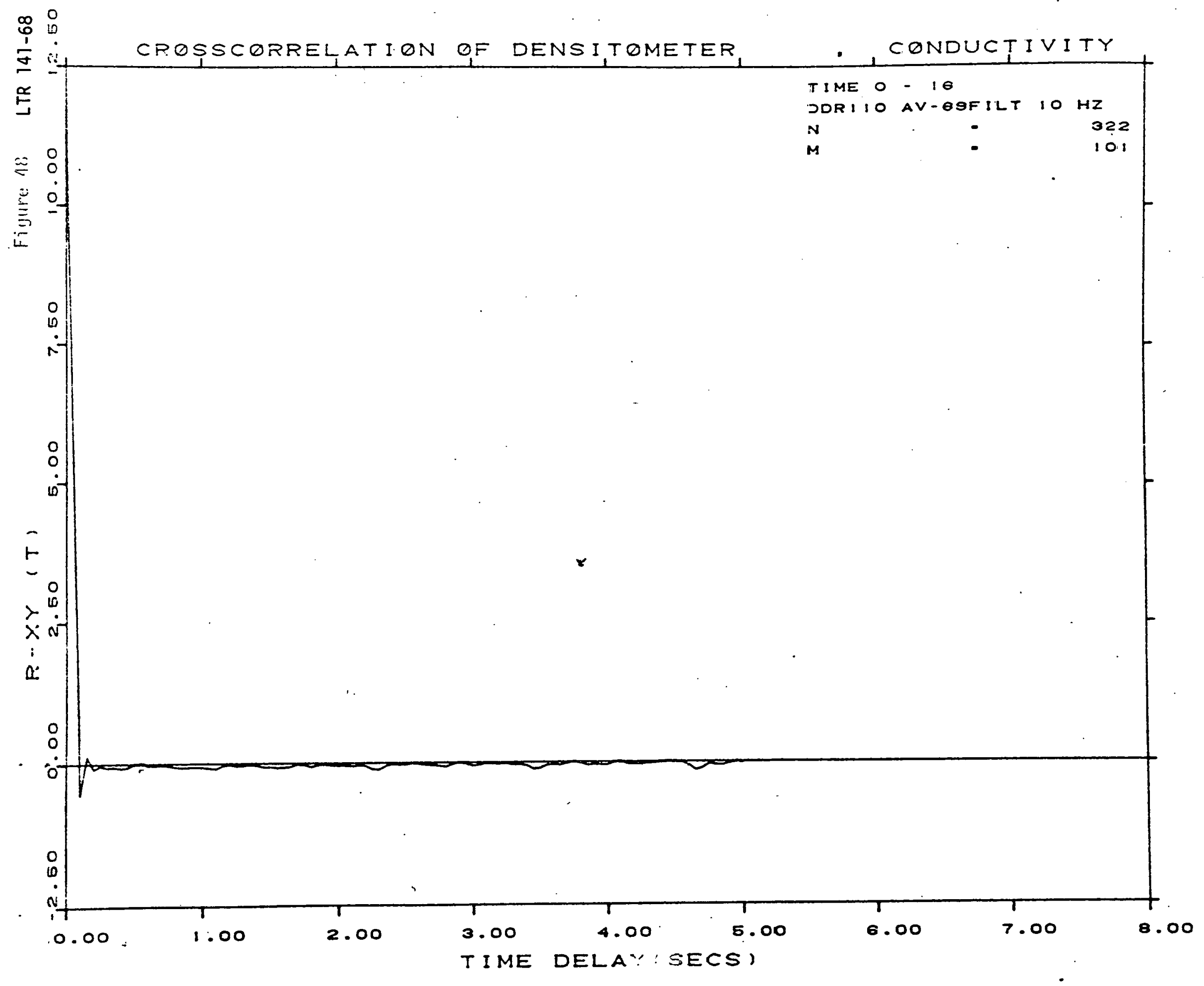




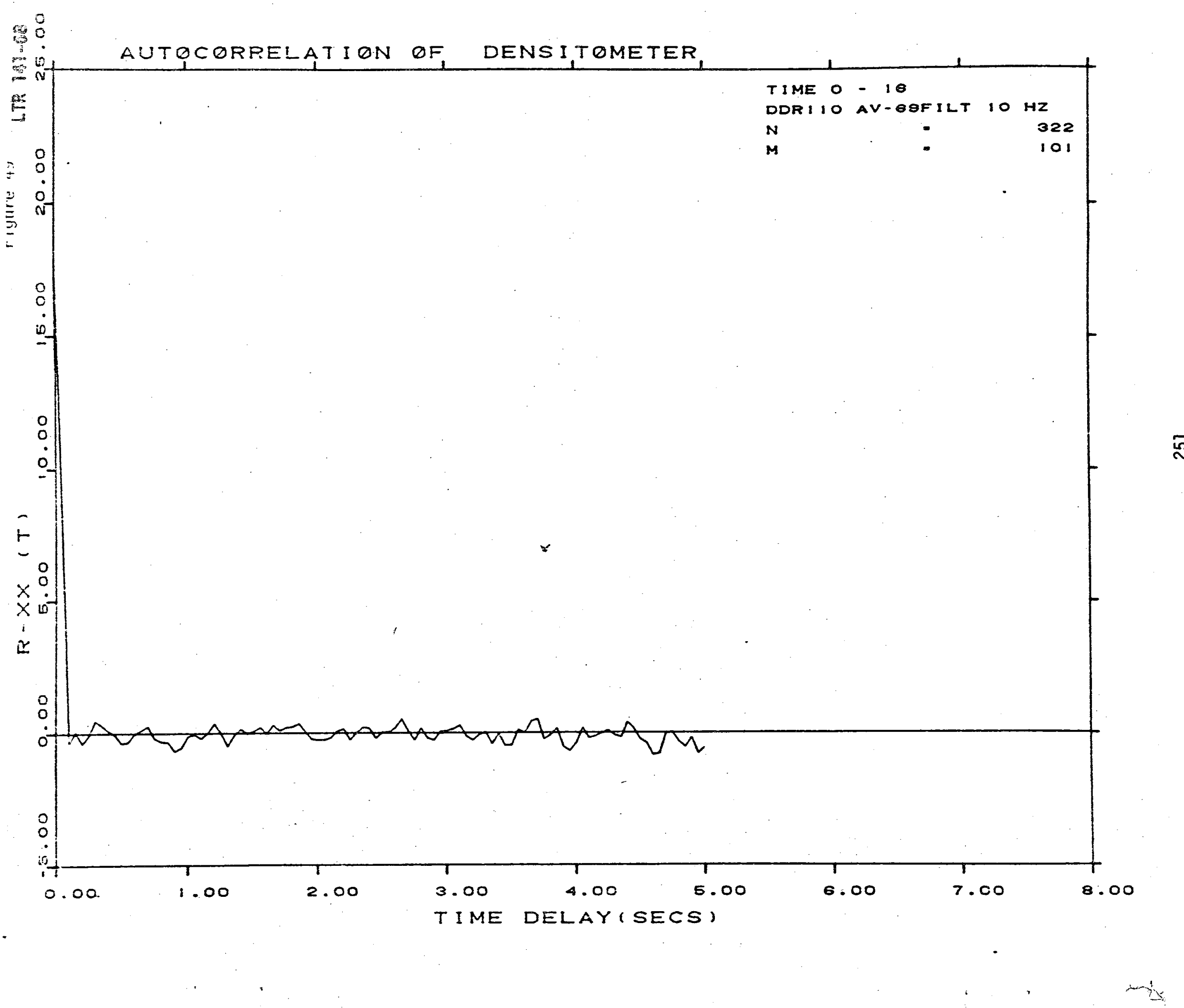


!. 


\section{APPENDIX $\mathrm{H}$}

VERTICAL FLOW TESTS OF CONDUCTIVITY AND

ULTRASONIC VOID FRACTION DETECTORS 
LTR 141-68 


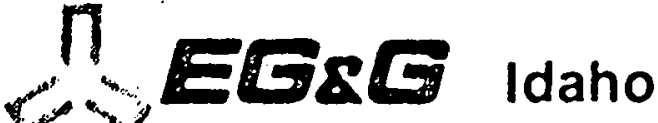

\section{INTEROFFICE CORRESPONDENCE}

date July 12,1977

to M. E. Buchanan

trom

R. R. Good

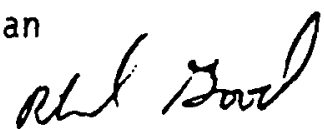

subiect VERTICAL FLOW TESTS OF CONDUCTIVITY AND ULTRASONIC VOID FRACTION DETECTORS - RRG-9-77

Ref: a. R. R. Good Itr to M. E. Buchanan, Rrg-8-77, Analys is of Conductivity Probe in a Horizontal Test Section, July 1, 1977.

b. G. D. Lassahn 1tr to M. E. Buchanan, GDL-2-77, Panámetrics U1trasonic Void Sensor, June 8, 1977.

A test series has been conducted at the air water flow loop to evaluate the conductivity and ultrasonic void fraction detectors. The test was designed to be comparable to other tests (see Rrg-8-77) designed to test void fraction probes. A single beam gamma densitometer located approximately 6 inches upstream was used as a reference: The test series included flow rates ranging from $145 \mathrm{gpm}$ to $0 \mathrm{gpm}$ for water and 67 c.f.m. to 0 c.f.m. for air. All other test conditions were held constant as possible. The test section was located in a yertical pipe section approximately 20 diameters downstream of a $90^{\circ}$ elbow. No attempt was made to stabilize the flow prior to the test section.

The data was taken on 59 different test runs. Each data run consisted of 16 seconds of data during which all test parameters were held constant, Time averaged values for each data run were analyzed. Also, a complete statistical analysis of several data runs were conducted.

The data analysis indicated that the ultrasonic probe signal was a strong function of void fraction and a weak function of the mass flow past the probe. The conductivity probe signal was a strong function of void fraction and exhibited no correlation to mass flow rate. The in depth statistical analysis indicated that the uitrasonic probe signal carried significant information in the $10-50 \mathrm{~Hz}$ band which was not evident in either the gamma densitometer or conductivity probe signals. Figures 12 through 19 show Power Spectral Densities for each device urider nearly identical flow conditions. These PSD's clearly show the difference ir. the signal frequency distribution between the uitrasonic probe and conductivity probe. The cross correlations generally indicated better agreement between the conductivity probe and gamma densitometer than the uitrasonic probe and gamma densitometer. Figures 28 through 31 evidence the difference in the cross correlations.

Time averaged data for the ultrasonic probe is presented in Figure 1. Each line represents a set of data points taken at a constant water flow 
M. E. Buchanan

July 12, 1977

RRG-9-77

Page 2

rate. The goodness of fit $\left(R^{2}\right)$ of each data set is greater than .98 , which is indicative of low noise, highly linear data. The differences in the slope and zero offset of each data set are indicative of the dependence of this measurement on mass flow rate. Table 1 presents the statistics of the preceeding data sets.

Figure 2 presents the time averaged data for the conductivity probe. The conductivity probe and ultrasonic probe time averaged data sets represent the same set of flow conditions. Table 2 presents the statistics at the data conductivity data.

Figures ${ }^{*} 4$ through 31 presents the results of the statistical analysis, they consist of time histories, power spectral densities (PSD), probability density functions (PDF) and cross correlations of the test series. The data presented represent identical flow conditions ( $35=34 \mathrm{gpm}, 22.5 \mathrm{c} . \mathrm{f} . \mathrm{m}$. $36=34 \mathrm{gpm}, 45 \mathrm{c} . \mathrm{f} . \mathrm{m}$.) for each transducer tested. The PSD's indicate the frequency content of the signal, the PDF's show the degree of scatter. in the data, and the cross correlations indicates the agreement between the gamma densitometer signal and the test transducer signal. An offset was introduced into the ultrasonic signal after the time averages were taken. The source of the offset is not known. The offset results in the negative values shown in the PDF's and time histories of the ultrasonic signal. Figure 3 shows this offset and confirms that it is constant throughout the data. The offset has no significant effect on the cross correlations or PSD's.

The data indicates that both devices, ultrasonic probe and conductivity probe, are capable of measuring void fraction. The accuracy of the ultrasonic probe is approximately $+2 \%$ with repeatibility of $+12 \%$ RG yielding an overall accuracy of $+\overline{7} 2.17 \% \mathrm{RG}$. The accuracy of the conductivity probe (see $R R G-8-77$ ) is $+8 \%$ RG with repeatability $+6 \% R G$ giving an overall accuracy of $+10 \% R G$. The ultrasonic probe appears to possess the capability for higher accuracy than the conductivity probe; if the problem of mass flow sensitivity can be overcome. The ultrasonic probe appears to have a significant portion of its information in the 10 - $50 \mathrm{~Hz}$ band, whereas both the conductivity probe and gamma densitoneter signals of interest. are less than $10 \mathrm{~Hz}$. The frequency distribution of information in ultrasonic signal could account for the small correlation between the gamma densitometer and uitrasonic signal. The reasons for the frequency distribution of the signals is not currently understood.

* In all figure titles void fraction refers to ultrasonic probe, cond. refers to conductivity probe. 
M. E. Bucharian

July 12, 1977 RRG-9-77

Page 3

jm

Attachments

cc: A. E. Arave

R. H. Averill

E. T. Fickas

N. W. Shurtiiff

Central Files

R. R. Good File

L. D. Goodrich $/ \mu$ 
LTR 141-68

\section{TABLE I}

Time Averaged Data Statistics U1trasonic
$D_{\phi}$
$D_{1}$
$R^{2}$

Data Set

1

3

4

6.580

$4.791 \mathrm{E}-03 \quad .998$

5

6.568

5.267 E-03 $\quad .997$

$5.575 \mathrm{E}-03 \quad .985$

* Data set 2 contained two few good data points to be useful. 
TABLE 2

TIME AVERAGED DATA STATISTICS - CONDUCTIVITY

$\begin{array}{cccc}\text { Data Set } & { }^{{ }^{*} C_{\phi}} & { }^{*} C_{1} & R^{2} \\ 1 & 221.85 & 101.11 & .93 \\ 2 & 220.37 & 100.40 & .97 \\ 3 & 220.37 & 100.40 & .98 \\ 4 & 221.04 & 100.60 & .98 \\ 5 & 215.76 & 98.26 & .96\end{array}$

* where $\rho=c_{0}-c_{1} \cdot \ln \left(V_{c}\right)$ 


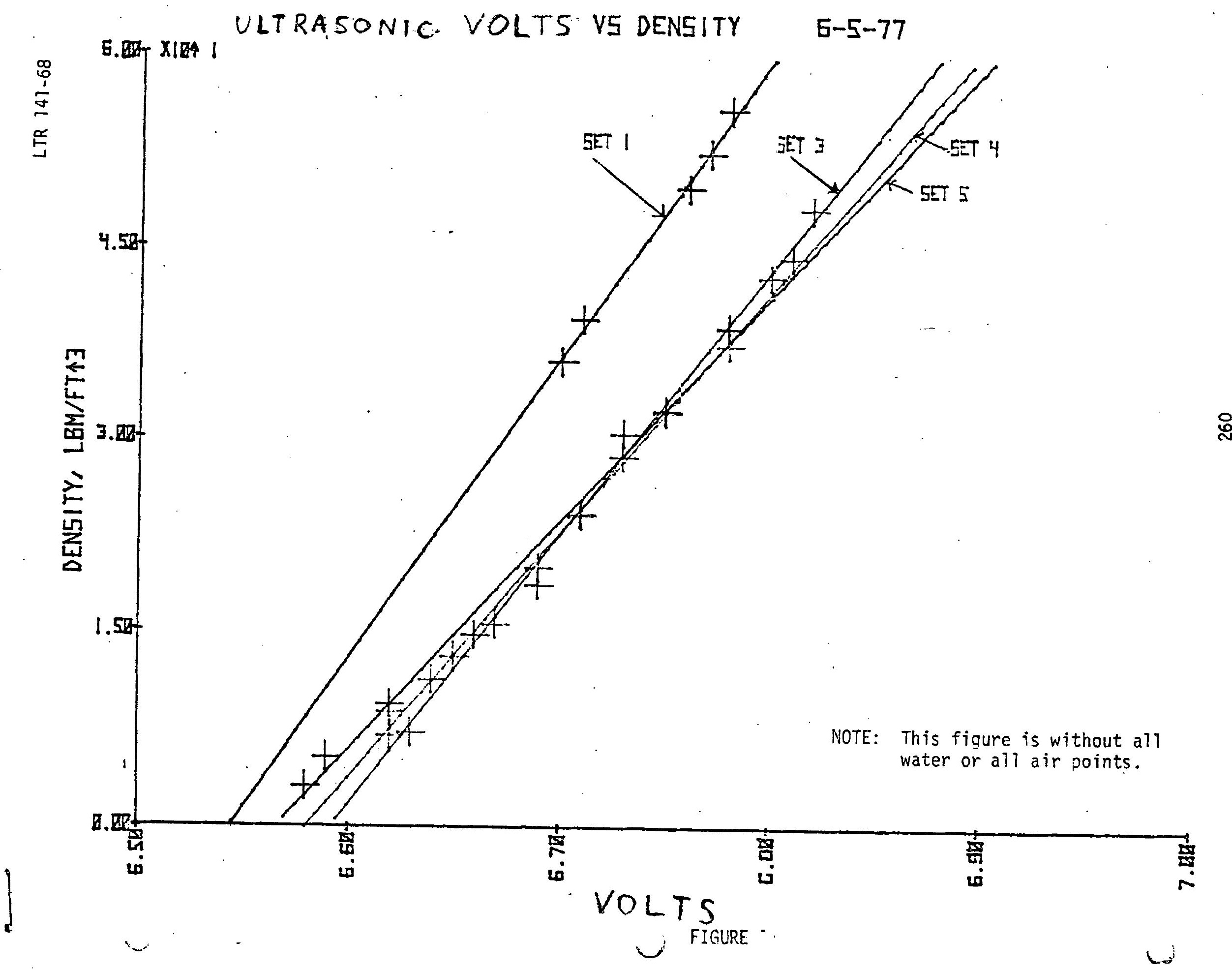

웅 
: DENSITY FRDM EAMMA DENSITDMETEP VS CONDUCTIVITY VOLTS ALL POINTS

$\frac{1}{5}$
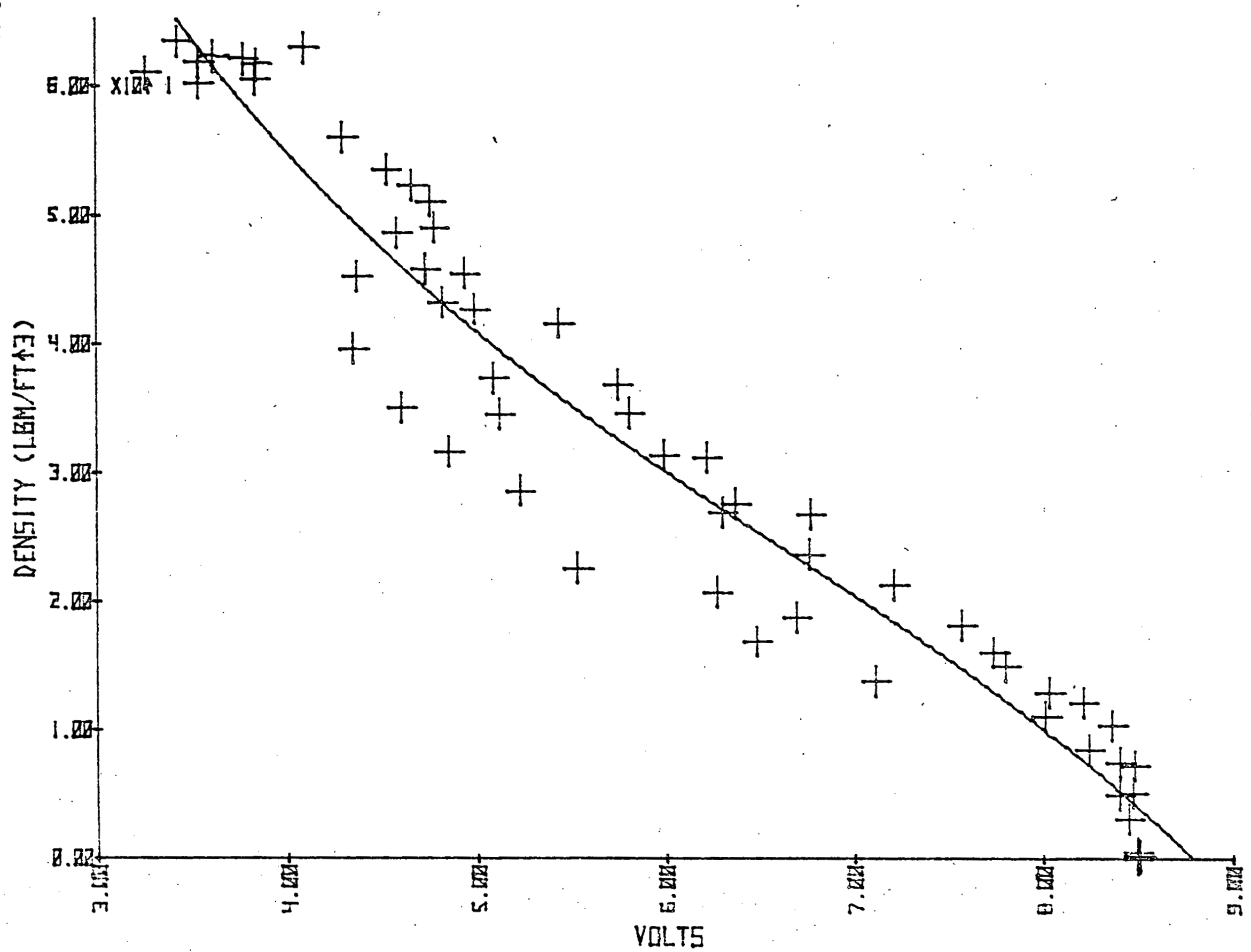

FIGURE 2 


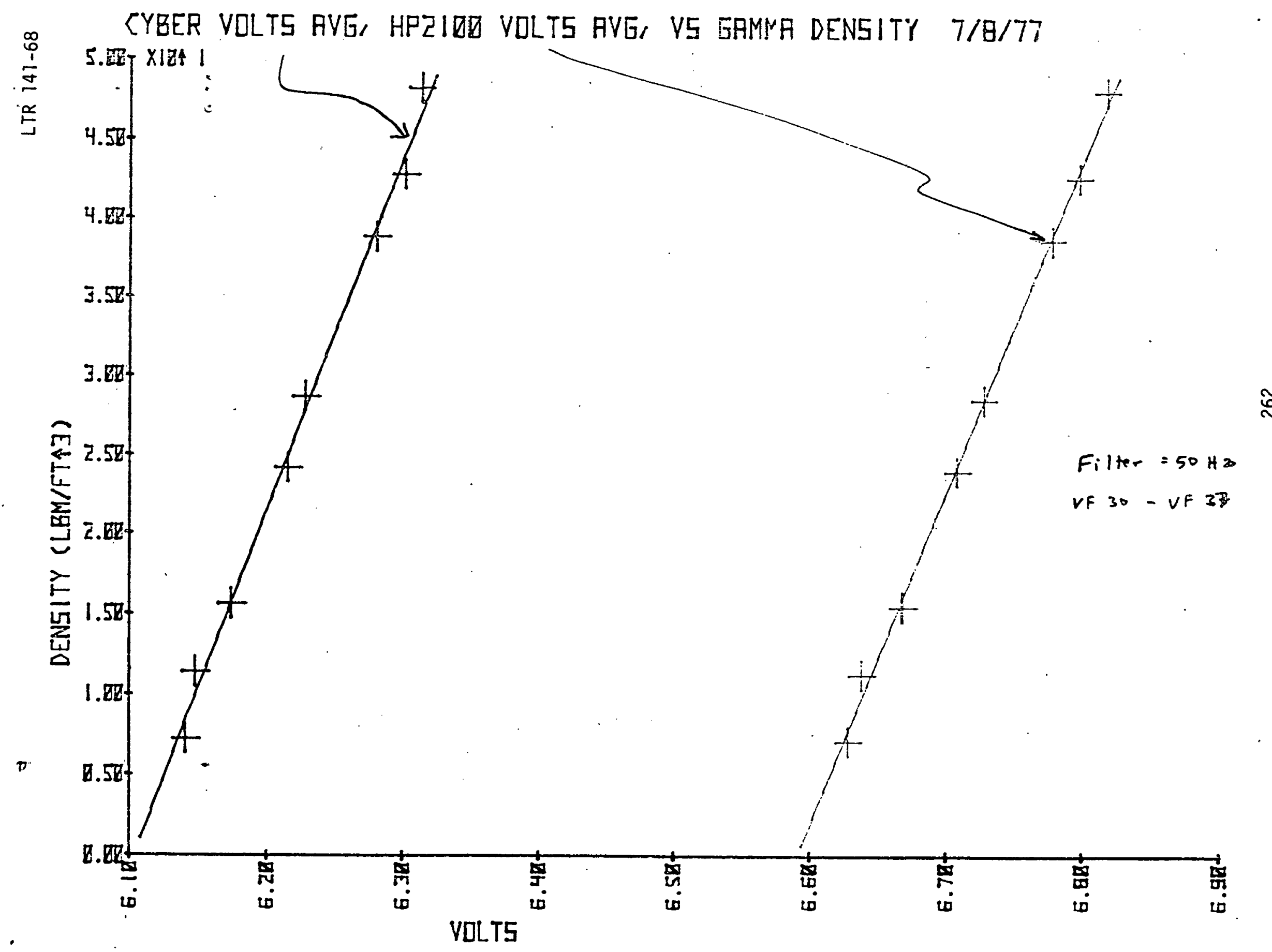

FIFURE 3 
\begin{tabular}{l}
$\infty$ \\
0 \\
1 \\
$\vdots$ \\
\hdashline \\
\hdashline
\end{tabular}

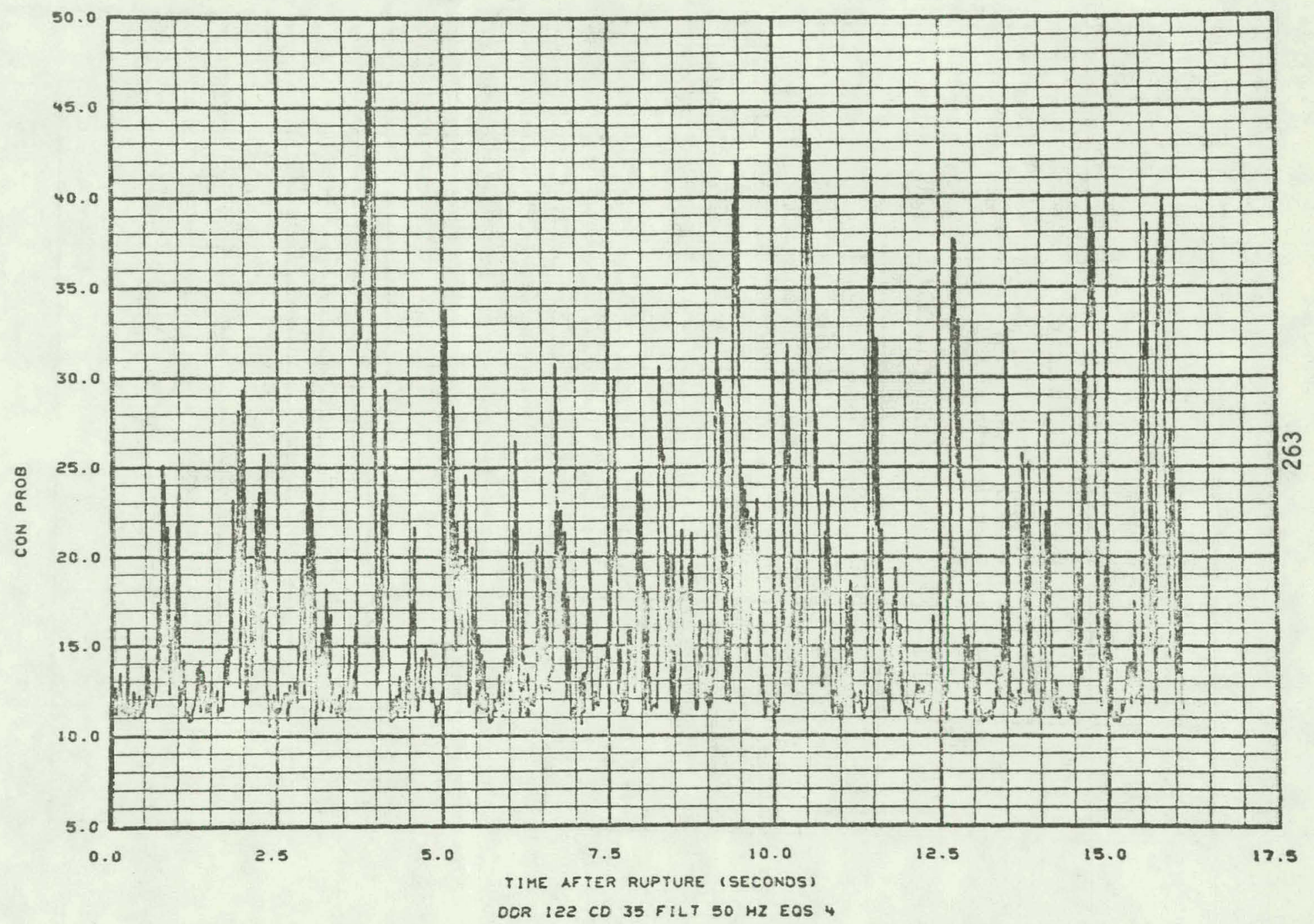


25.

so.

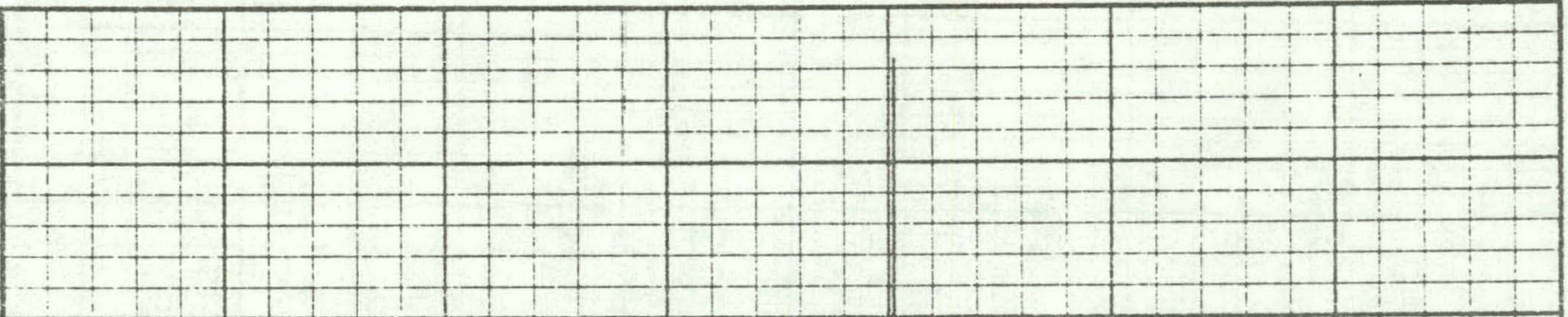

25

5

25.

$$
0.0
$$

2.5
5.0

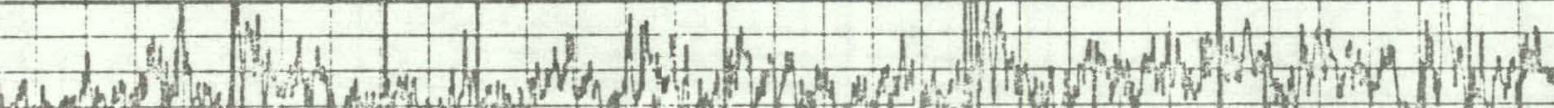

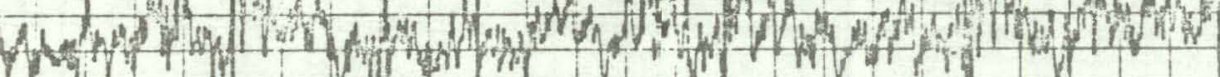

$-100$

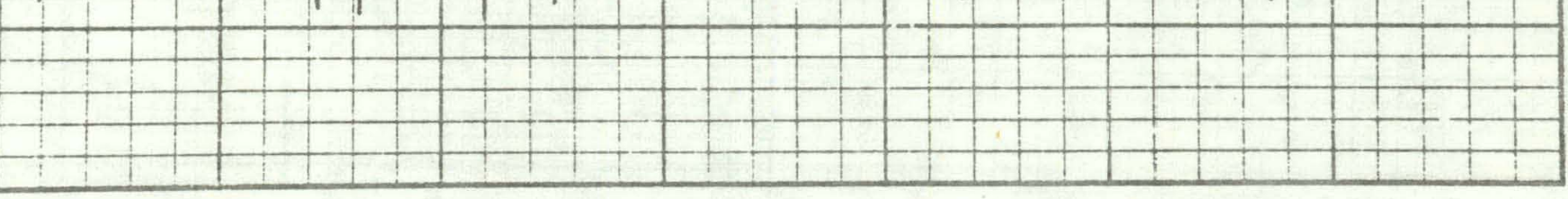

10.0

TIME AFTER RUPTURE (SECONDS)

DORIZO VF-35 $50 \mathrm{HZ}$ FILT TIME O -16 SEC

FIGURE 5 


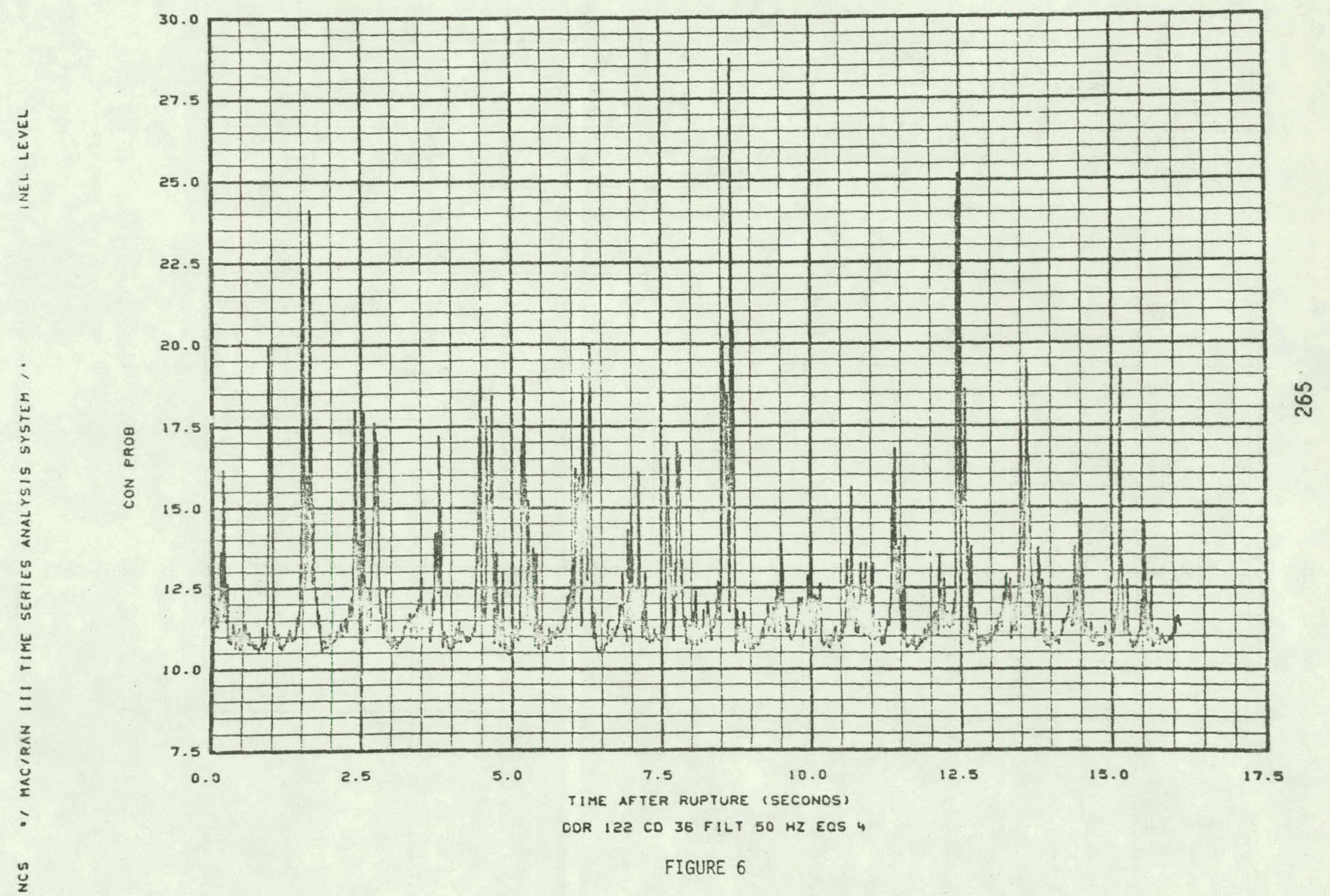




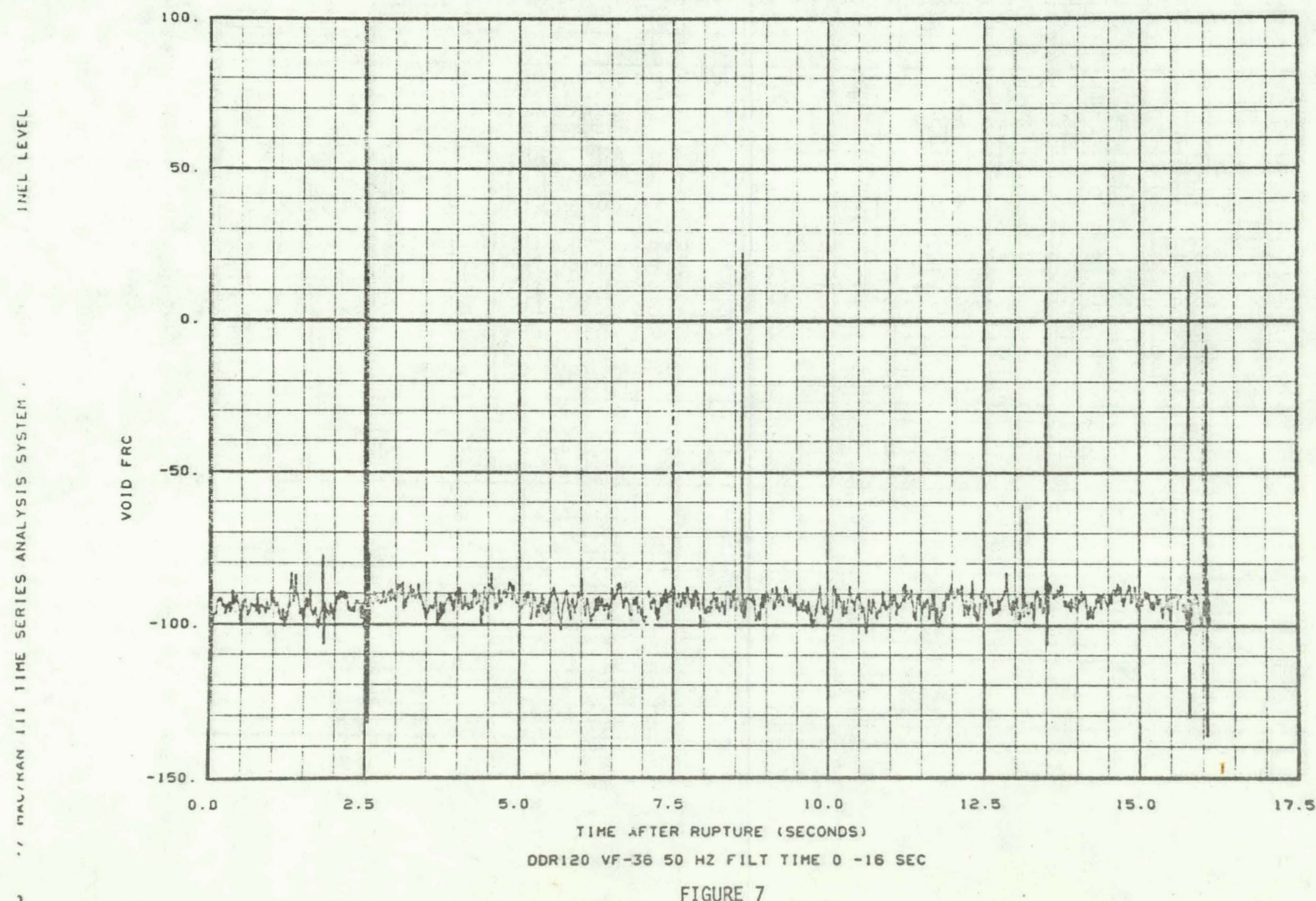




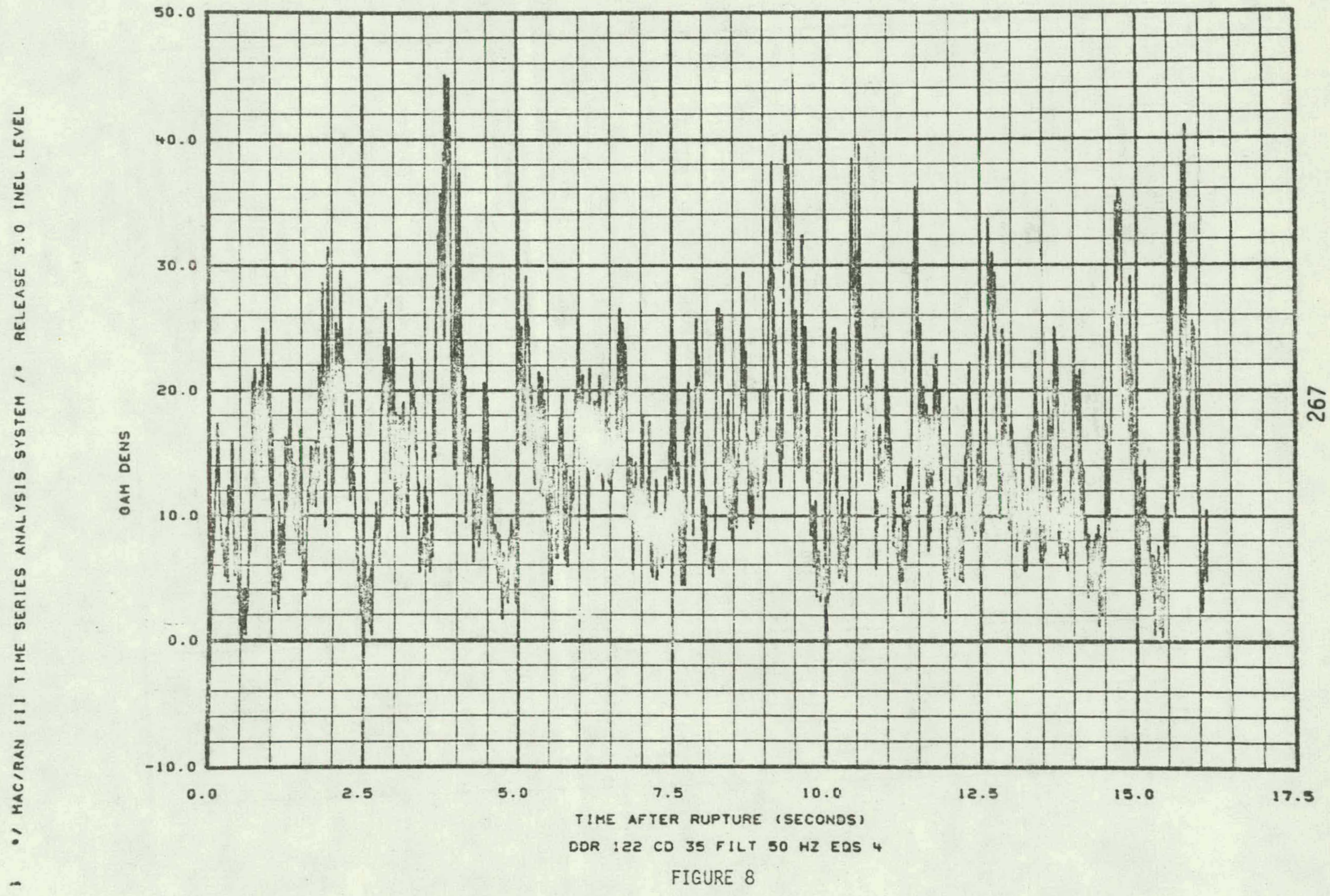




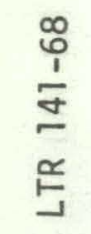

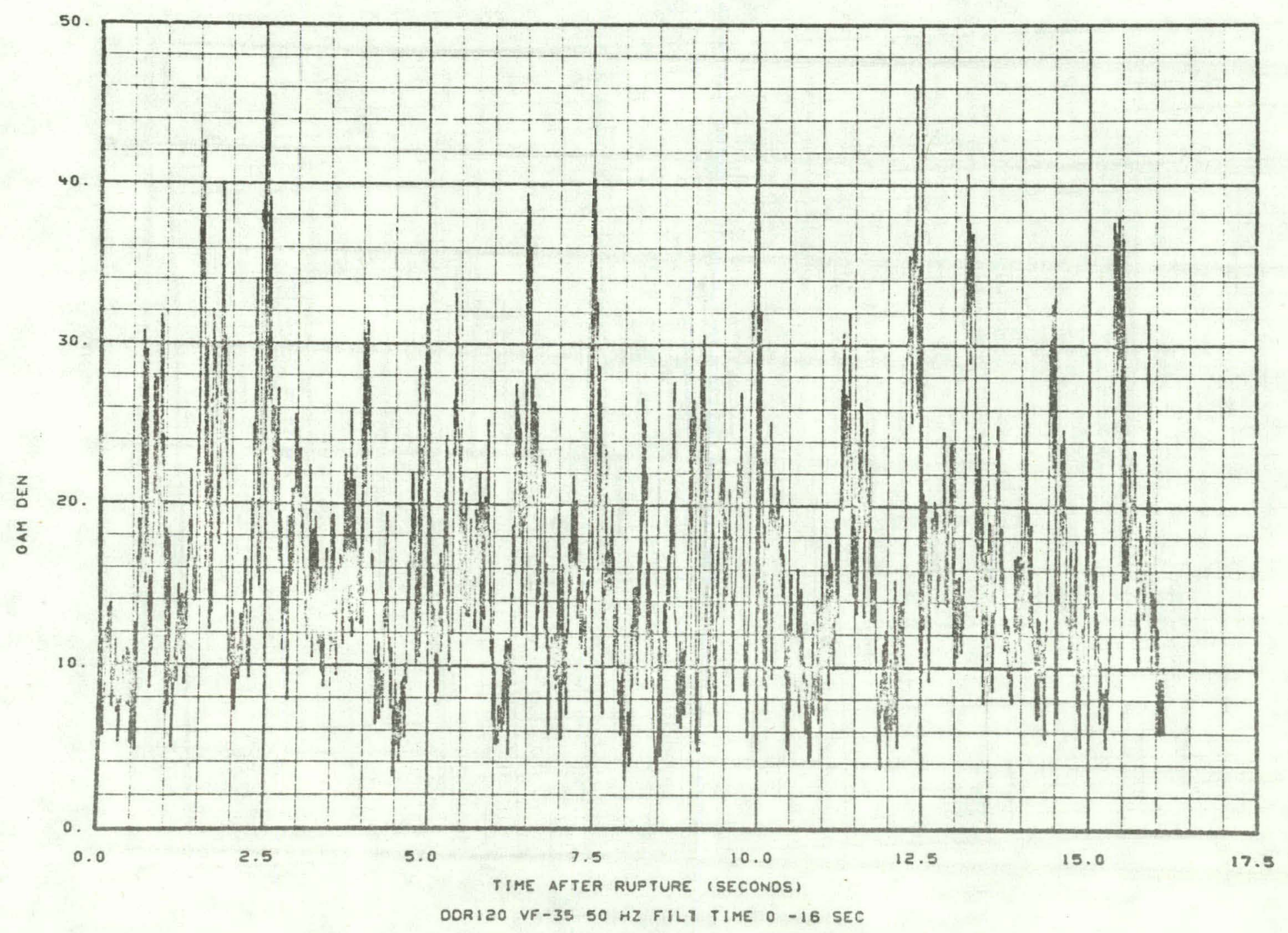

FIGURE 9 


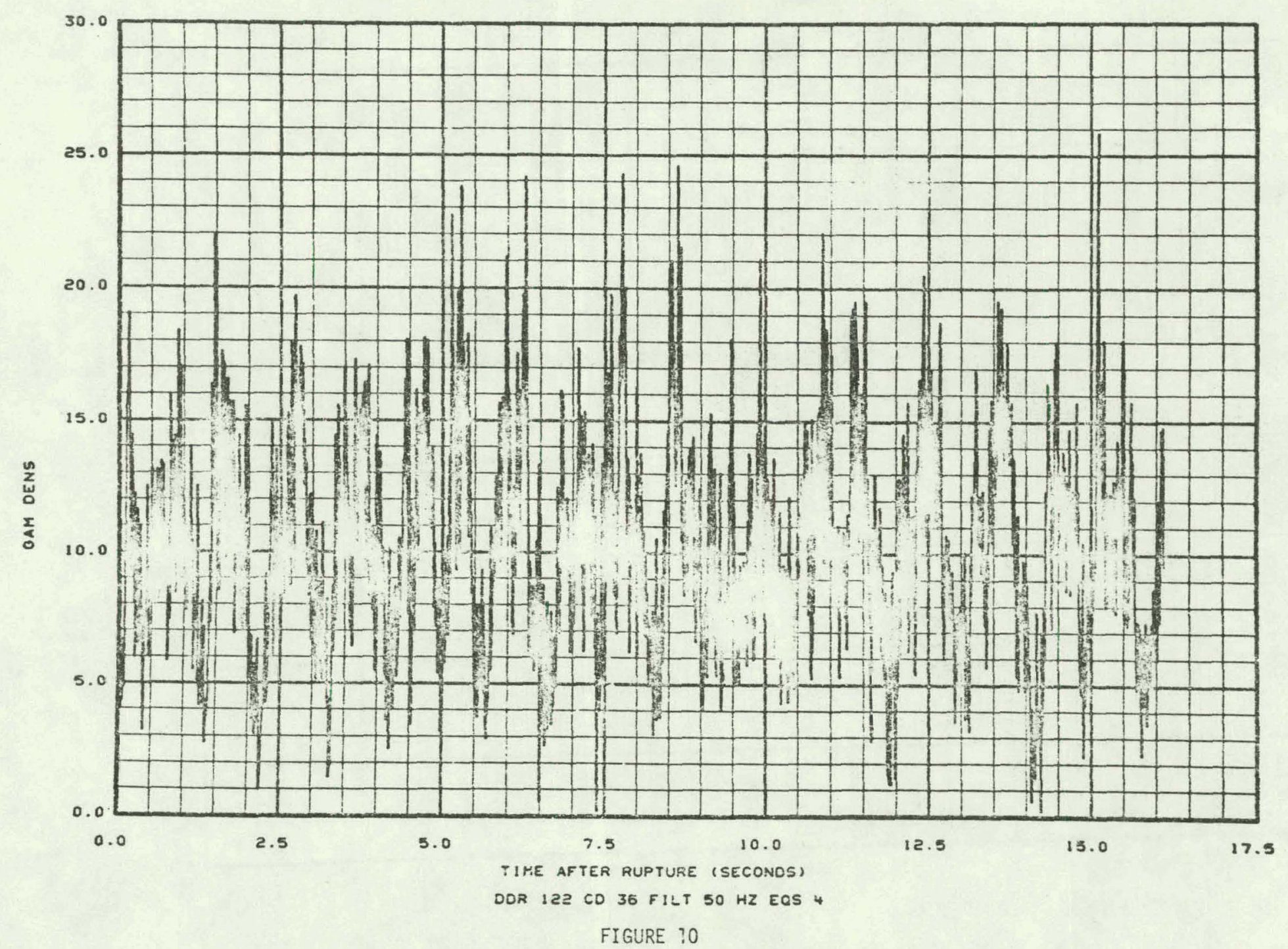




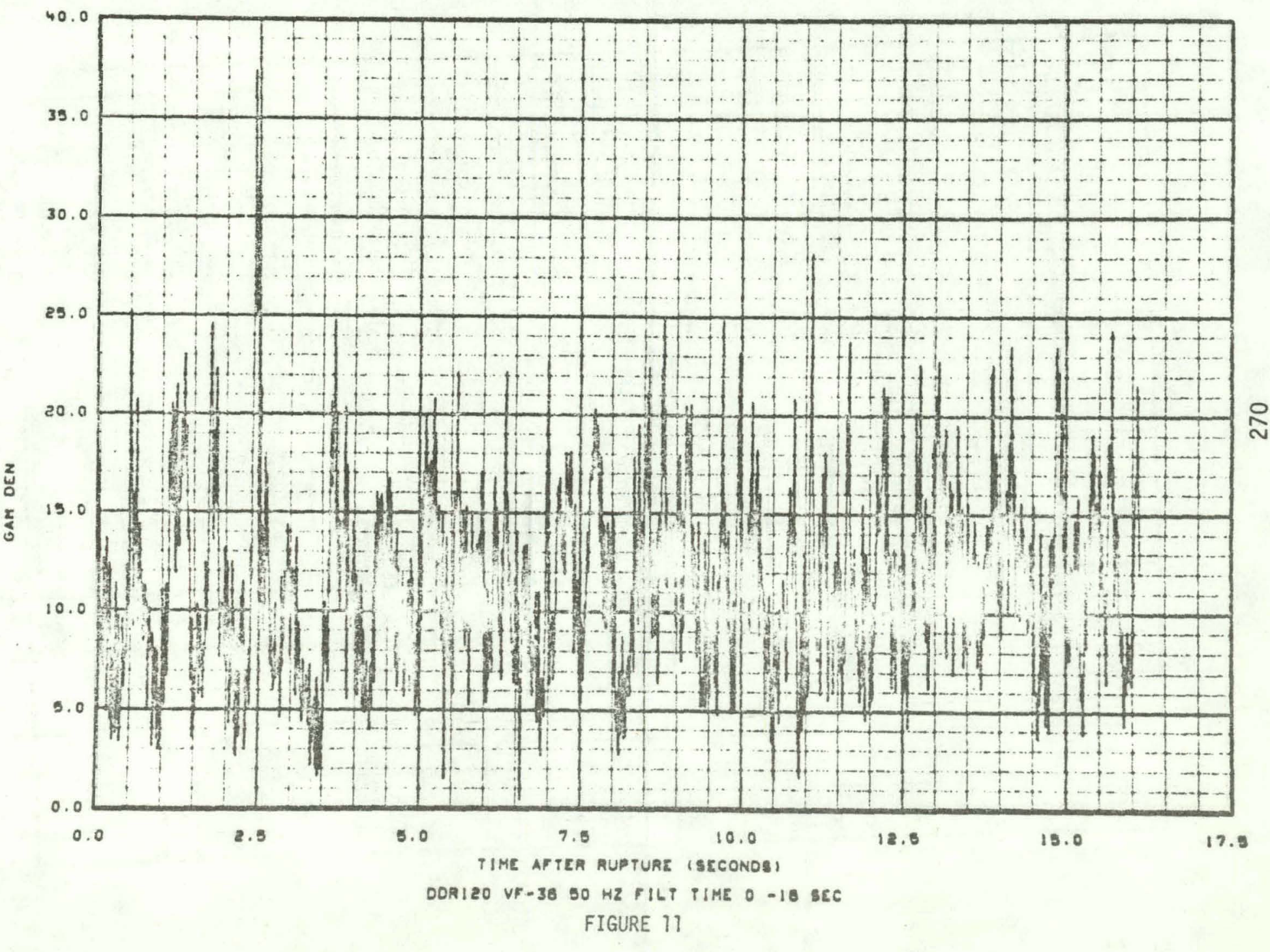




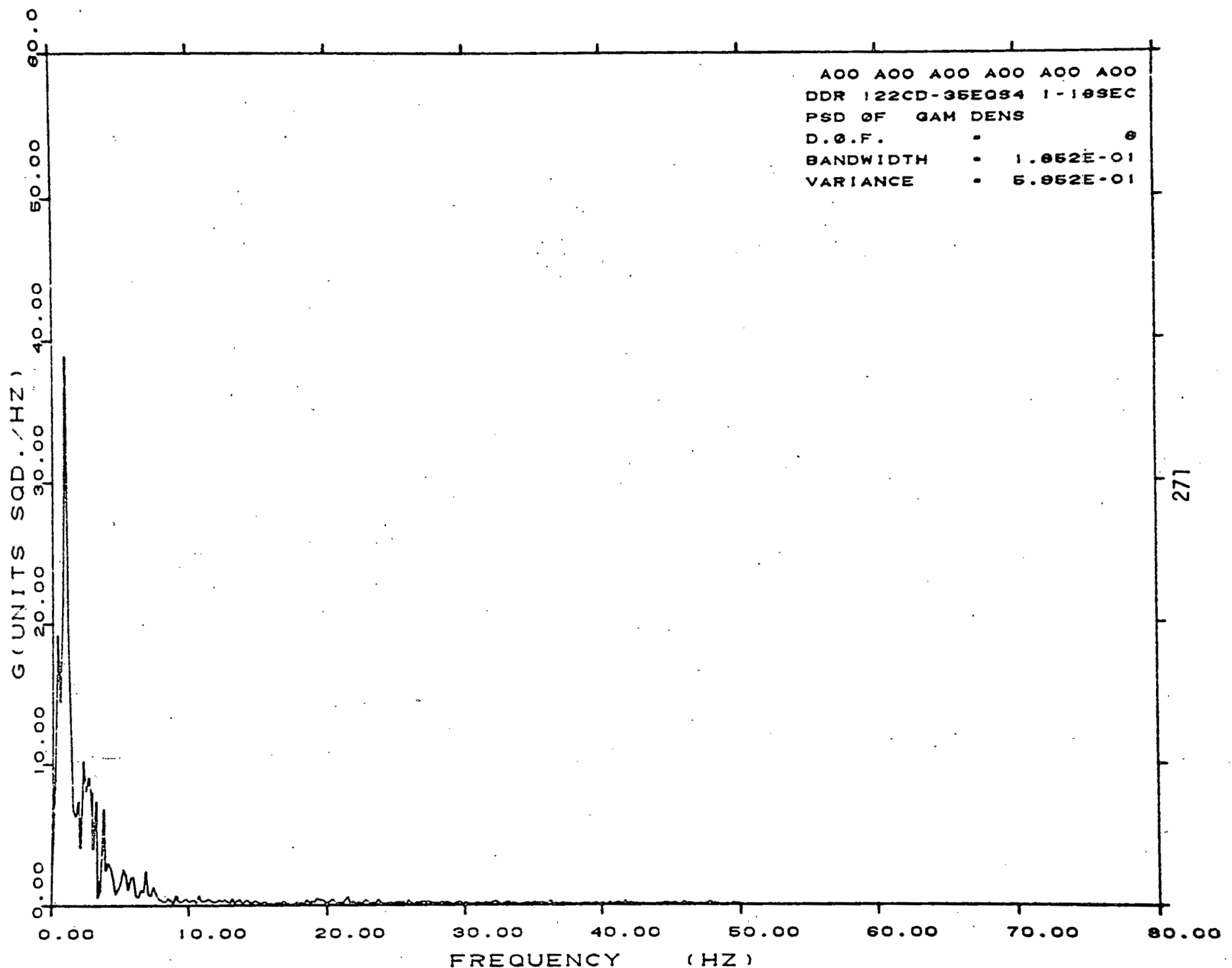




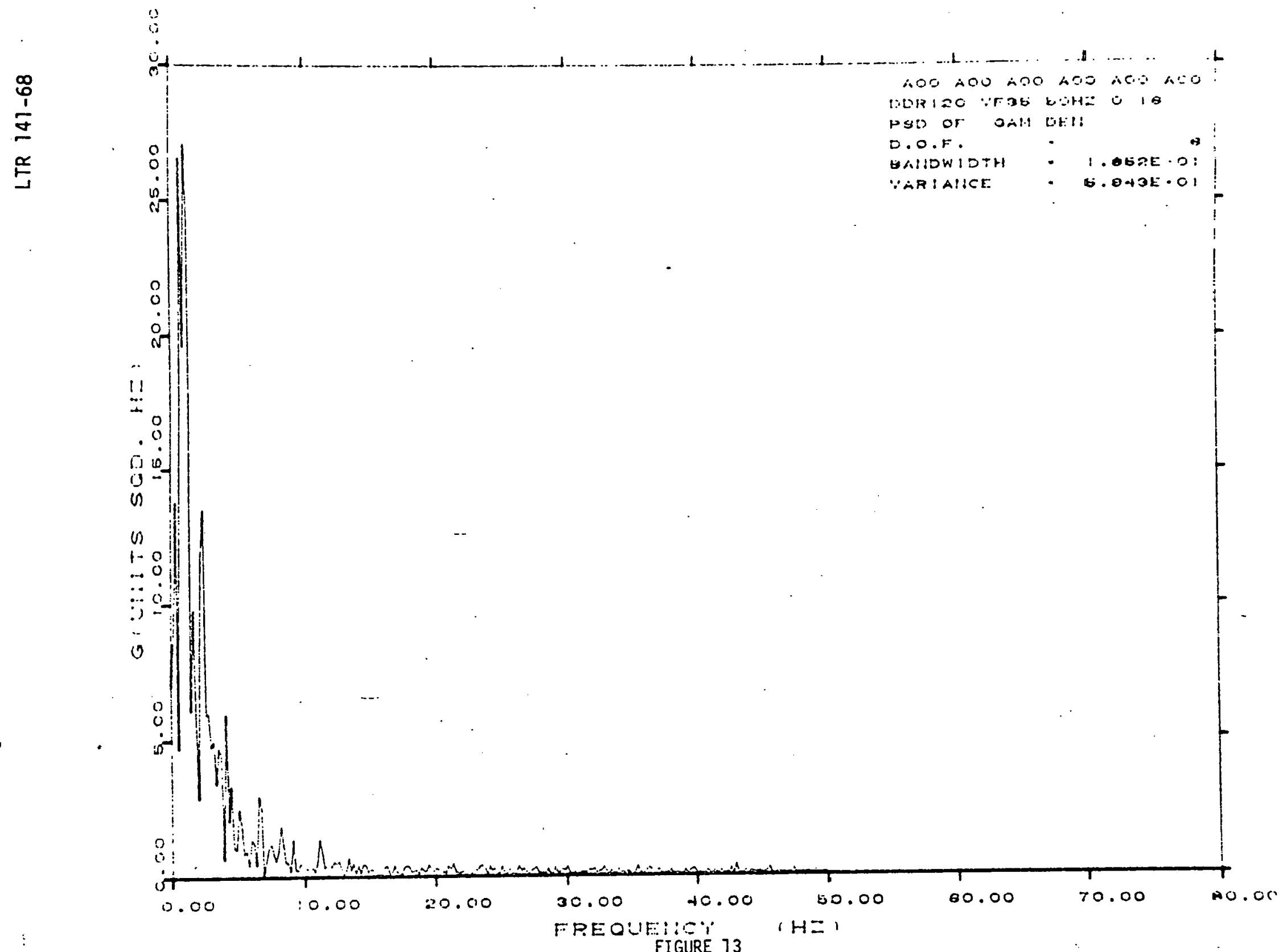




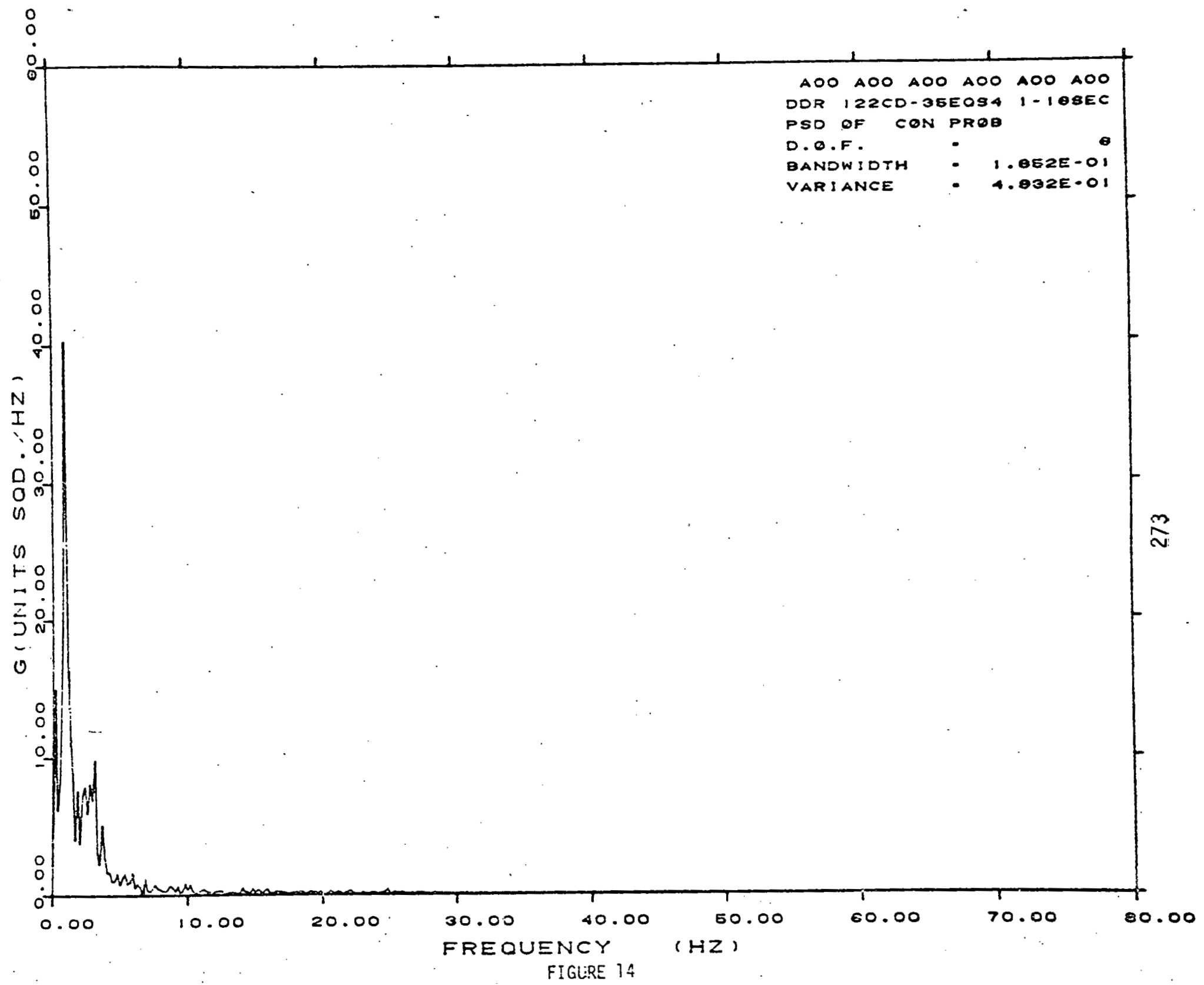




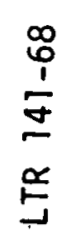

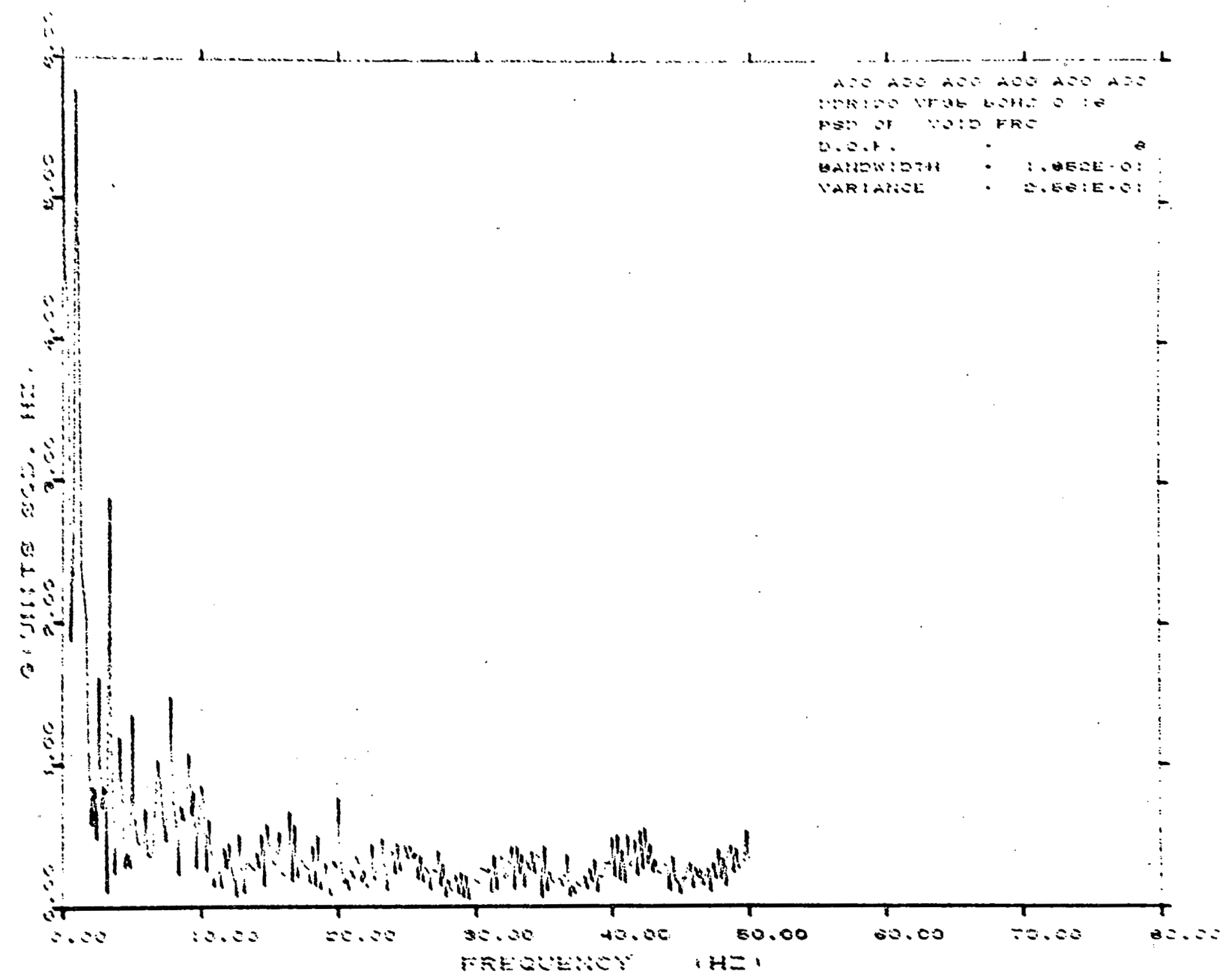

FIGURE 15 


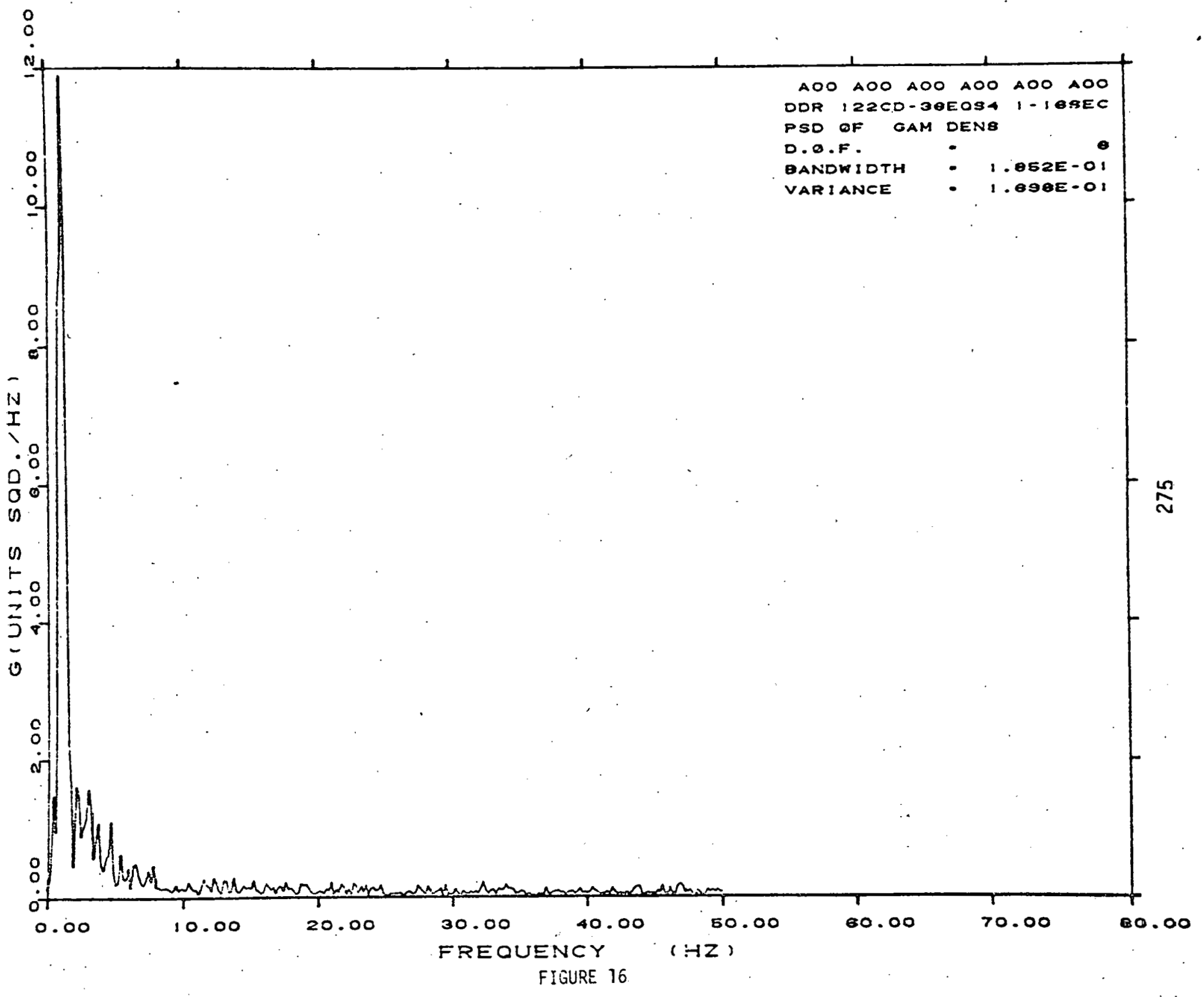




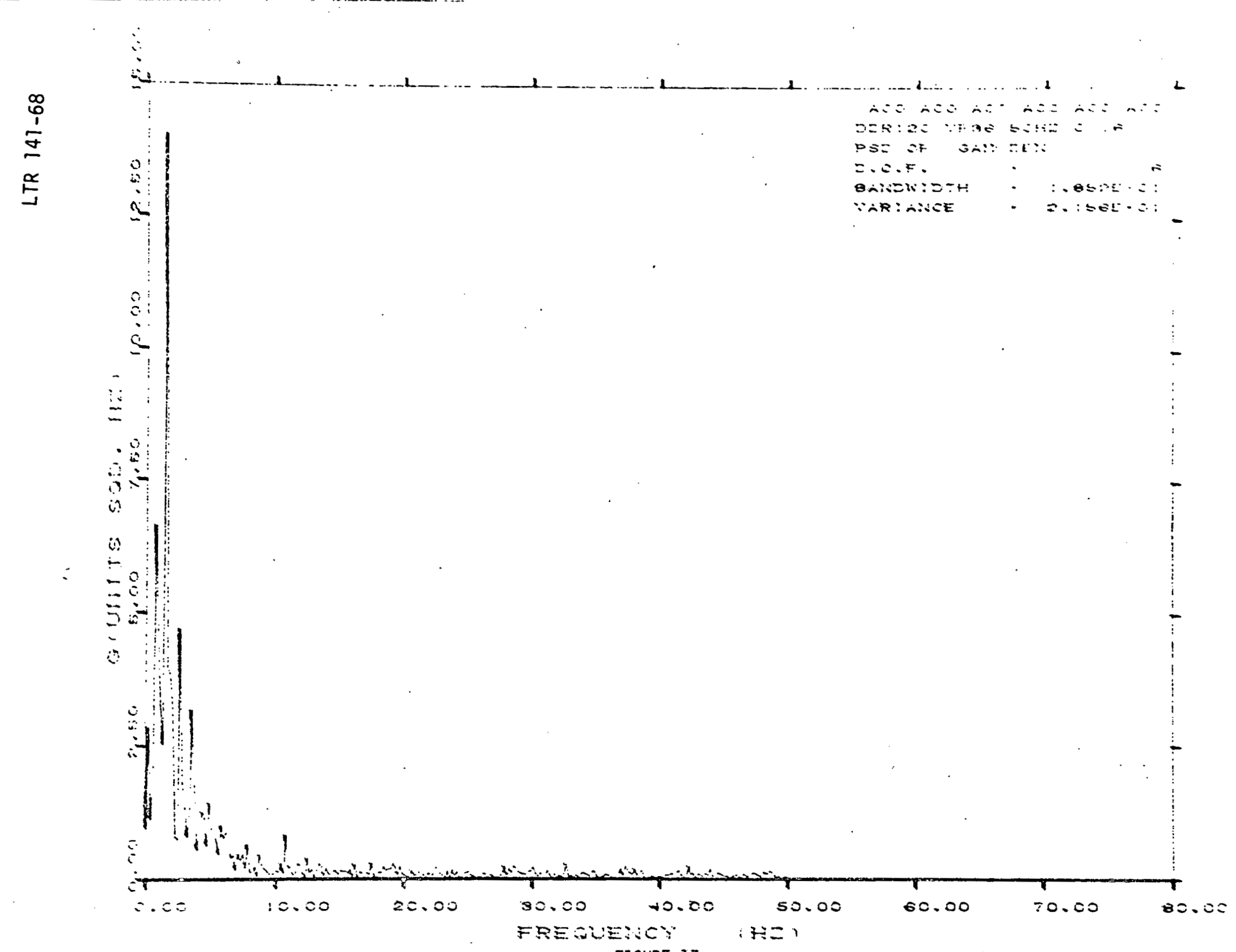

FIGURE 17 


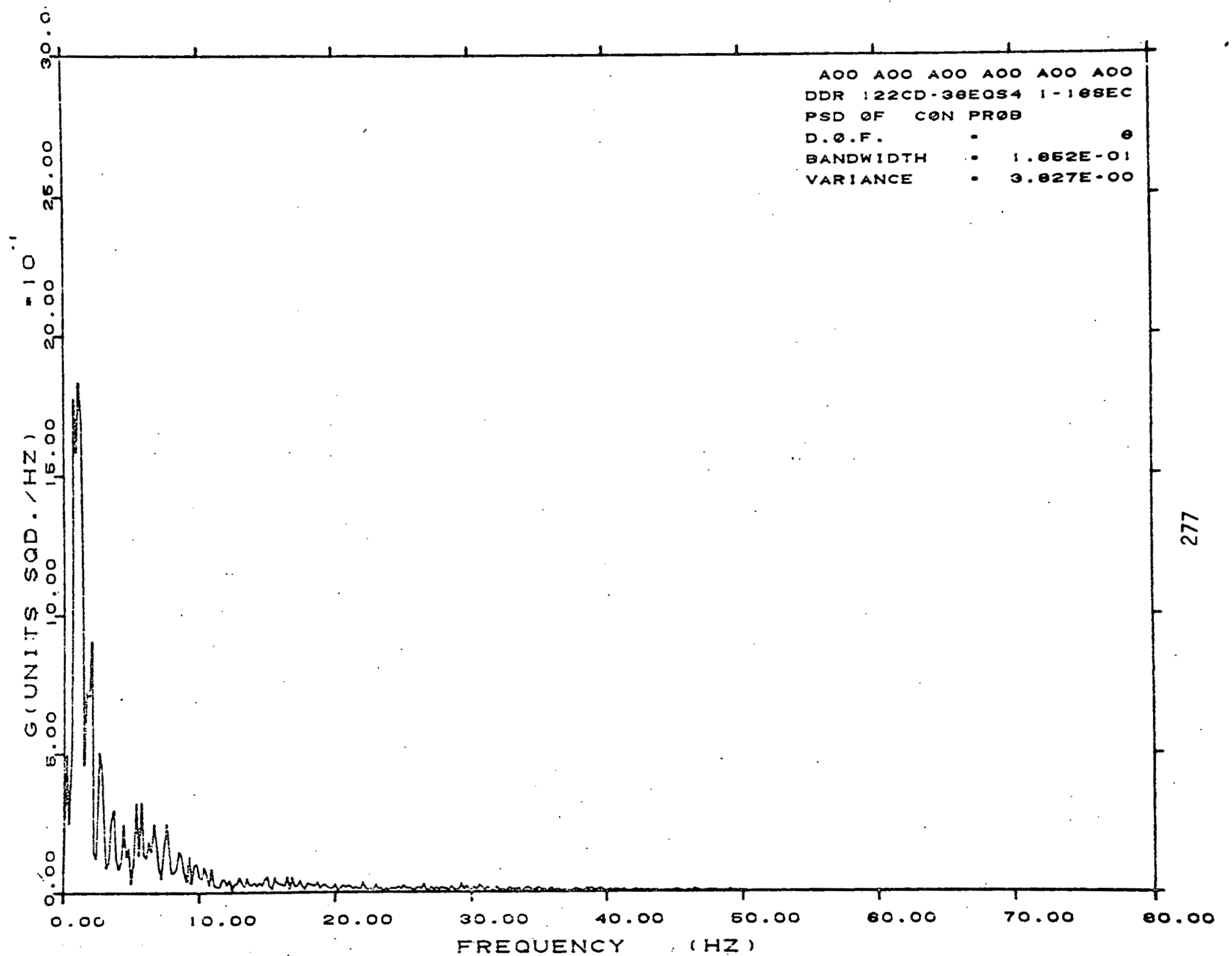

FIGURE I8 


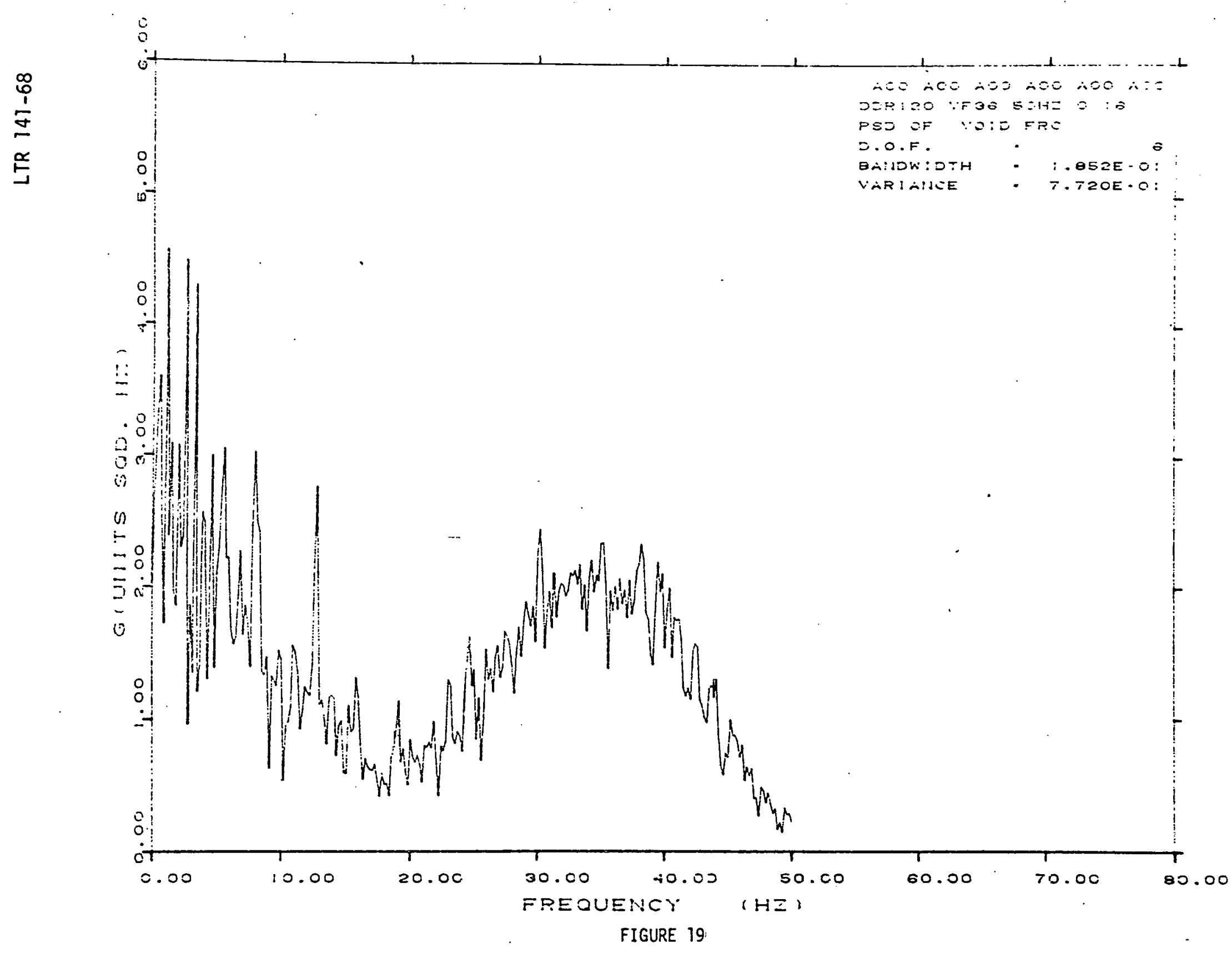




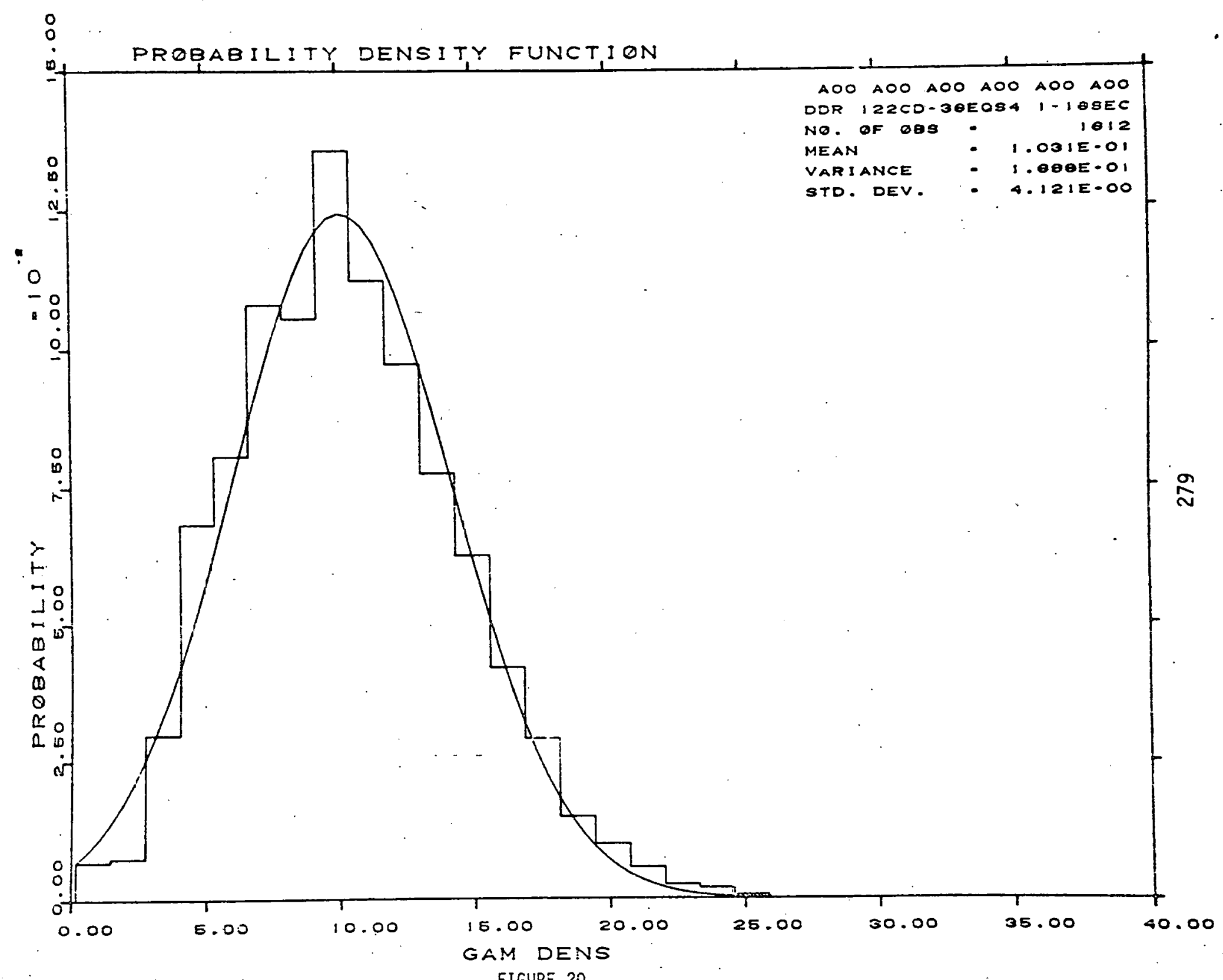




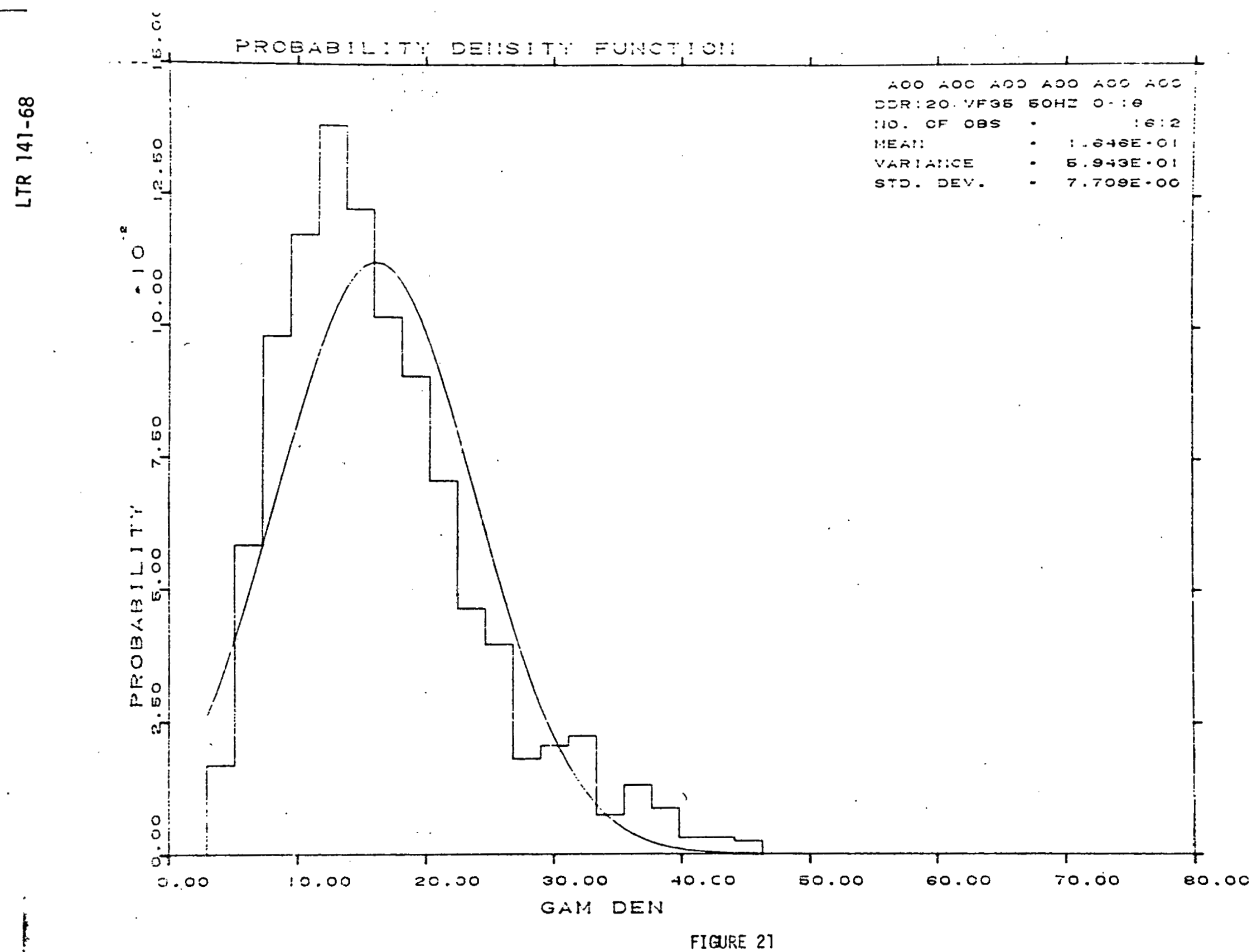




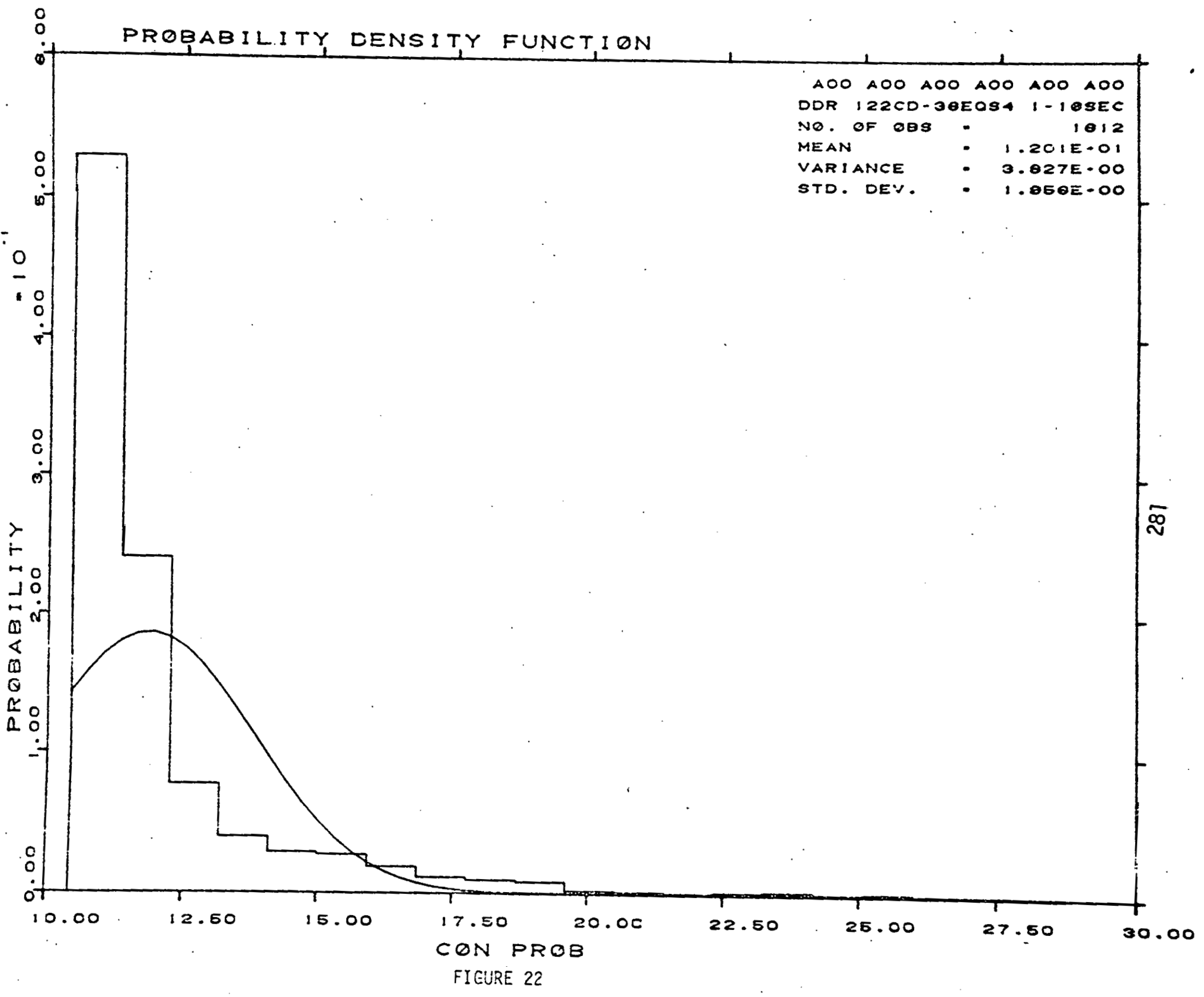




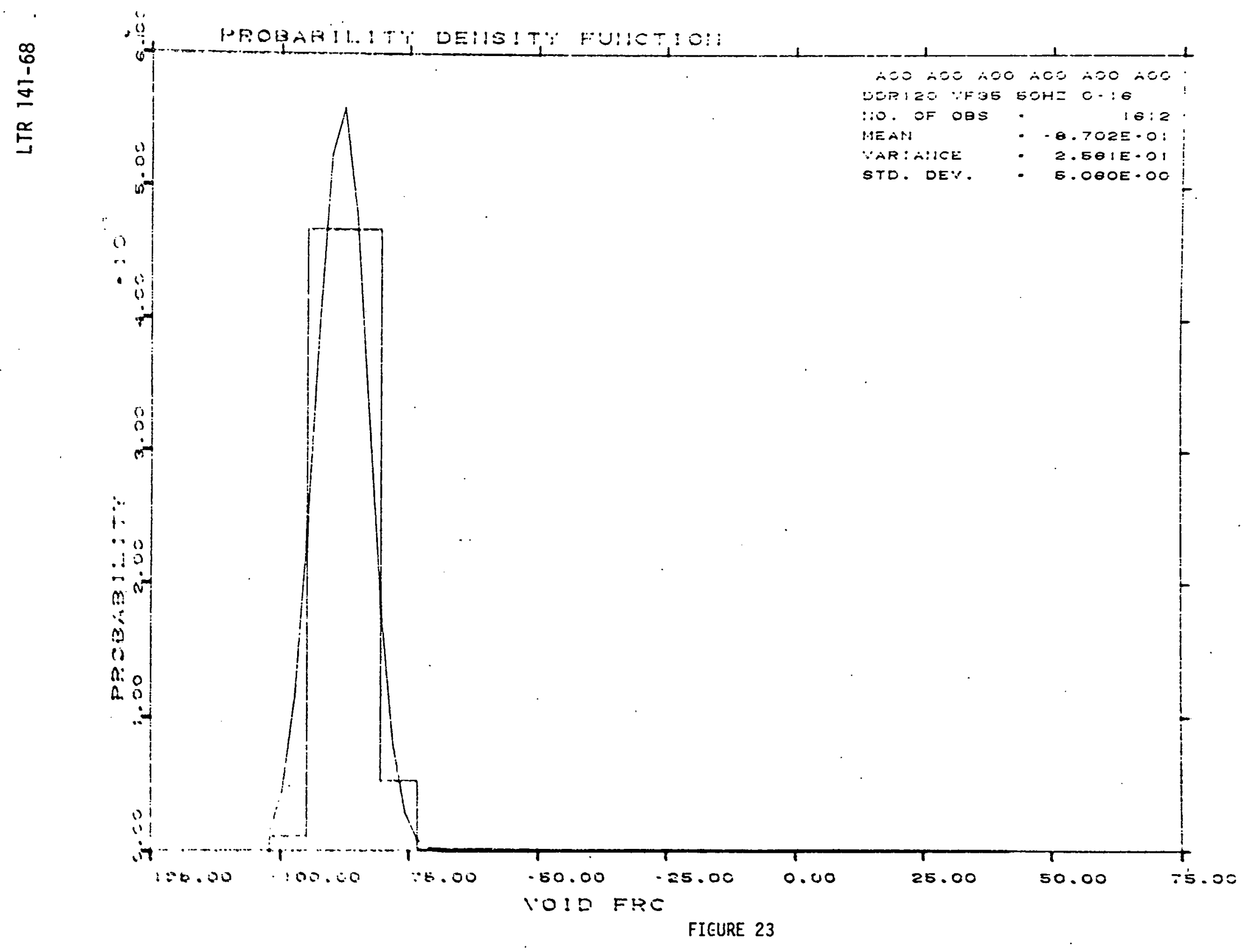




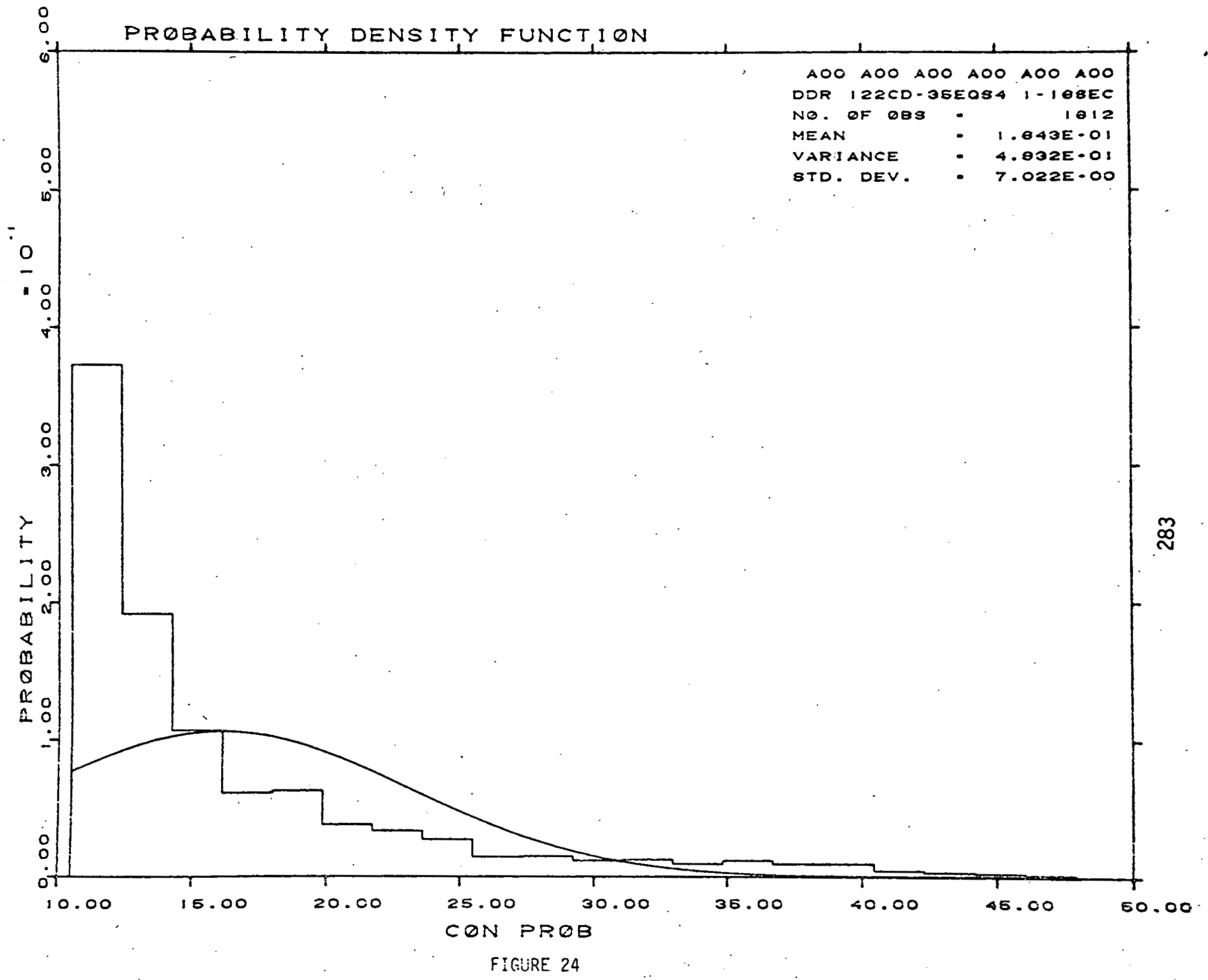




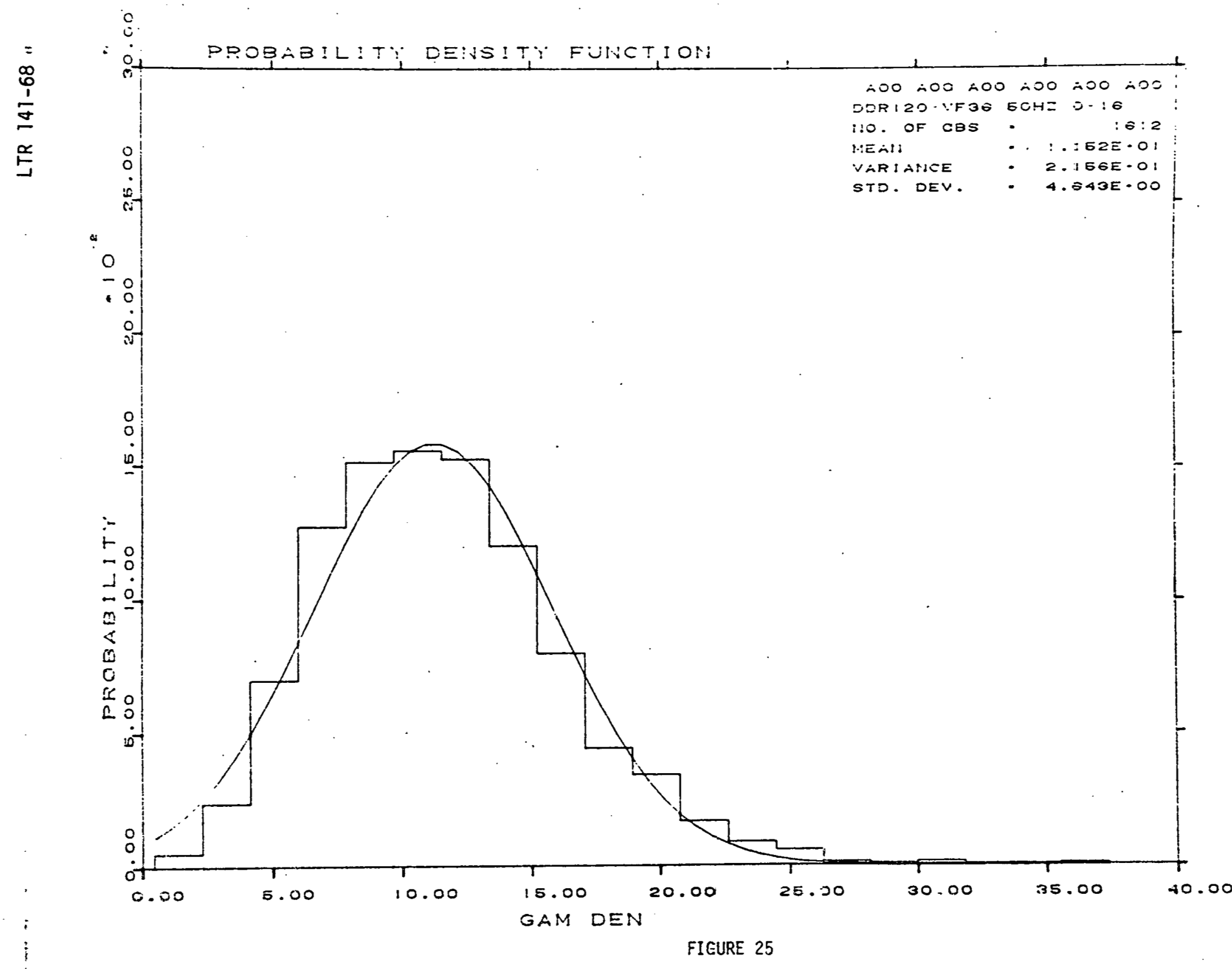




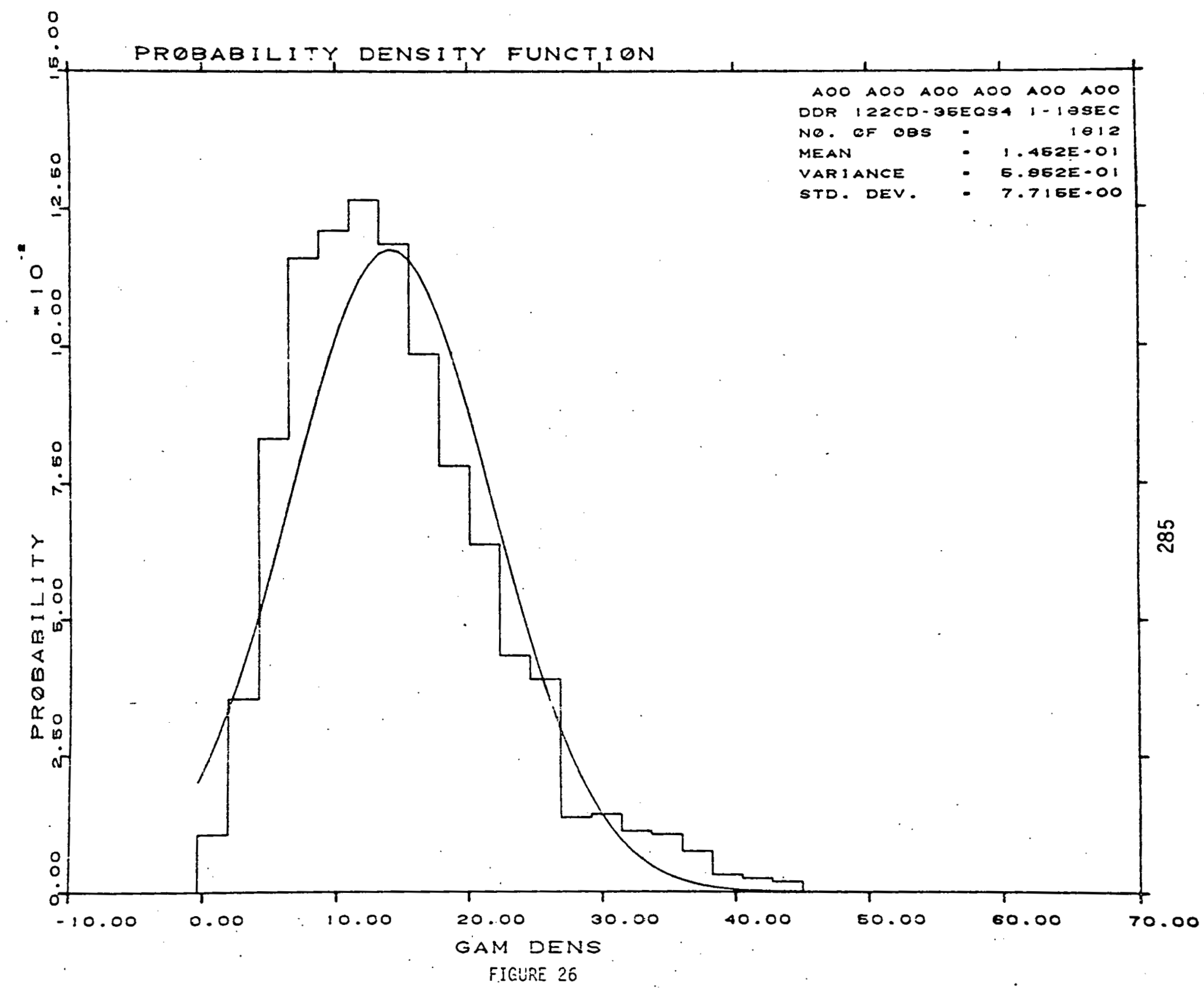


$\infty$
0
$\frac{1}{5}$
$\stackrel{5}{上}$

PROBABI:ZTY DEI:S:T: FUUT:OU

AOO $200200 \therefore 00$ ACo 200

ODR:20. $\because F 36$ 5OH= D.:

1:O. CF OBS I D:

$\because$ VAA::

$-0.2+4 E \cdot \sigma:$

VARIATICE

- T.720E-0:

$\stackrel{-}{0}$

STD. DEV. - 0.787E-00

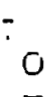

-

$c$
0
0
0

(1)

.

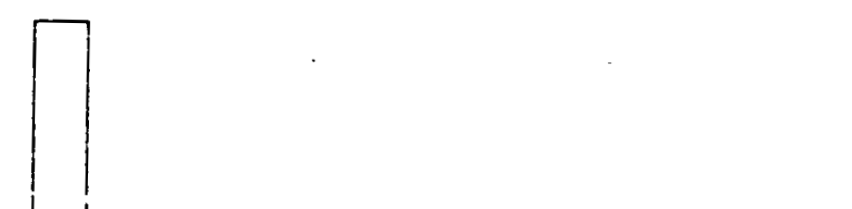




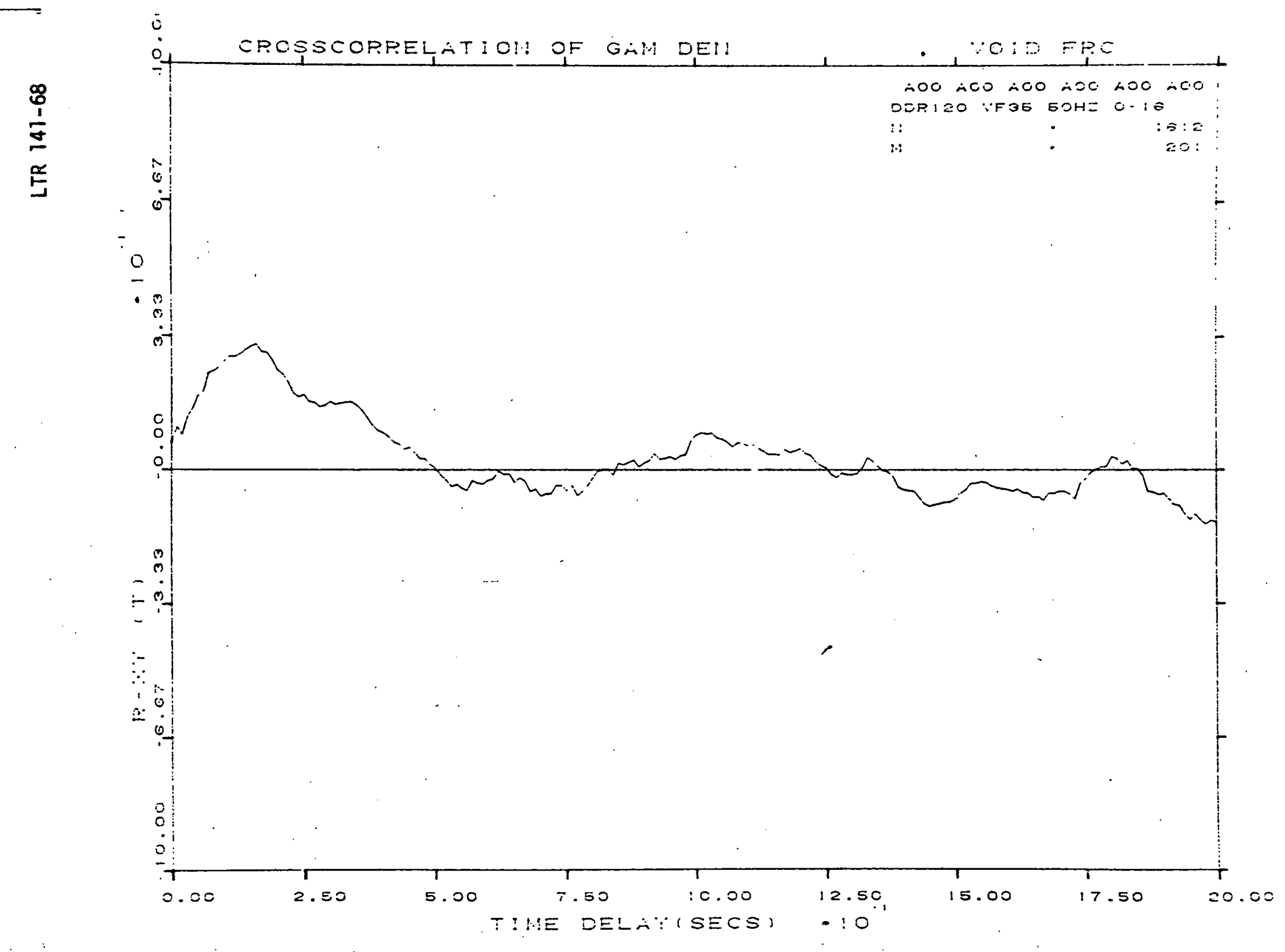

FIGURE 28 


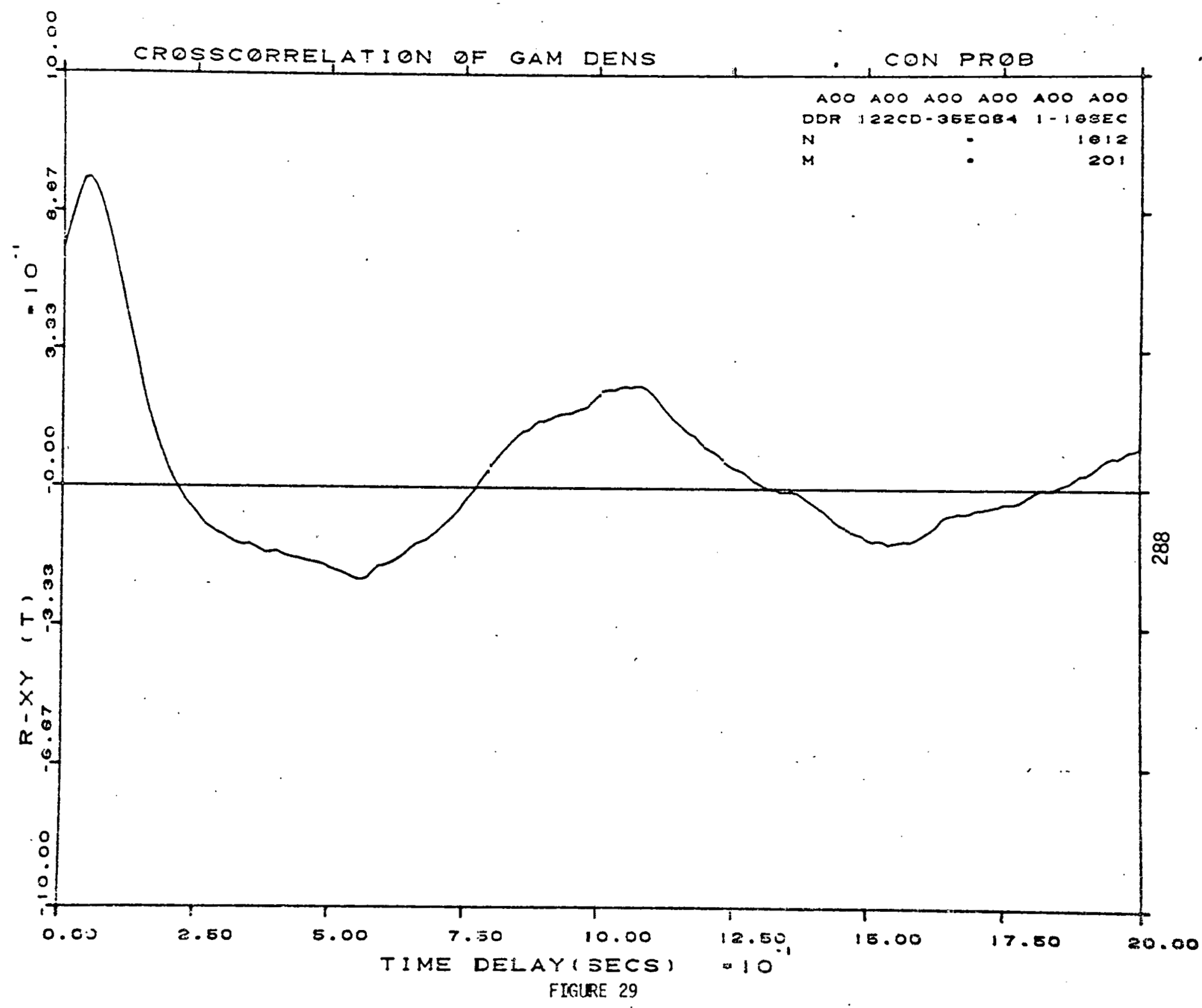




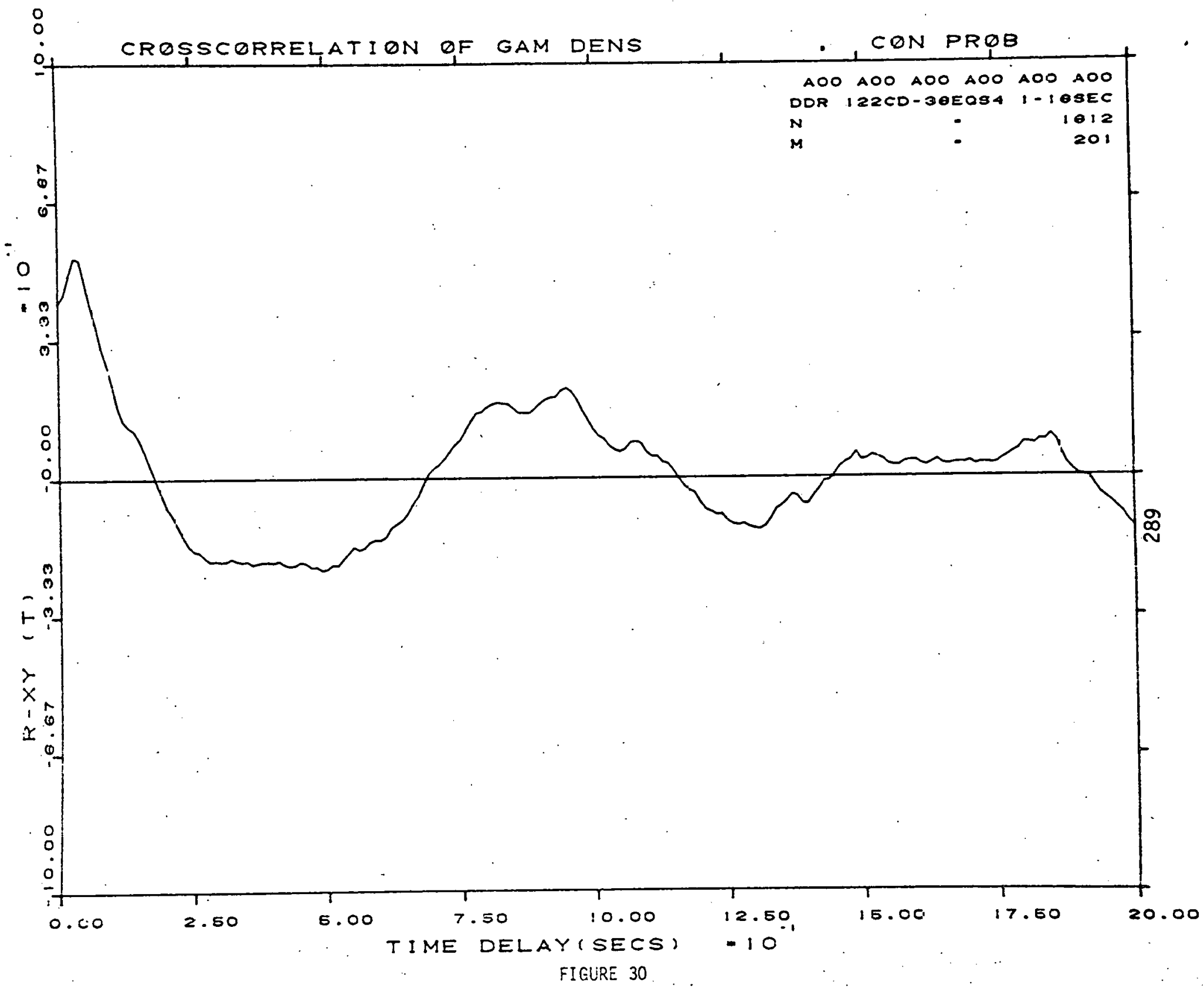




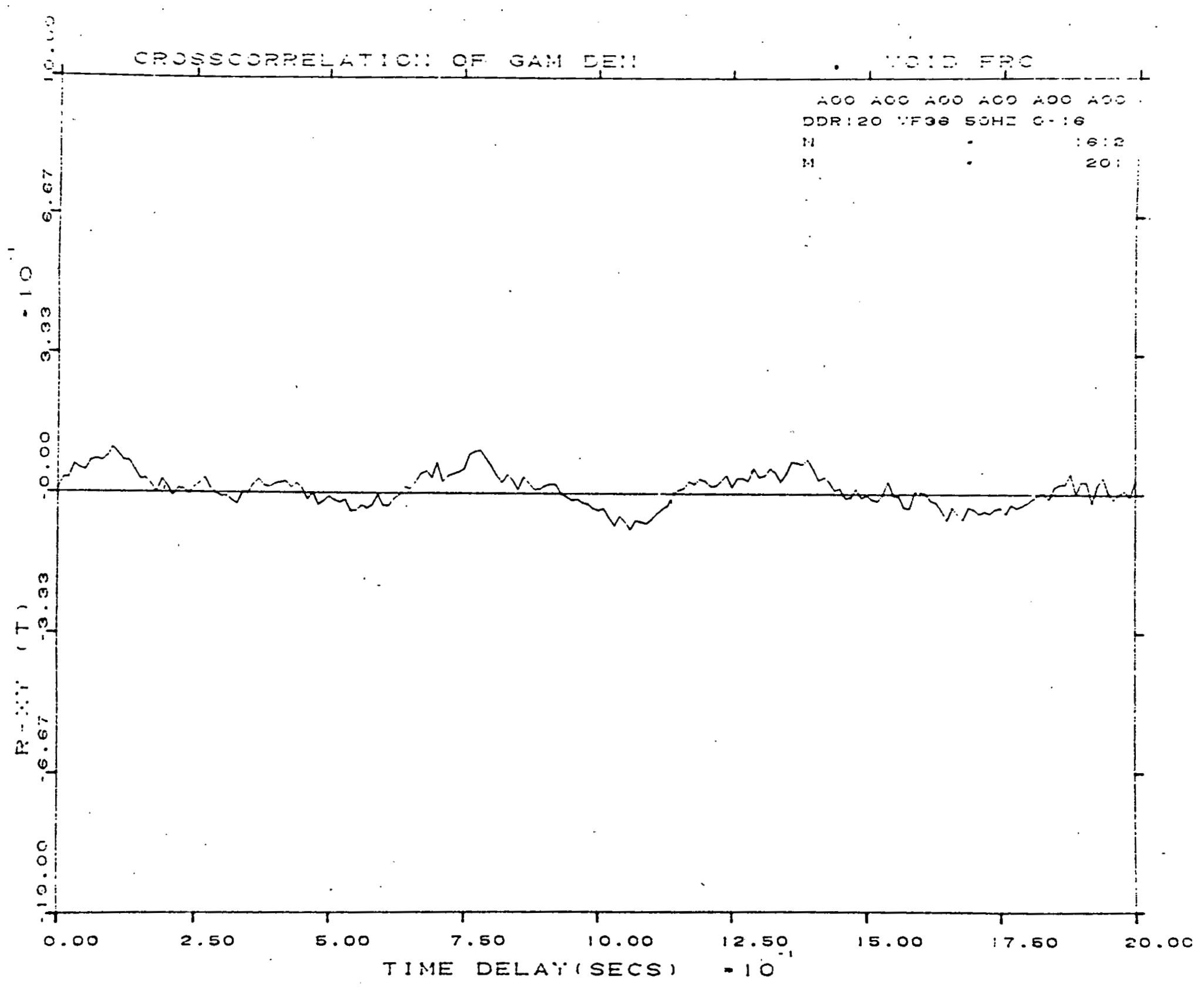

FIGURE 31 
APPENDIX I

ULTRASONIC SENSOR IN

STEAM-WATER MIXTURES 
LTR 141-68 


\title{
II. EESG Idaho
}

LTR 141-68. .

\section{INTEROFFICE CORRESPONDENCE}

\author{
date July 25,1977 \\ 10 M. E. Buchanan \\ trom G. D. Lassahr \& $\&$ \\ subject ULTRASONIC SENSOR IN STEAM-WATER MIXTURES - GDL-4-77
}

We would expect that an ultrasonic device does not sense simply the average density of a two-phase fluid, because the relatively large compressibility of the gas phase has the effect of reducing the effective density of the fluid. This effect is strongly dependent on the locations of the two phases relative to the sensor surface. If the sensor is surrounded by a film of gas with thickness appreciably greater than the amplitude of the sensor vibrations, the effective density of the fluid is very small because there is little sensitivity to the liquid beyond the gas film. If there is a film of liquid covering the sensor, the effective density of the fluid should be approximately the liquid density multiplied by the volume of the liquid in the film divided by the total measurement volume (the volume in which the measurement system can detect the presence of a small bubble in liquid). Under some conditions, one might expect that thin film interference effects (standing waves in a fluid film next to the sensor) might further complicate matters, but these effects probably average out with broad band ultrasonic pulses. In short, it seems that an over-simplified but possible reasonable guess for the effective fluid density (the parameter measured by the ultrasonic device) is the average density of the fluid multiplied by the fraction the sensor surface that is wetted by the liquid:

$$
\begin{aligned}
& \rho_{\mathrm{e}} \approx \bar{\rho}\left(1-\alpha_{s}\right)=\left[\alpha \rho_{g}+(1-\alpha) \rho_{l}\right]\left(1-a_{s}\right) \\
& \text { where }{ }_{e} e \text { is the effective fluid density } \\
& \bar{r} \text { is the average density of the fluid in the measurement } \\
& \text { as is the fraction of the sensor surface that is covered } \\
& \text { with gas } \\
& \alpha \text { is the void frartion of the fluid } \\
& \mathrm{p} g \text { is the gas density } \\
& \rho_{\ell} \text { is the liquid density }
\end{aligned}
$$

In some average sense, $\alpha_{\text {s }}$ should equal $a$ if we can neglect effects like boiling or condensation at the sensor surface or adhesion of one fluid 
M. E. Buchanan

July 25,1977

GOL-4-77

Page 2

phase to the surface. Then we get:

$$
\rho_{e} \approx \bar{p}(1-\alpha)=(1-\alpha)^{2} \rho_{l}+\alpha(1-\alpha) \rho_{g} \text {. }
$$

Of course, this expression is based mostly on conjecture. The actual dependence of the sensor response on $\rho, \rho$, and $\alpha$ (and perhaps other fluid properties like flow velocity) ${ }^{g}$ should be determined by careful experiment.

taw

CC: A. E. Arave

L. D. Goodrich $j^{\mu}$ 


\author{
APPENDIX $\mathrm{J}$ \\ ELECTRONIC CIRCUIT SIGNAL PROCESSING \\ AND FOR REDUCING CONDUCTIVITY \\ VOID FRACTION DATA
}


LTR 141-68

-

1 


\section{Idaho}

\section{INTEROFFICE CORRESPONDENCE}

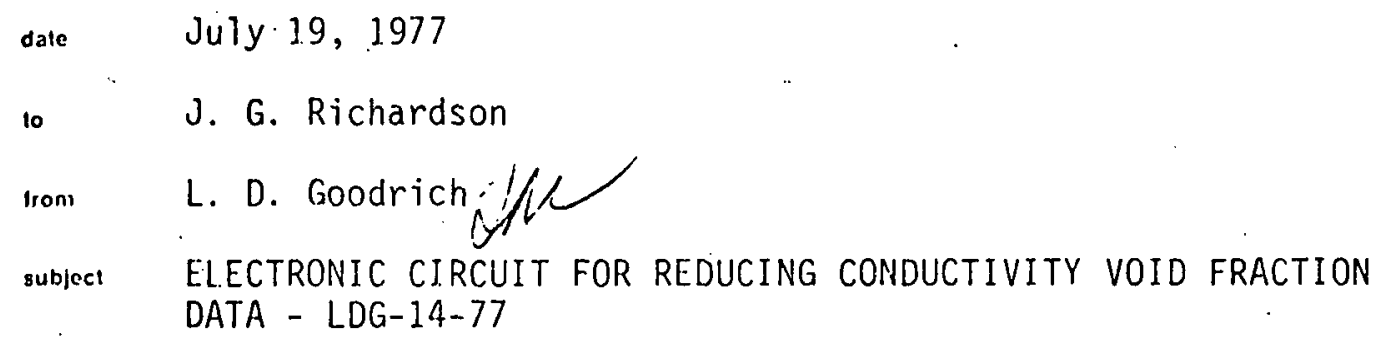

Attached is a paper on conductivity void fraction transducers. Figures 6 and 7 show a method of reducing data to make the probe insensitive to temperature and chemistry changes. We would like you to evaluate this method and determine if it is possible to make a circuit for our conductivity void fraction testing. Your comments on the temperature compensation technique (Figure 2) would also be appreciated. An answer within one month would be appreciated.

\section{taw}

CC: Min Egrachanan

M. R. Clements

R. R. Good

R. R. Rohrdanz RiEf

R. D. Wesley 


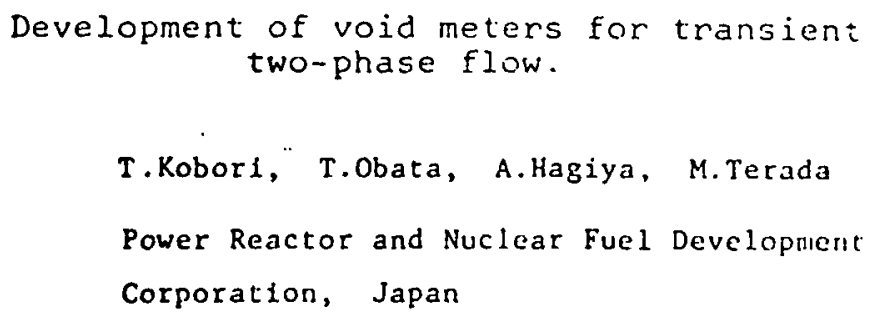

Abstract

Several kinds of void meter have been developed at PNC Japan, in urder to study the reactor engineering safety problems such as blow down, pump malfunction and other accidents.

In this paper, we describe and experimental study of processing signals of Inpedance void meter and contact needle probe.

Probe signal of the impedance vold meter is compensated by addil:g signal of thermocouple and adjusting span between zero and 100\% void fraction so as to keep the span constant. A clecult wao dovelnped for automatic compensation.

Needle contact probe are manufactured as small as possible to measure the vold fraction with a higher degree of accuracy. On the other liand, the prohe should have enough strength for severe condition induced by fast transient. Therefore, probe should have blgger size than expected from measurement point of view. For such probe, new signal processing method is developed: signal differentiation. Probe signals are, first, clipped, then differentiated to shape into square wave. Void fraction data processed by this method agrie well with gamma attenuation method. 


\section{Developments of void meters for transient two phase flow. \\ T.Kobori, T.Obata, A.Hagiya, M.Terada \\ Power Reactor and Nuclear Fuel Development \\ Corporation, Japän}

Vold meters have been developed for transient two-phase flow studies. Th1s paper describes an atrempl: to compensate the fluid cemperature effect of the Impedance void meter.

Signal processing of the needle contact void meter is also described. Signals are processed in two ways; viz. slice, and differenciation method. Vold fraction data are compared with the gamma attenuation method.

\section{Introduction}

over the past few decades, various instruments have been developed by many researchers for two-phase flow and bolling heat transfer studies (1).

Recently, special types of instruments, various kinds of vold meters In particular, have been developed for the study of reactor safety problems such as blow down, putap malfunction and other accidents (2), (4).

At PNC several types of vold meter for hydrodynamic experiments have been developed, eg., gamma attenuation method, multi-element impedance void meter, single-element lapedance vold meter and contact needle probe ${ }^{(3)}$. This paper describes an experimental scudy of processing signals from the Impedance vold meter and the contact needle probe.

\footnotetext{
2. Temperature compensation of impedance void meter Impedance vold meters are widely used to obtain void fraction data under fast transient two-phase flow such as blow down, flow decay or fast depressurization, because this type of void meter has a very short response
} 
time.

The overall fropedance value $\dot{z}$ of the void meter for any void fraction depends on the fludd resistivity $R$ and the capacitance $C$ of the two-phase wixture; these depend on the void fraction and the cemperature of the min:ture, since the resistivity and the dielectric constant of the liquid phativ both decrease markedly with tenperature, while, for steam, these values irr almost constant.

$$
i=\frac{R}{1+j w C R}
$$

During fast transient two-phase flow, the signals of the iolpedance void meter change with the void fraction as well as with the remperature. Therefore, these effects must be compensated in order to obtain accurate void fraction data.

Figure 1 shows that zero drift changes by $-10 \sim+30 \%$ with temperatures between $20 \sim 300^{\circ} \mathrm{C}$ for four kinds of water conductivity, expressing zerodrift: as the equivalent vold fraction. Quantitatively, these values are not general since the capacitance between clectrodrs shanges with their configuration and s1ze, but they indicate the qualitative trend for temperature effect.

Conceptual 1dea and circult diagram for temperature compensation are shown respectively in

Figures 2 and 3.

Signal output of the circult without compensation shows that,because of the constant dielectric property of steam, the signal for $100 \%$ void fraction does not vary. On the contrary, the signal for

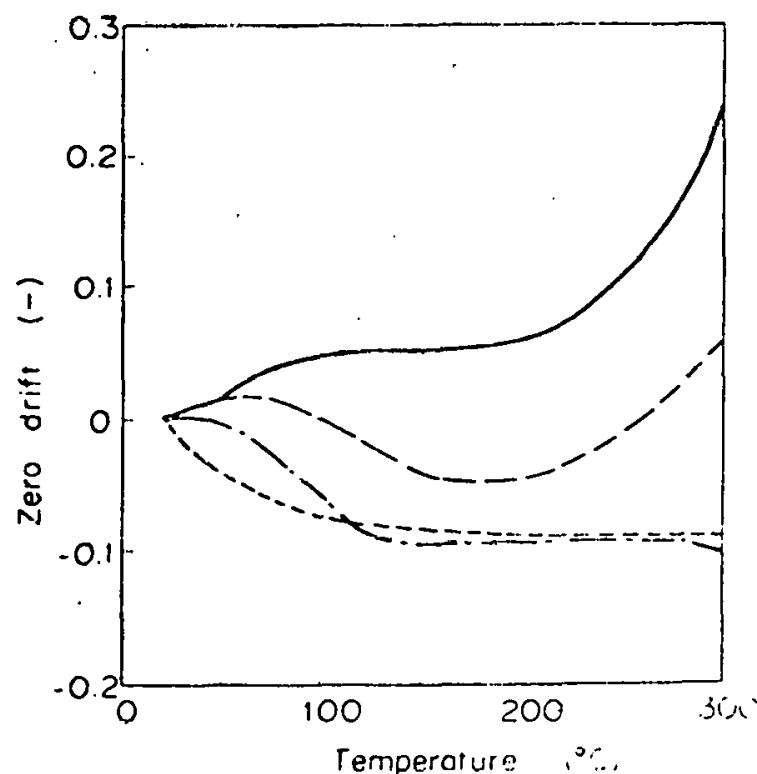

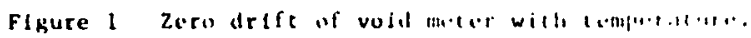

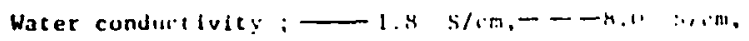
$--24.0 \mathrm{~s} / \mathrm{cm} .---120 \mathrm{~s} / \mathrm{sm}$ 


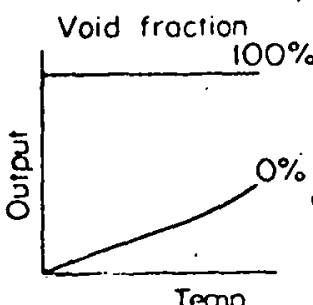

(a) Un-compensoled

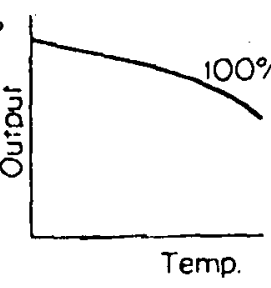

(b) Zero-drift compensoted

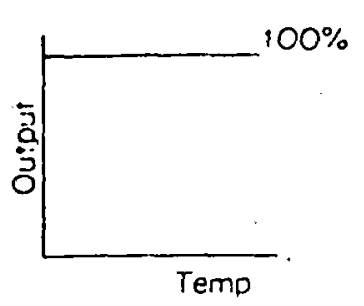

(c) Spon odjusted

Figure 2 Temperature compensation of Impedance void meter

$0 \%$ void fraction varjes as shown in Figures 1 and $2(a)$. The stgnal. from a theinocouple produces some value for compensation and is added to the void probe signal. Then, the zero drift compensated signal is obtained as in Figure 2(b) where the signal for $100 \%$ void

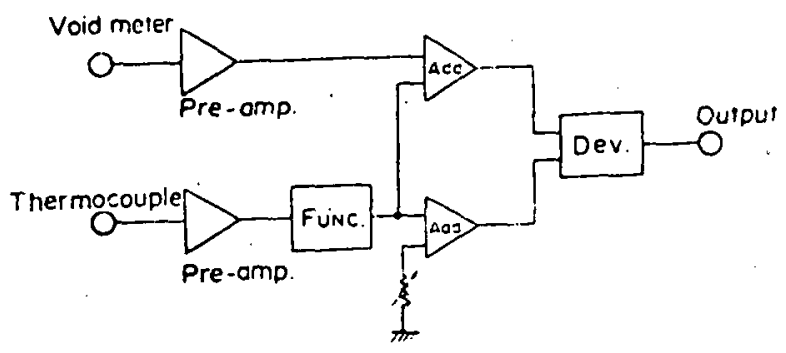

Figure 3 Circuit diagran of vold reter amplifier

fraction changes due to the compensation mentioned above. In other words, the span between zero and 100\% vold fraction changes.

The span should be adjusted for easy reading by divluing the signal with a value proportional to each span, according to temperature. The void meter output is indicated by the meter with a constant span for any temperature of the fluid.

\section{Signal processing of needle contact probe}

\subsection{Optimization of slice level}

Needle contact probes are used for measurements of local void distribution In a flow passage under steady state conditions. However, it may also be possible to apply this probe for other uses, such as diatinction of flow 
pattern, counting the number of bubbles, and measurtment of stean passige time even under transient conditions.

In order to obtain the void fraction data, signals from the needle contact probe are sliced at proper level, then the steam passage time is counted. The probe signals show a longer rise time as the probe enters a bubbla, and a shorter fall-time on exit. Moreover, these rise and fall times are aifuctud strongly by fluid velocity and probe size. Therefore, void fraction dita are affected by the slice level, as shown in Figures $4(a)$ and (b). These figures show that the effect of the slice level is greater for higher fluid velocity and higher void fraction.

In Figure 4, vojd fraction data obtained from the differentiated method mentioned later, are plotted with an open circle symbol on the sliced void fraction data.

These differentiated void fraction data indicate optimum slice level, and are replotted with void fraction as abscissa for three mass velocities and three Ladlal pnsitions on semilogarithmic graph paper in Figure 5. It is evident from this figure that the optimum slice level $\delta$ is not giedty affarted by mass velocity and radial pusition and relates only to void fraction $\alpha$ as follows.

$$
\log \delta=a \alpha+b
$$

However, it is difficult to use the equation in such a form from the point of view of actual application, because the void llaction irself is contained in this correlation, and it is necessary to recalculate co obtain void friction data.

\subsection{Signal differentiation method.}

As mentioned in the preceding section, void fraction measurcdby the slice method is affected significantly by the slice level. In order to obluin the accurate vold fraction, the proper slice level should be clinsen before tiaking the measurement. The optimum slice level depends not only on the void friction Itself, but also on the configuration and size of the vold probe, which re- 


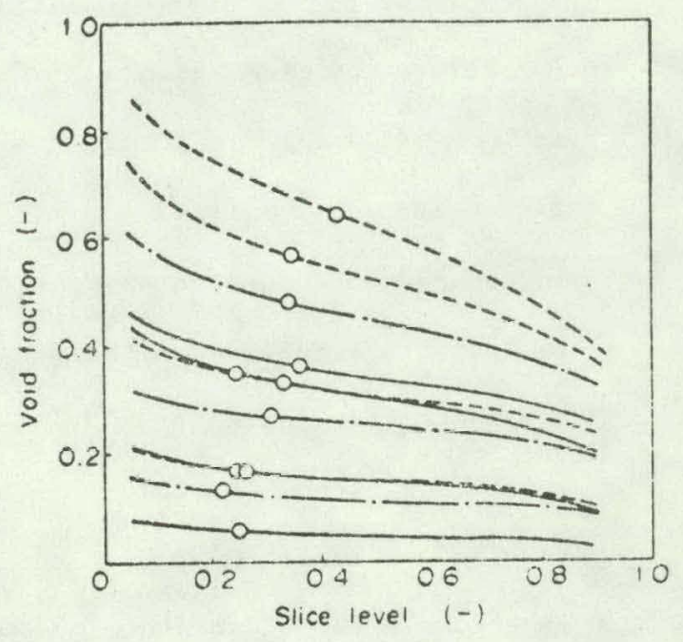

(a) $G=630 \mathrm{~kg} / \mathrm{tn}^{2} \mathrm{~s}$

(b) $\mathrm{C}=1890 \mathrm{~kg} / \mathrm{m}^{2} \mathrm{~s}$

Figure 4 Effect of slice level on signal processcd void eration

$$
r / R=0.14, \longrightarrow 0.46, \ldots-\cdots 3
$$

O V Vold fraction processed by differentiation

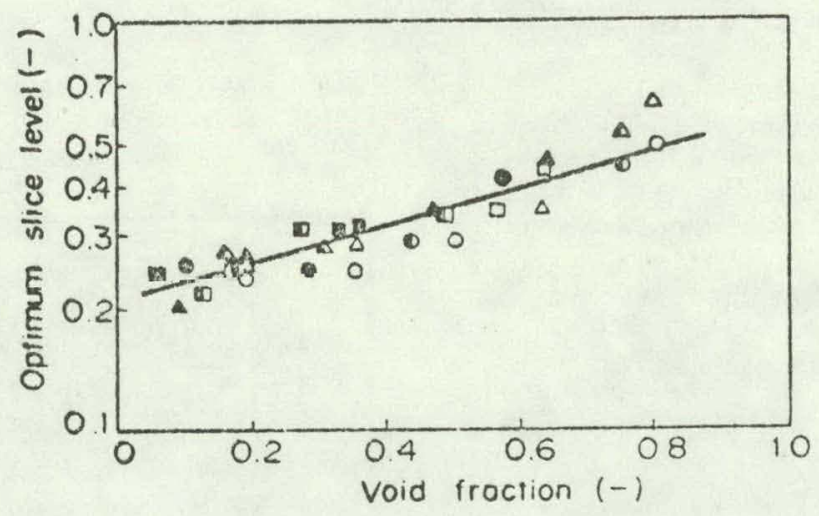

Figure 5 Optimum slice levil

$$
G=\begin{array}{cccc}
r / R=0.14,0.46,0.73 \\
630 \mathrm{~kg} / \mathrm{m}^{2} \mathrm{~s} & 0 & 0 \\
1260 & \Delta & \Delta \\
1890 & \square & \square
\end{array}
$$


quires much effort and care. Another signal processing method is now introduced, viz, signal differentiation.

Before differentiating signals, the probe signal should be clipped,as shown In F1gure 6, at appropriate upper and lower levels in order to eliminate noise at liquid and steam phase levels. The clipped signals can then be differentiated and shaped to a squared wave by triggering at the beginning of the rise and fall of differentiated signals. Our observation tests on the behavior of the two-phase flow indicate that probe signal starts to rise and fall at the moment when the tip of the probe makes contact with the surface of the steambubble. Shaped signals, therefore, corespond to the accurate void aignals obtained with very small contact neddle probe, even if a big probe is used. Ihis sigual differentiating method is considered to give accurate void fraction data, regardless of mass velocity, probe size and other factors.

Figure 8 shows data processed by this method in comparison with void fraction data measured by the gamma attenuation method, in a round tube of $75 \mathrm{~mm}$ diameter.

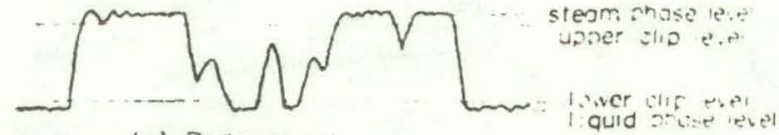

(a) Probe signa

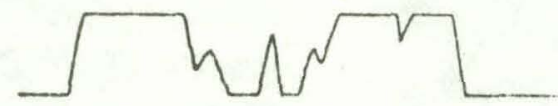

(b) Clipped signol

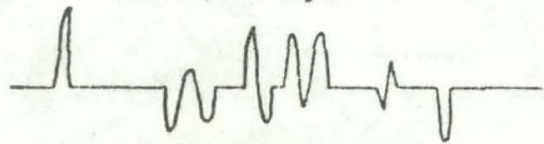

(c) Differentiaied signal

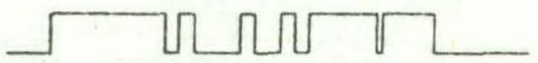

(d) Shaped signol

Figure 6 Signal processing of contact needle probe

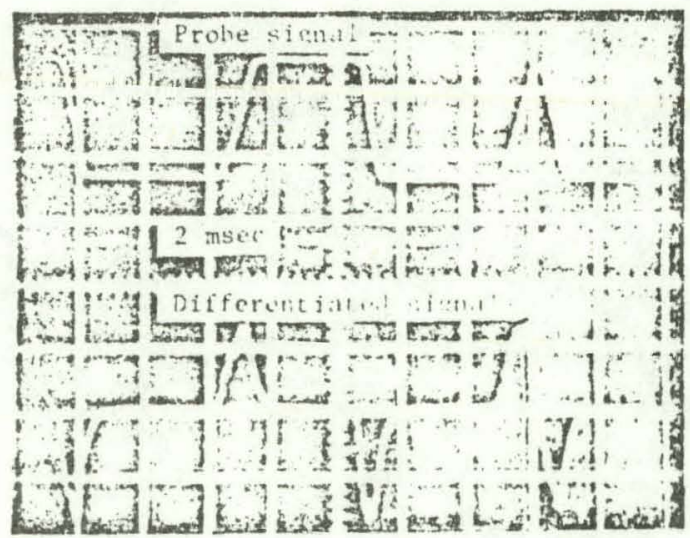

Figure 7 An example of probe signal and differentiated sistlals

Both are in agreement. 

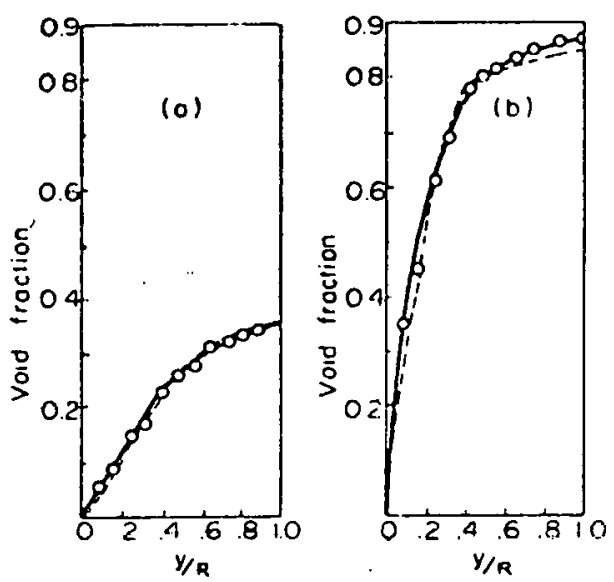

Figure 8 Comparison of differentiationprocessed void fraction with gamma attenuation methus;

- This mechod, - - - - Camma atcenuat ion

4. Conclusion

The following conclusions may be drawn from the results of this work.

(1) Probe signals from the impedance void meter can be compensated by maintajulng a constant span between 0 and $100 \%$ void fraction.

(2) A signal differentiation method of contact needle probe has been developed and compared with other methods to check its applicability for vold meter.

The authors wish to express their thanks to the staff of the heat transfer Test Laboratory at PNC 0-aral Engineering Center for their cooperation to this work.

\section{REFERENCES}

(1) ASME ed. 1969 Two-Phase Flow Instrumentation.

(2) Cimorelli, L., \& Premoli,d. 1966 Measurement of void fraction with impedance gauge technique, Energia Nucleare 13,12.

(3) Obata,T., Kobori,T., \& Hayanizu,Y. 1975 The development of two-phasc flow Instrumentation at 0-aral Engneering Center, JUICE Meeting for Hoavy Hacer Reactor.

(4) Smith,A.V. 1975 A fast response multi-beam X-ray. absorption technique for Identifying phase distributions during steam-water blowdowns.

J.Br.Nucl. Energy Soc., 14, 227. 
LTR 141-68

$\because$ 
L'TR 141-68

APPENDIX K

SELECTION MATRIX 
LTR 141-68 
APPENDIX K

SELECTION MATRIX

\subsection{INTRODUCTION}

A selection matrix (see Table $K-I$ ) was constructed to determine which detector should be developed for the LOFT reactor core inlet application. The matrix was divided into two sections: (a) Technical Evaluation of Transducers and (b) Evaluation of Schedule for Implementing Detector Technology. Each section was based upon evaluation factors, weighting factors and a rating scale. A.confidence level was established for each detector per evaluation factor. The confidence level was based upon the amount of data available to determine the rating factor: A discussion of the evaluation factors in the matrix follows:

\subsection{Technical Evaluation of Transducers}

\subsubsection{Meets Measurements Requirements Based on Air-Water Perform-} ance Test Results;

(1) Accuracy, Response and Range. The air-water test data indicated that both detectors would be acceptable as a void fraction detector in an air-water environment to the LOFT accuracy requirements. (See Table $K-I$ for rating scale). These requirements are important to the acceptability of the performance of both detectors; therefore, a high weighting factor was assigned.

(2) Expected Steam Water Performance. No steam-water performance data is available for either device when used as a void fraction detector. Both detectors are expected to 
exhibit about the same performance in steam-water environment.

\section{1 .2 Sensitivity to Other Parameters}

(1) Measurable; Pressure and Temperature. Pressure and temperature can be measured in the region where the detector will be installed and the effects of these parameters can be calibrated out or the data compensated for by modeling. Since these effects are minor a low weighting factor was assigned.

(2) Unmeasurable; Flow and Chemistry. Flow and chemistry are difficult to determine as functions of time and are important as to the acceptability of the detectors. A high weighting factor was assigned. The air-water data indicated the ultrasonic detector was extremely sensitive to different flow rates, while the conductivity detector is sensitive to chemistry.

1.1.3 Meets Operation Requirements; pressure, temperature, chemistry radiation and flow. Eacls detector appears to meet the environmental operatluii condition as shown in Table I (page 4). Both detectors were rated the same and a high weighting factor was assigned.

1.1.4 Meets Survivability Requirements, Design Life. The ceramic seal used in the conductivity detector will degrade over the 10,000 $\mathrm{hr}$. operation, causing an impedance change. Using a different signal processing scheme the impedance change can be compensated for (see Appendix I).

1.1.5 Modeling Ability, Analytical Model, Data Reduction. The ultrasonic detector is very difficult to model and extensive work must be performed to obtain a model. The conductivity detector has been modeled, [3] therefore, the conductivity detector is rated higher as to modeling ability. 
1.1.6 Signal Processing, Complexity. The ultrasonic detector at the present has the most complex signal processing system, but implementing a signal processing scheme to eliminate an impedance change in the conductivity detector would require a more complex signal processing scheme. Therefore, both detector.signal processing systems were rated the same.

The totals for the technical evaluation of the detectors indicated that the conductivity detector system rated higher than the ultrasonic detector system; also the confidence level of the conductivity detector was higher because there was more data available on the performance of that detector.

\subsection{Evaluation of Schedule for Implementing Detector Technology}

Evaluation of Schedule for Implementing Technology, was necessary because for the LOFT Reactor Core Inlet application a restrictive schedule must be met. The evaluation factors were:

1.2.1 Development To Date. At the present time the ultrasonic detector is further along in the development stage than the conductivity detector.

1.2.2 Development Time to Meet Application Deadline. Due to progress of the present development it appears that the ultrasonic detector systeli would be the most likely system to meet the schedule deadline for the LOFT reactor core inlet application.

Combining the totals of parts 1 and 2 , the selection matrix indicates that the ultrasonic detector receives the highest rating for the LOFT reactor core inlet application. Therefore, it is recommended that the ultrasnnic detector be used for the core inlet application. 


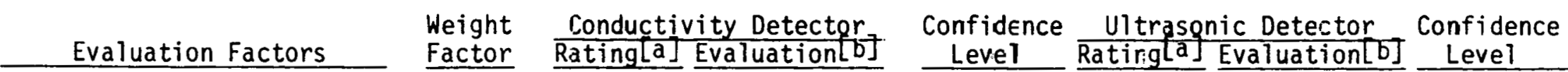

\section{Technical Evaluation of Transducer}

1. Meets Measurements Requirements Based on AirWater Performance Test Results

a. Accuracy, Response and Range

b. Expected Steam Water Performance

3

0.90

$0.7 C$

3

0.9

0.90

0.05

0.15

0.50

3

0.15

0.30

2. Sensitivity to other Parameters

a. Measurable (PressureTemperature)

b. Unmeasurable (FlowChemistry)

$0.02 \quad 4$

$4 \quad 0.08$

0.54

1.0

4

0.08

1.0

0.18

3

0.80

2

0.36

0.50

3. Meet Operation Requirements Pressure/Temperature Chemistry/Radiation Flow

0.20

1.30

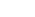

0.60

0.80

4. Meets Survivability Requirements Design Life

0.20

5. Modeling Ability Analytical Model/Data Reduction 0.10
0.30

D. 85

3

0.30

0.80

6. Signal Processing Complexity

TOTAL $\frac{0.05}{1.00} \quad \underline{3}$

$\frac{0.15}{2.92}$

$\frac{0.50}{80 \%[c]} \quad 3$

$\frac{0.15}{2.74} \quad \frac{0.50}{73 \%[c]}$




\section{Evaluation Factors}

Weight Conductivity Detector Confidence

U1trąsonic Detector

Confidence

Evaluation of Schedule for Implementing Technology

1. Development to Date

0.50

2

1.0

3

1.5

2. Development Time to

Meet Application

Deadline

\begin{tabular}{llll} 
& 0.50 & 2 & 1.0 \\
TOTAL & 1.00 & & 2.0 \\
TOTAL & 2.00 & & 4.92 \\
\hline
\end{tabular}

$\frac{1.5}{3.0}$

[a] Rating: Integer range 1 to 4

1 = Not acceptable; not within state-of-the-art.

2 = Acceptable in some cases; pushing state-of-the-art.

3 = Acceptable in most cases; at the state-of-the-art.

4 = Acceptable in all cases; well within the state-of-the-art.

$\underline{\text { Confidence }}=$ Percentage confidence in the rating based on the data, experience and engineering judgement.

[b] Evaluation = Weight $\times$ rating; the product of the rating with weight.

[c] Overal1 Confidence Level $=\sum$ (confidence $x$ weight), summation of the product of confidence with weight for each evaluation factor. 